349 


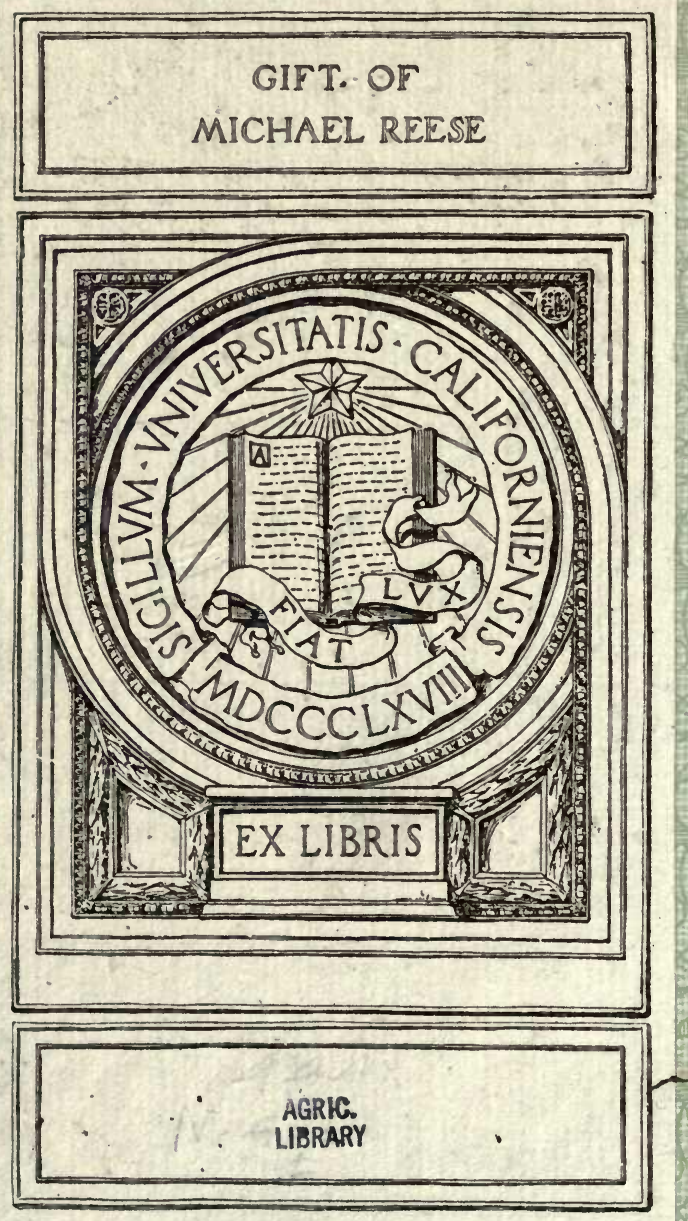




\section{A TEXT-BOOK OF}

\section{PLANT DISEASES}

Caused by Cryptogamic Parasites

BY

GEORGE MASSEE, F.L.S.

PRINCIPAL ASSISTANT (CRYPTOGAMS), ROYAL HERBARIUM, KEW
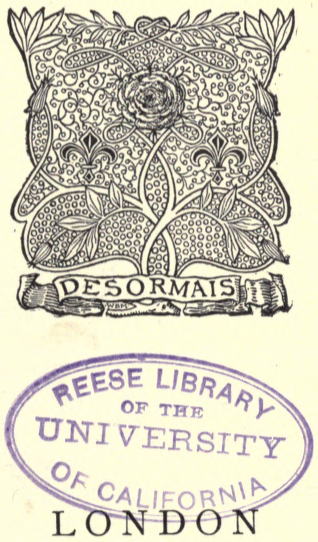

DUCKWORTH and CO.

NEW YORK: THE MACMILLAN COMPANY

I 899 


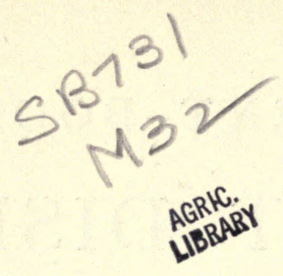

80391

Edinburgh: T. and A. Constable, Printers to Her Majesty 


\section{PREFACE}

THE aim of this book is to enable those directly occupied in the cultivation of plants, and with but a limited period of time available for study, to determine the nature of diseases caused by parasites of vegetable origin; to apply in the most approved manner those curative and preventive methods which experience has shown to be most successful in combating the particular form of disease under consideration; and finally, to include in the daily routine of work precautionary measures which, without being costly, frequently prevent a slight disease from assuming the proportions of an epidemic.

Those desirous of obtaining fuller information respecting the life-history of the parasites mentioned in this book, also of others not included, can do so by. consulting the literature indicated under the different species. In connection with this part of the subject, it may be well to state definitely that success in the study of plant diseases, or Vegetable Pathology, must necessarily be preceded by a correct knowledge of the broad principles of the normal mode of plant life, known as Vegetable Physiology; and 
even apart from the subject of diseases, the cultivator of plants possessed of such knowledge should succeed better than another following blindly the 'rule-of-thumb' method, if there is any truth in the saying that 'knowledge is power.'

A certain amount of repetition will be observed; this is quite intentional. Not possessing the fascination of a novel, it is not for a moment expected that the contents of this book will be read from cover to cover even by those most immediately concerned in its contents, but rather that the particular disease respecting which information is desired will be directly sought; hence under each disease curative and preventive methods are fully explained, in preference to referring to another disease where the line of treatment is somewhat similar.

The numerous references to literature given indicate my indebtedness to other workers in the domain of Plant Pathology, to each of whom I offer my hearty thanks.

GEO. MASSEE. 


\section{CONTENTS}

\section{INTRODUCTION}

PAGE

Amount and kind of knowledge required by practical menFamiliarity with names and habits of parasites-Preventive measures-Cures-Rule-of-thumb methods of doubtful value, . . . . . . . . . . . . .

\section{FUNGI}

Nature of fungi--Saprophytes-Parasites-Mode of growth of fungi-Reproduction of fungi-How parasitic fungi infect their victims-How the spores of fungi are dispersed - Modes of dissemination of disease that can be prevented -Danger connected with pruning-Selection of shade trees,

\section{LICHENES}

Nature of lichens-Saprophytes or parasites? . . . $\quad 29$

\section{ALGAE}

Nature of Algae,

\section{MYXOGASTRES}

Nature of Myxogastres or 'Slime fungi'-Germination of spores-Plasmodium stage, . . . . . . 


\section{BACTERIA}

Nature of Bacteria-Groups of Bacteria-Nitrification induced by Bacteria, .

\section{FUNGICIDES}

Nature of Fungicides - Solutions - Powders - Bordeaux mixture-Ammoniacal solution of copper carbonatePotassium sulphide solution-Iron sulphide solutionPermanganate of potash solution-Sulphur-LimeResin wash-Jensen's hot-water treatment for wheat and oat smut-Paraffin-Formalin-Lysol-Resin compound - Fumigation with hydrocyanic acid gas-Sterilising soil - Poisonous properties of fungicides, . . . .

\section{ECONOMIC CONSIDERATIONS}

Statistics relating to losses caused by grain rust in PrussiaLoss through rust of wheat in Australia-Destruction of vineyards in the United States caused by fungi, . .

\section{SPRAYING}

Various methods of spraying-Spraying apparatus, . .

\section{FUNGOUS PARASITES}

Descriptions, with preventive and curative methods, of the various kinds of parasitic fungi attacking plants of economic importance,

\section{MYXOGASTRES}

Description of the diseases popularly known as 'Finger-andtoe ' and Brunissure, 


\section{BACTERIA}

Bacterial diseases of plants, . . . . . . . . . 338-342

\section{LICHENES}

Injuries caused by lichens, and means of prevention, . $\quad$ - 342-345 DISEASES OF UNCERTAIN ORIGIN, · . 345-449

Scientific Descriptions of the Fungi enumerated as Causing Diseases, . $\quad . \quad$. $\quad . \quad$. $\quad$. $349-443$

AdDENDA, $\quad . \quad$. $\quad . \quad$. $\quad . \quad$. $\quad . \quad 444-446$

\section{INDEXES}

Index of Parasites, Fungicides, and Botanical Terms, 447-452 Index of Host-Plants, . . . . . . . $453-45^{8}$ 
. 


\section{LIST OF FIGURES}

\begin{tabular}{|c|c|c|c|c|c|}
\hline \multirow{2}{*}{\multicolumn{4}{|c|}{ pple, section of diseased ${ }^{\text {PAGE }}$}} & \\
\hline & & & & Gloeosporium fructigenum & \\
\hline $\mathrm{br}$ & • & . & 24 & Gloeosporium nervisequum & \\
\hline rmillaria mellea . & 2 & 202, & 205 & Gnomonia erythrostoma & \\
\hline yta pisi. & . & - & 276 & osporangium clavariae & \\
\hline ora apii & & . & 316 & forme . & \\
\hline ercospora circumsciss & & . & 318 & Helminthosporium turcicum . & \\
\hline porium epiphyl & & & 308 & vastatrix & \\
\hline n fulvum & & . & 3 I2 & echinulatum & \\
\hline laviceps purpurea & $\theta^{\circ}$ & . & 123 & iedermayeri & \\
\hline olletotrichum linden & nuthi- & & & m pinastri & \\
\hline anum & . & . & 289 & bile & \\
\hline ium ribicolum & • & . & 234 & mato . & \\
\hline didus . & . & - & 60 & ora pinitorqua & \\
\hline aii & . & . & I64 & sp. $\quad$. & \\
\hline alycina & . & . & 146 & lacrymans & \\
\hline um macu & atum & . & 277 & grossul & \\
\hline leproides & . & . & 226 & ena. & \\
\hline pichloe typhina & • & • & 126 & $\mathrm{ma}$. & \\
\hline Exoascus deformans & • & - & 83 & m harknessi . & \\
\hline uni & - & - & 86 & ra schleideni . & \\
\hline Exol & & - & I68 & Pestalozzia guepini & \\
\hline Fomes annosus & 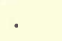 & - & 183 & Peziza vesiculosa & \\
\hline Fomes fomentarius & . & . & 186 & Pholiota adiposa . & \\
\hline terosporu & & . & $33^{2}$ & Phoma sanguinolenta & \\
\hline copersici & - & . & 329 & Phragmidium rubi-idaei . & \\
\hline dendritic & & . & 303 & am subcorticatu & \\
\hline n pirinum & ${ }^{\circ}$ & - & 305 & Phyllactinia suffulta & \\
\hline loeosporium ampelo & & & 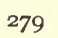 & Phyllosticta prunicola & \\
\hline
\end{tabular}




\begin{tabular}{|c|c|c|c|c|c|c|}
\hline & & PAGE & & & & \\
\hline Phytophthora infestans & & 63 & Rosellinia necatrix & & ${ }^{\circ}$ & . \\
\hline Phytophthora omnivora & & 67 & Rosellinia radiciper & rda & . & - \\
\hline Plasmodiophora brassic & cae & . 335 & Sclerotinia fuckelia & & . & \\
\hline Plowrightia morbosa & . & . $\quad$ I37 & Sclerotinia sclerotic & orum & & \\
\hline Plasmopara viticola & - & $\cdot 9,7 \mathrm{I}$ & Sclerotinia urnula & & . & \\
\hline Polyporus betulinus & - & . 190 & Sphaerella fragrari & & . & \\
\hline Polyporus hispidus & . & $\therefore \quad 192$ & Stereum frustulosu & & . & \\
\hline Polyporus sulphureus & . & . 195 & Stereum hirsutum & & & \\
\hline Polystigma rubrum & . & . 135 & Taphrina bullata & & . & \\
\hline Poria vaporaria & . & . $\quad \mathbf{I} 8 \mathbf{I}$ & Tilletia tritici . & & $\cdot$ & \\
\hline Pseudopeziza trifolii & . & . $\quad$ I44 & Uncinula spiralis & & · & \\
\hline Puccinia asparagi . & . & . 240 & Urocystis colchici & . & . & \\
\hline Puccinia graminis . & . & I2, 248 & Urocystis occulta & . & 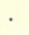 & \\
\hline Puccinia pringsheimian & & . 243 & Uromyces betae & . & 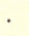 & \\
\hline Puccinia pruni & . & $\cdot 25^{\mathrm{I}}$ & Uromyces colchici & : & 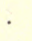 & \\
\hline Pythium de baryanum & . & 55 & Ustilago avenae & & 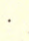 & . \\
\hline Rhizopus necans . & . & $5^{8}$ & Ustilago hordei & . & . & . \\
\hline Rhytisma acerinum & . & . $\quad 143$ & Vermicularia circin & lans & . & \\
\hline
\end{tabular}




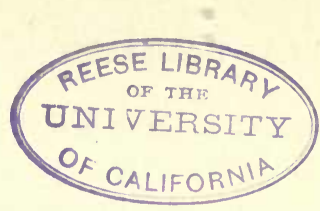 \\ PLANT DISEASES}

\section{INTRODUCTION}

THE knowledge necessary to enable the horticulturalist, farmer, or forester to utilise to the fullest extent the discoveries of specialists relating to plant diseases, and also to convey to others an intelligible account of the particular form of disease respecting which information is desired, may be arranged under three sections, as follows :-

I. Familiarity with the general appearance and name of the most frequent groups of parasites; their varied modes of attack, and the special conditions favouring the same; also the relationship between the different forms assumed by certain parasites during different periods of their existence.

This last item of knowledge would, in one instance, have saved from destruction a quantity of valuable young standard pear-trees that were attacked by the pear leaf cluster-cup fungus (Gymnosporangium sabinae). These trees were cut down for the avowed purpose of preventing the spread of the disease; at the same time the solitary juniper plant (Juniperus sabinae), the real cause of the mischief, was, through lack of knowledge, allowed to stand.

il. Preventive Measures. - The old maxim, 'Prevention is better than cure,' embodies the keynote to success 
in combating plant diseases ; in fact, if preventive measures were intelligently, rigorously, and persistently carried out, based on knowledge corroborated by repeated experiments, it might safely be predicted that the frequent wholesale destruction experienced at the present day would not be repeated.

III. Cures.- - Sometimes the attempt at effecting a cure is a success; frequently not. 'To the practical man, who naturally hopes for a cure at every stage of a disease, the result is generally disappointing. In the majority of instances where an annual plant is attacked, cure is practically impossible, and in the case of perennials, the prospect of a profitable crop for that year is slight. In such instances, however, the disease can be arrested in its course, and a recurrence prevented.

Many people are apt to ridicule and throw discredit on subjects with which they are not familiar, and possibly some may consider that the items of knowledge indicated above as being essential to a thorough grasp of the subject can lead to no good. To those with the mind thus constituted we fully agree that the attempt would result in no good: 'A man convinced against his will, is of the same opinion still.' On the other hand, the mind that can grasp the fact that a certain amount of knowledge is essential to the successful issue of any undertaking, will, it is confidently hoped, not encounter any great difficulty in acquiring a sound knowledge of the broad outlines of the subject. The experience of many of the most successful horticulturalists and others testifies that it well repays the time devoted to the study.

The following remarks, written more than half a century ago by the pioneer of Vegetable Pathology, so far as the 
subject of plant diseases is concerned, are unfortunately to a great extent true at the present day :-

'Every day's' experience shows the wisdom of encouraging amongst gardeners a higher order of education. It is not enough for the present state of cultivation, or the requirements of intelligent masters, that they should be content to follow in their predecessors' steps without attempting anything beyond the usual routine, and taking advantage of local circumstances either for the prevention of evil or material improvements. Under a narrow system of education and a low standard of qualifications, it may be well to fall in with the common saw, "But he is a safe man and will make no experiments," but a sound stock of principles will at once dissuade from all unsafe experiments, and give the power of meeting difficulties which to others would be insurmountable' (Berkeley, Gard. Chron., Nov. 27, r847).

The rule-of-thumb method of doing anything is pure mimicry, that is, imitating more or less exactly, depending on the amount of mimicry possessed by the operator, the actions of some one else, without knowing or caring for the reason why. Too much of this checks progress; the usual reply, that our forefathers succeeded without learning all that is by some considered essential to success at the present day, is not sound argument.

'Knowledge is power,' and the man who possesses the greatest range of knowledge relating to his special subject is the one most likely to succeed. Hence it follows that a knowledge of the broad principles regulating the mode of life of those groups of parasites which prove so injurious to cultivated plants should be clearly grasped; and as the fungi are most numerous, they will be dealt with first. 


\section{FUNGI}

A terse definition of the nature of a fungus is not possible. Toadstool, mushroom, rust, mildew, and mould are popular names for different groups of fungi, of which we have above four thousand species in Britain alone, whereas the Fungus-flora of the world includes above fifty thousand species.

Accepting the fact that fungi are true plants, there is one important feature in their life-history which must be clearly understuod, in order to realise why so many fungi prey upon and kill plants belonging to other groups of the Vegetable Kingdom. This feature relates to nutrition. It is well known that flowering plants derive one portion of their food from the soil, and another portion from the air. These substances are inorganic, that is, they are not the direct products of a living body, but under the influence of the chlorophyll or green colouring matter present in leaves these substances become converted into plant food, an organic substance, the direct result of work done by the living green leaves.

Now, fungi are entirely destitute of chlorophyll, hence they cannot assimilate inorganic food, but require organic food, and this they obtain by feeding on the bodies of other plants. For this reason we always find fungi following in the wake of flowering plants. Some few fungi obtain their food from animal bodies, living or dead. The different methods adopted for securing this organic food enable us to divide the fungi into two groups.

I. Saprophytes.-Those fungi are termed saprophytes that live on dead organic matter, as dead wood, heaps ot dead leaves, etc. ; and as such are not injurious to living 
plants, they require no further notice in this work. The great majority of gill-bearing fungi, or Agarics, belong to this section.

II. Parasites.-The enormous assemblage of fungi that obtain their food directly from living plants, and consequently act prejudicially to a certain extent on the host, or plant on which they are parasitic, belong to the present category. As too familiar examples may be enumerated the various rusts, bunts, and smuts of cereals, also the many mildews of living plants, along with numerous other minute fungi which do not possess popular names, and whose effects on their victims are usually attributed to other than the true cause.

As a qualification of the above definitions, it must be remembered that, under certain conditions, fungi which usually live as saprophytes may become parasites, and some such are to be numbered amongst the most destructive of fungi known. On the other hand, many dire parasites can live as saprophytes during certain periods of their existence.

Mode of Growth of Fungr.-Gardeners and others are often much disappointed, and their belief in the efficacy of successfully combating plant diseases is lessened, when they submit examples of plants which are stated to be showing the first symptoms of disease, and receive in reply the statement that it is too late to effect a cure, but that the disease may, with the exercise of sufficient care and attention, be prevented from spreading. This unfortunate condition of things is due to the fact that what the practical man considers as the first stage of a disease, the pathologist knows to be in many instances the last stage. This difference of opinion may be explained as follows :- 
In preparing a mushroom-bed, it is well known that the spawn or mycelium must grow and spread in the soil for some time before it yields a crop of mushrooms. The spawn or mycelium is the vegetative part of the fungus, doing the same kind of work done by the root and leaves of a flowering plant, that is, obtaining and assimilating food. The part popularly called a mushroom does not represent the entire fungus plant, but is in reality only the fruit of the fungus or sporocarp, its use being to produce spores, the equivalents of seeds; and it appears above the surface of the soil so that the ripe spores may be scattered by wind and rain, the mycelium or vegetative portion of the fungus remaining underground.

As a second example, take the black smut of oats. It is well known that the only time this fungus can inoculate and enter the tissues of the oat plant is just after the oat seed has sprouted. At this period, if germinating smut spores are present in the soil in which the young oat plant is growing, their germ-tubes readily penetrate the delicate tissues of the young oat, and once inside, the mycelium of the fungus grows along with the oat plant until the latter is nearly mature, when the fungus produces its powdery black mass of spores in the fruit of the oat. To the popular mind the appearance of the sooty mass of spores, being the first outward and visible sign of the disease, is considered as an early stage of its appearance, whereas the mycelium of the fungus has been feeding on the substance of the oat plant for months, in fact from the very earliest stage of its existence.

As a rule the vegetative part of a fungus remains out of sight, penetrating the tissues of the matrix, or substance on which it is growing, the fruiting portion or sporocarp of the 
fungus alone coming to the surface; and as the production of fruit is the final act in the life of the fungus, it may be accepted that the fungus has done its worst when it produces fruit.

The above account shows that the argument frequently brought forward, that as the fungus (sporocarp) has only appeared on dying or dead parts, it cannot be the cause of the disease, is not necessarily correct. On the other hand, the presence of a fungus on a diseased portion does not necessarily prove that the fungus was the cause of the disease. This has to be proved or refuted by proper methods.

An exception to this rule is met with in the group of fungi represented by the hop mildew (Sphaerotheca castagnei,Lév.), where the mycelium or vegetative portion of the fungus is quite superficial, forming white patches on the surfaces of living leaves; certain short branches of the mycelium, called haustoria or suckers, pierce the epidermis of the leaf, enter the cells, and absorb the food required by the fungus. The mycelium consists of very slender, thin-walled tubes called hyphae. In the fruit and certain other structures these hyphae are densely interwoven, forming solid parts; and often the walls of the hyphae are thickened to such an extent that a structure as hard as wood is produced.

REPRODUCTION of FUnGi. - The majority of fungi are short-lived, and the arrangements for reproduction, or the continuation of the species, are usually provided for on a very lavish scale. In this respect again, fungi differ very materially from flowering plants. In the latter there is only one form of fruit produced, the seeds of which reproduce the species; whereas in the great majority of parasitic fungi there are at least two distinct forms of fruit, and in many kinds three or even four distinct and very different-looking 
forms of fruit are produced throughout the season, each performing a function not capable of being done by any one of the other forms. These different kinds of fruit have received special names, the value of which it is important to clearly understand.

Taking as a first illustration the Vine Mildew (Plasmopara viticola, De Bary), we find that early in the summer the leaves of diseased plants are more or less covered with a delicate white mildew on the under surface, which.is the summer fruit, or conidial form of reproduction of the fungus (Fig. I, I). This fruit originates from mycelium present in the tissues of the leaf, the fruiting branches emerging through the stomata or breathing pores of the leaf, for the purpose of dispersing their conidia in the air. This mildew, when examined under the microscope, is found to consist of numerous much-branched hyphae, the tip of each branch bearing two or three minute reproductive bodies or conidia (Fig. I, 2). Without at present entering into details, these conidia are capable of germination the moment they are mature; and being produced in immense numbers and in rapid succession throughout the summer months, and being readily dispersed by wind, rain, insects, etc., those that happen to be deposited on the surface of a damp, healthy vine leaf, germinate at once, enter the tissues of the leaf, form a mycelium, and in a very short period of time produce the white mould on the surface of the leaf, which in turn becomes a centre of disease, producing conidia ready to be scattered and further extend the mischief. This explains the rapid extension of a disease which has once gained a foothold among plants of the same kind that are grown in considerable numbers, and in contact with each other, as in vineyards and field crops generally. 


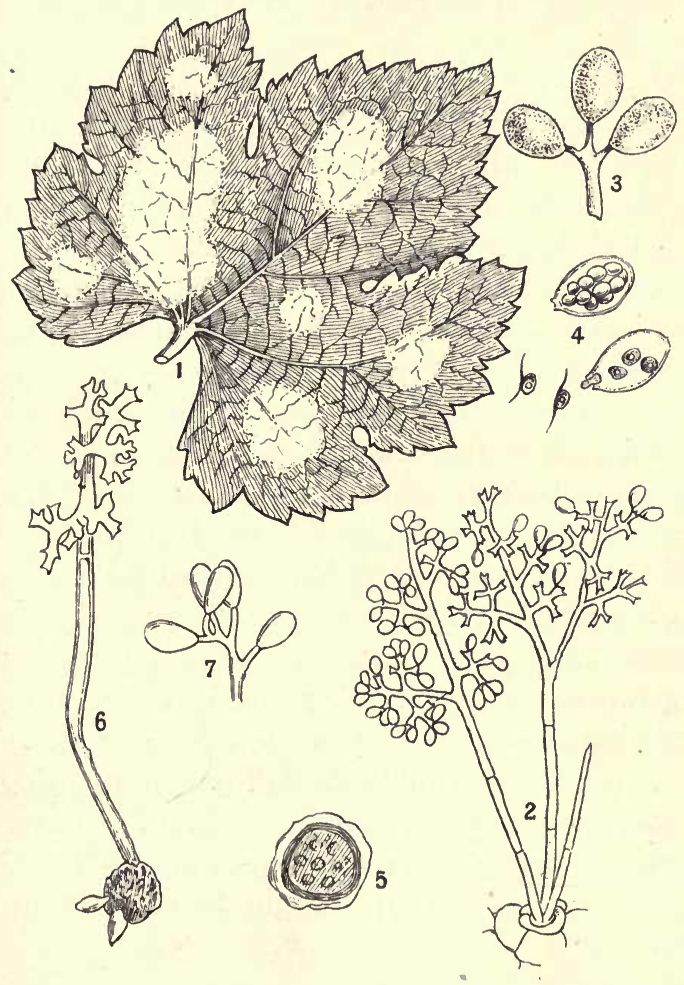

Fig. I.-Vine Mildew (Plasmopara viticola). 
The function of the rapidly grown, quickly germinating conidia, produced thronghout the summer season, while the host-plant is in the full vigour of growth, is to enable the fungus to extend its geographical area of distribution.

When the vine leaves begin to fade, the production of summer fruit ceases; and after the leaves have fallen, the same mycelium, which during the summer has given origin to conidia, now produces a second kind of reproductive body called winter fruit, or technically oospores. These bodies are also sometimes called resting-spores, from the fact that, unlike conidia, they will not germinate the moment they are mature, but only after a period of rest. Oospores are spherical bodies of a dark brown colour, furnished with a very thick, protective cell-wall, and are produced, often in immense numbers, in the tissues of dead leaves (Fig. I, 5). Although such diseased leaves often decay and disappear during the winter or early spring, the oospores they contained are not destroyed, but retain their vitality, lying on the ground, and germinate about the month of May, producing two or three germ-tubes much branched at the tip and bearing conidia similar to the summer form of fruit (Fig. I, 6). These conidia are dispersed by wind, and those that happen to alight on the surface of a young, damp vine leaf, germinate, enter the tissues of the leaf, form a mycelium, which soon gives origin to the summer form of fruit.

The function of oospores or the winter. form of fruit is that of continuing the species in time, or from one season to another; enabling it to tide over that period of the year when its host-plant is also in a resting condition. 
The rust of wheat (Puccinia graminis) has a more complicated life-history, possessing four distinct structures connected with reproduction, and, like many of its allies, lives on different host-plants during different stages of its development. Heteroecism is the term used to denote fungi that require to grow on two distinct hosts to complete the full cycle of their development.

The spring condition of wheat rust, called the Aecidium or 'cluster-cup' stage, occurs on the leaves, young shoots, sometimes also on the flowers and young fruit, of the barberry (Berberis vulgaris), under the form of clusters of minute cup-shaped structures with white, fringed margins, and filled with golden-yellow spores (Fig. 2, 8 and ro).

Other bodies, considered to be in some way connected with reproduction, known as Spermogonia, are produced by the fungus on barberry leaves, accompanying the aecidium condition, but nothing definite is known respecting them.

The mature aecidium spores are scattered by wind, and those that happen to alight on the leaves of wheat or various other grasses, germinate if the surface is damp; the germ-tube enters the tissues, where it forms a mycelium, and in a very short time produces dense groups of rustcoloured uredospores, which burst through the tissues of the leaf, forming the rust-coloured streaks on its surface, known as wheat-rust (Fig. 2, I and 2). Uredo or summerspores are produced in immense numbers throughout the summer months, thus securing the spread of the disease.

During the autumn teleutospores or winter-spores are produced by the mycelium that gave origin to uredospores earlier in the season. The streaks formed on the leaves by the teleutospores are much darker in colour than those produced by the uredospores (Fig. 2, 5). The teleuto- 


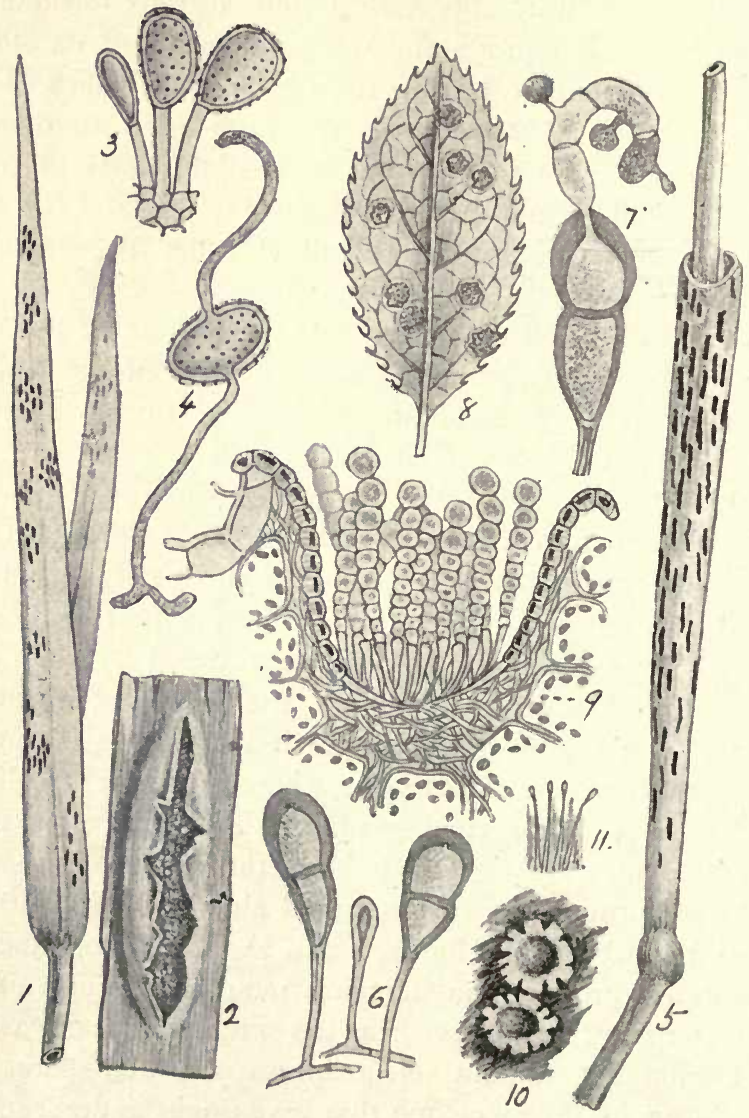

Fig. 2. - Rust of Wheat (Puccinia graminis). 
spores remain firmly attached to the leaves, and may often be found in a living condition on rotten straw in a manure-heap.

During the spring following their production, the teleutospores germinate, giving origin to a few very minute reproductive bodies called secondary-spores (Fig. 2, 7), which are dispersed by wind. Such of these as alight on barberry leaves give origin in turn to the aecidium or cluster-cup stage of the fungus.

The above account briefly describes the complete lifecycle of wheat rust ; but it is important to remember that the continuance of the species does not require that it should be repeated every season. The uredo or summerspore condition alone is sufficient to perpetuate the disease from year to year, growing during the winter on the leaves of wild grasses in sheltered situations, as hedg€ ':anks, etc., and passing from thence to young wheat.

In addition to the above, and other modes of reproduction by means of various kinds of conidia or spores, fungi are also reproduced by the mycelium or vegetative portion of the fungus, which under certain conditions becomes highly specialised for this purpose. The most usual form of vegetative reproduction consists of densely compacted masses of hyphae called Sclerotia. These sclerotia are globose or irregularly shaped masses, varying in size from that of a pin's-head to a cricket-ball, depending on the fungus to which they belong. The outside is generally blackish, the inside white. These bodies are formed, often in large numbers, in the substance of the plant on which the fungus is growing. When the hostplant decays, the sclerotia remain in the soil in an unchanged condition until the following season, when 
they produce some form of reproductive body which inoculates the young host-plant. In many instances sclerotia are formed in living parts of the host, especially in bulbs, where they remain latent until the bulb produces a new growth, which is infected in due course.

From the above account it will be seen that sclerotia perform the same function as winter-spores, remaining passive during the resting condition of the host, and producing fruit when the latter commences a new growth.

How Parasitic Fungi Infect their Victims. - The conidia or spores of numerous parasitic fungi, carried by wind, rain, or other agents, are deposited on the leaves, fruit, or other parts of the host-plant, germinate at once, and enter the tissues. This may be considered as the most direct and general method of infection.

Armillaria mellea, an exceedingly common gill-bearing fungus, or 'toadstool,' very destructive to forest and orchard trees, illustrates a second mode of attack.

The fungus often lives as a saprophyte, growing in dense clusters on decaying stumps, etc. Its mycelium forms thin, cordlike strands which radiate in all directions. in the soil; and if one of these strands of mycelium comes in contact with the living rootlets of a tree, its tissues are attacked, the mycelium of the fungus enters the rootlet, adopts a parasitic mode of life, spreading further and further into the tissues, until finally the whole root-system of the living tree is enveloped in a white, felty mycelium, which gradually extends up the trunk, ending in the death of the tree.

In the meantime, numerous strands of mycelium originating from the diseased tree are traversing the soil in every direction in search of other victims, and by this 
means neighbouring trees may eventually be destroyed by the mycelium spreading originally from a single centre of infection.

A third mode of attack is practised by certain fungi known as wound-parasites; that is, fungi whose spores are not capable of directly penetrating living tissues, but at first require to live as saprophytes, changing gradually to a parasitic mode of life. This is effected by the spores of such fungi germinating on a wounded surface, as a broken branch, pruned branches, the cut surface of which has not been properly protected, bruises caused by hailstones, the nibbling of rabbits, mice, etc. The mycelium first produced lives in the decaying tissues of the wound, and gradually attacks the adjoining living tissue.

Forest and fruit trees are more especially attacked by wound-parasites belonging to the genera Polyporus and allied forms. As a rule, the heart-wood is first attacked, the mycelium gradually extending to the circumference, until finally the trunk becomes quite hollow, owing to the wood being reduced to powder by the corroding action of the mycelium of the parasite.

Hollow trunks are generally due in the first instance to the attacks of parasitic fungi, and are not, as popularly supposed, the result of old age and what is termed natural decay.

How the Spores of Fungi are Dispersed.-Mention has already been made of the dispersal of spores by wind, which must be considered as the most general agent for enabling spores to reach a position suited to their requirements; at the same time, experiments indicate that spores are not transported over those immense distances that was at one time considered probable. The influence of wind 
in disseminating spores is most apparent where numerous plants of the same kind grow in close proximity, as in the case of a field of corn, when a gentle breeze is sufficient to bring diseased and healthy plants in contact; and if the leaves are damp with dew or rain, such conditions are highly favourable to a rapid extension of disease.

Heavy rain washes spores to the ground, where they germinate and perish in the absence of the proper host; whereas a slight shower or gentle drizzle favours the spread of a disease, by washing spores from one part of a plant to another or on to adjoining plants.

Insects, birds, snails, and slugs are known to be unconscious agents in the dispersion of spores, whereas dogs, hares, rabbits, etc., running through a field of corn, potatoes, or turnips, act after the fashion of wind, by bringing into contact adjoining plants.

Spores or fragments of mycelium capable of growing are too frequently transported from infected to healthy localities by human agency. As illustrations may be mentioned the spores of the 'finger-and-toe' disease of cabbages and turnips, which are readily transported in soil adhering to cart-wheels, tools, shoes, etc. Spores are also readily transported by clothing; a gardener moving about among a number of closely packed chrysanthemums can hardly fail to brush off some of the powdery uredospores of the chrysanthemum rust, if such is present, and will as certainly have the spores brushed off his clothing by other plants.

Parasitic fungi attacking plants grown under glass are to a great extent deprived of those means of spore dissemination so efficient to fungi growing in the open air. This loss is, however, perhaps more than compensated for by those 
modes due to human agency already mentioned; and perhaps the most efficient method of all is that effected by syringing. By this means spores are dispersed over every part of a house, some of which, in the ordinary course of things, will fall upon damp leaves. Syringing is simply tempting Providence in those instances where the house contains plants of one kind only, and where the presence of a disease is known, or even suspected.

It has been suggested, in the case of the chrysanthemum rust epidemic, that in one instance the disease was introduced owing to syringing the plants with rain water, supposed to contain the spores of the fungus that had been carried from the roof into the cistern.

I am quite conscious of the fact that the practical man will retort, Gardeners must move about among plants, and spraying is a necessity. This may be considered good argument; nevertheless, it is well to be in possession of all known facts bearing on the movements of the enemy, as such knowledge must precede any attempt to apply a cure.

So far as danger from the use of water is concerned, this can be obviated by adding a wineglassful of paraffin to three gallons of water. This proportion is sufficient to destroy germinating spores, and will not injure, but in reality benefit, the plants in other ways.

Modes of Dissemination of Disease that CaN BE Prevented.-Dr. Erwin F. Smith, an American vegetable pathologist, said, in a lecture on plant diseases, 'Competition is not likely to decrease, nor are prices likely to advance very much, and the profits must come from avoiding losses.' Hence the following suggestions :-

Probably the commonest source of plant infection arises 
through carelessness in not promptly destroying by burning diseased plants, fruits, bulbs, etc., which in most instances can be readily done without much expense or loss of time. For instance, it is not unusual to see quantities of diseased leaves and fruit on the ground in orchards. If such are allowed to remain, the fungi present continue to produce spores, or winter-spores or sclerotia are formed; and although the leaves and fruit ultimately decay and disappear, the spores and sclerotia do not perish, but remain on the ground until the following spring, when they give origin to spores that are conveyed to the young leaves, and the disease appears once more. Of course, the cultivator of plants cannot directly prevent the diffusion of spores by wind or other agents; but what he can do-and what it pays to do-is, by systematic cleanliness and promptitude, to prevent, to a very great extent, the formation of spores on the plants over which he exercises control.

Burn all diseased plants, fruit, and bulbs, and do not throw them on the manure-heap, which means securing a recurrence of the disease.

It has been already explained that the majority of parasitic fungi possess more than one form of fruit; and furthermore, the summer form of fruit is the one that produces a quickly spreading disease or epidemic, usually appearing in late spring or early summer, and continuing to extend its ravages throughout the season, unless checked.

When a disease appears, remove the diseased plants, and spray the remainder at intervals with solution of potassium 
sulphte if growing indoors, or with dilute Bordeaux mixture if outdoor shrubs or trees.

Numerous diseased portions of plants find their way to the manure-heap, either directly - which is a serious mistake to commit at any time or under any circumstances-or indirectly, after being used for fodder, as rusted straw of cereals, chaff, also roots, tubers, etc. In a sweating, moist manure-heap, the numerous spores and sclerotia present in such diseased plants find a congenial home, multiplying rapidly under various spore-forms as saprophytes; and if the manure is used while fresh or green, a disease will in all probability follow, if the plants manured happen to be of the kind the fungus-spores can attack. 'Smut' of cereals, drooping disease of paeonies, and many other diseases, have been proved to have been introduced with manure.

The practice of burying prunings, as followed in some tea plantations, should be discontinued. Such should be burned. The small amount of advantage gained in the way of manure is not a sufficient justification, as against the possible, or probable, danger of further spreading a disease by following this practice.

Do not throwe diseased plants on to the manure-heap, nor into piggeries, etc. Fresh or green manure should not be used for land intended for cereals. Only old and thoroughly rotten manure should be placed on the ground over the roots of rose trees, young orchard or forest trees, or over perennials that die down in the autumn.

The destructive sugar-cane disease (Trichosphaera sacchari) was disseminated wholesale by the thoughtless 
practice of using diseased canes for purposes of propagation. Bulbs or tubers infested with sclerotia naturally produce diseased plants; it is for this special object that the sclerotia are present. Cuttings from diseased plants are prone to perpetuate the disease, even if the particular cutting used appeared to be free from the disease. To understand this statement, it must be remembered that when the mycelium of a parasitic fungus has entered the tissues of a host, it usually spreads far beyond those points where it announces itself by killing portions of the host, and producing its fruit on the surface of such dead or dying parts. Furthermore, mycelium possesses the power of remaining latent for a long period of time, and of assuming an active condition when favourable circumstances present themselves.

Finally, the seed of diseased plants often produces diseased seedlings, as in the 'sleepy disease' of tomatoes. An instance of this kind came under my observation : a fine hollyhock growing in my garden was severely attacked by the hollyhock rust (Puccinia malvacearum), the calyx and even the carpels being studded with the small brown, wartlike pustules of teleutospores. The seed of this diseased plant was sown in due course, and, in a large percentage of the seedlings, the characteristic fruit of the fungus appeared on the cotyledons.

Cuttings from diseased plants should not be used for propagation. Bulbs or tubers produced by diseased plants perpetuate the disease, and do. so with certainty if sclerotia are present. Seed produced by diseased parents should not be sown. Seedsmen should be required to give a guarantee that seed offerea for sale was obtained from healthy plants. 
Certain especially destructive forms of fungi are capable of living and extending in a vegetative manner in the soil, and are consequently combated with great difficulty. Such fungi are unfortunately equally capable of becoming true parasites when the mycelium comes in contact with the roots of living plants, and possess the further distinctly objectionable peculiarity, from the human standpoint, of not being so fastidious in their choice of a host as is customary with fungi, but attack, almost indiscriminately, every plant that comes in their way. Among such may be enumerated white root-rot (Dematophora necatrix), New Zealand root-rot (Rosellinia radiciperda), tree rootrot (Armillaria mellea), conifer root-rot (Fomes annosus), and various others.

Where rotting of the roots of trees is caused by fungi that extend their range by means of mycelium spreading in the soil, it is advisable, as suggested by Hartig, to isolate such diseased trees by a narrow trench about eight inches deep, making the trench sufficiently distant from the trunk so as to be outside the spread of the roots. Throwe the soil removed inside the trench.

Many parasitic fungi can only live on one particular host-plant, and the majority are confined in their ravages to closely related plants, or at most to plants belonging to the same Order. Hence a disease spreads quickly when numerous plants of the same kind grow in close proximity, whereas when the vegetation is of a mixed character, those plants not susceptible of the disease intercept numerous spores, and thus to a great extent protect the susceptible plants. 
It is an indisputable fact that the presence of numerous plants of the same kind, and of the same age, massed together, not to say crowded, favours the spread of a given disease; in fact, all epidemics on a large scale naturally require such conditions, as the potato disease (Phytophthora infestans), rust of wheat (Puccinia graminis), vine mildew (Plasmopara viticola), larch canker (Dasyscypha calycina), and others.

It is fully realised that in many instances myriads of plants of the same kind, and of the same age, must exist, as in the case of cereals, and in fact practically all field crops ; nevertheless it is well that the disadvantage of this method should be known, even if it cannot at present be obviated.

On the other hand, is it absolutely necessary, or even advisable, to crowd a house with tomatoes alone, or with chrysanthemums, or to plant pure forests or plantations? Experience proves that such a proceeding is not conducive to the well-being of plants so treated, and it rests with the practical man to avoid the danger as far as possible.

Avoid massing together plants of the same kind whenever circumstances permit.

Mention has already been made of the group of fungi called wound-parasites on account of their gaining admission to living tissues through some wound or broken surface. Many such wounds are beyond the control of human agency, either to avert or to protect from serving as a starting-point for the attacks of fungi. Among these are wounds caused by hailstones, cracks and wrenches 
produced by the weight of snow lying on branches, frost, punctures made by insects, animals, etc. On the other hand, many wounds are well under control; broken branches should be removed, the 'snag' sawn off, and the wounded surface protected. In pruning, every wound should at once be protected by a coat of tar; and just now, when it is the rage to prune almost every kind of tree, however beautiful and flowing its natural contour, into a conical monstrosity resembling in outline those wonderful toy trees made in Germany, the wounds made are so many, that if not promptly protected, attack from some fungous foe is practically certain. The danger may not be evident at once, perhaps not for several years, but the following quotation on pruning young trees, from Schlich's Manual of Forestry, may be accepted as authoritative :-

'As a general rule, plants should not be pruned unless it is absolutely necessary. Every cut produces a wound, exposing the plant to disease, which may ultimately render it unfit for the purpose for which it has been grown. Recent researches have shown that the unhealthy condition of timber trees may be due to spores of fungi entering the tissues through wounds received at a very early age.'

Wounds made by pruning should be immediately protected by a coat of tar or some other substance capable of preventing the germination of spores on the cut surface.

Most people have observed that even in the worst cases of a disease, certain plants remain unscathed, and in certain instances it has been proved that the descendants of these plants also possess-we had almost written inherited-this 


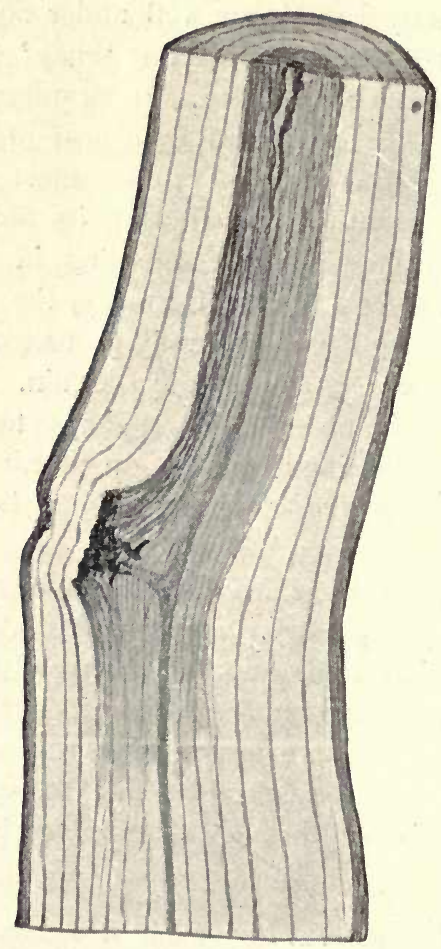

Fig. 3. - Section of the stem of a young apple-tree, showing the effect of pruning and not protecting the cut surface. The shaded portion is diseased, and the tree died from the effect some years after the fungus first attacked it. 
immunity. It is also an established fact that in many instances certain forms or varieties of a cultivated plant are much more resistant to disease than others. This idea has been clearly established by Dr. Cobb in connection with wheat and its fungous enemy (Puccinia graminis). Unfortunately, it has also been demonstrated that varieties that have been proved to be comparatively immune in one particular district are equally or even especially susceptible to the disease when removed to another locality; or forms that have behaved in an encouraging manner for a certain period of time have afterwards lost this power. Nevertheless, it is encouraging to know that in particular districts certain varieties are more disease-proof than others, and in all probability further investigation of this phase of the subject will result in the development of disease-resisting varieties. This peculiarity turns on some, probably slight, modifications, morphological or physiological. But it is always well to remember that however much the host-plant may succeed, aided or unaided, in guarding itself against its foe, fungi, on the other hand, have proved themselves equally capable of adaptation to existing circumstances.

Evidence forthcoming supports the idea that, by careful and continued selection, disease-proof varieties of plants may be produced and perpetuated.

Care should be taken to prevent the spread of disease directly by human agency. This too frequently occurs, especially in the case of those fungi whose mycelium spreads in the soil; also resting-spores and sclerotia. These are carried from place to place by the soil adhering to shoes, tools, cart-wheels, etc. Summer-spores are also diffused by adhering to clothing. 
In many instances where the soil has become infested with resting-spores or sclerotia, it is very unwise to continue growing the same kind of crop, and under the circumstances rotation of crops ; selecting those that the fungus present in the soil does not attack is undoubtedly the best thing to do under the circumstances. Deep ploughing is sometimes resorted to for the purpose of burying the spores or sclerotia, but for other reasons this cannot always be done. Where rotation of crops cannot be followed out, very frequently what is termed a trap-crop is found to be useful in clearing the soil of disease germs.

As an illustration of this method, we may take the case of the disease known as 'finger-and-toe' of cabbages, turnips, radishes, and other cruciferous plants. The myxogaster causing 'finger-and-toe' is essentially an underground organism, living on organic matter in the soil, or as a parasite in the roots of plants. It has been proved that in the case of badly infected soil, if a crop of any quick-growing cruciferous plant is grown early in the season, the plants become diseased. After the trap-crop has thus caught up the disease, it should be removed at once, and immediately afterwards the same ground may be planted with cabbages or turnips, which will remain free from the disease. This method would undoubtedly prove of great service in many forms of disease, where the inoculating bodies are present in the soil. The points to remember are: the trap-crop should consist of some plant readily susceptible to the disease it is intended to catch, and that after becoming diseased, it should be removed before spores or sclerotia are produced.

Rotation of crops and the employment of trap-crops are to 
be recommended for the purpose of checking disease, especially in those instances where the inoculating bodies are present in the form of resting-spores or sclerotia in the soil.

Shade trees are commonly employed in tropical countries for the purpose of affording shelter to plants under cultivation, especially in the case of tea, coffee, and cacao.

This is a subject worthy of much more attention than it appears to have received up to the present, although Dr. Watt has some remarks to the point in connection with tea culture in India.

There is grave danger of introducing or perpetuating disease unless great care is exercised in the selection of shade trees.

As previously stated, parasitic fungi as a rule confine their attacks to closely allied plants, or at most to plants belonging to the same Order. For this reason it would not be advisable to utilise as shade trees such as are closely allied to the plants under cultivation.

Another point of importance is to ascertain whether fungus parasites likely to attack cultivated plants are present on wild plants in the jungle or forest.

Hemileia canthii, Berk. and Broome, infests Plectronia campanulata, Bedd. (=Canthium campanulatum, Thwaites), a wild plant common to Ceylon and India, and the parasite on the leaves of this plant is so close to the Hemileia vastatrix, Berk., the coffee leaf disease, that it is doubtful whether the two parasites are not identical, the minute differences observable being due to difference of host. Again, Hemileia woodii, Kalchbr. and Cooke, appears to be not uncommon on two small trees allied to the coffee plant, Vangueria infausta, Bruch, and Vangueria latifolia. 
The former occurs in tropical and South Africa, the latter in Natal. The same parasite also occurs on leaves of an unknown plant from Natal. This parasite again is so close to that of the coffee leaf disease, that it is almost certain, opportunity afforded, the parasite would pass from one to the other. To start a coffee plantation in the neighbourhood of the Vangueria would in all probability mean disaster. Allied plants usually require the same food constituents, whereas plants belonging to different Orders in many instances do not rob each other of the same kind of food derived from the soil, but actually mutually benefit each other. The value of rotation of crops turns mainly on this feature in plant life. It has been known for centuries that the fertility of the soil could be increased by the growth of leguminous plants, and Dr. Watt-Pests and Blights of the Tea Plant, p. 169-has shown that leguminous trees, as Acacia dealbata, Dalbergia assamica, Albizzia stipulata (sau tree), and others belonging to the same family, proved highly beneficial to the tea plant by enriching the soil, in addition to serving the function of a shade tree.

Finally, success in eradicating plant diseases depends almost entirely on universal co-operation. It is comparatively waste time and money attempting to hold a particular disease in check, especially in those instances where spores are carried by wind, if your neighbour, whose plants are suffering from the same disease, does not exercise ordinary precautions. 


\section{LICHENES}

The immense number of plants belonging to this family differ from fungi in possessing chlorophyll, and consequently can assimilate inorganic matter. A lichen in reality consists of a body formed of two distinct elements, a fungus and an alga, the two living together and mutually assisting each other in the procuration and assimilation of food, a condition known as mutualism; differing widely from those cases where a parasitic fungus lives on another plant, in which case the parasite has all the advantage;. and the host, or plant preyed upon, all the disadvantage.

Lichens often form leafy expansions covering the trunks of trees, and such are not parasites, although their presence does not benefit the tree, especially when young. On the other hand, many lichens vegetate in the living bark or on coriaceous evergreen leaves, especially in the tropics, and may fairly be considered as parasites.

\section{ALGAE}

Seaweeds are the best-known representatives of this family, although numerous representatives live in freshwater streams, dicches, and ponds. All the members possess chlorophyll; nevertheless, some of the simplest forms are parasitic on higher plants, while others live in a condition of mutualism.

\section{MYXOGASTRES}

The Myxogastres or 'Slime-fungi' were at one time considered as belonging to the fungi, but are now separated on account of important structural differences, and by some are considered as belonging to the animal rather than the vegetable kingdom. 
The spores on germination give origin to amoeboid bodies capable of exercising a sluggish movement. These bodies coalesce in quantities to form a naked mass of protoplasm, also capable of movement, called a plasmodium. This represents the vegetative stage. No mycelium is developed during any period. The plasmodium eventually becomes stationary, and resolves itself into a mass of minute spores.

Several organisms considered to belong to this group are suspected as being parasitic on plants, the best known and most destructive being the one causing 'finger-and-toe' disease in cabbages, turnips, etc. (Plasmodiophora brassicae).

\section{BACTERIA}

These infinitesimally minute organisms, popularly termed 'germs' or 'microbes,' are better known as the cause of numerous animal diseases; in fact, it is only in comparatively recent times that bacteria have been connected with plant pathology. At the present day numerous plant diseases are attributed to bacteria, some truly, others doubtfully so.

Bacteria are distinguished according to their shape :-

(I) Cocci are spherical, either solitary or united in groups.

(2) Bacilli are straight rods.

(3) Spirilla are spirally curved rods.

Numerous forms of bacteria possess the power of voluntary movement, due to the presence of minute cilia or flagella.

Multiplication takes place in two distinct ways: (I) by fission-hence the name Schizomycetes sometimes given to the group. When an individual has attained the normal size it divides into two portions, each of which continues to grow until the normal size is reached, when the process is 
repeated. (2) By spores, which are termed endogenous, when formed within the cell ; arthrogenous, when portions separate from the cell and gradually develop into distinct individuals.

The changes effected by bacteria on the substance on which they are living are very varied, and included under the term metaboiism. Bright colours are often produced; odours agreeable or otherwise are also common; some again induce phosphorescence. Putrefaction and fermentation also result.

Certain species possess the property of forming nitrates by the conversion of ammonia into nitric acid, saltpetrepotassium nitrate-being one of the ultimate products.

A most important feature to remember, from the standpoint of the cultivator of the soil, is the fact that what has been termed 'nitrification' of the soil, or the fixation of nitrogen in a form that can be readily assimilated by plants, to whose existence it is indispensable, is effected by bacteria present in the soil; hence it is important, in attempting to destroy fungous germs present in the soil, not to make use of substances also capable of destroying the indispensable bacteria present.

\section{FUNGICIDES}

The various preparations applied to plants for the prevention of diseases caused by parasitic fungi are called fungicides.

A fungicide to be of value should possess the following points : (I) Destroy the parasite without injuring the host. (2) Be easy to prepare and to apply. (3) Cost moderate or even cheap. 
From amongst the numerous solutions and powders that have been experimented with, the following have proved most effective :-

\section{Solutions}

(x) Bordeaux mixture.

(2) Ammoniacal solution of copper carbonate.

(3) Solution of potassium sulphide (liver of sulphur).

(4) Solution of iron sulphate.

(5) Solution of potassium permanganate (=Condy's fluid).

(6) Paraffin. Formalin. Lysol.

PowDERS

(I) Sulphur.

(2) Quicklime.

Bordeaux Mixture.-This substance is universally admitted to be the most effective fungicide known. Its various advantages are indicated as follows by Professor B. T. Galloway of the United States Department of Agriculture: (x) Its thorough effectiveness as a fungicide; (2) its cheapness; (3) its safety from a hygienic standpoint ; (4) its harmlessness to the sprayed plant; and (5) its beneficial effects on plants other than those resulting from the mere protection against the attacks of parasites.

The same high authority gives the following improved method of preparing Bordeaux mixture :-

'All things considered, it is believed that the best results will be obtained from the use of what is known as the 50-gallon formula of this preparation. This contains :

Water . . . 50 gallons.

Copper sulphate . . 6 pounds.

Unslacked lime . . 4 pounds. 
'In a barrel or other suitable vessel place 25 gallons of water. Weigh out 6 pounds of copper sulphate, then tie the same in a piece of coarse gunny sack, and suspend it just beneath the surface of the water. By tying the bag to a stick laid across the top of the barrel, no further attention will be required. In another vessel slack 4 pounds of lime, using care in order to obtain a smooth paste, free from grit and small lumps. To accomplish this, it is best to place the lime in an ordinary water-pail and add only a small quantity of water at first, say a quart, or a quart and a half. When the lime begins to crack and crumble, and the water to disappear, add another quart or more, exercising care that the lime at no time gets too dry. Towards the last, considerable water will be required, but if added carefully and slowly, a perfectly smooth paste will be obtained, provided, of course, the lime is of good quality. When the lime is slacked, add sufficient water to the paste to bring the whole up to 25 gallons. When the copper sulphate is entirely dissolved and the lime is cool, pour the lime milk and copper sulphate solution slowly together into a barrel holding 50 gallons. The milk of lime should be thoroughly stirred before pouring. The method described ensures good mixing, but to complete this work, the barrel of liquid should receive a final stirring, for at least three minutes, with a broad wooden paddle.

'It is now necessary to determine whether the mixture is perfect-that is, if it will be safe to apply it to tender foliage. To accomplish this, two simple tests may be used. First insert the blade of a penknife in the mixture, allowing it to remain for at least one minute. If metallic copper forms on the blade, or, in other words, if the polished surface of the steel assumes the colour of copperplate, the 
mixture is unsafe, and more lime must be added. If, on the other hand, the blade of the knife remains unchanged, it is safe to conclude that the mixture is as perfect as it can be made. As an additional test, however, some of the mixture may be poured into an old plate or saucer, and while held between the eyes and the light, the breath should be gently blown upon the liquid for at least half a minute. If the mixture is properly made, a thin pellicle, looking like oil on water, will begin to form on the surface of the liquid. If no pellicle forms, more lime should be added.'

It is very important to remember that air-slacked lime should never be used in the preparation of Bordeaux mixture, since its use results in injury to the foliage.

The adhesive property of Bordeaux mixture is much increased by adding soft soap in quantity equal to that of the copper sulphate. This is especially necessary when spraying smooth or waxy leaves, the soap increasing the tendency of the liquid to spread instead of forming into large drops, which roll off the surface of the leaf.

Since the discovery of Bordeaux mixture by Millardet in I 885 , the general tendency has been to reduce its strength; and even prepared in the proportions given above, it sometimes slightly scorches tender, young foliage. Hence it is advisable to dilute the mixture for spring spraying, using the full strength when the leaves are full grown, and again reducing the strength when spraying young fruit. Apples, pears, and cherries may be sprayed until half grown, when the operation should cease, otherwise the ripe fruit is liable to be spotted.

With the dilute mixture found to be efficient, the sprayed foliage does not present the appearance of having been whitewashed to the same extent as when a denser mixture 
was used. Nevertheless, the effect produced is perhaps sufficient to forbid its use in private or public parks or gardens, or conservatories. On the other hand, to the horticulturalist or fruit-grower, where appearances can be ignored, Bordeaux mixture is at once the most effective and cheapest fungicide that can be used.

As a typical illustration of the value of spraying with Bordeaux mixture, the following is taken from Bulletin No. 7 of the United States Department of Agriculture, entitled, 'The Effect of Spraying with Fungicides on the Growth of Nursery Stock.'

Seedlings or grafted stocks of pears, cherries, plums, apples, etc., are subject to various fungous diseases which attack the foliage, causing the latter to fall prematurely, and as a result the following are some of the effects produced :-(I) In the case of seedlings the active wood ripens so that the buds cannot be inserted, or if they are inserted the union with the stock is imperfect, and in consequence the bud eventually dies; (2) if the bud or graft should grow, its development is checked by the annual early loss or drying-up of its leaves. This brings about a stunted development, from which it is doubtful if the tree ever recovers.

The experiments were conducted on a large scale, and continued for three consecutive years, each tree being sprayed five times each year. An equal number of unsprayed trees, growing under similar conditions, afforded the basis from which the following conclusions were made.

The cost of treating nursery stock with Bordeaux mixture, the only preparation that can be unqualifiedly recommended, need not exceed 25 cents per Ioo० trees the first season. The second year the cost of the work 
will be also 25 cents, while the third year the cost will be increased to 35 or 40 cents per 1000, making the total cost of treating trees until the buds are two years old from 85 cents to $\$$ I per 1000 .

The net profit resulting from the work in case of the pears and cherries ranged from $\$ \mathrm{I}$ to $\$ 40$ per I 000 trees, the average being \$I 3 per rooo.

In conclusion, it may be said that as a whole the experiments clearly show that spraying nursery stock with fungicides is thoroughly practicable; that it results in better trees; and finally, that it yields a handsome profit.

Ammoniacal Solution of Copper Carbonate

$\begin{array}{lcc}\text { Water } & \cdot & \text { I6 } \\ \text { Carbonate of copper } & \cdot & \text { I ounce. } \\ \text { Carbonate of ammonia } & \cdot \quad 5 \text { ounces. }\end{array}$

Mix the carbonate of copper and the carbonate of ammonia, and dissolve it in about a quart of hot water. When thoroughly dissolved, add 16 gallons of cold water.

A second method of preparation, as follows, is recommended by Professor Galloway :-

\begin{tabular}{|c|c|}
\hline Water & 45 gallons. \\
\hline Strong aqua ammonia & 3 pints. \\
\hline Copper carbonate & 5 ounces. \\
\hline
\end{tabular}

The copper carbonate is first made into a thin paste by adding a pint and a half of water. The ammonia water is then slowly added, and if of the proper strength, i.e. 26 degrees, a clear, deep blue solution is obtained, which does not become cloudy when diluted to 45 gallons.

This preparation, being a perfectly clear liquid, can be 
used in greenhouses and elsewhere, where, for reasons already stated, Bordeaux mixture could not be applied. It is especially useful against the large group of parasitic fungi having superficial mycelium - Perisporiaceae - including such pests as rose mildew (Sphaerotheca pannosa), and hop mildew (Sphaerotheca castagnei). It may also be generally used where the object is to check the spread of a disease extending by means of conidia.

\section{Potassium Sulphide Solution}

$\begin{array}{lll}\text { Water } & \cdot & 2 \frac{1}{2} \text { gallons. } \\ \text { Potassium sulphide } & \text { r ounce. }\end{array}$

Dissolve the potassium sulphide, popularly known as liver of sulphur, in a quart of hot water, then make up to $2 \frac{1}{2}$ gallons with cold water. This is also a clear liquid, and like the former can be easily used without any clogging at the nozzle of the sprayer. It is useful for checking the spread of an epidemic, and has proved successful against the chrysanthemum rust (Puccinia hieracii).

\section{Iron Sulphate Solution}

Water . . . 50 gallons.

Sulphuric acid . . r pint.

Iron sulphate . . 25 pounds.

Pour the sulphuric acid upon the iron sulphate, and then add by degrees the 50 gallons of water. A metal vessel must not be used for the preparation of this mixture, as it would be acted upon by the sulphuric acid; a barrel is the best to use.

This preparation may be used with great advantage in 
those cases where a disease has previously existed, as it destroys resting-spores that may be concealed in crevices of bark, brickwork, or on the ground under fruit trees.

In spraying fruit trees, vines, etc., the trunk and branches should be thoroughly drenched; but it is all-important to remember that the spraying should be done during the winter, or at all events some time before the leaf-buds begin to swell, otherwise the foliage would be completely destroyed.

This preparation should not under any circumstances be applied to leaves or fruit.

Permanganate of Potash Solution.-This is the wellknown liquid called 'Condy's Fluid.' However, the most economical method is to buy the potassium permanganate in the form of crystals, which dissolve quickly in water. The solution should be pale rose colour, and has proved of use in arresting the spread of various kinds of rust. For instance, if the leaves of seedling hollyhocks attacked by rust (Puccinia malvacearum) are sponged with this solution, the disease is checked; rusted carnations also benefit by being sponged, or, if circumstances admit, submersed in the solution. Potassium permanganate is too expensive for use in spraying on a large scale; besides, the solutions previously mentioned are more effective. On the other hand, it may be used in small gardens or for greenhouse plants with advantage.

Sulphur. - This is used as a dry powder, in the finely precipitated condition known as 'flowers of sulphur,' and has been in vogue for many years previous to the discovery of liquid fungicides. It is most effective against the fungi popularly called mildews, belonging to the Perisporiacene, where the mycelium is entirely superficial, usually forming 
a more or less dense white felt on the surface of living leaves, as the hop mildew (Sphaerotheca castagnei).

The finely powdered sulphur is dredged on the leaves from a vessel resembling a large pepper-pot, or blown on by means of specially contrived bellows or other apparatus; or frequently the primitive method of enclosing the sulphur in a coarse canvas bag fixed to the end of a pole, which serves as a handle, is used as a dredger. The leaves should be damp when the sulphur is applied.

In some instances better results follow when finely powdered quicklime is mixed with the sulphur, taking care to always have an excess of sulphur. Quicklime may also be laid on the ground in the spring under perennial plants that have suffered from disease and where sclerotia or other resting forms of reproductive bodies fall to the ground, as the products of germination are frequently killed by the lime.

Many other fungicides have been recommended for special diseases, and their application might possibly be extended with advantage in many instances.

As the result of numerous experiments made with the object of checking the destructive sooty mould infesting orange and other citrous fruits, Mr. Webber, a member of the U.S. Department of Agriculture, strongly recommends the following, known as the resin wash :-

Resin

Caustic soda (98 p.c.)

Fish oil, crude

Water, to make
20 pounds.

$4 \frac{1}{2}$ pounds.

3 pints.

I 5 gallons.

Boil the resin, caustic soda, and fish oil mixed with water until the resin is dissolved, then make up to fifteen gallons with water. This is the stock solution. To use, add nine parts of water to one part of the stock solution. 
An American correspondent states that carnation rust can be arrested by spraying with a solution consisting of one ounce of arsenic dissolved in a little alcohol, and mixed with 100 gallons of water. Care is required on the part of the operator, on account of the poisonous nature of the active ingredient.

Paraffin, a wine-glassful to two gallons of water, is stated to have checked the spread of the chrysanthemum rust (Puccinia hieracii); possibly other rusts would succumb to similar treatment, which is in other respects not at all injurious to plants.

Jensen's Hot-Water Treatment for Wheat and OAT SMUT. - This method, which experience has proved to be highly satisfactory, is reproduced as given in the latest and most approved manner by Swingle, in the Year-Book of the U.S. Department of Agriculture for 1894 :-

' Provide two large vessels, preferably holding at least 20 gallons. Two wash kettles, soap kettles, wash boilers, tubs, or even barrels, will do. One of the vessels should contain warm water, say at $110^{\circ}$ to $120^{\circ} \mathrm{F}$., and the other scalding water, at $132^{\circ}$ to $133^{\circ} \mathrm{F}$. The first is for the purpose of warming the seed preparatory to dipping it into the second. Unless this precaution is taken it will be difficult to keep the water in the second vessel at the proper temperature. A pail of cold water should be at hand, and it is also necessary to have a kettle filled with boiling water from which to add from time to time to keep the temperature right. Where kettles are used, a very small fire should be kept under the kettle of scalding water. The seed which is to be treated must be placed, half a bushel or more at a time, in a closed vessel that will allow free entrance and exit of water on all sides. For 
this purpose there can be used a bushel basket made of heavy wire inside of which is spread wire netting, say I 2 meshes to the inch; or an iron frame can be made at a trifling cost, over which the wire netting can be stretched. This will allow the water to pass freely and yet prevent the passage of the seed. A sack made of loosely woven material, as gunny sack, can be used instead of the wire basket. A perforated tin vessel is in some respects preferable to any of the above. In treating stinking smut of wheat, the grain should first be thrown into a vessel filled with cold water; then, after stirring well, skim off the smutted grains that float on the top, and put the grain into the basket or other vessel for treatment with hot water. This skimming is entirely unnecessary with other grains, and even with wheat when only affected by the loose smut. Now dip the basket of seed in the first vessel containing water at $110^{\circ}$ to $120^{\circ} \mathrm{F}$.; after a moment lift it, and when the water has for the most part escaped, plunge it into the water again, repeating the operation several times. The object of the lifting and plunging, to which should be added a rotary motion, is to bring every grain in contact with the hot water. Less than a minute is required for this. preparatory treatment, after which plunge the basket of seed into the second vessel, containing water at $132^{\circ}$ to $133^{\circ} \mathrm{F}$. If the thermometer indicates that the temperature of the water is falling, pour in hot water from kettle of boiling water until the right degree is maintained. If the temperature should rise higher than $133^{\circ}$, add a little cold water. In all cases the water should be well stirred whenever any of a different temperature is added. The basket of seed should very shortly after its immersion be lifted and 
drained, and then plunged and agitated in the manner described above. This operation should be repeated six or eight times during the immersion, which should be continued ten minutes. In this way every portion of the seed will be subjected to the action of the scalding water.

'After removing the grain from the scalding water, spread on a clean floor or piece of canvas to dry. The layer of grain should not be over 3 inches thick.

'The important precautions to be taken are as follows :(I) Maintain the proper temperature of the water $\left(132^{\circ}\right.$ to $\mathrm{I} 33^{\circ} \mathrm{F}$.), in no case allowing it to rise higher than $135^{\circ} \mathrm{F}$.; (2) see that the volume of scalding water is much greater (at least six or eight times) than that of the seed treated at any one time; (3) never fill the basket or sack containing the seed entirely full, but always leave room for the grain to move about freely; (4) leave the seed in the second vessel of water ten minutes.'

Resin Compound.-Professer Webber gives the following formula :-

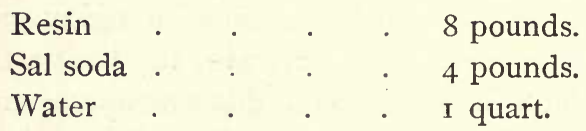

After boiling, add sufficient water to make five gallons of stock solution.

Place the resin and sal soda in a comparatively large kettle with one quart of water. Boil, meanwhile stirring briskly, until the resin and sal soda are thoroughly melted together and form a frothy mixture without lumps. Now add about four gallons of cold water, pouring it in rather slowly and with short intervals between to avoid chilling the mixture too suddenly. When all the water has been 
added, bring to a boil, then pour out the hot solution, straining it through a coarse cloth, and add sufficient water to make exactly five gallons of the solution. This, if correctly made, forms a thick, dark brown, translucent, syrupy solution, which may be preserved as a stock solution.

For use in treating the sooty mould following the white fly (Aleyrodes citri), dilute this stock solution in the proportion of one part to seven parts of water.-Proc. Ninth Ann. Meeting Florida State Hort. Soc., 1896.

Fumigation with Hydrocyanic Acid Gas.-Fumigation may be accomplished by placing over the tree a tent of some closely woven material, as 8-ounce duck or drilling. This should be oiled and painted black if the treatment is to be made in daylight. The edges of the tent are held down by a few shovelfuls of earth. For generating the gas, fused 98 per cent. potassium cyanide, commercial sulphuric acid, and water are used, in the proportion of I ounce (avoirdupois) of potassium cyanide to I fluid ounce of sulphuric acid and 2 fluid ounces of water. To give the proper concentration of gas, the quantities to be used vary somewhat with the size of the tree. It is estimated that each 180 cubic feet of space enclosed in the tent will require about I ounce of potassium sulphide and the other materials in proportion. The water and sulphuric acid are placed together in an earthen vessel in the order named, ${ }^{1}$ and the vessel is placed under the tent. The potassium cyanide is then dropped in, and the operator quickly

1 To avoid explosions, the sulphuric acid should always be poured slowly upon the water instead of pouring the water on the sulphuric acid. 
withdraws from the tent and closes the opening. Care must be exercised in applying this method of treatment, as the potassium cyanide and the gas generated are poisonous.-Webber, U.S. Dept. Div. Veg. Phys. and Path., Bull. No. I 3 .

Sterilising Soil.-As already stated, it often happens that where large numbers of plants are grown in a limited space, and consequently crowded, a wave of disease spreads rapidly, not unfrequently destroying the entire crop.

When this occurs in houses, the most certain method for preventing a reappearance of the disease, especially if it is intended to continue growing the same kind of crop, is to remove the whole of the soil, thoroughly sterilise the building from top to bottom with a solution of iron sulphate, and put in fresh soil.

Where the disease is due to a root parasite, as in the 'sleeping' disease of tomatoes, this method is undoubtedly the most reliable, and in the end least costly.

However, practical men state that this method is not always practicable; consequently the next best thing to do is to sterilise the soil - that is, endeavour to destroy all the mycelium, resting-spores, sclerotia, etc., that may be present.

This can be effected with more or less certaintydepending on the thoroughness with which the work is done-by various methods.

Thoroughly mixing the soil with quicklime, where the crop will admit; or watering with a solution of soluble phenyle, or with a liquid known in the trade as Jeyes' fluid. The proportions for either of the two last mentioned substances are, one ounce to a gallon of rain-water. 
The soil should be thoroughly wetted through, and allowed to remain for a week before anything is sown or planted.

The above solutions may also be applied with benefit where fungi, as Armillaria mellea, and other root parasites appear around the roots of trees, etc.

Mr. G. Abbey, a constant contributor to the Journal of Horticulture and Cottage Gardener on the subject of plant diseases-to whom, I am afraid, I am too selfish to admit the full extent of my indebtedness for the numerous practical hints on the various diseases to which plants are subject, the outcome of many years of experience-suggests the following as remedies against eelworm, mites at the root, and wireworm :-

'Dress the land in the spring, just before sowing seeds or setting plants, with nitrate of soda, $\mathrm{I}_{4}^{\frac{3}{4}}$ lbs. per rod, $2 \frac{1}{2} \mathrm{cwt}$. per acre, having it crushed fine, and evenly distributed when the ground is moist, but with a prospect of fine weather or only slight showers for a few days. This will kill slugs and leather-jackets, as well as eelworms, root mites, and wireworms.

'Kainit, also crushed fine, may be used similarly to the nitrate of soda at the rate of $2 \frac{1}{4} \mathrm{lbs}$. per rod, $3 \frac{1}{4} \mathrm{cwt}$. per acre. In using these substances separately there is danger of getting too much growth in the plant from the nitrate of soda, and too little, if not some retardation, by the use of the kainit; and in cases of land broken up from old pasture, or badly infested with grubs and wireworms, the quantities separately are not only insufficient, but not the correct thing for the crop, say potatoes. In that case, $\mathrm{I}_{\frac{3}{4}} \mathrm{cwt}$. of nitrate of soda and $3 \frac{1}{4} \mathrm{cwt}$. of kainit, mixed, per acre, or $3 \frac{1}{2} \mathrm{lbs}$. per rod, will give a 
good account of the parasites the land contains, and produce excellent results in the crop. Half the amount of this mixture suffices on ordinary land, and is just as good for tomatoes as for potatoes.'-Journ. Hort. and Cott. Gardener, July 25, I895.

The above is introduced for the reason that when applied to tomatoes, the crop invariably remained untouched by fungous parasites.

\section{POISONOUS PROPERTIES OF FUNGICIDES}

From time to time the serious question as to the advisability of using fungicides, more especially Bordeaux mixture, on account of their poisonous properties, has been discussed, and the tone at one time assumed seemed likely to deal a death-blow to their use.

The two leading points in the discussion were:(I) danger to human life by partaking of fruit sprayed with Bordeaux mixture; and (2) injury to the soil caused by the constant application of the same solution.

The subject has been investigated, either directly or indirectly, by leading European and American chemists, and the verdict is that there is no risk whatever in partaking of fruit that has been sprayed, provided the precautions given below are observed, and that the soil is in no way injured by the quantity of the mixture it receives.

The important points to be kept in view in spraying fruit with Bordeaux mixture are, to decrease the strength of the solution as the fruit approaches maturity, and to cease spraying altogether some little time before the fruit is fully ripe. Lettuce and similar crops that mature 
quickly should not perhaps be sprayed with Bordeaux mixture.

This subject is fully discussed, and accompanied by a voluminous quotation of literature bearing on the subject, by Dr. Fairchild, in Bull. No. 6, U.S. Department of Agriculture.

\section{ECONOMIC CONSIDERATIONS}

In attempting to furnish statistics bearing on the subject of loss owing to plant diseases, or the gain resulting from the use of preventive and remedial measures in combating these pests, it is with regret we have to admit the fact that it is necessary to search the literature of other nations for information.

In Tubeuf and Sinith's Diseases of Plants (Engl. ed.), p. 84, we find the following account :-

'In the Zeitschrift für Pflanzenkrankheiten, 1893, the International Phytopathological Commission gave, from estimates furnished by the Prussian Statistics Bureau, a review of the losses in Prussia from grain rust. Amongst other estimates we find that in $189 \mathrm{I}$ the wheat harvest of Prussia reached a total of $10,547, \mathrm{r} 68$ doppelcentner ( $\mathrm{I}$ doppelcentner $=\mathrm{I} \circ 0$ kilogramme), which at 22 marks per d.c. $=£ \mathbf{I}, 459,690$ sterling. Of this 3,3 r6, 059 d.c., or $£ 3,593,75^{8}$, was depreciated by rust. The rye harvest was $30,593,75^{8}$ d.c. at 22 marks, of which 8,208,9 3 d.c., or $£ 8,896,364$, was depreciated by rust. Oats reached $32,165,473$ d.c. at 16 marks, of which 10,325, 124 d.c., or $£ 8,138,023$, falls to be deducted on account of rust. Thus on the crops, wheat, rye, and oats, the loss reached the sum of $\mathcal{L}_{20}, 628,147$ sterling, or almost a third of 
the total value of the crops. The year I89r was a very unfavourable one, but even taking the estimate at the half of the above sum, we have a yearly loss by rust amounting to $£$ ro, 000,000 sterling.

"In Australia the loss in the wheat harvest of $1890-91$ on account of rust has been estimated at $£ 2,500,000$ sterling.

'Consideration of the loss of sums of money like these, which might be considerably reduced if energetic and universal measures were employed against fungoid plantdiseases, will serve to emphasise the importance of remedial measures. It must also be borne in mind that the use of diseased fodder, especially hay, grass, or grain, infested by rust or smut fungi, is productive of serious results to the various animals of the farm; while the use of meal or flour contaminated with smuts, stinking-smuts, or ergot, is dangerous to mankind.'

- Professor Newton B. Pierce, U.S. Department of Agriculture, Farmers' Bulletin No. 30, writes as follows on the subject of 'Grape Diseases on the Pacific Coast':-

'As near as can be learned, the disease first appeared in 1884 ; in 1885 many vines were killed, and in 1886 extensive vineyards were destroyed by it in the vicinity of Anaheim, Cal. From this time on the disease spread, until now the whole vine-growing regions are denuded and the disease is at work 50 miles from the point where it began its ravages. Up to the present time, as before stated, 30,000 acres of vines have been destroyed, causing a direct and indirect loss of not less than $\$ 20,000,000$.'

The above quotations indicate the extent of injury done by fungi and other enemies, and undoubtedly the unwritten experience of others who have suffered, if

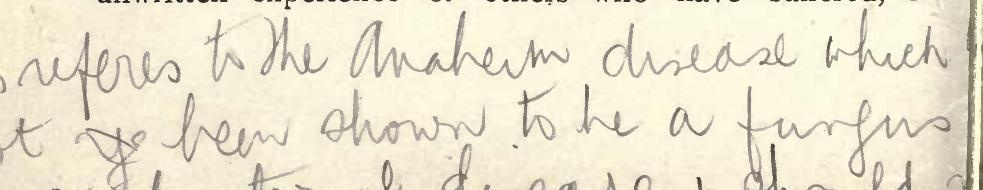


recorded, would furnish evidence of losses of equal or even greater magnitude. I have been informed that sometimes $£ 200$ is lost through disease in a single tomato-house in Guernsey.

It is in new countries, where cultivators of plants are comparatively free from the trammels of prejudice, and do not everlastingly confront you with the statement that their forefathers did not have recourse to remedial measures for the prevention of disease, that we look for corroboration or refutation of the supposed efficacy of the means advocated for arresting the progress of plant diseases.

For information on this point we naturally turn to the United States, where the subject has been more thoroughly and universally investigated-not in a rule-ofthumb manner-by highly qualified scientific men, located in every part of the country, for a longer period of time than in any other country in the world. The fact that spraying plants for prevention of disease is now universally recognised and practised in the United States, proves that the State did not commit a mistake in affording every facility for the development and continuation of such research.

The following extract is from a report by Professor B. T. Galloway, Chief of the Division of Vegetable Pathology, U.S. Department of Agriculture :-

'Mr. D. M. Wyngate has a large vineyard near Marlborough, New York, and at my request has furnished a careful estimate of the profit derived the present season from treatments suggested by this Division. His vineyard contains 7450 Concord and rooo Delaware vines. The vineyard last year was not treated, and yielded 
I 9,690 pounds of fruit, which sold for $\$ 625.87$. This year the same vineyard was treated seven times, as follows :-

' ( I) March I, simple solution of copper applied to canes and posts.

'(2) Just before blossoming, with Bordeaux mixture B.

'(3) Just after the grapes had formed, with Bordeaux mixture, same as 2.

(4) July, same as 2 and 3.

' $(5,6$, and 7$)$ At regular intervals between July ro and August 25, with eau céleste.

'The total cost of the foregoing treatment, including a Eureka sprayer, was \$II2.52, divided as follows :-

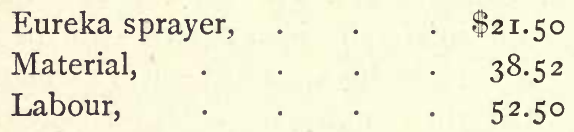

The yield of fruit this season was 53,430 pounds, which sold for $\$ 2 \mathrm{I} 8 \mathrm{I} .39$. Thus it will be seen that the yield for 1890 (treated) exceeded that of 1889 (untreated) by 33,740 pounds, while there was a net increase in the profits of $\$$ I 555.52 .

'Turning now to another class of plant diseases, we will give the results of a series of experiments personally conducted the past two seasons in the nurseries of Franklin, Davis, and Co., near Baltimore. In the spring of 1889 this firm set out a block of 50,000 pear seedlings with the expectation of budding them the following July. As a rule seedlings of this kind are attacked by leaf blight (Entomosporium maculatum, Lév.) as soon as the foliage appears, and in consequence it is a rare thing that more than half of the buds take. In the hope of saving the 
foliage, the Bordeaux mixture was applied seven times during the season at a total cost of $\$ 60$, and as a result less than one-tenth of I per cent. of the buds failed to take. This year the same treatment was continued at an additional expense of $\$ 60$. Many of the buds have made a growth of ro feet during the season, and as the block now stands it is worth fully $\$ 7000$. From control experiments and from the experience of previous years, it is safe to say that this amount is fully double what the trees would have been worth had they been left untreated. These facts are sufficient to bring out clearly the point we wished to make, namely, that spraying for plant diseases can be done at a handsome profit. In the light of our present knowledge the work must be regarded as a legitimate part of one's business. In other words, the farmers, gardeners, and fruit-growers who neglect such work at the present day are as much to blame for short crops as those who fail to perfectly manure and cultivate the soil.'

\section{SPRAYING}

There is a difference of opinion amongst experts as to the relative efficacy of a very fine, as compared with a somewhat coarse, spray. With cyclone and eddy-chamber nozzles, it is possible to throw a spray so fine that it hangs like a mist in the air and does not fall to the ground. Such fine spray is best for indoor work, but it is not so well adapted as a somewhat coarser spray for ordinary outdoor operations, except when the material to be sprayed is low and easily reached, in which case a fine spray is most economical and effective, as there is less waste of material, 
it being possible to reach with certainty the exact portions desired.

On the other hand, a very fine spray does not readily reach the tops of fruit or other trees, consumes more time in application, and much is wasted by wind driving the spray in a wrong direction.

Again, if the spray is too coarse, it forms drops which either roll off the foliage, or, if they remain, injure the leaves by producing a scorched appearance.

The various devices for spraying are numerous, ranging from the hand syringe, useful for spraying in houses, to huge steam-power contrivances carrying a tank holding roo gallons or more of solution, and forcing a spray to the top of a large tree. Perhaps the most generally useful form is the barrel pump, intended to be fixed to a good cask mounted on a wheel-barrow.

I have seen very effective spraying done with a simple. bucket-pump costing half-a-crown, the nozzle consisting of two flat, parallel pieces of tin, the outlet being narrowed by hammering until a spray of the required degree of fineness is produced.

If Bordeaux mixture is used, some arrangement, automatic or otherwise, should be present to keep the solution uniformly mixed, otherwise one portion of the spray will be too diluted to effect the desired object, and another portion so concentrated as to injure the foliage.

Although the first cost is greater, it proves most economical in the end to have all the pump fittings made of hard brass formed of copper and tin. Soft brass composed of copper and zinc should be avoided, as it is corroded by ammonia.

In spraying plants, it must be remembered that efficacy 
does not turn on the amount of solution poured over a plant, but on the amount of the solution that adheres to the foliage, therefore the periods indicated for a renewal of the operation must of necessity be modified according to circumstances. A heavy rain following spraying would wash off the greater portion of the fungicide at once, and to wait for ten days before repeating the spraying under such circumstances would evidently be courting disaster.

It has been suggested that mixing a small quantity of dessicated white of egg or dried blood with a fungicide greatly adds to its adhesive property.

When fruit is commencing to ripen, spraying should cease, otherwise the fruit is liable to become spotted, and its market value consequently depreciated.

Lodeman, The Spraying of Plants, Macmillan and Co., 1896.

\section{FUNGI}

\section{PHYCOMYCETES}

Seedling Cabbage Disease

(Olpidium brassicae, Dang. =Chytridium brassicae, Wor.)

Young cabbage plants are frequently destroyed by this fungus when growing in damp, shady places. The stem is attacked and the plant droops, and then falls over and dies.

The fungus consists of a single cell, and sometimes two or three are located in one of the cells of the host. The 
fungus emits a long tube which passes through the tissue of the host, and through this tube the zoospores formed in the fungus cell escape, and inoculate other plants. Thickwalled, warted resting-spores are also present in the epidermal cells of the host.

Preventive Means.-Dry, airy localities should be selected for seed-beds. Where the disease has existed, the ground should not be used for the same purpose for some time. Remove and burn dying plants to prevent the resting-spores remaining in the soil.

Woronin, Rungsh. Jahrb. I878, p. 557, pl. 31, figs. I2-I6.

\section{'DAMPING OFF'}

\section{(Pythium de baryanum, Hesse.)}

The term 'damping off' is applied to a disease of seedlings, characterised by the falling over and dying of the plantlets, due to the destruction of the fundamental tissue of the stem just above ground by a fungus called Pythium de baryanum. Seedlings of cruciferous plants are more especially attacked, but it also attacks maize, millet, clover, mangel, cucumber, and has been recorded as occurring on the prothalli of Lycopodium and Equisetum. Conidia, sporangia, and sexually produced oospores are formed by the fungus, but never in the tissues of the host, always on its surface, or on the adjoining soil, if sufficiently wet.

The conidia form one or two germ tubes almost immediately after they are mature; or, under certain circumstances, after a longer or shorter period of time, even extending to several months. A second kind of conidia require a period 
of rest before germination takes place. The sporangia possess a single tubelike projection into which the protoplasm passes and forms a sphere at its tip, which breaks up into biciliate zoospores.

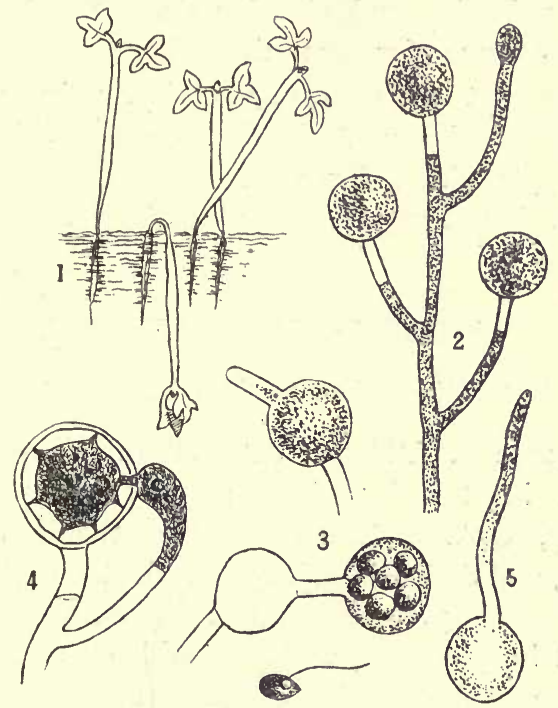

Fig. 4.-Pythium de baryanum. I, seedlings of cress (Lepidium sativum) attacked by the fungus; 2, mycelium bearing conidia at the tips of the branches, $\times 300 ; 3$, sporangia in different stages, also a free zoospore, $\times 300 ; 4$, an oosphere, with the antheridium or male organ, which has pierced the wall of the oosphere and inserted a slender tube, for the purpose of allowing the contents of the antheridium to mingle with those of the oosphere. After this blending of the contents of the two organs, the oosphere becomes enclosed in a thick wall, to form the oospore or sexually produced resting-spore, $\times 300 ; 5$, a germinating conidium, $\times 300$.

Both oospores and resting conidia remain on the ground and produce zoospores after a period of hibernation. 
Preventive Means. - This disease only occurs where the ground is very wet and the light dull. If seed beds are formed where the drainage is good, and a fair share of sunshine allowed, the fungus is completely held in check, as its reproduction and diffusion depend entirely on the constant presence of water in the soil.

De Bary, Bot. Ztg. I881, p. 357, Tab. 5, figs. I-7.

Marshall Ward, Quart. Journ. Microscop. Sci., vol. xxiii. (1883), p. 487, pl. 24, figs. I-Iо.

Massee, Brit. Fung., p. I33, pl. 3, fig. 39.

\section{DAMPING-OFF PROTHALLIA}

\section{(Pythium intermedium, De Bary.)}

Dr. George F. Atkinson detected this fungus on fern prothallia in the botanical conservatories of Cornell University, U.S.A. The affected prothallia were quite soft, limp, and darker in colour than the healthy ones.

'If the pots or vessels in which the prothallia are grown are rested in sphagnum, a layer of which can be placed in the bottom of the wardian case, and after the young prothallia have started, all the watering be applied through this, the prothallia will do much better than if surface watering is practised, and far better than where the pots are rested in a vessel partly full of water. The air of the wardian case or of the house should not be kept too damp.'

Atkinson, Bull. 94, Cornell Univ. Agric. Expt. Station, p. 247 , I plate.

This Bulletin contains valuable information on the life-history of other allied species, and is beautifully illustrated. 


\section{- JAPAN LILY DISEASE}

(Rhizopus necans, Massee.)

During recent years a destructive wave of fungous disease almost completely ruined the crop of lily bulbs (Lilium speciosum, and L.auratum) raised in Japan for exportation to Europe.

The bulb is the part attacked, which in the earliest condition shows a slight discoloration at the base when cut open. The disease extends rapidly, the entire bulb becoming discoloured, and finally soft and rotten. Numerous experiments proved the disease to be caused by a parasitic fungus called Rhizopus necans. This fungus can live as a saprophyte on the humus in the soil, and attacks the bulbs when lifted. It is a wound-parasite, and usually obtains access to the bulb through broken roots.

Diseased bulbs that have become rotten show a white weft of mycelium, from which numerous clusters of fruit resembling miniature pins with black heads stand erect; these are the conidial or summer fruit of the fungus. Resting-spores are produced in the tissues of the decayed bulb.

Preventive Means.-In most cases inoculation takes place when the bulbs are taken up for exportation. If submerged in a one per cent. solution of salicylic acid for twenty minutes, and afterwards thoroughly dried, the spores of the fungus are destroyed. The bulbs should be thoroughly diry before packing, otherwise if there is the least tendency to 'sweating,' and there happens to be any diseased bulbs present, the disease spreads rapidly. The fungus is presumably abundant as a saprophyte in the soil 


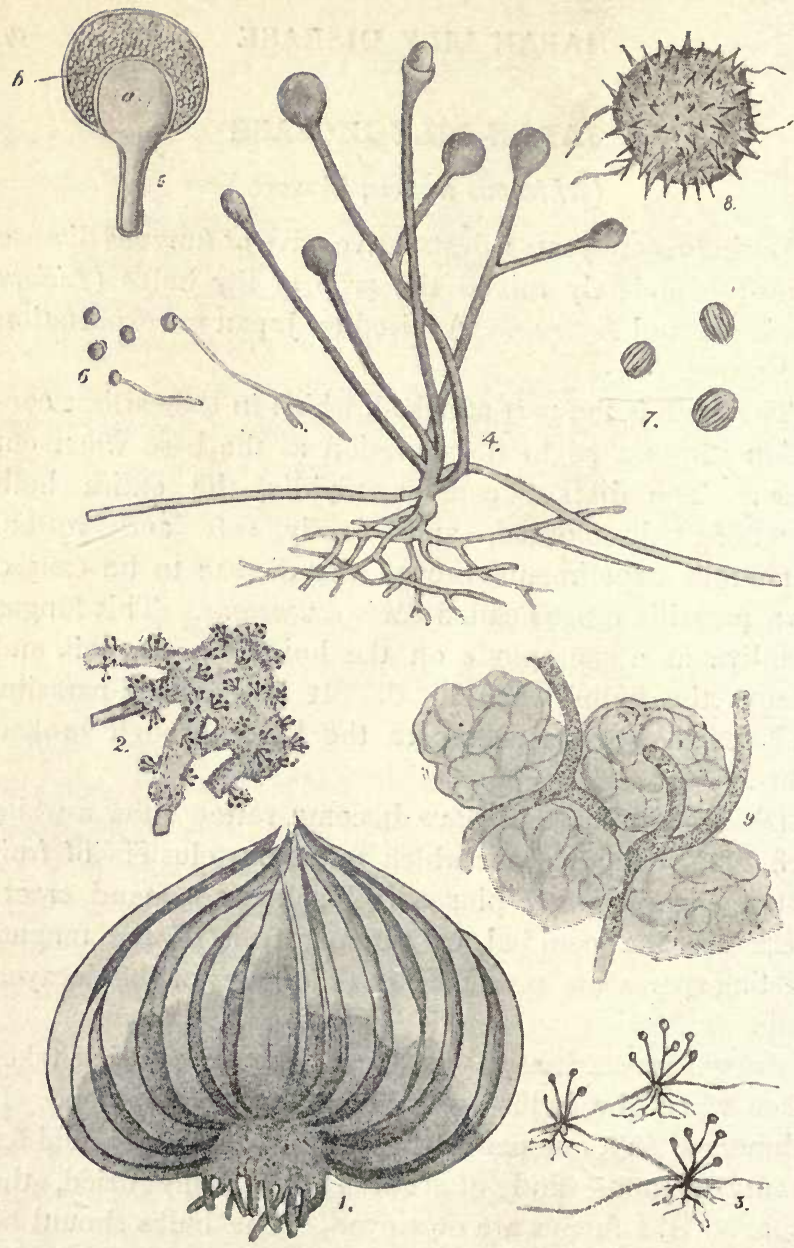

Fig. 5. - R hizopus necans. I, section of a diseased lily bulb, the dark portion at the base of the bulb is the part attacked by the fungus; 2 , portion showing the fungus in the fruiting condition, growing on the roots of a bulb, natural size; 3 , cluster of the fruit-bearing branches of the fungus, $\times_{5} ; 4$, a cluster of the sporangeal form of fruit, $\times 50 ; 5$, diagrammatic section of a sporangium; $a$, columella; the portion $b$, between the columella and the outer wall of the sporangium, is filled with conidia; 6 , spores, some of which are germinating, $\times 200 ; 7$, spores, showing the delicate markings on the epispore, $\times 700 ; 8$, mature zygospore, $\times 200 ; 9$, mycelium of the fungus running between cells filled with starch, $\times 300$ (from Kezv Bulletin). 
in which the bulbs are grown after the disease has once appeared, consequently the same ground should not be again planted with bulbs for some years. Lime or some similar available substance would assist in freeing the soil from the pest.

Diseased bulbs should not be allowed to lie and rot on the soil, but should be collected and burned, otherwise the resting-spores present in the tissues pass into the soil and renew the disease.

Massee, Kerw Bulletin, 1897, p. 87, I plate.

Rhizopus nigricans, Ehr., is stated by Dr. HalstedN. Jersey Agric. Coll. Expt. Station, Bull. 76, figs.-as causing a soft rot of sweet potatoes in America. The fungus enters the root at points where the surface is broken, develops especially after the roots are stored, more particularly if 'sweating' takes place, thus agreeing in all essential points as to mode of attack with Rhizopus necans, and in all probability the remedial measures indicated under the last-named fungus would be applicable in the present instance.

\section{WHITE RUST OF CRUCIFERS}

\section{(Cystopus candidus, Lév.)}

This fungus has a world-wide distribution, and attacks numerous cruciferous plants, both cultivated and wild. In Britain it is most abundant on the common weed called shepherd's-purse (Capsella bursa-pastoris), attacking every part of the plant above ground, and producing much distortion of the affected parts, which are snow-white, and present a polished appearance at first, owing to the forma. 
tion of dense cushions of conidia produced in chains beneath the epidermis; finally the conidia become free, rupture the epidermis, and appear on the surface as a fine white powder. On germination the conidia produce zoospores which eventually germinate, and enter into the tissue of seedlings through the stomata.

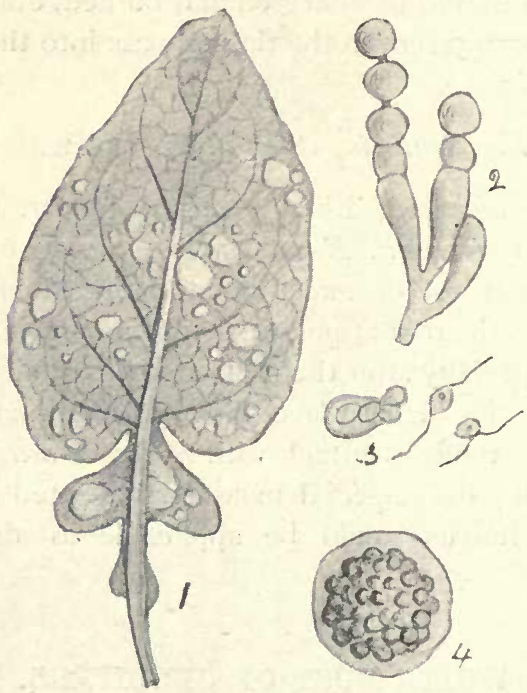

Fig. 6.-Cystopus candidus. I, diseased leaf of cabbage; 2, chains of conidia, $\times 350 ; 3$, conidium germinating and producing zoospores, $\times 300 ; 4$, ripe oospore, $\times 300$.

Oospores are not formed by the fungus parasitic on shepherd's-purse, but are produced in considerable numbers in the tissues of many hosts.

After passing the winter in a resting condition, the oospores liberate enormous quantities of zoospores, which attack seedling crucifers. 
The 'Kerguelen's Land Cabbage' (Pringlea antiscorbutica), although exempt from the disease in its native land, could not be kept in cultivation at Kew, owing to the attacks of this parasite.

Among economic plants attacked may be mentioned horse-radish, cabbage, radish, cress, wall-flower. The caper plant (Capparis spinosa) also suffers.

Preventive Means. - Infection only takes place during the seedling stage, hence the disease does not spread among older plants.

Diseased plants, both wild and cultivated, should be destroyed.

De Bary, Ann. Sci. Nat. (Bot.), ser. iv., vol. 20. Prillieux, Malad. des Plantes Agric., i. p. 62, figs. Wager, Ann. Bot., vol. x. p. 89.

Cystopus tragopogonis, Schröt. $=$ Cystopus cubicus, De Bary. This fungus forms white blisters on various umbelliferous plants, goat's-beard (Tragopogon), scorzonera, salsify, etc., frequently attacking all the plants in a bed, and doing considerable injury. In this species the terminal conidium of a chain differs in structure from the remainder in having the wall thick throughout, whereas the others have a thin wall with an equatorial thickened band. The oospore has the epispore or outer wall densely covered with minute warts or papillae, whereas the same structure in Cystopus candidus is ornamented with large, irregularly-shaped warts. 


\section{THE POTATO DISEASE}

\section{(Phytophthora infestans, De Bary.)}

This terrible scourge was first observed near Boston, U.S., also in Denmark and Norway, between 1840 and I 842 , and by 1845 it had spread over Europe, doing immense damage. Although the injury done at the present day is not so severe as during the first decade after its invasion, it is still with us, and during damp, warm seasons still does a considerable amount of injury. In addition to the cultivated potato (Solanum tuberosum), the parasite also attacks several cultivated exotic species of Solanum, the common British wild Solanum dulcamara, and more especially the tomato.

The earliest indications of the disease are the appearance of small brownish blotches on the leaves; these gradually increase in size, followed by a curling of the leaves, and in an exceptionally severe attack the leaves and stems become blackened and decayed within a few days, emitting a disagreeable smell. If the brown spots on the under side of a leaf are examined with a pocket-lens, numbers of delicate white threads will be seen, especially towards the circumference of the diseased patch. Higher magnification reveals that these delicate threads are simple or branched conidiophores, which originate from the mycelium of the fungus, ramifying the tissues of the leaf, and emerge singly or most frequently in small clusters through the stomata of the leaf, for the purpose of producing conidia on the surface of the leaf, whence they are readily dispersed by wind, rain, passing animals, etc. The conidia are eggshaped and colourless, and are produced at the tips of the conidiophores, but when a conidium is once formed, the 
branch or axis bearing it continues to elongate in the same straight line, leaving the conidium apparently attached to

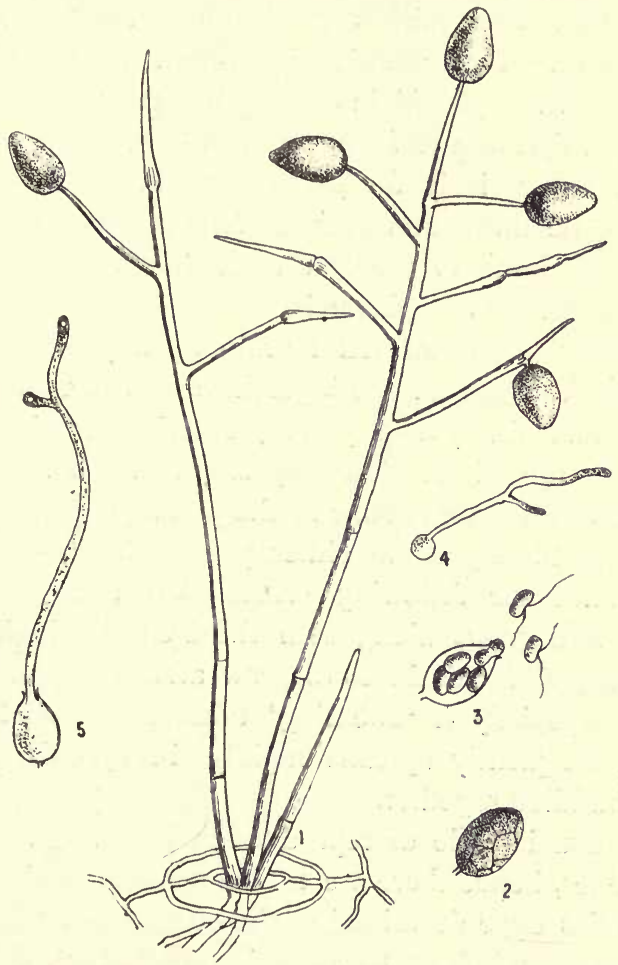

Fig. 7.-Phytophthora infestans. I, a cluster of conidiophores with conidia, $\times 400 ; 2$, a free conidium showing its contents breaking up nto zoospores, $\times 400 ; 3$, a conidium germinating and liberating zoospores, $\times 400 ; 4$, a zoospore that has become passive and germinated, $\times 400 ; 5$, a conidium germinating by the protrusion of a germ-tube, $\times 400$.

its side. After the branch has grown for some time, a second conidium is produced at its tip, to be again left 
behind by the continued growth of the branch above it. This peculiar mode of reproduction is the only constant feature that distinguishes the genus Phytophthora from Peronospora. The conidia give origin to a number of zoospores when placed in a drop of water, or on a damp surface, as that of a leaf covered with dew. The zoospores move about actively for some time in the water, and finally settle down and emit a slender germ-tube, which enters the tissue of the leaf through a stoma, or bores directly through the epidermis.

Conidia that are washed by rain upon young tubers of the potato that are exposed, produce zoospores, and these latter infect the young potato, entering its tissues and forming a mycelium. The mycelium of the fungus also passes down diseased stems of the potato, and thus infects the tubers, the mycelium either passing into a latent condition until the following season, when it renews its activity and grows along with the stems springing from the tuber; or it continues to grow after the potatoes are stored, especially if 'sweating' takes place, and in this manner frequently spreads rapidly through the mass of tubers huddled together.

The sexual mode of reproduction is not developed in this species, hence there are no oospores or resting-spores. The bodies once described as the oospores of this species were proved to belong to a species of Pythium living as a saprophyte on tubers killed by the Phytophthora.

Preventive Means. - Much has been written on this phase of the subject, and the outcome is not all that could be desired. Spraying with Bordeaux mixture has, in the hands of many experimenters, proved beneficial, and furthermore, apart from its action on the fungus, has 
greatly improved the yield. Potatoes obtained from a diseased crop should never be used as 'sets,' on account of the probability, almost certainty, of the presence of mycelium in the tubers.

Diseased stems, leaves, and tubers should not be allowed to lie and rot on the ground, neither should they be thrown into the piggery nor on the manure-heap ;-burning is the most effectual method. The disease is most severe where potatoes are grown in a low, damp district.

Although all known varieties of potato are susceptible to the disease, some are much more so than others, and endeavours should be made to secure those varieties least susceptible to the disease in a given district.

De Bary, Journ. Roy. Agric. Soc. Engl., vol. xii., 1876.

Jensen, Mem. Soc. Agric., vol. cxxxi., I 877 .

Smith, Gard. Chron., July I 875 .

Marshall Ward, Diseases of Plants, p. 59, figs.

Prillieux, Malad. des Plantes Agric., vol. i. p. 78, figs. (1895).

\section{LIMA BEAN MILDEW}

(Phytophthora phaseoli, Thaxter.)

A destructive disease has been described as attacking Lima beans (Phaseolus lunatus) in the United States. The pods are more especially attacked, less frequently the leaves and petioles; it is not uncommon on the young shoots.

Diseased pods show white felty patches which sometimes extend over the entire surface; the young shoots are also swollen and distorted. The disease spreads rapidly. 
Preventive Means.-Spraying with dilute Bordeaux mixture.

Thaxter, Bot. Gazette, vol. xiv. p. 273, I889.

\section{BEECH SEEDLING MILDEW}

(Phytophthora omnivora, De Bary. Phytophthora cactorum, Schröt.)

Hartig has investigated this fungus more especially as a parasite attacking seedlings of the beech (Fogus sylvatica), although, as one of its specific names would lead one to expect, it attacks many different plants, more especially in the seedling condition, among which may be enumerated, Cactus, Acer, Fraxinus, Robinia, Fogopyrum, Sempervivum, Clarkia, and various conifers.

In seedlings the appearance of dark-coloured blotches on the cotyledons or the primary leaves indicates the presence of the fungus ; dark lines also frequently occur on the stem below the cotyledons, and when this is the case, recovery is impossible; whereas if the upper leaves only are attacked, the plantlets may recover.

Gaps are often made in seed-beds by this fungus, which spreads rapidly when once introduced. The spread of the disease is favoured by damp weather, retarded by drought.

In this species the mycelium is furnished with minute, roundish haustoria, which pierce the cells and absorb nourishment. Lemon-shaped, papillate conidia are produced on the surface of diseased portions. These are carried by wind or rain to neighbouring plants, where they germinate, enter the tissues, and thus extend the disease. 
Sexually produced oospores or resting-spores are also produced in the interior of diseased portions of the host.

Preventive Means.--Seed-beds should be freed from

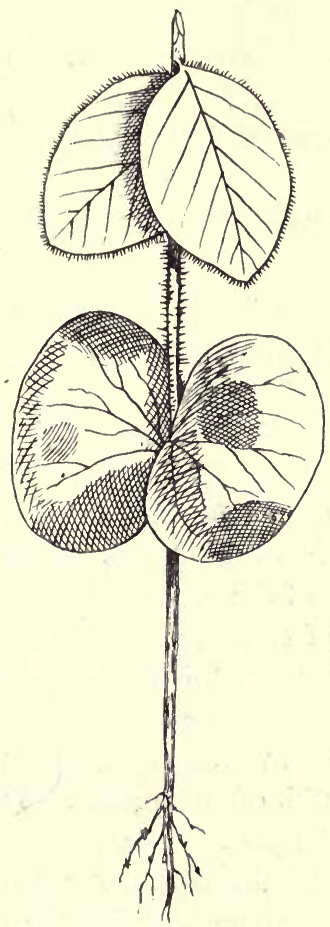

Fig. 8.-Phytophthora omnivora. A beech seedling attacked by the fungus. The dark stem below the cotyledons, and the blotches on both cotyledons, caused by mycelium in the tissues.

shade if the disease appears, as if the young plants dry quickly the conidia are prevented from germinating. All diseased plants should be carefully and promptly removed. 
Hartig states that the oospores retain their vitality for four years; hence soil that has produced diseased plants should not be used again.

Hartig, Unters. aus dem Forstbot. Institut, 1880, p. 33, I plate.

De Bary, Beitr. zur Morphol. und Phys. der Pilze, i881, p. 22.

Hartig and Somerville, Diseases of Trees, p. 38, figs.

\section{CACAO POD DISEASE}

(Phytoplithora omnivori, De Bary.)

This disease has been recognised for some years past, but has recently become much more general and destructive to cacao pods in Trinidad. The same fungus is probably the cause of the cacao-pod disease in Ceylon.

The symptoms of disease are a darkening of the 'shell' of the pod, which almost invariably commences at one end, and gradually extends over the entire surface. After a while the fruit of the fungus shows on the surface as a delicate white mould, often appearing first in the furrows on the surface of the pod.

The white mould represents the conidial form of reproduction, and lasts for some weeks, the numerous conidia produced being carried by wind to other pods, which in turn become diseased.

The mycelium of the fungus permeates and destroys the entire substance of the pericarp or 'shell,' and often also attacks the seeds. Numerous resting-spores are formed in the diseased fruit, and are liberated when the tissue decays, 
when they germinate and start the disease the following season.

Preventive Means.-Spray with dilute Bordeaux mixture, commencing when the fruit is quite young, and continue at intervals as required.

Remove all diseased fruit from the trees, as when once attacked it is valueless, and only serves to spread the disease if allowed to remain.

Do not allow diseased fruit or 'shells' to remain on the ground in the plantation, as the commencement of the disease each season depends on resting-spores present in such material.

The fungus is known to attack a large number of different plants; and it will be important to ascertain whether it is present on other plants in the neighbourhood of the plantation. Seedlings are often attacked.

The disease is most abundant in low, damp situations, or where the trees are much shaded.

Massee, Kere Bulletin, I 899.

\section{GRAPE MILDEW}

(Plasmopara viticola, Berl. and De Toni.)

This destructive fungus is a native of the United States, being parasitic on various kinds of wild vine met with in that country, and also on cultivated vines. It was introduced into France about the year 1878 , along with American vines that were imported to replace those destroyed by the Phylloxera, also a pest of American origin.

In France the poles used for supporting vines are 
frequently impregnated with sulphate of copper to prevent decay, and it was observed during the autumn of r 884 that vines supported on poles treated in this manner were comparatively free from mildew. It is interesting to note, in connection with the above discovery, the extension of a rule-of-thumb practice into an important and indispensable branch of modern horticulture, when fully explained and utilised in a scientific or methodical and exact manner. The value of sulphate of copper in preventing the decay of the poles depended entirely on the property it possessed of preventing the attacks of fungi, which would otherwise soon have destroyed the wood. Although this explanation was not probably known at the time, or even suspected, until its action in arresting the growth of mildew on living vines was observed, it must be considered as suggesting the idea of fungicides and spraying, which at the present day is practised with very beneficial results by all intelligent plant cultivators in every country, probably least so in Great Britain.

Mildew attacks the foliage, young shoots, tendrils, flowers, and young fruit of the vine, but usually appears first, and is most abundant, on the leaves, where its presence is indicated by the appearance of pale green or yellowish spots on the upper surface. These spots usually continue to increase in number and size, and gradually change to a brown colour as the tissue of the leaf dies; finally the leaf becomes brittle and falls, often within ten days or a fortnight of the first indication of disease. Very frequently nearly all the leaves of a vine are attacked, and their premature fall arrests the development of the fruit, even if the latter is not directly attacked by the fungus; the tree is also so weakened that the pro- 


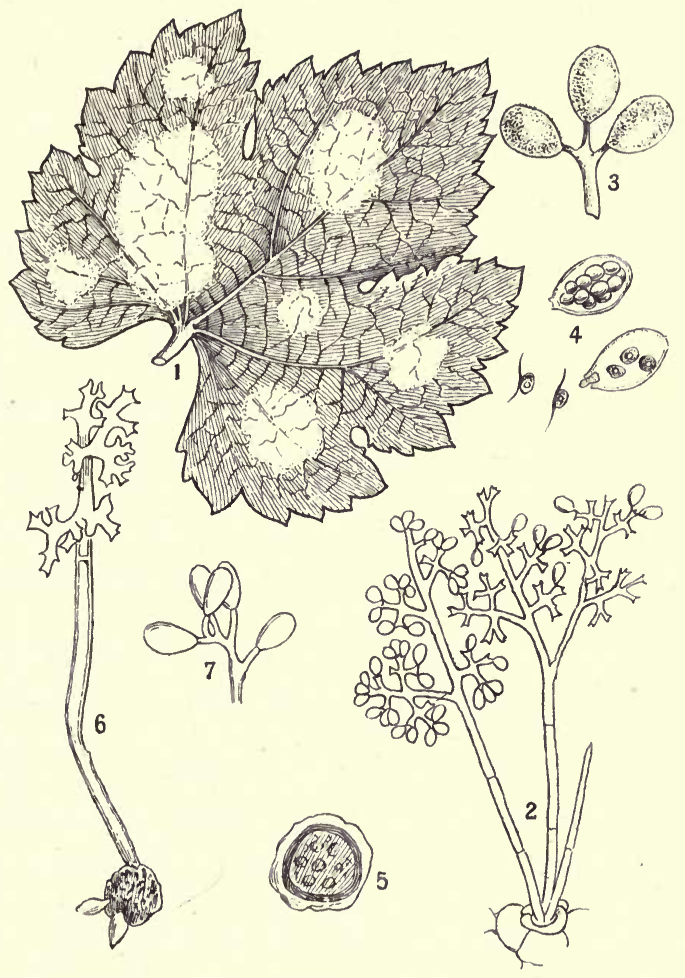

Fig. 9.-Plasmopara viticola. I, Under surface of a vine leaf showing patches of mildew ; 2 , group of conidiophores bearing conidia, $\times 80 ; 3$, three conidia, $\times 300 ; 4$, conidia forming zoospores; in $a$ the zoospores are yet within the conidium; in $b$ two zoospores have escaped from the conidium, $\times 300$; 5 , mature oospore or resting-spore, $\times 300 ; 6$, an oospore germinating and producing a conidiophore, highly mag. (after Prillieux); 7, autumnal form of conidiophore bearing a few large conidia, highly mag. (after Prillieux). 
duction of an average crop of fruit the following year is very doubtful. Soon after the appearance of the pale patches on the upper surface of the leaf, corresponding areas on the under surface will be found covered with a very delicate white mildew. This is the fruit of the fungus, which has sprung from the mycelium present in the tissues of the leaf, and has come to the surface through the stomata or breathing pores, to form its conidia or reproductive bodies in the air, where they have an opportunity of being carried by wind, rain, etc., on to the surface of other leaves, where, if conditions are favourable, they germinate within a few hours, entering the tissues of the leaf, and thus starting a new centre of disease. As the conidia are produced in immense numbers, even on a single leaf, it can be seen how rapidly the disease may spread after its first appearance.

The conidiophores are repeatedly branched near the tip, the conidia are oval, and produced in twos or threes at the tips of the branches. On germination the conidia produce zoospores, which soon become stationary and germinate. A second form of conidial reproduction is sometimes produced late in the season, differing from the one already described in the much larger and fewer conidia, which are borne on very short, sparingly branched conidiophores. During the autumn the winter form of fruit or resting-spores are produced in great numbers in the tissues of diseased leaves. The tips of certain branches of mycelium present in the leaves become swollen, and after a sexual process of fertilisation assume a spherical form, develop a thick, coloured wall, and remain in an unchanged condition in the tissues of dead and fallen leaves. If the leaves decay, the resting-spores are not 
injured, but rest on the soil until the following spring, when they germinate, producing two or three conidiophores similar to those growing on the leaf during summer. The zoospores, from the conidia of these germinating restingspores or oospores, being carried by the wind, etc., on to the young vine-leaves, germinate, enter the tissues, and in turn produce the mildew or summer form of the fungus.

Preventive Means.-In Britain, where vines are grown in houses, and comparatively few in number in any one establishment, but little difficulty should be experienced in completely arresting any outbreak of mildew. If the disease appears, spray with dilute Bordeaux mixture as a check to the spread of the disease, for it must be borne in mind that when the mycelium has once entered the tissue of a leaf it cannot be destroyed without also destroying the leaf - the wisest thing to do,-but spraying will prevent the germination of spores on leaves that are yet healthy. In such cases the vines should also be sprayed soon after the fruit is set, and, if necessary, continued at intervals of a fortnight until the fruit begins to ripen. Diseased leaves should be removed, as they soon die, and are but of little service to the vine, whereas, if allowed to remain, they probably assist in spreading the disease. All fallen leaves should be carefully collected and burned, otherwise the presence of resting-spores in their tissues will in all probability infect the vine the following season.

In all instances where the disease has previously existed, it would be wise to thoroughly drench the vines, during winter before the leaf-buds move, with a solution of sulphate of iron.

M. Louis Sipière, writing in the Acad. des Sci., I895, states that lysol, a preparation of carbolic acid, is very 
efficacious against insects and fungus-spores. It is cheaper and more easily employed than either sulphur or Bordeaux mixture. The proportions to be used are 5 grams of lysol to one litre of water. Three applications are necessary -spring, early summer, and late summer.

Viala, Les Maladies de la Vigne, p. 57, figs.

Cooke, Gard. Chron., Jan. 2, 1894.

Prillieux, Malad. des Plantes Agric., vol. i. p. 97, figs.

Massee, Gard. Chron., July 2 I, I 894.

\section{LETTUCE MILDEW}

(Bremia lactucae, Regel. = Peronospora gangliformis, De Bary.)

This fungus often proves very destructive to cultivated lettuce, especially when grown in houses, where the constantly humid atmosphere favours its development. The leaves become more or less covered on the under surface with an exceedingly delicate white mould, turn yellow, and die, the whole plant being stunted in growth. Chicory and artichokes are sometimes also severely attacked, as are also cultivated cinerarias.

The fungus occurs on many wild composite plants.

Preventive Means.-Dilute Bordeaux mixture checks the spread of the disease where it can be applied, which is not the case with lettuce. Houses that become infested should not be again used for the forcing of lettuce for some time, lest resting-spores in the soil inoculate the crop.

This species is very sensitive to a lowering of temperature, and can be checked if the temperature of a house can be suddenly lowered for a short period. 


\section{ONION MILDEW}

\section{(Perenospora schleideni, Ung.)}

This well-known and destructive parasite occurs wherever the onion is cultivated. The first symptom of its presence is a small yellowish patch on one or more of the leaves. These discoloured patches are soon covered with a delicate white bloom, looking like hoar-frost, which quickly changes to a greyish-lilac colour. In the meantime, the diseased patches extend until the entire leaf is usually affected, which ultimately dries up and falls back. A long neck or stalk between the bulb and the base of the leaves is almost constant in diseased plants. The bulb is not attacked; but if, as is usually the case, the disease appears early, the bulb remains very small.

If a small fragment of the delicate mildew from the surface of a leaf is examined under the microscope, it will be seen to resemble a miniature forest ; numerous branches of the fungus spring from the mycelium present in the tissues of the leaf, and push into the open air through the stomata or pores of the leaf for the purpose of producing spores. Each branch of the fungus, when it has passed outside the leaf, divides into numerous branchlets, each of which bears a spore, or reproductive body, at its tip. These minute spores, which are produced in immense numbers, are carried by wind or rain on to the surface of neighbouring healthy leaves, where they germinate at once, enter the tissues of the leaf, and give origin to a mycelium that soon produces fruiting branches, which grow through the stomata of the leaf and form their spores in the air, which serve in turn for the infection of other plants.

A second mode of reproduction is possessed by the 
fungus. Numerous globose, thick-walled bodies, called resting-spores, are produced on the mycelium present in the tissues of the decaying leaves, These resting-spores

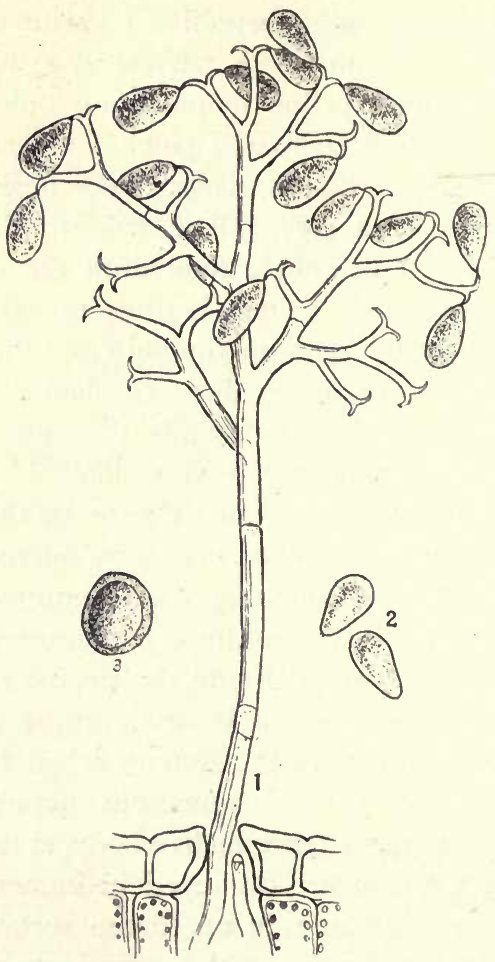

Fig. 10.-Peronospora schleideni. I, a conidiophore that has emerged through a stoma of the leaf, $\times 300 ; 2$, free conidia, $\times 300 ; 3$, a resting-spore, or oospore, $\times 300$.

do not germinate until the spring following their production, when they inoculate the young onions and start the disease afresh. During the winter the leaves containing 
these resting-spores completely decay, but the spores remain unchanged in the soil until the return of spring.

Preventive Means.-In the early stage of the disease its spread may be checked by dusting with powdered quicklime and sulphur, using twice as much lime as sulphur. This is best applied with bellows, and when the plants are damp. Spraying with sulphide of potassium-half an ounce to a gallon of water-will also answer the purpose.

Prevention rather than cure, however, should be the constant aim, and this can be assured if the known means for securing it are systematically and thoroughly carried out.

It has already been stated that the first appearance of the disease in the spring depends on the presence of resting-spores of the fungus, which are produced in the leaves previously killed by the summer form of the fungus. Therefore, relative immunity from disease depends on the amount of care exercised in collecting and burning all such diseased leaves. If allowed to lie on the ground and rot, the resting-spores are set free in the soil; and as they retain their vitality for at least two years, there is a constant and practically a certain danger of the disease breaking out afresh. This may appear a tedious, and some will say impracticable, method of preventing the disease; nevertheless it is certain. If practicable, onions should not be grown on the same land more than once in three years, as at the expiration of this period all resting-spores present in the soil are dead. Damp and shaded situations favour the spread of the summer, or mildew, form of the disease.

Prillieux, Malad. des Plantes Agric., vol. i. p. I43, figs. 


\section{COLOCASIA DISEASE}

(Peronospora trichotoma, Massee.)

Colocasia esculenta, Schott, an important food-plant in the West Indies, is known by one or other of the following names in the different islands: 'Cocoes,' 'Tayas,' 'Tanias,' 'Tanniers,' 'Eddoes.'

In the early stage of the disease a 'tuber' presents a number of yellow dots when cut across, which correspond in position to the vascular bundles; these become darker in colour, and finally the entire substance, except a thin periphoral portion, becomes blackish and decayed, but remains fairly dry. The conidial stage of the fungus appears on the surface, and oospores are numerous in the decayed tissue. The disease attacks the roots after they are lifted.

Preventive Means. - The roots should be thoroughly dried, and only sound ones used for propagation. Soil that has produced a diseased crop should not be used again for colocasias for two or three years.

Morris and Massee, Journ. Linn. Soc., 1887, p. 45, figs.

Peronospora trifoliorum, De Bary.--'This species attacks numerous plants belonging to the Leguminosae, cultivated and wild; Trifolium, Lupinus, Medicago, Lotus, Coronilla, Melilotus, Ononis, etc.

The leaves become covered with a pinkish-grey down, due to the numerous conidiophores. The conidia are broadly elliptical, greyish-lilac. Oospores smooth, reddish brown. When clover or lucerne is attacked, the leaves turn yellow and fall, and the only remedy against a repeti- 
tion of the disease is to cut the crop before oospores are formed.

Peronospora parasitica, De Bary.-This species attacks numerous wild and cultivated plants belonging to the Cruciferae. Among the latter may be enumerated turnips, radishes, rape, cabbage, wallflower, cress, etc. Diseased parts are covered with a very delicate white mould, and are often distorted.

Peronospora schachtii, Fuckel.-The central young leaves of beet and mangold are frequently destroyed by this parasite : and if its attack is continued, favoured by damp weather, the plant is killed. Serious injury has been done on several occasions to the beet crop in France. The conidiophores form dense, greyish-lilac patches of mildew on the under surface of the leaves, which soon become dry and perish. Numerous restingspores are formed in the dead leaves, hence it is important that all diseased plants should be collected and burned, and not allowed to lie and rot on the ground. Alternation of crops is the best course to pursue after the disease has been present.

Peronospora effusa, Rab., forms delicate greyish-lilac mouldy patches on the under surface of spinach leaves, and when present in quantity proves very destructive, as it spreads rapidly. It also occurs on wild plants, as goosefoot (Chenopodium). Spraying is practically impossible in this case, but diseased plants should be collected and destroyed, otherwise the resting-spores formed in the decayed soil find their way into the soil, and are liable to infect future crops. 


\section{VIOLET MILDEW}

\section{(Peronospora violae, De Bary.)}

This pest is not uncommon on the leaves of Heartsease (Viola tricolor), and has of late years done considerable injury to the cultivated Neapolitan violet. The under surface of the leaves is more or less covered with a somewhat dense, dingy, pale violet-grey felt, and later in the season oospores are formed in the dying parts of the host.

The fungus is most abundant during damp weather.

Preventive Means. - So far as I am aware, no liquid fungicides have been experimented with. Probably potassium sulphide spray might prove beneficial. Plenty of air and not too much water retards the spread of the fungus.

\section{CUCUMBER AND MELON MILDEW}

(Peronospora cubensis, Berk. and Curt.)

Forms a very delicate white mould on the under surface of various cucurbitaceous plants under cultivation, as cucumber, melon, squash, etc. Often proves very destructive if allowed to run its course unchecked. Known in the United States, and recently in England. I have also seen the fungus on leaves of Cucurbita pepo, and Cucumis sativa from Tokyo, Japan.

Preventive Means. - Spray with dilute Bordeaux mixture, taking care to reach and wet the under surface of the leaves, which is not an easy matter, but it must be done. 


\section{TOBACCO MILDEW}

\section{(Peronospora hyoscyami, De Bary.)}

In Europe this fungus is not uncommon on the leaves of Henbane (Hyoscyamus niger). Farlow has recorded that it is parasitic on Nicotiana glauca in California, whereas it occurs as a destructive parasite on cultivated tobacco in Queensland, from whence specimens were sent to Kew for determination as far back as 1887 .

Preventive Means.-Spraying with dilute Bordeaux mixture has been found effective in checking the spread of the pest.

\section{MAIZE MILDEW}

(Peronospora maydis, Racib.)

In Java the maize or Indian corn crop suffers severely from the attacks of a Peronospora. Young plants are attacked; as a rule the first two or three leaves are healthy, later ones becoming whitish or very pale green, and soon afterwards the plants droop and die.

The conidia emerge through the stomata. The disease appears in twelve to eighteen days after infecting a leaf with conidia.

It is supposed that the disease has passed from some native grass to the maize.

Preventive Means.-No experiments are recorded. Oospores present in the soil are considered as the principal factors in infection.

Care should be exercised to prevent the disease from 
extending to other maize-growing countries. So far as is known, it is at present confined to Java.

Raciborski, Ber. deutschen Bot. Gesell., vol. xv. p. 475, figs. $1-4$ (1897).

\section{ASCOMYCETES}

\section{GYMNOASCACEAE}

\section{LEAF CURL}

\section{(Exoascus deformans, Fckl.)}

This parasite is very destructive to the foliage of the peach; the leaves of the almond are also sometimes attacked. The disease, which is very widespread, is popularly known as 'leaf curl,' or simply as 'curl,' owing to the fact that diseased leaves become much curled, distorted, and thickened, and of a pale yellowish green, then rosy or purplish colour; finally the convex portions of the diseased leaves become covered with a very delicate whitish bloom, which presents a minutely velvety appearance when seen through a pocket-lens. This appearance is caused by the fruit of the fungus, which bursts through the cuticle, and comes to the surface of the leaf for the purpose of enabling the spores to be diffused.

The young shoots are also often more or less swollen and distorted by the fungus, whose mycelium is perennial in the branches, and each season passes into the leaf-buds, which consequently contain the mycelium of the fungus in their tissues when they expand the following spring. New cases of infection must necessarily arise from the presence of spores floating in the air and alighting on 
young leaves or twigs, but it is not definitely known in what manner this takes place. When once attacked, a

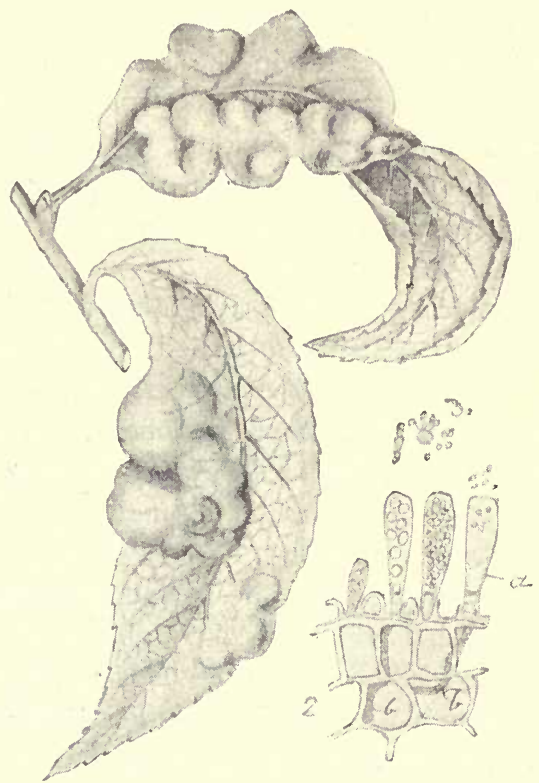

Fig. II.--Exoascus deformans. I, two peach leaves curled by the fungus; 2 , portion of the fungus on the surface of a leaf; $a$, asci containing spores, $\times 300 ; 3$, spores from the asci producing secondary spores by budding. There are at first eight spores in each ascus, but by a process of budding each spore produces numerous very minute secondary spores, so that eventually the ascus is quite filled with secondary spores ; $\times 300$.

tree rarely entirely recovers, but as a rule becomes more diseased as time goes on, owing to the spread of the 
perennial mycelium, and to the infection of healthy shoots by spores produced on the diseased portions. In those years when the disease is especially abundant, it is not unusual to find the trees completely divested of leaves before midsummer. Later in the season a second crop of leaves appear, and these are not attacked by the fungus; nevertheless a considerable amount of damage is done, the crop of fruit in such cases is practically lost, and in the autumn it is found that the wood is imperfectly matured.

Preventive Means. - This is a disease which, if systematically and persistently attacked, could be well kept in check. Diseased fallen leaves should be collected and burned; or better, those branches bearing diseased leaves should be pruned back beyond the point of infection, and thus get rid of the perennial mycelium, which, if allowed to remain, follows the developing shoots year by year. There should be no hesitation about the pruning, as when a branch is once attacked, all beyond the point of infection is diseased, and does not produce fruit, but only fungus spores, which assist in spreading the disease. I have proved by repeated observations that the mycelium does not travel backwards from the point of infection, but forwards ; in other words, it follows the new growth.

The disease is least abundant, or often entirely absent, in those comparatively rare instances where a genial spring has allowed the foliage to quickly attain its full growth without a check, whereas it is rampant when the leaves have commenced growth under favourable auspices, and are afterwards checked by a sudden fall in temperature. During the temporary cessation of growth of the leaf, the mycelium of the fungus spreads rapidly in its 
tissues; and soon after growth of the leaf recommences, the fungus manifests its presence by causing curling and discoloration of the tissues. On the other hand, when evidence of the activity of the fungus has been unmistakable, its further course has been completely checked by a sudden increase of temperature. The disease was very abundant in the south of England during the season following the exceptionally cold winter of $1894-95$.

Spraying with dilute Bordeaux mixture just when the leaf-buds are beginning to expand, and again after an interval of three weeks, would be beneficial as a safeguard against inoculation from wind-borne spores.

Rathay, Österr. Bot. Ztg., I880, No. 7 ; and in LxxxuI. Bande der Sitzb. d. K. Akad. d. Wissensch., I. Abthl. I88 I.

\section{'POCKET-PLUMS,' or 'BLADDER-PLUMS'}

\section{(Exoascus pruni, Fckl.)}

The widespread disease of plum-trees, known in different districts by one or other of the above names, is caused by a minute parasitic fungus, the mycelium of which is perennial in the host-plant, living in the tissues of the young branches, and extending into each new growth of the host that is formed beyond the point at which the branch was first infected by the parasite. In this instance the fruit alone is modified and destroyed by the fungus, whereas in allied species the leaf is the part which serves for enabling the fungus to develop its fruit, and expose its spores on the outside of the host, so that they may be readily dispersed by wind and other agents when mature. 
When the flowers are formed, the mycelium of the fungus travels from the interior of the branch bearing the flower into the young ovary, the result of which is that instead of developing into a normal plum, it grows, under irritating influence of the parasite, into a deformed, useless structure

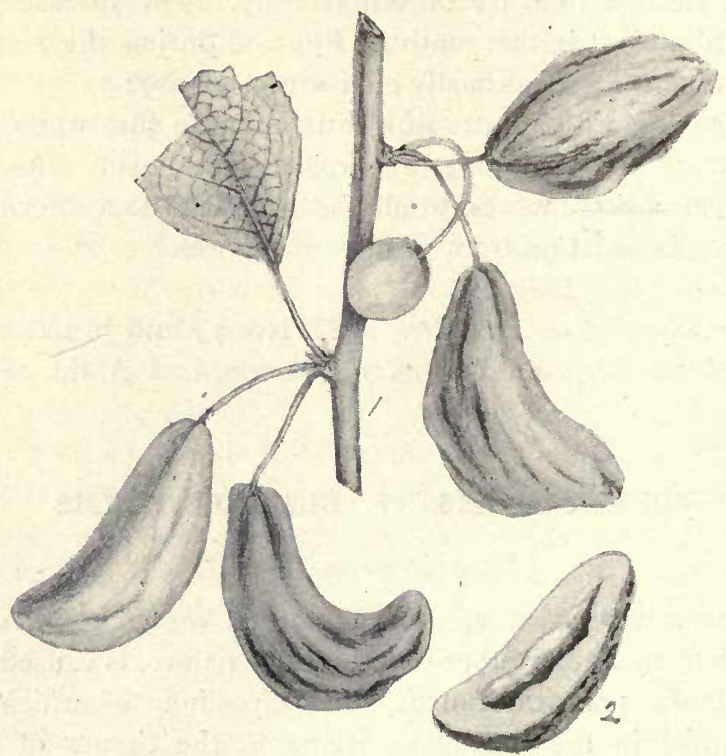

Fig. 12.-Exoascus pruni. I, portion of a branch bearing three diseased plums ; 2 , section through a diseased plum.

of variable form and size, shaped like a finger or a club, often more or less curved and flattened, and having the surface irregularly wrinkled or warted, at first of a yellowish colour, afterwards becoming tinged with dingy red. The entire structure is dry, and not at all fleshy or succulent like a 
normal plum. These bodies are also hollow, the 'stone' containing the seed not being developed. About the middle or end of July these malformations are covered with a very delicate bloom which is whitish at first, but becomes tinged with yellow at a later stage. This apparent bloom is in reality the fruit of the fungus, and if a fragment is examined under the microscope, is found to consist of myriads of upright, closely packed, clubshaped cells or asci, each of which at first contains eight spores or reproductive bodies. These asci spring from the mycelium buried in the tissue of the bladder-plum, and have burst through the cuticle for the purpose of liberating their spores in the air.

In addition to attacking various kinds of cultivated plums, the fungus also deforms the fruit of the sloe or blackthorn, the bullace, and the bird-cherry.

Preventive Means. - As already stated, the mycelium of the fungus is perennial, hibernating in the tissues of the young branches of the host-plant in winter, and extending into the flower-buds so as to reach the young ovaries, where it forms its fruit as already described. It follows that when the mycelium of the fungus has once gained an entrance into the tissues of a tree, external applications are of no service; moreover, I find from a series of observations that the fungus does not spread backwards in the branch beyond the point of infection, but only grows along with the new shoots. 'Therefore, if infected branches are pruned back beyond the point where the disease shows itself, it would be arrested, to the extent due to the presence of perennial mycelium in the branches. This pruning may be carried out without hesitation, as diseased branches never recover and bear good fruit, but 
simply go on producing fungus spores which serve for the inoculation of healthy trees or branches. Unfortunately our knowledge of the life-history of this fungus is incomplete; we do not know, as yet, in what manner the spores of the fungus gain access to the plum-tree in the first instance, neither do we know the particular part of the tree attacked; but the sudden appearance of the disease in districts where it was previously unknown proves conclusively that inoculation by means of spores, which are probably transported by wind, insects, or other agents, does take place.

The chances of infection by floating spores can be considerably reduced by collecting and burning all diseased fruit before the fungus appears on the surface to liberate its spores. When a tree is once infected, the disease usually appears year after year in greater quantity than before, and, as already stated, cure is then practically impossible, and the wisest policy is to cut such trees down, and replace by healthy ones.

If your neighbour's trees, over which you can exercise no control, are diseased, it would be wise to ward off the chance of your own trees becoming infected, by spraying with Bordeaux mixture at intervals from the period of the expansion of the leaves until the fruit is set.

Of course the wild trees previously mentioned as being hosts of the parasite should not be allowed to grow, unless for some definite reason, in the neighbourhood of plumtrees; and if so, should be carefully watched.

Sadebeck, Die parasitischen Exoasceen, p. 44.

Marshall Ward, Diseases of Plants, p. 107, figs. 


\section{'WITCHES' BROOMS' OF CHERRY}

\section{(Exoascus cerasi, Sadeb.)}

This disease, which is not uncommon on the Continent, is rare in Britain. Cherry-trees attacked by this disease show dense tufts of branches growing as it were from a single point, and presenting the appearance of the abnormal developments so much more abundant on the birch, and known popularly as 'witches' brooms,' 'witches' besoms,' ' birds' nests,' etc., in different parts of the country. These tufts never bear fruit, and the leaves produced on such abnormal branches are thick and leathery, of a sickly greenish yellow or tinged red, and in due course present a hoary appearance due to the presence of the fruit of the fungus on their surface.

Preventive Means. - The best way of getting rid of the fungus, the mycelium of which is perennial in the diseased parts, is to cut out the tufts, which not only disfigure the tree, but continually add to the chances of extending the disease.

The following species also occur in Britain :-

\section{'WITCHES' BROOMS' OF SILVER BIRCH}

$$
\text { (Exoascus turgidus, Sadeb.) }
$$

This forms the familiar dense tufts of branches on the silver birch.

\section{'WITCHES' BROOMS' OF ALDER}

(Exoascus amentorum, Sadeb.)

This species deforms and much enlarges the scales of the female catkins of the alder. 


\section{PEAR LEAF BLISTER}

(Taphrina bullata, Tul.)

This fungus often causes irregularly shaped, thickish blisters or swollen patches to appear on pear leaves. Quince leaves are also stated to be sometimes similarly attacked. The blisters are green at first, then dark brown,

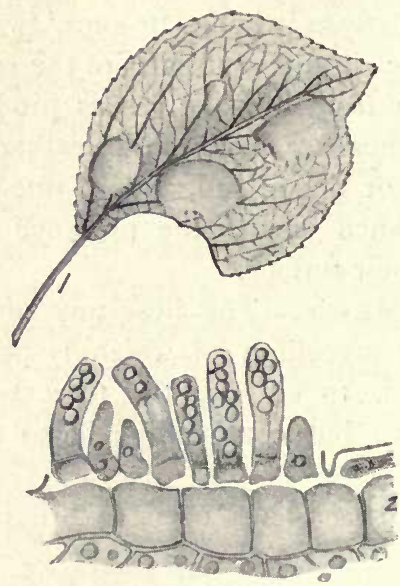

Fig. 13.-Taphrina bullata. I, leaf of pear-tree with blisters caused by the fungus; 2 , asci with spores seated on the epidermis of a leaf, $\times 300$.

and finally become delicately frosted on the under surface with the fruit of the fungus, which bursts through the cuticle. The leaves do not curl as in the 'leaf curl' of the peach, but remain flat.

Preventive Means. - The mycelium is not perennial in the branches of the host-plant in the species of Taphrina, as is the case with the species of Exoascus, hence its 
appearance year by year depends entirely on the hostplant being infected by spores floating in the air, or carried by some outside agency. Collecting the diseased leaves from large trees is not practicable; but this is an easy matter, and well worth the trouble, in the case of nursery stock, and is the most certain means of stamping out the disease. Spraying with dilute Bordeaux mixture two or three times, at intervals of a fortnight, until the leaves are full grown, holds this, and many other pests, in check, which are otherwise always ready to attack, and consequently retard the growth of, young trees.

The following species of Taphrina also occur in Britain. If such become a nuisance, the preventive means suggested under Taphrina bullata will be found adequate :-

\section{ALDER IEAF BLISTER}

(Taphrina sadebeckii, Johans.)

Forms small white or yellowish patches on the under, less frequently on the upper, surface of the leaves of alders.

\section{POPLAR LEAF BLISTER}

(Taphrina aurea, Fries.)

Forms large golden-yellow blisters, concave on the under surface of the leaf, convex on the upper surface, on the leaves of different kinds of poplar. 


\section{POPLAR FRUIT BLISTER}

(Taphrina johansonii, Sadeb.)

Attacks the carpels of the aspen, causing them to become very much swollen and change in colour to a bright golden yellow.

\section{ELM LEAF BLISTER}

(Taphrina ulmi, Johans.)

This fungus forms blisters on the leaves of the common elm, and on those of the wych elm. These patches are at first dark, dingy green, then blackish-brown, and often cover a great portion of the leaf.

\section{PERISPORIACEAE}

\section{Powdery Mildew of Vine}

(Uncinula spiralis, Berk. and Curt.)

The conidial stage of this fungus has been known in this country since 1845 , when it was described by the Rev. M. J. Berkeley under the name Oidium tuckeri. It is probably a native of the United States, where it is common on both wild and cultivated vines. The fungus forms white or greyish-white patches on the upper surface of the leaves, young shoots, and fruit. After the patches have been present for some time, numerous short branches of the mycelium grow erect, each branch becoming converted at its upper part into a chain of oblong conidia. The terminal conidium is the oldest, and when mature falls off, the one 


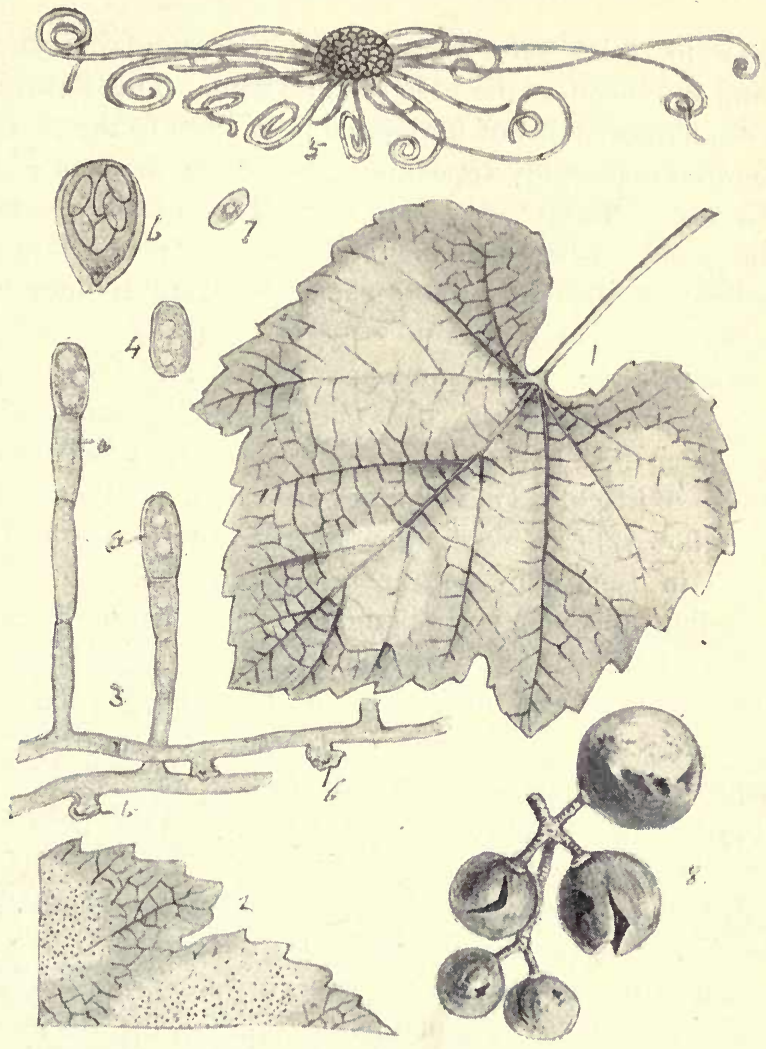

Fig. I4.-Uncinula spiralis. I, fungus forming white patches on the upper surface of a vine leaf; 2 , part of a vine leaf with the fungus bearing perithecia; 3 , portion of mycelium bearing erect chains of conidia at $a, a$; and haustoria which send slender tubes into the living cells of the leaf, $b, b, \times 300 ; 4$, a single free conidium, $\times 300 ; 5$, a perithecium with its curled appendages, $\times 100 ; 6$, an ascus containing six spores, $\times 300 ; 7$, a free ascospore, $\times 300 ; 8$, grapes attacked by the disease. 
below following suit; at the same time new conidia are being produced at the base of the chain. This formation of numerous chains of upright conidia gives to the patches a minutely powdery appearance, hence the popular name. Myriads of conidia are produced throughout the summer, and being washed by rain on to the surface of healthy portions of the vine, where they germinate at once, the disease spreads rapidly.

Towards the end of summer a second and higher form of fruit develops on the patches of conidia-bearing mycelium, first appearing as yellow points, which finally change to black. These bodies are called perithecia, and are hollow spheres, containing in their interior spores produced in asci. The perithecia are provided with several spreading appendages or branches, each of which is more or less spirally curved at the tip. The ascospores are liberated from the perithecia in the spring, when they germinate and give origin to the conidial form of the fungus. The conidial form of the fungus was the only one known in Europe until quite recently, when the perithecia were observed in France.

Preventive Means.-According to Professor Galloway, the disease is easily checked. 'It succumbs readily to sulphur, either in the form of flowers of sulphur, or solutions of the sulphide. In applying the sulphur, bellows should be used, and the first applications should be made ten or twelve days before the flowers open, the second when in full bloom, and a third three weeks or a month later, if the disease seems to be on the increase. The best results are obtained with the thermometer ranging from $80^{\circ}$ to $100^{\circ}$ F. In this temperature fumes are given off which quickly destroy the fungus. We have obtained excellent results in 
treating this disease with a solution made by dissolving half an ounce of potassium sulphide to the gallon of water. The preparation is cheap, and can be quickly and effectually applied with any of the well-known spraying pumps. The greatest care should be exercised in making the second spraying, which, by the way, should be at the same time as that mentioned for the flowers of sulphur, in order to protect the blossoms from the fungus.'

Berkeley, Gard. Chron., Nov. 27, 1847.

Scribner, U.S. Dept. Agric., Bull. I r.

\section{GOOSEBERRY LEAF MILDEW}

(Microsphaera grossulariae, Lév.)

During certain seasons the leaves of gooseberries are more or less covered on the upper surface with a very delicate, whitish, powdery-looking mildew. When the mycelium is well established on the leaf, numerous erect chains of conidia appear. Later in the season perithecia are produced, at first yellow, finally blackish, which contain resting spores produced in asci in their interior. The appendages of the perithecia are branched in a complicated manner at the tip.

Preventive Means.-Spray with potassium sulphide solution, commencing first when the leaves are unfolding.

\section{HOP MILDEW}

(Sphaerotheca castagnei, Lév.)

This scourge of hop-fields is also parasitic on numerous wild plants belonging to various Orders. It first appears 
as very delicate white patches on both surfaces of the leaves, being usually most abundant on the under side; during damp weather the patches increase in size, often covering the entire surface of the leaf and presenting a mealy appearance, due to the presence of numerous white

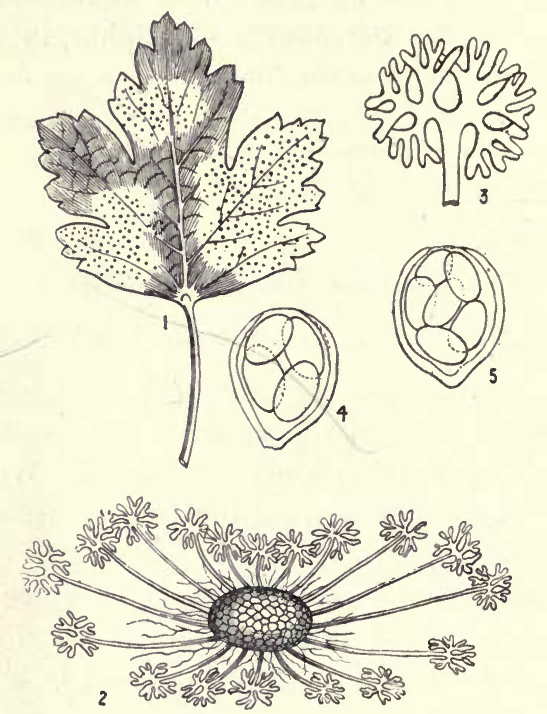

Fig. I5.-Microsphaera grossulariae. I, gooseberry leaf with fungus; 2 , a perithecium with its appendages, $\times 75 ; 3$, tip of an appendage, $\times 300 ; 4,5$, asci containing spores, $\times 400$.

conidia, which, as usual in the Erysipheae, are produced in erect chains, the terminal ones falling off as they become mature, young ones at the same time forming at the base of the chain. By this method enormous quantities of conidia are produced throughout the summer months, and 
being distributed, as fast as they appear, by rain, wind, insects, etc., greatly facilitate the rapid spread of the disease. As the season advances, the patches become darker in colour, due in part to the presence of the ascigerous form of fruit, the tiny perithecia being first yellow and finally blackish-brown. Each perithecium contains a single ascus enclosing eight spores. This stage matures during the winter on the dead parts of the hop or other host-plant; and it is due to the germinating ascospores in the early summer that the disease first appears. So long as the mildew is confined to the hop leaves, but little injury is done; but if it passes on to the inflorescence, and attacks the young cones, serious damage may result.

Preventive Means. - Flowers of sulphur sprinkled over the foliage checks the disease. Being a superficial parasite, spraying with potassium sulphide solution or other fungicide would probably be yet more effectual, if commenced sufficiently early. Aphides and insects should be kept in check, as these greatly assist in diffusing conidia. Weeds should not be allowed, as the fungus is common on many kinds, and may from thence pass to the hop.

De Bary, Fungi, Mycetozoa, etc. (Engl. ed.), p. $20 \mathrm{I}$.

Marshall Ward, Diseases of Plants, p. I49, figs.

\section{AMERICAN GOOSEBERRY MILDEW}

(Sphaerotheca mors-uvae, Berk. and Curt.)

The finer varieties of imported gooseberries have for several years suffered severely in the United States from the effects of a minute fungous parasite which attacks the young leaves and buds, first appearing as a cobweblike 
mildew, which at a later stage becomes covered with a delicate white powder, due to the formation of myriads of conidia. During the early summer the diseased leaves become brown and dead. The young fruit is also attacked, usually becoming distorted and dwarfed.

Preventive Means. - Spraying with potassium sulphide has given satisfactory results; the first application should be made before the buds expand, and continued at intervals of ten or fifteen days as required.

Halsted, Rep. U.S. Dept. Agric., I887, p. 373.

\section{HAZEL LEAF MILDEW}

(Phyllactinia suffulta, Sacc.)

The under surface of hazel and filbert leaves is not unfrequently more or less covered with a delicate white mildew, which commences as scattered patches; these under favourable conditions grow into' each other and cover the entire surface of the leaf.

Numerous minute, blackish perithecia are formed during the summer. The appendages of the perithecia are spinelike, straight, unbranched, and have a swollen base.

Preventive Means.-Similar to those given under gooseberry leaf mildew. The fungus is also parasitic upon the leaves of hawthorn, elm, ash, beech, birch, alder, willow, oak, hornbeam, honeysuckle, spindle-tree, cornel, and sea-buckthorn.

\section{POWDERY MILDEW OF CHERRY}

(Podosphaera oxyacantha, De Bary.)

This pest is more especially injurious to young cherrytrees, but also attacks the apple, peach, quince, and other 
cultivated and wild plants belonging to Rosaceae; it also occurs on species of Vaccinium and Diospyros.

It appears on young leaves and tender shoots as small

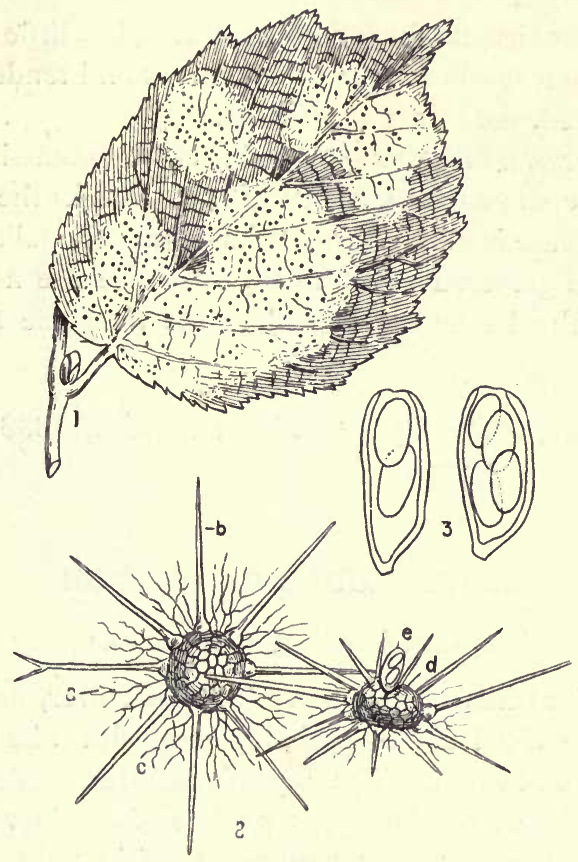

Fig. 16.-Phyllactinia suffulta. I, hazel leaf with fungus ; 2 , perithecia, $a$; appendages, $b$; mycelium, $c$; ascus escaping from a perithecium, $e, \times 75 ; 3$, asci containing spores, $\times 300$.

white patches, which soon spread and run into each other, forming a thin white felt; both surfaces of the leaf are attacked. Chains of conidia are first formed, and later in 
the season minute black ascigerous fruit appears; each perithecium contains a single ascus, and near its apex bears a cluster of almost erect appendages, with muchbranched tips.

If the fungus attacks full-grown leaves, but little injury is done; whereas when quite young leaves and tender shoots are attacked, the injury is often severe.

Preventive Means.-Spraying with potassium sulphide, if commenced sufficiently early, checks the disease. If the disease is allowed to run its course, the fallen leaves should be gathered and burned, otherwise the ascigerous fruit on the leaves will inoculate the trees the following season.

Galloway, U.S. Dept. Agric. Ann. Rep., 1888, p. 352, pl. vii.

\section{SOOTY MOULD OF ORANGE}

\section{(Meliola-Various Species.)}

The black incrustation covering the leaves, and sometimes also the fruit, is probably met with wherever the orange is cultivated. The mycelium forms a black, compact membrane on the upper surface of the leaves, which not unfrequently cracks and peels off in patches. The fungus is not parasitic, but appears to assimilate the ' honey-dew' secreted by aphides and other insects, which it almost invariably follows; hence, if the trees are kept free from such insects, sooty mould could not exist. The fungus causes injury by preventing the leaves from performing their functions; fruit covered by the fungus is also materially injured, and often rendered unsaleable. 
Probably no group of fungi are so imperfectly understood as the black members of the Perisporiaceae, excepting the genus Meliola, which has been recently monographed by Gaillard. The sooty mould is probably caused by different species in different countries, as shown by

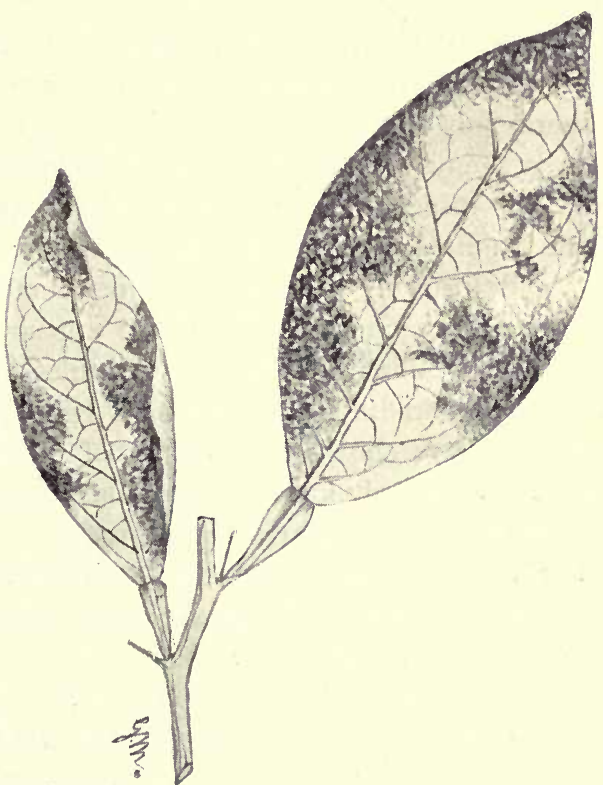

Fig. 17.-Meliola sp. Sooty mould of orange and citron on orange leaves.

M'Alpine. In Europe and the United States the disease is generally attributed to Meliola penzigii, Sacc., and $M$. camelliae, Sacc. Both these are, however, excluded from Meliola by Gaillard, who, however, has not indicated their affinities; hence it is convenient for the present to use the 
names already given. For the present purpose, however, this is unimportant, as it is the insects that have to be dealt with directly, and not the fungi.

Preventive Means. - Swingle and Webber have demonstrated that 'resin-wash' is effective, inasmuch as it destroys the 'honey-dew' secreting insects. Spraying should be done when the insect is in the larval or pupal stage; and it is important that the under surface of the leaves be thoroughly wetted. Webber has observed that members of a genus of fungi called Aschersonia are parasitic on the insects forming 'honey-dew,' and are often present in immense numbers; and sees in the introduction and fostering of these parasites a means of keeping the insects in check. The fungi appear under the form of small yellowish or orange pustules on the leaves, and such should be looked upon as friends wherever observed. I have shown that species of Aschersonia -which hitherto were only known to produce a conidial form of reproduction on living leaves-produce an ascigerous form of fruit, following the conidial stage, on fallen, dead leaves; consequently such dead leaves should be allowed to remain to produce the ascigerous fruit, and thus further aid in the multiplication of the fungus. Fumigation with hydrocyanic acid gas is also very effective; treatment to last about forty-five minutes. Should be done when the temperature is low.

Swingle and Webber, U.S. Dept. Agric. Dept. Veg. and Physiol., Bull. No. 8.

Webber, l.c., Bull. No. I3.

Massee, Journ. Bot., vol. vi. p. 357, pl., for description of ascigerous stage of Aschersonia. 
Capnodium citricolum, M'Alpine.-This fungus, known as 'Black-blight' in Australia, appears to be widely distributed on living leaves of orange and lemon trees in the last-named country. As is the case with allied forms, this species appears to require the previous presence of aphides or scale insects to furnish 'honey-dew' for its nourishment; consequently the mode of treatment already given would be found effective.

M'Alpine, Proc. Linn. Soc., N.S. Wales, I896, p. 469, I $2 \mathrm{pl}$.

\section{MANGO BLACK-BLIGHT}

(Dimerosporium mangiferum, Sacc.

= Capnodium mangiferum, Cke. and Broome.)

This fungus forms intensely black, velvety patches on both sides of the mango leaves (Mangifera indica), sometimes entirely covering the leaf; and as the fungus spreads quickly, owing to its varied modes of reproduction; much injury is done to the trees. It is certain that this species, like many other black, incrusting, non-parasitic fungi, follows aphides, scale, or other 'honey-dew'-producing insects; hence the preventive means necessary are those calculated to destroy the insects; resin-wash being a proved remedy.

\section{SPHAERIACEAE}

Sugar-Cane Disease

(Trichosphaeria sacchari, Massee.)

This is a wound fungus, gaining access to the interior of the sugar-cane through the broken ends of lateral 
shoots, dead leaf bases, etc., but more especially through the wounds made by the moth-borer (Diatraea saccharalis, Fabr.), or the shot-borer (Xyleborus perforans, Wall.). When the mycelium attacks the living tissues it usually first follows the vascular bundles, which assume a bright red colour, characteristic of the incipient stage of the disease. Eventually two conidial forms of fruit are produced, microconidia and macroconidia, which burst through the siliceous cuticle of the cane, and form sooty streaks on the surface. Finally, the ascigerous form of fruit is developed only on very old and much decayed canes. The disease has been most severe in the West Indies, but has also been recorded from Mauritius, India, Java, and Queensland.

Preventive Means. - When the mycelium once gains an entrance to the tissues of a cane, it spreads throughout its entire length. Diseased canes yield little or no sugar, and consequently were used for propagation, being cut into pieces about one foot long. Diseased canes were also left lying about on the ground, affording every facility for the spread of the disease. Now that the fields are kept clean, and only healthy canes used for propagation, the terrific wave of disease, which for a time paralysed the sugar industry in Barbados and other West Indian islands, is disappearing.

Massee, Ann. Bot., vol. vii. I pl. (1893).

Went, Ann. Bot., vol. x. p. 583 , pl. 26. 


\section{BLACK ROT OF GRAPES}

(Guignardia bidwellii, Viala and Ravaz.)

This fungus is probably the most destructive and widespread of enemies against which viticulturalists in the United States have to cope. The disease was introduced into Europe along with vines imported from North America to replace those destroyed by the Phylloxera, itself a pest of American origin, being first observed in France by Professor Viala in 1885 .

During certain seasons the crop of grapes is much injured in this country; and when once established, it is only by exercising the greatest amount of promptitude and cleanliness that the fungus can be exterminated. As a rule, young shoots and leaves are first attacked, the disease appearing under the form of small brownish patches, somewhat resembling the blotches caused by sun-scald. About a fortnight later, the fruit shows symptoms of disease; small blackish or brownish spots appear at different points on the surface; very soon the fruit becomes black, shrivelled, and hard, but as a rule does not drop off. If examined with a pocket lens at this stage, the surface of the patches will be seen to be studded with minute black points. These points are pycnidia or summer fruits, which produce innumerable minute bodies called stylospores or reproductive bodies in their interior. The stylospores ooze out of a small opening at the top of the pycnidia in the form of slender threads, being held together by a sticky substance; they are however readily separated by dew or rain, and those that happen to be carried on to the surface of a damp grape germinate at once, enter the tissues, and soon give origin to a diseased spot, which in course of time produces more stylospores. 
Two other forms of summer fruit are also produced by the fungus under certain conditions.

Finally, a fourth and higher form of fruit appears on diseased grapes that are lying on the ground during the winter months; in this form the spores are produced in asci, and mature during the following spring. It is supposed, but not yet definitely proved, that the spores of this winter form of fruit start the disease afresh in the spring.

Preventive Means.-All diseased fruit, whether hanging on the vines or lying on the ground, should be collected and burned; otherwise there is a danger, amounting almost to a certainty, that the disease will appear during the following season. In like manner all fruit showing the least trace of 'spot' or summer stage of the disease should be promptly removed before the stylospores are ripe, so as to check as much as possible the spread of the disease. In those instances where the disease has previously existed, the vines should be sprayed with Bordeaux mixture just when the leaf-buds are expanding, and again at intervals. After the fruit is half-grown, ammoniacal solution of copper carbonate should be used for spraying instead of the Bordeaux mixture, so as to avoid spotting the fruit. It has been demonstrated in the United States that spraying with Bordeaux mixture not only checks the disease, but also keeps the vines healthier and more prolific than unsprayed vines that have not suffered from the disease.

Scribner, Bot. Gaz., vol. xi. p. 297 (contains the first account of the ascigerous form of fruit).

Viala and Ravaz., Le Black Rot, 1886.

Massee, Gard. Chron., Jan. 26, 1895, figs. 


\section{STRAWBERRY LEAF SPOT}

(Sphaerella fragariae, Tul.)

The leaves of cultivated strawberries are too frequently attacked by this fungus, which is widely distributed. Small dusky spots first appear on the upper surface; as these continue to increase in size for some time, and run into each other, large blotches are often formed. The central part of each blotch changes to a pale grey or almost white, and is bordered by a reddish line. Next, minute white tufts of mould appear on the white central spots; these constitute the conidial condition of the fungus-once considered as a distinct species called Ramularia tulasnei.

Later in the season the higher stage of the fungus appears on the white patches, under the form of minute black points; these are perithecia containing spores produced in asci. Minute sclerotia are also formed in the fading leaves.

Conceptacles resembling the perithecia in form are sometimes present, containing myriads of very minute conidia.

The ascospores and sclerotia germinate the following season; the spores thus produced start the disease again. If the leaves become badly diseased, the crop of fruit is materially affected, if not completely lost ; moreover, the plants become so weakened through loss of leaves that they are comparatively worthless the following season.

Preventive Means.-The disease can be checked by spraying with Bordeaux mixture. If the disease has existed previously, spraying should commence when the leaves unfold, and be repeated at intervals as required 
until the flowers appear. The disease is often very severe in the United States. Professor Trelese has the following note on its prevention:- 'The most convenient way of effecting this is by mowing badly rusted beds soon after the fruit is gathered, covering the dry tops with a light coating

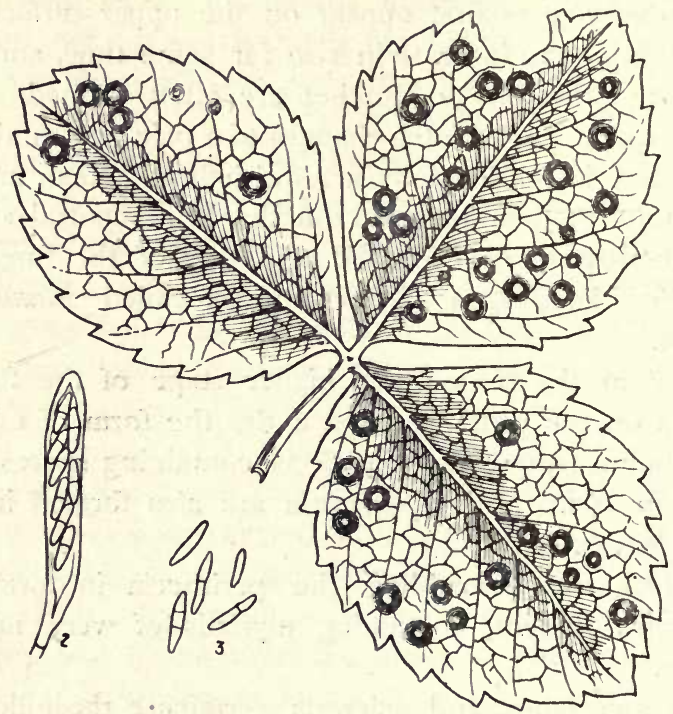

Fig. 18.-Sphaerella fragrariae. I, strawberry leaf diseased; 2 , ascus with eight spores from a perithecium of the Sphaerella or ascigerous condition, $\times 300$; 3 , conidia of the Ramularia stage, $\times 300$.

of straw, or harrowing up the old mulching, and burning them. This may seem harsh treatment for the plants, but it has been resorted to by many berry-growers for the destruction of insects with most satisfactory results; and every one who has tried burning over a strawberry bed has 
been surprised by the vigorous and healthy appearance of the new foliage which soon unfolds.'

Tulasne, Fungoŕm Carpologia, vol. ii. p. 108, pl. xxxi. Prillieux, Malad. des Plantes Agric., vol. ii. p. 268, figs.

\section{BEETROOT AND MANGEL ROT}

(Sphaerella tabifica, Prill. and Del.

=Phoma tabifica, ", ",

=Phoma betae, Frank.)

During the past few years the beet crop in France and Germany has suffered severely from a fungous disease. About the month of August the largest leaves droop to the ground, as is frequently the case during very hot, dry weather. This drooping, however, is due to the upper surface of the leaf-stalk having been more or less disorganised by a parasitic fungus; whilst patches, bordered by an orange-brown zone, are present, often 20-25 $\mathrm{mm}$. long, and finally the tissue becomes brown and dead. This disease passes from the large leaf-stalks into the root, penetrating to the heart, and from thence attacking and killing the young heart-leaves. Superficial minute perithecia containing numerous minute conidia, produced at the tips of conidiophores, appear on the bleached, dead parts of the leaf-stalk. Sometimes these reproductive bodies are also produced on the lamina of the leaf, on rounded patches of a pale brown colour with darker concentric lines. This is the Phoma stage. Later in the season the ascigerous, or Sphaerella, condition appears on the dead petioles, in the places previously occupied by the Phoma. The dead heart-leaves are often more or less 
covered with greenish-brown velvety patches consisting of Alternaria, Cladosporium, and Macrosporium spores; whether any of these are included in the life-cycle of the Sphaerella is not yet known. Apparently the same disease has been recorded by Dr. M'Weeney as attacking stored mangel in Ireland.

Preventive Means.-As the disease appears somewhat late in the season, it has been recommended to lift the crop, if the disease appears, before the fungus passes from the leaves to the root. All diseased leaves should be collected and burned or buried, otherwise the ascigerous condition develops on the dead parts, and a return of the disease the following season would probably result. Great care should be taken not to include diseased roots in storing.

Frank, Zeitschr. fïr Zuckerrubenind., I892, p. 904; and Zeitschr. für Pflanzenkr., vol. iii. p. 90, figs.

$\mathbf{M}^{`}$ Weeney, Journ. Roy. Agric. Soc., ser. III. vol. vi. pt. 3. (1895) figs.

Prillieux, Malad. des Plantes Agric., vol. ii. p. 263, figs. (1897).

\section{CHERRY LEAF SCORCH}

\section{(Gnomonia erythrostoma, Auersw.)}

A disease which every now and again proves destructive to the cherry crop in various parts of Europe. The leaves are attacked, soon presenting a scorched appearance, withering, but hanging on the tree throughout the winter. Long, slender, colourless, curved conidia are first pro- 
duced in perithecia seated on discoloured spots on the leaves. During the winter, the ascigerous form of fruit is also produced on the dead, hanging leaves.

Preventive Means.-All the dead, infected, hanging

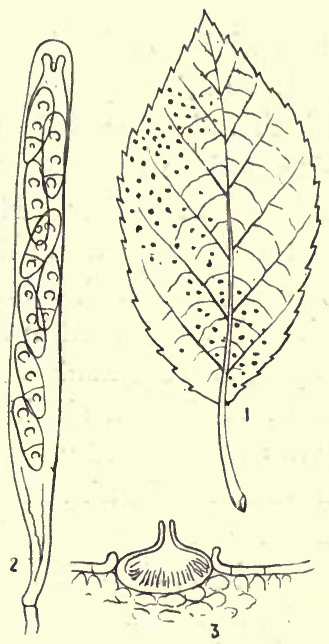

Fig. I9.-Gnomonia erythrostoma. I, a diseased, dry, shrivelled leaf that has been flattened out to show the fungus ; 2 , ascus and spores, $\times 300 ; 3$, section through a perithecium and portion of the leaf in which it is imbedded, slightly $\times$.

leaves must be collected and burned. This must, to succeed, be general throughout the infected district.

Frank tells of one district in Prussia where this method was carried on for two seasons, after which the cherry crop, which had been completely ruined, was restored to its former productiveness. 


\section{OAK CANKER}

(Diaporthe (Chorastate) taleola, Sacc.

Aglaospora taleola, Tul.)

Oak-trees are susceptible to this disease up to the age of about forty years. Brown dead patches of the cortex indicate the presence of this disease; and as these patches are usually of large size, and on different sides of the trunk, the cortex is killed and the tree dies. Numerous stromata are formed in the dead cortex ; these first bear a crop of new-moon-shaped, or sickle-shaped, colourless conidia, and at a later stage perithecia are formed in the black stromata. These are flask-shaped, and the necks of two or three perithecia grow together and form a single common neck or opening, which grows to the surface. Through this neck the ascospores pass out into the air at maturity.

The ascospores have a single median septum, from which three spines project; there is also a spine at each end of the spore. Both conidia and spores are capable of inoculating the tree, germinating first on a wounded portion of the cortex.

Preventive Means.-Hartig suggests that when the disease appears in a wood, the younger diseased trees should at once be felled. This gives the remaining trees a better chance of recovery, and reduces the chances of infection caused by the friction of branches of adjoining trees, which injures the bark; on such wounds the spores or conidia frequently commence their attack.

Hartig, Forstlich-naturwiss. Zeitschr., Jan. I893. Hartig and Somerville, Diseases of Trees, p. 99, figs. 


\section{VANILLA DISEASE}

(Calospora vanillae, Massee.)

Some years ago the vanilla industry in the Seychelles was threatened owing to the attack of a fungus. Material was forwarded to Kew for examination, and the pest proved to be the fungus named above, which occurs on the living leaves and stems as minute dull red or ambercoloured, subtremelloid specks, springing in groups on slightly discoloured patches. This stage of fungus agrees with the form-genus Hainesia. As the diseased parts of the vanilla plant (Vanilla planifolia Andr.) wither, the Hainesia condition is followed by a Cytispora, and finally by an ascigerous stage. These forms are considered as later developments of the Hainesia, and the whole has been named Calospora vanillae, Massee.

The same fungus, showing all three stages, has been received at Kew from Antigua, New Granada, attacking the same host-plant.

Preventive Means.-Clearing away and burning all diseased plants, which were allowed to lie and rot on the ground, has resulted in suppressing the disease, which is most prevalent in low or badly drained districts.

Massee, Kew Bulletin, May and June, I892, I pl.

\section{PINE LEAF FUNGUS}

(Herpotricha nigra, R. Hartig.)

Abies excelsa, Juniperus communis, and $J$. nanus are attacked. It is also very destructive to young larches in elevated regions. The chocolate-coloured mycelium of 
this species completely invests branches and young trees in a dense weft. The lower branches of young trees pressed to the ground by snow are often held in this position by the mycelium. After the leaves are killed they do not fall to the ground but remain anchored to the branches by the fungus, and their surface becomes covered with a brown felt of hyphae on which perithecia are produced in considerable numbers. The fungus is met with in elevated regions more especially, and grows actively under the snow.

Preventive Means.-Nurseries should not be formed at high elevations, nor in valleys where the snow lies for a long time.

Hartig, Alleg. Forst. und Jagd., Zeit. 1888.

Prillieux, Malad. des Plantes Agric., vol. ii. p. 2 I 2, figs.

\section{SILVER FIR LEAF DISEASE}

(Acanthostigma parasiticum, Sacc. Trichosphaeria parasitica, R. Hartig.)

This fungus is abundant in young fir-woods, attacking more especially the silver fir (Abies pectinata), less frequently spruces. The mycelium is at first white, then yellowishbrown, and covers the under surface of the branches. The leaves are first killed, but do not fall to the ground, being held to the branch by cobweblike mycelium. At a later stage the twigs are also killed. In crowded woods the mycelium passes readily from tree to tree, doing a considerable amount of injury. The perithecia are formed 
on a stroma developed on the dead leaves, and are characterised by the presence of radiating brown hairs springing from their upper surface.

The parasite is most abundant in damp situations and where the trees are crowded. In dry, airy districts but little harm is experienced.

Hartig, Alleg. Forst. und Jagd., Zeit. Jan. I884.

Prillieux, Malad. des Plantes Agric., vol. ii. p. 208, figs.

\section{NEW ZEALAND WHITE ROOT-ROT}

(Rosellinia radiciperda, Massee.)

This fungus is closely allied to the European white root-rot (Rosellinia necatrix). Mr. Allan Wight of New Zealand describes its ravages as follows:-'This fungus, in the mycelial stage, attacks a great variety of tree roots, amongst the most conspicuous of which are the apple, pear, peach, and all other common orchard trees. The white-thorn is also very subject to its attacks, as well as a great many Abies, and several of the native trees and plants. It also attacks the cabbage, the potato, docks, sorrel, fern, and, in fact, is almost omnivorous. Its movements are uncertain ; sometimes a tree here and there dies, sometimes a whole row, and very often acres are swept off.'

The bark just underground, or the roots, are first attacked, and presently a delicate white mycelium is seen on the surface of diseased parts. This mycelium forms white strands which run a few inches underground until another victim is reached. As the disease progresses, numerous 


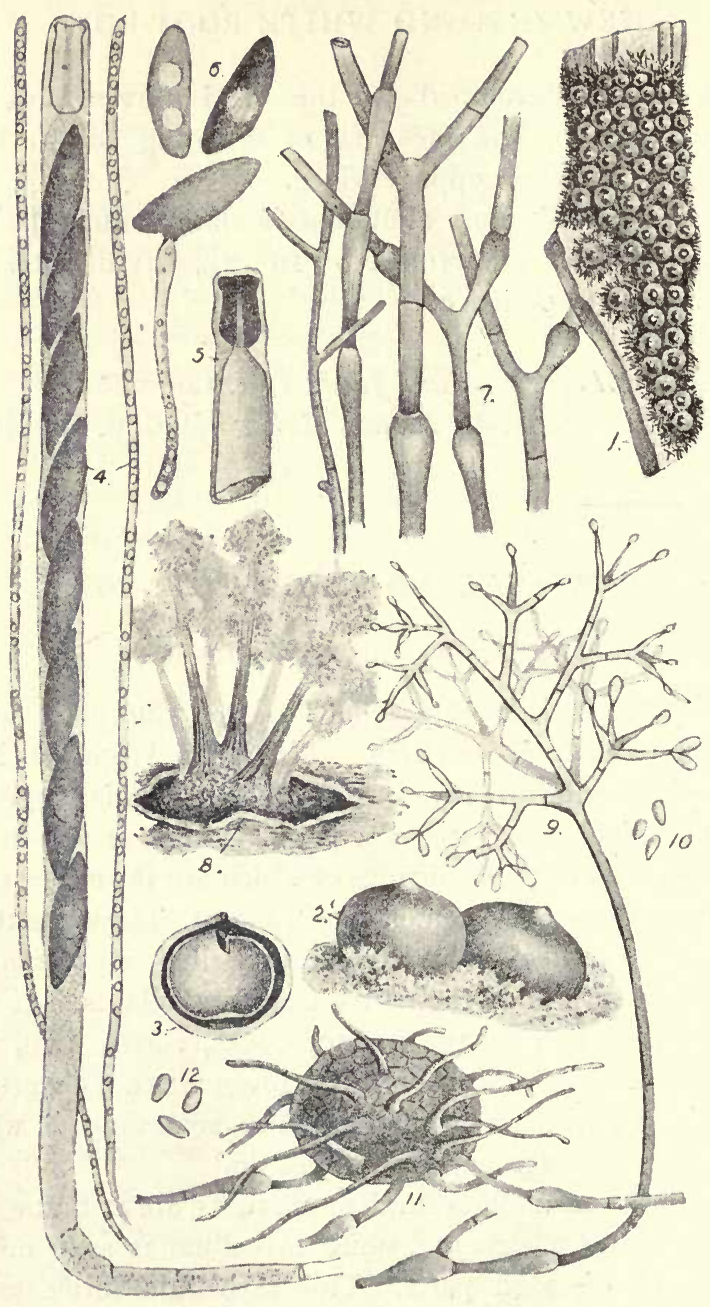

Fig. 20.-Rosellinia radiciperda. I, Ascigerous stage of the fungus showing the perithecia, natural size; 2 , perithecia enlarged; 3 , section of same, showing the wall to consist of two layers ; 4 , ascus containing spores, also paraphyses, $\times 300$; [Description continued on p. i17. 
minute black sclerotia, which eventually give origin to a conidial form of fruit, are formed in the cortex of diseased portions. Next the mycelium becomes dark-coloured and gives origin to globose, black bodies, called pycnidia, containing stylospores or minute reproductive bodies in their interior. Finally the ascigerous form of fruit is produced on trunks or stumps that have been dead for some time.

Preventive Means. - Those recommended under Rosellinia necatrix are applicable.

The following remarks appeared in the Kew Bulletin in connection with this disease :-

'Stagnant water should not be allowed to remain in the soil, as this favours the spread of the fungus. Finally, in those cases where the fungus has completely devastated large areas, it is probable that such will be deserted as unprofitable, the trees being allowed to lie and rot, and the fungus to spread in the soil. This is disastrous, being in fact a nursery for the development and diffusion of the enemy. It is not the object of this note to suggest whose business it is to prevent such shortsightedness, but to impress emphatically that such a condition of things should not be tolerated.'

Massee, Kew Bulletin, I896, p. I, I pl.
Wight, Journ. Mycol., vol. v. p. I99.

5, tip of an ascus after treatment with a solution of iodine, showing the arrangement for effecting the opening or dehiscence of the ascus for the escape of the spores, $\times 300 ; 6$, ascospores, one of which is germinating, $\times 450 ; 7$, brown mycelium with swellings at intervals, $\times 350 ; 8$, a black sclerotium bursting through the cortex of a root, producing several clusters of conidiophores bearing conidia, $\times 40 ; 9$, a single conidiophore bearing conidia at its branched tip, $\times 300$; 10, free conidia, $\times 300$; II, a pycnidium springing from the coloured mycelium, $\times_{40} ; 12$, stylospores developed in the interior of pycnidia, $\times 300 .-$ (From Kew Bulletin.) 


\section{WHITE ROOT-ROT}

(Rosellinia necatrix, Prill. and Del. = Dematophora necatrix, Hartig.)

Fortunately this scourge is rare in Britain, although too well known on the Continent, where it attacks vineyards, orchards, etc., in a wholesale manner. One of the marked peculiarities of the present fungus is its power of becoming parasitic upon a large number of plants belonging to widely separated Orders; in fact, it may be stated broadly that it attacks every plant with which it comes in contact.

Hartig enumerates the following as having been destroyed by the fungus: vines, fruit-trees, potatoes, beans, beet, young maples, oaks, beeches, pines, and spruces. As with Armillaria mellea, the mycelium of the fungus under consideration spreads rapidly underground, and when it comes in contact with the rootlets of a plant it kills them, and gradually works its way into the tissues of the larger branches of the root. In the case of large plants, the mycelium, after travelling along the tissues of the root up to the base of the trunk, bursts through the cortex in the form of a snow-white, fluffy mycelium, which again enters the ground and spreads in search of fresh victims.

During the progress of the disease numerous minute sclerotia are formed in the cortex of the diseased roots; and if such roots happen to be exposed to the air, these sclerotia come to the surface and give origin to groups of minute, bristle-like, dark-coloured conidiophores which bear numerous conidia at their tufted tips.

A second kind of fructification sometimes occurs on decaying roots, under the form of minute, black con- 


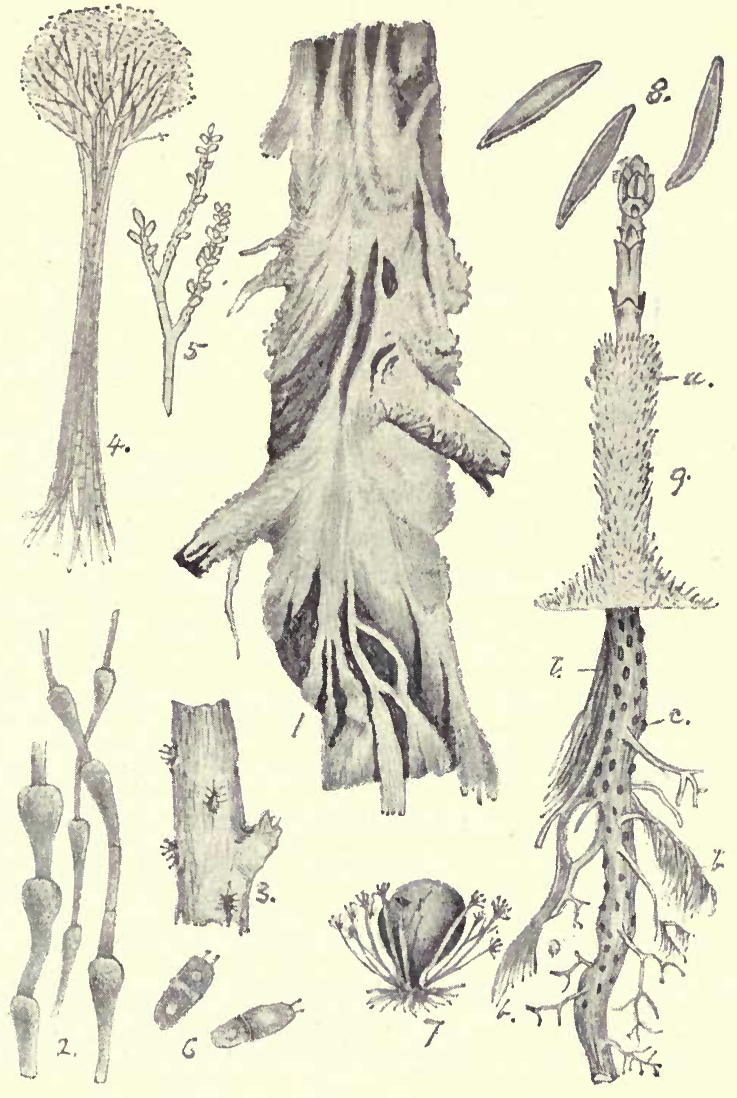

Fig. 21.-Rosellinia necatrix. I iportion the $\mathrm{H}_{j}$ root of an apple-tree partly covered with white, fleecy mycelium 2, brown hyphae showing pear-shaped swellings, $\times 300 ; 3$, portion of an apple-tree root with sclerotia bearing clusters of conidiophores, $\times 6 ; 4$, a single tuft of conidiophores, $\times 70 ; 5$, a branch of the last, bearing conidia, $\times 300 ; 6$, stylospores produced in pycnidia, $\times 300$ (after Viala); 7 , perithecium surrounded by conidiophores, $\times 6$ (after Viala); 8 , ascospores, $\times 350$ (after Viala); 9, a sycamore infected with the fungus. The portion above ground is represented some fourteen days anterior to the rest. The plant is enveloped in the white woolly mycelium, $a$; on the subterranean portion Rhizoctiniae, consisting of dark mycelium, $b, b$, are to be seen. Numerous sclerotia, $c, c$, project from the surface.-(After Hartig.) 
ceptacles called pycnidia, which produce in their interior numerous spore-like bodies called stylospores.

As previously stated, the mycelium is at first snow-white, but the older and exposed portions soon change to a smoky brown colour, and develop pear-shaped swellings at intervals throughout their length. According to Viala these swellings, under certain conditions, gradually become globose, and finally become free, and are capable of emitting a mycelium which forms a new plant.

Finally, the highest or ascigerous condition of fructification has been discovered by Viala ; the perithecia are comparatively large, black, and surrounded by the bristlelike conidiophores already described. This last form of fruit is rare, appearing only on trees that have been dead for a long time, and much decayed.

Preventive Means.-Owing to the subterranean habit of the fungus, spraying is out of the question, as is also a cure when the mycelium is once established in the roots. The soil should be well drained, as the fungus thrives best in places that are sodden with stagnant water. If the disease appears, affected plants should be isolated by digging a narrow trench about a foot deep round the trunk at such a distance as to include the main roots; and if roots are cut through, they should be followed and removed. All the removed soil should be thrown inside the trench. Trees that have been killed should be removed, and special care should be exercised in removing the stumps to get out all the roots possible, as if these are allowed to remain they will form centres of infection from which the mycelium will rapidly spread.

Weeds growing near to infected plants should also be removed and burned. A method that has proved benefi- 
cial in France is to expose the base of the trunk as far down as can be done without injury to the tree, and to powder both trunk and surrounding soil liberally with powdered sulphur, repeating the process at intervals.

Hartig, Unters. aus dem Forstbot. Inst. zu München, vol. iii. pp. 95-r $4 \mathrm{I}$.

Hartig and Somerville, Diseases of Trees (Engl. ed.), p. 82, figs.

Viala, Monog. du Pourridié des Vignes et des Arbres fruitiers, $5 \mathrm{pl}$.

\section{SEFDLING OAK DISEASE}

\section{(Rosellinia quercina, Hartig.)}

Hartig has described a disease which is common in Germany, attacking the roots of seedling oaks. It presents several features in common with the parasite called Dematophora necatrix, which, judging from the mature ascigerous fruit, as described by Viala, is also a species of Rosellinia.

The disease is most prevalent during wet seasons. Affected plants are indicated by withering of the leaves, and on being removed from the ground a white threadlike mycelium, along with minute black sclerotia, are found. These mycelial strands, which eventually become brown, traverse the soil and attack the roots of neighbouring plants.

Perithecia, producing ascospores, are also formed on dying roots. Conidia are also formed on branches of the mycelium running on the ground.

Preventive Means.-Diseased patches should be isolated by a trench, to prevent the spread of the mycelium. 
Dead and diseased seedlings should be removed and burned.

Hartig, Unters. aus dem Forstbot. Inst., vol. i. p. I. Hartig and Somerville, Diseases of Trees, p. 78, figs.

Rosellinia ligniaria, Nitschke.-This fungus has been observed by Mr. W. Carruthers, F.R.S., to attack living ash-trees, eventually causing death. Specimens were exhibited at the Linnean Society's meeting, December I6, I897.

\section{GUMMOSIS OF ACACIA \\ (Pleospora gummipara, Oud. = Coryneum gummiparum, Oud.)}

Oudemans states that the production of Arabian and Senegal gum is due to the presence of this fungous parasite on species of Acacia.

Oudemans, Hedreigia, I883, pp. г 31 and г6г.

\section{HYPOCREACEAE}

\section{ERGOT \\ (Claviceps purpurea, Tul.)}

This well-known disease is often abundantly developed in the ears of various cereals, especially rye; it also attacks various pasture grasses.

Inoculation takes place when the plants are in bloom, the mycelium developing in the ovary, replacing the seed. 


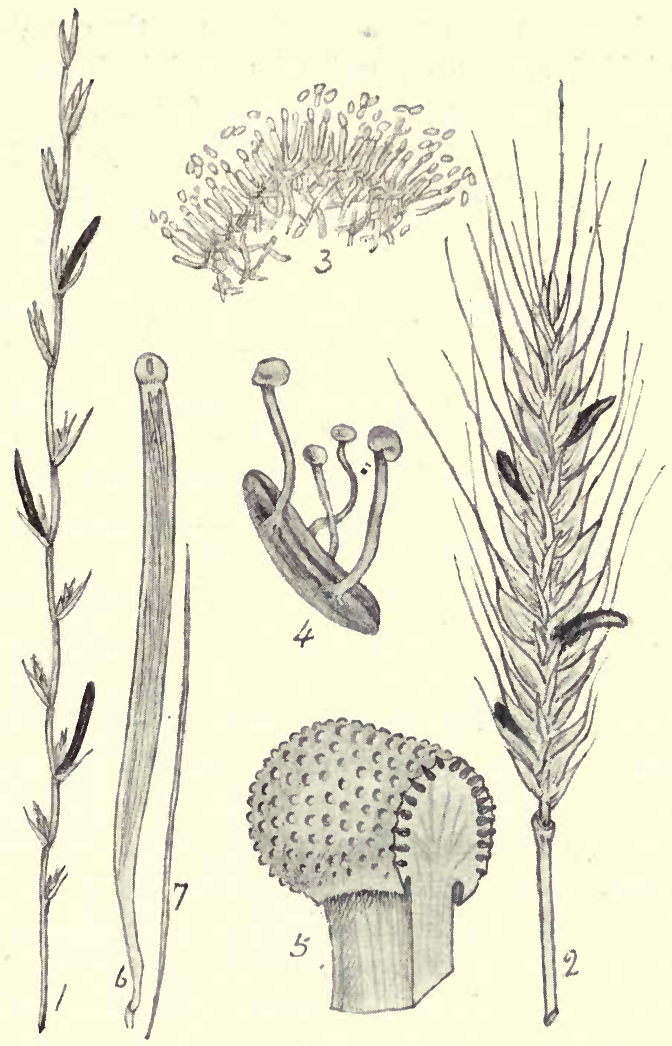

Fig. 22.-Claviceps purpurea. I, ergot on rye-grass ; 2 , ergot on rye; 3 , section of a portion of the conidial form of fruit, $\times 300 ; 4$, a sclerotium or ergot bearing the stalked, ascigerous form of fruit, natural size ; 5 , head of ascigerous form of fruit showing the warted surface due to the projecting mouths of the perithecia; also a section, showing the perithecia sunk in the fleshy stroma; 6 , an ascus, $\times 300 ; 7$, a single spore, $\times 300$. 
A whitish stroma forms on the surface of the ovary, having its wrinkled surface covered with conidiophores, bearing very minute conidia. When the conidia are mature, the stroma becomes bathed in a sweet syrupy substance or 'honey-dew,' which attracts insects, who unconsciously convey the conidia from one flower to another. As the conidia germinate at once, the disease, when once introduced, spreads rapidly. After the formation of conidia is completed, the stroma continues to increase in size, and becomes black externally, forming the hard, curved body known as ergot, or properly, a sclerotium. Many of these sclerotia fall to the ground, where they remain in a passive condition until the following spring, when they give origin to two or three stalked bodies which produce ascospores. Some of these spores, carried by wind, alight on grass flowers, and inoculation follows.

Apart from the direct loss of crop caused by ergot, its action on animal life is very disastrous. Rye bread, containing a considerable amount of ergot, causes a terrible malady, characterised by gangrene of the extremities. Abortion is also caused by partaking of the sclerotia along with food. A wholesale epidemic of cattle in the United States, at first considered to be the much-dreaded 'footand-mouth' disease, was proved to be caused by ergotised food.

Preventive Means. - The most certain method is to collect all the large black sclerotia possible, and, along with those separated from the grain cleansing, either burn, or better, sell them to a chemist for medicinal purposes. By persistent removal of sclerotia, the first or spring inoculation of grass flowers by means of ascospores is much reduced. If, in addition to this, wild grasses growing in 
ditches, on waste banks, etc., are kept cut, the conidial form of the fungus is prevented from developing; for if this happens, conidia are almost certain to be conveyed to cereals or pasture grasses by insects.

Tulasne, Ann. Sci. Nat., Ser. III. vol. xx. p. 5, pl. I-4 ( I 853).

Rep. Commis. Agric. U.S., 1884, p. 2 I 2 (for account of effect on cattle).

\section{REED MACE FUNGUS}

\section{(Epichloe typhina, Tul.)}

A peculiar fungus, strangling the grass on which it is parasitic. It first appears as a whitish crust of variable length, completely surrounding the upper leaf-sheath, causing abortion of the inflorescence, and checking growth above the diseased portion. When in quantity it does considerable injury if pasture grasses are attacked, and scarcely any species of grass is exempt from this parasite. According to Prillieux, grass containing much of this fungus proves injurious to horses. The stroma of the fungus is whitish at first, and in this condition bears numerous minute, elliptical, hyaline conidia, which are capable of germinating the moment they are mature, and thus ensure the rapid spread of the disease. At a later stage the stroma becomes ochraceous and rough with the projecting mouths of myriads of perithecia imbedded in its substance. The asci produced in these perithecia contain very slender, hyaline, needle-shaped spores.

Preventive Means.-A difficult fungus to eradicate, as it is often very abundant on grasses in uncultivated tracts. I once saw many acres of Agrostis canina, L., 
growing on Shiere Common, near Guildford, nearly every plant of which was attacked by the fungus. It is often
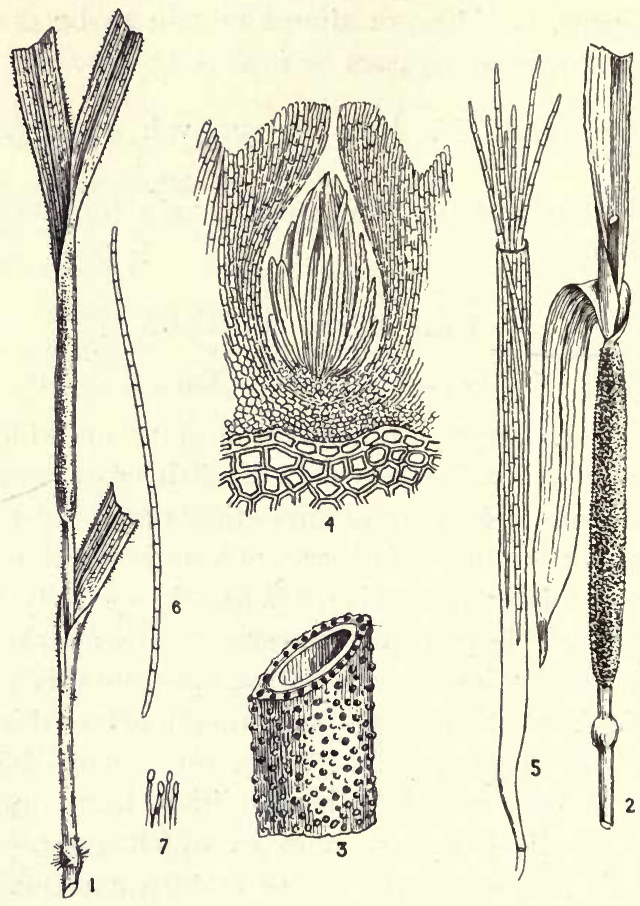

Fig. 23.-Epichloe typhina. I, fungus on leaf-sheath of Holcus mollis; 2, fungus on leaf-sheath of Holcus lanatus; 3. portion of fungus showing the warts on its surface corresponding to the mouths of the perithecia ; slightly $x$; 4 , section of a perithecium, $\times 200 ; 5$, an ascus showing the spores escaping from its apex, $\times 400 ; 6$, a single spore, $\times 400 ; 7$, conidiophores with conidia, $\times 300$.

abundant on the grass growing on ditch banks and other damp places, and from thence passes on to the pasture 
species of Poa, Holcus, Phleum, etc. If useless grass growing in damp places is cut as soon as the disease manifests itself, its spread is much retarded.

Tulasne, Fungi Sel. Carp., vol. iii. p. 24.

Prillieux, Malad. des Plantes Agric., vol. ii. p. 96, figs.

\section{APPLE-TREE CANKER}

(Nectria ditissima, Tul.)

This parasite by no means confines its attacks to the apple, but is equally common on the beech, and, according to Hartig, also invades the oak, hazel, ash, hornbeam, alder, maple, lime, dogwood, and bird-cherry.

The fungus is usually a wound-parasite, its conidia or spores germinating in the first instance on some wounded surface, and from thence invading the healthy tissues. The bark is first attacked and destroyed, often cracking in a concentric manner; afterwards the wood is also destroyed, the canker often completely girdling small branches. As a rule a thickened, irregular margin of living bark forms round the wound, giving a rugged appearance to the parts attacked, and very characteristic of the disease. Not unfrequently several diseased spots appear on a branch at places where there is no evidence of external inoculation, and Hartig explains this by assuming that when the fungus has once gained admission to the living tissues through a wound, the mycelium travels in the substance of the branch, bursting through the bark at intervals to form its fruit on the surface. The fungus is somewhat capricious, not attacking the margin of the wound equally all round, but often concentrating its work of destruction at one 


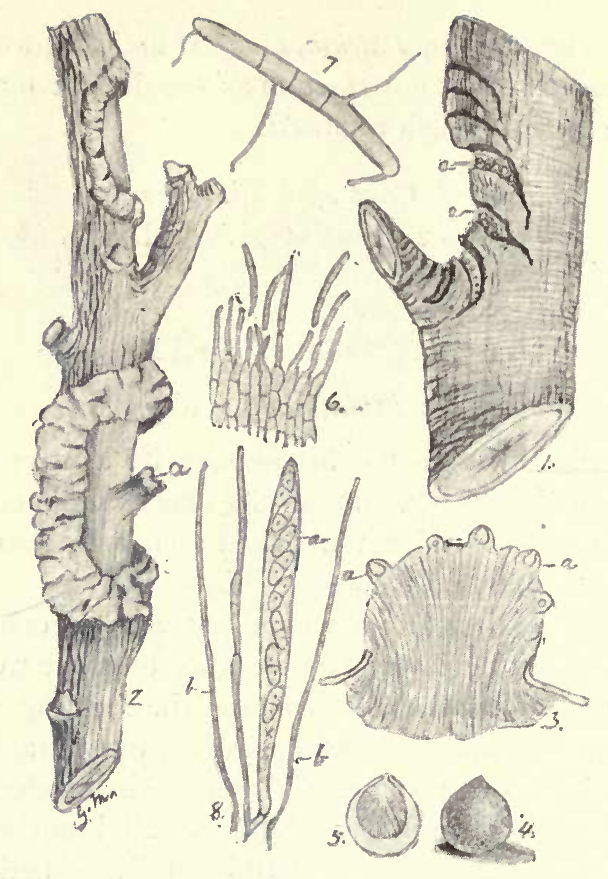

Fig. 24.-Nectria ditissima. I, a branch recently attacked, the disease entered at the axil of the small branch; $a, a$, perithecia ; 2 , a branch that has been diseased for some time, showing a rugged raised margin round the wounds; the end of the broken branch, $a$, is the point where the fungus gained an entrance into the branch; 3 , section through a stroma containing perithecia, $a, a$, on its surface, $\times 30 ; 4$, a single perithecium, $\times$ 100: 5 , section of a perithecium, $\times 100 ; 6$, portion of a stroma bearing conidia, highly mag. (after Hartig); 7, a single conidium germinating, highly mag. (after Hartig); 8, portion of the contents of a red perithecium ; $a$, an ascus containing eight $\mathrm{I}$-septate spores $; b, b$, paraphyses, $\times 300$. 
particular point, and then moving to another, resulting in the canker spots having a very irregular outline.

At those points of the wound where the mycelium is most vigorous, small white cushions or stromata appear in the autumn, bearing on their surface very minute conidia, which become free at maturity, and germinate at once.

During the following spring, a second form of fruit, consisting of clusters of minute, blood-red perithecia, appear on the cushions which during the previous autumn bore conidia. These perithecia contain in their interior numerous asci, each enclosing eight spores.

Preventive Means.-Badly diseased branches should be removed and burned. Where the canker is sight the affected part should be cut out, and the wound coated with tar.

Hartig has observed that aphides are often present along with the fungus, and these may assist in spreading the disease by carrying conidia, and even unconsciously introduce them into the punctures they make, hence it would be advisable to apply an insecticide.

Old cankered fruit-trees that have been destroyed by this or other fungi are too frequently allowed to remain standing long after it is admitted that they are of no value, except for firewood. Such trees are in reality acting as nurseries for the growth and dispersion of fungus parasites, and should be removed without delay.

Plowright, Gard. Chron., April 19, I884, figs.

Hartig and Somerville, Diseases of Trees (Engl. ed.), p. 9 I. 


\section{SPRUCE NECTRIA}

(Nectria cucurbitula, Fries.)

Hartig has furnished us with an elaborate account of this wound-parasite, of which the following is an abstract.

The spruce is most frequently attacked, rarely the silver fir or Scots pine. Entrance to the tissue of the tree is often through wounds made by the larva of the moth called Grapholitha pactolina, also through bruises caused by hail, or cracked branches.

The cortex is the portion most directly affected by the fungus, although when this is killed, and especially when it happens near the top of the tree, the wood also dries up, and the top of the tree becomes yellow, withers, and dies.

The mycelium is most luxuriant in the sieve-tubes of the soft-bast, and grows most vigorously when the growth of the tree is at a standstill. If the dead bark is almost constantly damp, numerous whitish stromata burst through to the surface; these first bear conidia, followed at a later period by crowded red perithecia containing spores formed in asci.

Preventive Means. - It is considered advisable to cut off and burn the tops of dead trees to prevent the spread of the disease.

Hartig, Unters. aus dem Forstbot. Inst. zu .Vünchen, vol. i. p. 88, I pl.

Hartig and Somerville, Diseases of Trees, p. 89, figs. 


\section{CORAL SPOT DISEASE}

(Nectria cinnabarina, Fries.)

The numerous bright, coral-like warts, about the size of a millet seed, thickly studded over the surface of dead branches, have probably been noticed by most people at one time or another. These are the conidial condition of Nectria cinnabarina. The conidia are exceedingly minute, and produced in myriads. During the autumn and early winter, these warts assume a darker red colour, and become minutely warted, due to the formation of the second or ascigerous form of fruit.

The fungus often lives as a parasite, but is also a woundparasite, attacking various trees-sycamore, lime, horsechestnut, and more especially the red currant.

The spores or conidia germinate on the surface of a wound, and the mycelium passes into the living tissue, where it extends until a portion of the branch is killed, when the bright-coloured fruit is formed on the surface.

Preventive Means.-As the mycelium spreads quickly in the branches much beyond the point where it indicates its presence externally, cuttings should not be taken from diseased trees.

Diseased branches should be cut off and burned, as should also rotten sticks lying on the ground.

Cooke, 'A Currant Twig and Something on it,' Gard. Chron., Feb. 28, I87 I.

Mayr, 'Ueber den Parasitismus von Nectria cinnabarina,' Unters. a. d. Forstbotan. Inst. zu München, vol. iii. p. I, I 883 .

Durand, Cornell. Univ. Agric. Expt. Station, Bull. 125. 


\section{EGG-PLANT ROT}

\section{(Nectria ipomoeae, Hals.)}

The Fusarium condition causes stem-rot of the eggplant (Solanum melongena, L.) and sweet potato (Ipomoea batatas, Poir.), covering the withered stems with a white mould. At a later stage clusters of flesh-coloured perithecia appear. The disease usually commences near the ground-line, and spreads both into the stem and the root.

Halsted, Ann. Rep. N. Jersey Agric. Expt. Station, I89I, p. 28I, figs.

Nectria vandae (Wahrlich) is a parasite on the root of Vanda suavis in cultivation.

Nectria goroshankiniana (Wahrlich) is also parasitic on the root of cultivated plants of Vanda tricolor.

Wahrlich, Bot. Ztg., July 23, I886.

\section{CACAO DISEASE}

Mr. J. B. Carruthers, who has spent some time in Ceylon investigating the destructive disease attacking the cacao tree, has published his report, of which the following is a summary. The name of the fungus causing the disease is not given, but the account leaves little doubt that it is a species of Nectria, allied to the species causing canker in the wood of the apple-tree.

The first indication of disease is a darkening of a patch of the cortex; if this patch is cut out it is found to be 
soft and of a claret colour and full of moisture. At a later stage minute white pustules appear, especially in cracks ; these eventually become pink. During the white stage very minute oval conidia are produced in immense numbers, and later on larger, crescent-shaped conidia appear. Finally, when the cortex is dead, or nearly so, a third ascigerous form of fruit develops; the sporangia being globose, crimson, and grouped in clusters.

The disease often spreads rapidly; in one instance a diseased patch more than two feet long, and reaching almost round the tree, had formed ten days after inoculation.

Preventive Means. - The most satisfactory method is to cut out the diseased patch, along with a margin of apparently sound cortex. Covering the wound with tar is not recommended.

Carruthers, The Tropical Agriculturalist, Nov. I, I898, p. 359 .

\section{MUSHROOM DISEASE}

\section{(Hypomyces, sp.}

Cultivated mushrooms are frequently attacked by fungous parasites before they burst through the soil, and on appearing at the surface are completely covered with a more or less dense white felt of mould; in other instances the mould becomes tinted pale rose-colour; such mushrooms rarely increase in size, and never develop properly, but deliquesce and disappear. Sometimes the young mushrooms are only slightly diseased, and in such cases the young gills are not straight as is usual in healthy specimens, but more 
or less wrinkled and puckered, and covered with a delicate cobweblike white mycelium. All such are destroyed by the parasite at a later stage of development.

The parasites, so far as at present observed, belong to Verticillium and Mycogone, and are supposed to be conditions in the life-history of some species of Hypomyces, but this has not been demonstrated.

Preventive Means.-All diseased mushrooms should be carefully removed and burned as soon as they appear, otherwise the spores, which are formed in immense numbers, are diffused by wind, etc., over every part of the cave or cellar, and settle down on the soil when a new bed is prepared, and thus extend the disease. Spraying the walls and soil, in fact every internal part of the building, with $2 \frac{1}{2}$ per cent. of lysol before the spawn is deposited, destroys all spores present, and has been found to materially reduce the disease; it also destroys various insects, more especially Sciara ingenua, which often proves very destructive to the mushroom crop. The spores or germs of many kinds of mushroom disease are undoubtedly introduced along with the spawn. This danger can be avoided by using artificially prepared spawn formed from pure cultures of mycelium, which are placed in sterilised material. A further advantage in this method is that any particular strain of mushroom can be procured. This method is now commonly adopted in France.

A high temperature, and stuffy, stationary air, favour the disease.

Costantin and Dufour, Rev. Gén. Bot., vol. iv. pp. 40 I, 462,549 ; vol. v. p. 497 . 


\section{PLUM LEAF BLISTER}

\section{(Polystigma rubrum, Pers.)}

A parasite often proves injurious to plum and almond trees by destroying the foliage. It also attacks the sloe and white-thorn. Reddish patches appear on the leaf, most frequently, but not always, on the lower surface; these

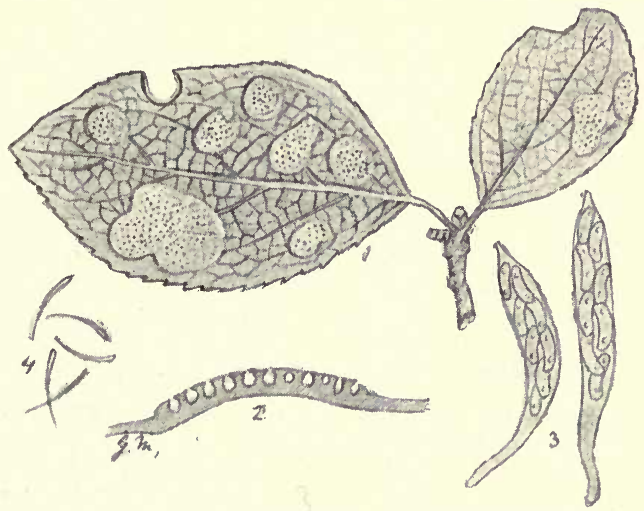

Fig. 25.-Polystigma rubrum. r, diseased plum leaves; 2 , section through a stroma, showing the perithecia; 3 , asci containing eight spores, produced in a perithecium, $\times 300 ; 4$, spermatia, produced in spermogonia, $\times 300$.

spots soon develop into thickened, cushion-like stromata, the surface of which, towards the end of June, becomes thickly studded with minute darker dots, which correspond to the mouths or openings of flask-shaped receptacles imbedded in the stroma, called spermogonia. These structures contain numerous slender, curved bodies, called 
spermatia, which escape through the mouth of the spermogonium as a mucilaginous mass, the component spermatia becoming liberated by dew or rain.

Spermatia continue to be produced until the autumn.

In the autumn perithecia are also developed in the stroma, their complete condition being attained during the winter after the leaves have fallen. The spores produced in the perithecia inoculate the young leaves of the host the following spring.

Preventive Means.-The injury occasioned by this parasite is in exact proportion to the amount of leaf surface it occupies, the mycelium not extending beyond the margin of the stroma. These patches, however, are sometimes of large size, covering the greater portion of the surface of the leaf, and, as frequently nearly all the leaves on a tree are attacked, ripening of fruit and maturing of the wood become impossible. The most effective means of preventing a repetition of the disease is by collecting and burning the diseased fallen leaves.

Frank, Ber. der Deutsch. Bot. Gesell., vol. i. p. $5^{8}$ (1883).

De Bary, Fungi, Mycetozoa, and Bacteria (Engl. ed.), p. 2 I 5 .

\section{BLACK KNOT}

(Plozerightia morbosa, Sacc.)

Undoubtedly the very worst fungous disease attacking cultivated plum and cherry trees known in the United States, to which country it is at present confined. According to Dr. Halsted it also attacks the following wild trees in that country:-Prunus chicasa, Mich., Prunus mari- 
tima, Wang., Prunus americana, Marsh, Prunus virginiana, L., Prunus serotina, Ehrb., and Prunus pensylvanica, L. The fungus is readily recognised by the formation of

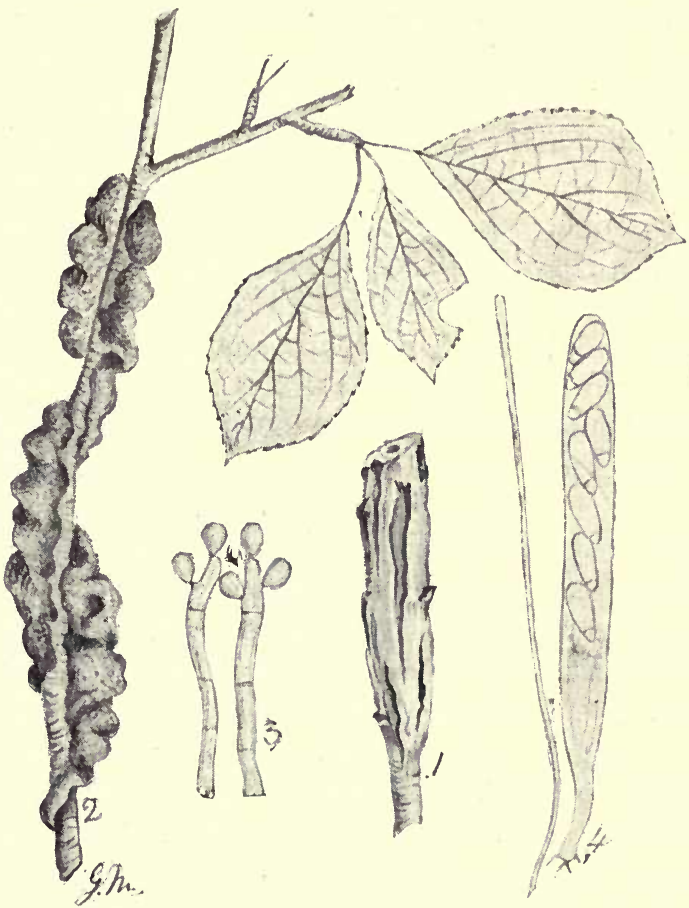

Fig. 26.-Plowrightia morbosa. I, portion of a plum branch showing the first stage of the disease; 2, plum branch with 'black knot,' the stroma bearing perithecia; 3 , conidiophores bearing conidia, $\times 300 ; 4$, ascus containing eight ascospores, $\times 300$.

black, rough excrescences on the branches; these are often several inches in length, and sometimes cause the 
branch to curve at the part attacked. The first indication of the disease is the swelling of the branch, followed by a longitudinal cracking and gaping of the bark, the wounded surface soon becoming covered with a dark olive velvety coating.

Examined under the microscope, this velvet pile resolves itself into myriads of upright, simple, or branched conidiophores, bearing conidia. These conidia are dispersed by rain, wind, etc., and those that are located on the tender bark of young shoots soon form the starting-point of new knots. Later in the season the olive mould disappears, and in its place a thick outgrowth of compact fungus mycelium, called a stroma, is produced, hard, nodulose, and black externally. During the winter numerous cavities are formed in the stroma, each containing many asci, enclosing eight spores each. In the spring the ascospores are liberated, and in turn infect the host. Other conidial forms of reproduction are known.

Preventive Means.-Dr. Halsted says: 'The remedies to be proposed are few in number, and easily applied. The old one of removing all the knots with a knife and burning them is highly recommended. However, when a tree is thoroughly infested, it is not easy to cut far enough below the excrescence to remove all the fungus. The writer has frequently seen vigorous trees, highly prized by the owner, so severely pruned as to leave only a few stubs in place of the branches, and upon the tips of each the next season would grow knots of considerable size. In all such cases there seems only one thing to be done, and that is to remove the whole tree and cast it into the consuming burn-heap-the sooner the better.'

All cultivated varieties are susceptible to the disease, 
if not equally so, and conidia or spores from any species of tree infested appear capable of inoculating any other species; hence the work of extermination of diseased trees must extend to wild as well as cultivated forms, and, furthermore, to ensure success, the movement must be general, experience having shown that it is of comparatively little use attending thoroughly to your own trees if your neighbour fails to follow suit. Legislative measures have been pressed into force in some of the States in the United States for the purpose of endeavouring to enforce this object.

Farlow, Bull. Bussy Inst., I875, 3 pl.

Halsted, $N$. Jersey Agric. Coll. Expt. Station, Bull. 78 figs.

Plozerightia ribesia, Sacc.--Occurs on living branches of red and black currant and gooseberry. Black patches are formed under the epidermis, through which the small black clusters of perithecia protrude, resembling rough, black warts.

\section{HYSTERIACEAE}

Pine Leaf-Cast

\section{(Lophodermium pinastri, Chev.)}

A tiny fungus, producing very minute, elliptical, black spots on the leaves of various species of pine, causing the leaves to fall prematurely, and consequently, especially in the case of seedlings and young trees, finally killing the plant. The following is abridged from Hartig's detailed account of the disease :- 
'Its presence is often first indicated on the primary leaves of seedlings by the appearance of brown blotches, the remainder of the leaf becoming purple red.

'A condition of the fungus termed spermogonia, forming

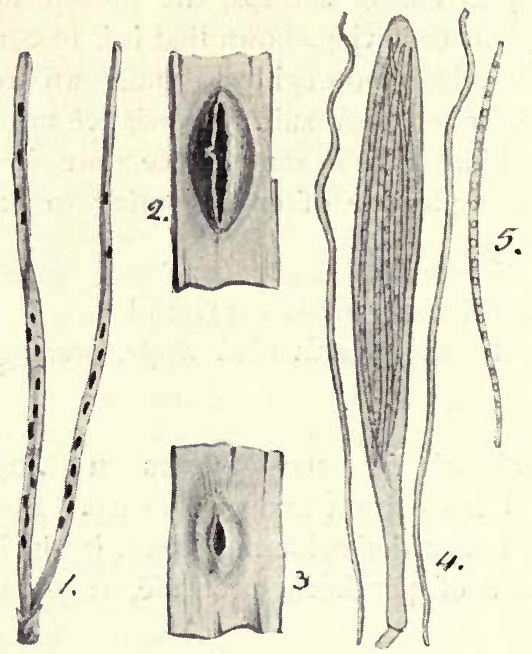

Fig. 27. - Lophodermium pinastri. I, leaves with the fungus, natural size; 2 , ascigerous form of the fungus, mag.; 3 , spermogonium of the fungus, mag. ; 4, ascus containing eight spores, also two paraphyses, highly mag. ; 5, a single spore, highly mag.

smaller black spots than the elliptical, ascigerous form, often appears first on the leaves, which it kills. The presumed reproductive bodies, called spermatia, formed in the spermogonia, have not been observed to germinate. The mature, ascigerous form only opens for the escape of the spores after long-continued rain, which thoroughly soaks 
the leaf, causing the asci to swell, and consequently rupture the apothecium.

'Diseased seedlings usually die, and do so with certainty unless about half the number of leaves escape the parasite.'

Preventive Means. - It is certainly not advisable to plant diseased year-old seedlings, nor those of two years old or more, as such rarely recover the effects of transplanting.

If the mycelium of the fungus passes into the tissues, and especially if the pith is browned, the plant is certain to die almost at once.

Seed-beds should not be exposed to the direction of the prevailing wind, especially if it blows over a diseased area, as spores are almost certain to be carried, and some of these are almost as certain to be deposited on the seedlings. Neither should the beds be formed under older pines, as such may possibly have some diseased leaves, and the spores would be washed down by rain. Weymouth pines are not attacked by this disease, and may take the place of pines destroyed by the disease if conditions are favourable for their growth.

Göppert, Verhandl. d. schlesischen Forstvereins, I 852, p. 67. Hartig and Somerville, The Diseases of Trees (Engl. ed.), p. I I o, fig.

According to Hartig the silver fir also suffers from leafcast, old trees even losing the majority of their leaves, due to a fungus called Hysterium nervisequium. The fruit forms a black line on the midrib on the under surface of the leaf. Another species of Hysterium, H. macrosporum, sometimes destroys the leaves of the spruce. A brown coloration indicates the presence of the mycelium of the 
fungus in the tissues of the leaf. At a later stage the fruit appears, mostly on the under side of the leaf, as long, shining, black streaks.

Hartig and Somerville, The Diseases of Trees (Engl. ed.), p. 108, figs.

\section{DISCOMYCETACEAE}

\section{Sycamore Leaf Blotch \\ (Rhytisma acerinum, Fries.)}

The large black patches so common on the upper surface of living leaves of the sycamore (Acer pseudoplatanus), maple (Acer campestre), A. platanoides, and A. rubrum, are of fungous origin, and when present in considerable numbers on almost every leaf on the tree, do considerable injury by preventing the leaves from performing their proper functions. The patches are yellow when they first appear in June or July, soon changing to pitch-black, having the surface wrinkled or corrugated. The patches become thickened and scab-like, due to the formation of a thin stroma, on the surface of which a crop of minute bodies called spermatia are produced in the autumn. These spermatia resemble very minute conidia in appearance, but have not been seen to germinate, and their function is unknown. In damp weather they ooze out from below the surface of the cuticle, and cover the surface of the black patches. During the winter, after the leaves have fallen, an ascigerous form of fruit is produced, the spores becoming mature in the spring.

Preventive Means.-It has been experimentally proved that the spores produced in asci will give origin to the black blotches, when placed on young, living leaves, and 
no other form of reproduction is known; hence, if diseased leaves are collected and burned before the ascospores are liberated in the spring, the disease will be arrested.

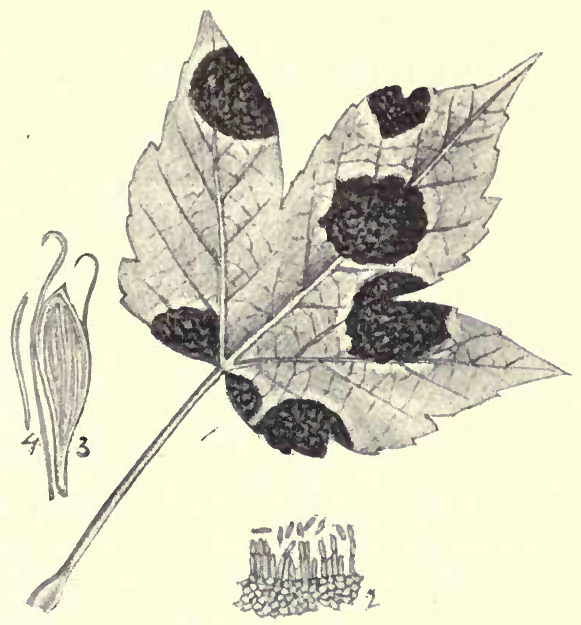

Fig. 28.-Khytisma acerinum. I, sycamore leaf with Rhytisma blotches; 2 , section through a portion of a black patch bearing spermatia, $\times 200 ; 3$, ascus containing spores, also two curved paraphyses, $\times 300 ; 4$, a free spore, $\times 300$.

The following species of Rhytisma also occur as parasites, and if injury is being done, the diseased leaves should be removed, to prevent inoculation the following spring :-

Rhytisma punctatum, Fr., forms large black blotches, surrounded by a yellowish line, on living leaves of Acer campestre, L., A. pseudoplatanus, L., and A. spicatum, Lam. In this species the black scab or crust is not continuous as in $R$. acerinum, but consists of closely crowded small pieces. 
Rhytisma salicinum, F., forms large pitchy-black patches on leaves of goat willow (Salix capreae, L.) and several other species of willow (Salix).

\section{CLOVER LEAF SPOT}

\section{(Pseudopeziza trifolii, Fckl.)}

A fungus that not unfrequently proves destructive to crops of lucerne (Medicago sativa) and clover (Trifolium). The leaves are attacked, and first show minute blackish

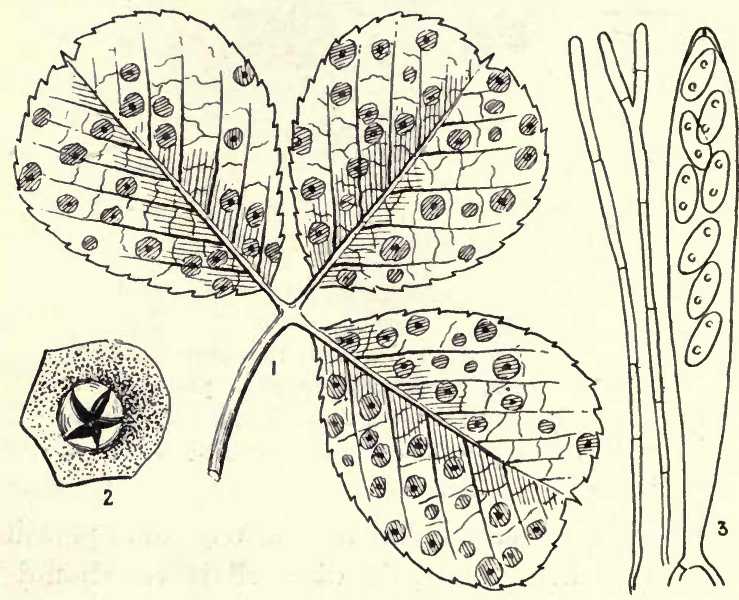

Fig. 29.-Pseudopeziza trifolii. I, a clover leaf badly diseased, nat. size; 2 , a pustule or fruit of the fungus bursting through the epidermis of the leaf, which is torn into triangular teeth, slightly mag.; 3 , an ascus containing eight spores, also two paraphyses, $\times 400$.

specks on the upper surface; these increase in size and extend through the substance of the leaf, showing on the 
under surface also. At a later stage a small brown pustule appears in the centre of each spot, and most frequently on the upper surface of the leaf, looking much like the brown pustule of teleutospores belonging to some Puccinia; but when examined under the microscope, the pustule is seen to consist of numerous asci, each containing eight colourless, elliptical spores. These ascospores escape when mature, and are scattered by wind, inoculating those leaves on which they happen to alight.

The disease when present usually assumes the character of an epidemic, due to the rapid and abundant diffusion of spores, and consequently considerably reduces the forage by preventing growth owing to the destruction of the leaves.

Preventive Means. - The disease readily survives the winter on stray plants in the field or on wild clovers, and unless precautions are taken is likely to infect the crop the following season. Burning over the field in late autumn or early spring, if there is not sufficient dry material present, straw or other refuse might be spread over the field and burned.

Frequent cutting of the crop prevents the disease from doing serious damage.

Combs, Iou'a State Coll. of Agric., No. 9, figs. (1898).

\section{LARCH CANKER}

(Dasyscypha calycina, Fuckel. = Peziza willkommii, Hartig.)

This beautiful little fungus is very destructive to the larch (L. europea), especially when crowded and growing 
in a low, damp situation. The ascophore is I to 2 lines across, saucer-shaped, without a stem, but attached by a narrow point, externally white and downy, inside or hymenium orange-red. Usually occurring in considerable numbers on the diseased spots.

The fungus is a wound-parasite, its spores entering the tissue through wounds caused by insects, hailstones, and

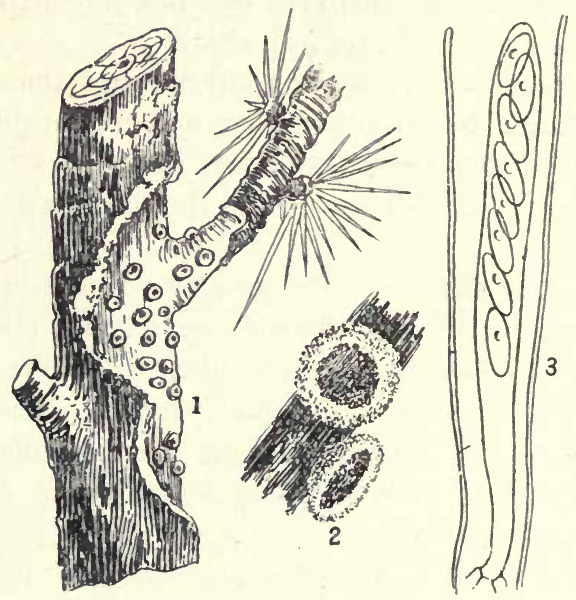

Fig. 30.-Dasyscypha calycina. I, portion of a larch branch diseased; 2, two fungi, slightly mag. ; 3, an ascus containing eight ascospores, also two paraphyses, $\times 300$.

more especially by branches being more or less split from the trunk by snow. The first indication of disease is the yellowing and wilting of the needles. If the base of a branch bearing such leaves is examined, a mass of resin will be found oozing to the surface through irregular fissures in the bark. By degrees the bark is entirely destroyed 
above the area occupied by the mycelium of the fungus; and, if conditions are favourable, the ascophores of the fungus appear on those sunk and diseased areas. During the summer the mycelium does not extend to any great extent owing to the formation of cork between the healthy and diseased portions of bark; but in the autumn the mycelium succeeds in entering the living bast, and consequently the canker-spot continues to enlarge year by year.

In those cases where the growth of the parasite is rapid, compared to the growth of the tree, the canker soon completely girdles the trunk or branches, the part beyond the region of disease dying. On the other hand, where the disease is confined to one side of the trunk or branch, the struggle between host and parasite may continue undecided for a long time. Hartig states that in the Tyrol he has seen larches still alive bearing canker wounds of a hundred years' standing.

In very damp localities larches soon die when attacked, and without any large canker wounds making their appearance. Under such circumstances the mycelium appears to spread quickly through the entire plant, as proved by the development of myriads of ascophores over every part of the tree, and not, as is usually the case in dry districts, confined to the canker-spots.

Preventive Means. - The larch is truly an inhabitant of Alpine regions; and although larch canker exists on trees growing in the higher Alps, nevertheless it never extends its ravages to the same extent as when the tree is planted in damp, stuffy lowland localities, hence such should not be selected.

The disease can be held in check by keeping a sharp 
look-out for the disease, and removing the canker-spots on their first appearance, immediately dressing the wounded portions with a wash of corrosive sublimate in methylated spirit, or with a strong solution of sulphate of iron, and afterwards painting over with tar. The fungicide and tar should be applied immediately the wound is made; to delay for a day or two is courting further disease.

Wilkomm, Mikroskopische Feinde des Waldes, vol.ii. p. I67. Hartig, Unters. aus dem Forstb. Inst., vol. i. p. 63. Hartig and Somerville, Diseases of Trees, p. I 7 , figs.

\section{VINE SCLEROTINIA}

\section{(Sclerotinia fuckeliana, De Bary.)}

This fungous pest of the vine has two very differentlooking forms of fruit. One form appears as a dense, velvety, olive-brown mould, exceedingly common on fading and dead leaves and herbaceous stems of plants, and which under certain conditions becomes a dangerous parasite. This is the conidial form of reproduction, and was at one time considered as an independent fungus, known as Botrytis cinerea. The second or ascigerous condition resembles a shallow wine-glass in miniature, not usually more than one-tenth of an inch across, supported on a long, slender stem, springing from a small black sclerotium, and brown in colour.

The conidial form is most injurious, and, unlike most parasites, attacks numerous plants belonging to widely separated families. It is especially destructive to vines, destroying the leaves, young shoots, and also the inflorescence and fruit. 


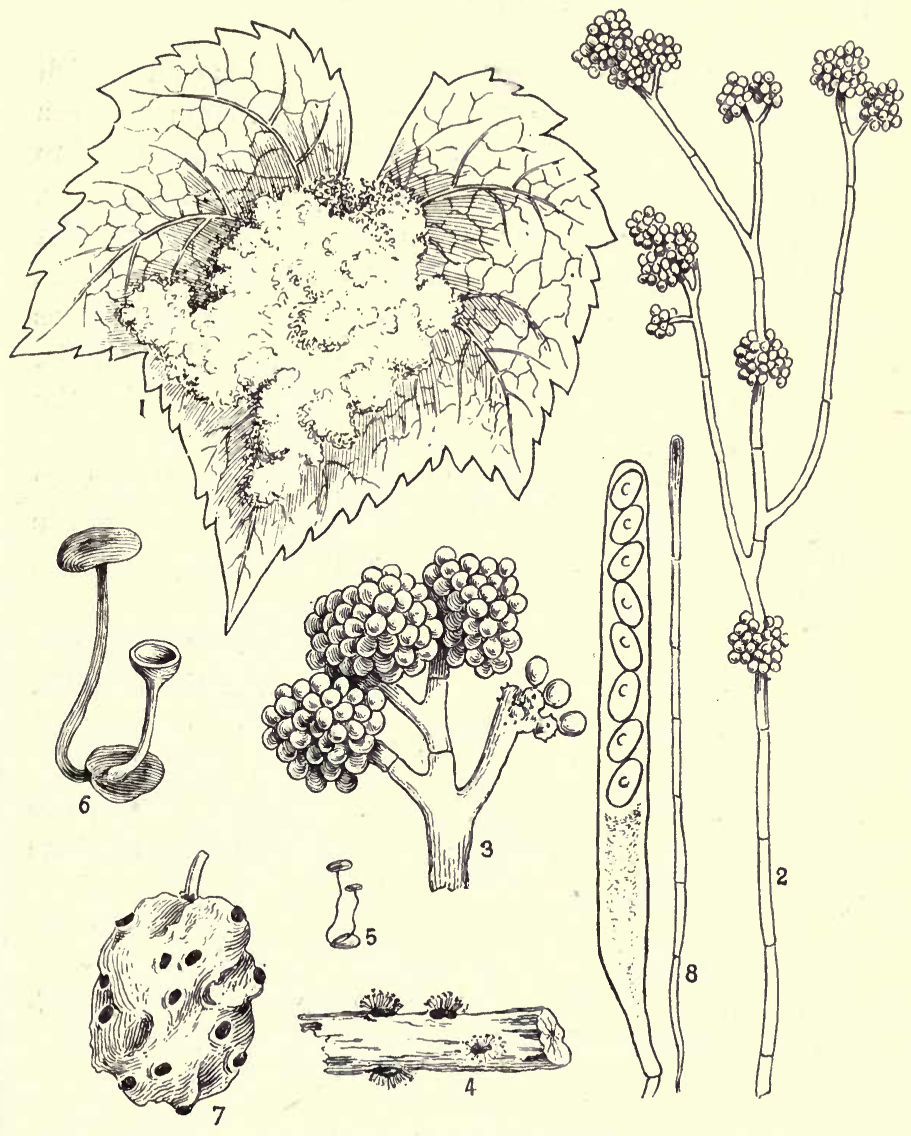

Fig. 3I.-Sclerotinia fuckeliana. I, vine leaf with the Botrytis form of the fungus growing on its surface; 2 , a conidiophore of the Botrytis with clusters of conidia, slightly mag.; 3 , a head of conidia, $\times 300 ; 4$, small black sclerotia bearing the Botrytis form of fruit ; 5, a sclerotium bearing two ascophores, nat. size; 6, the sane, more highly mag. ; 7 , a shrivelled grape with numerous sclerotia imbedded in its skin ; 8 , ascus containing eight spores, also a paraphysis, $\times 300$. 
As already stated, the conidial form appears as a greyish or brownish olive mould, often forming large patches which, when examined under the microscope, are found to consist of stout, erect, smoky-olive stems or conidiophores, more or less branched upwards, the tip of each branchlet bearing a cluster of broadly elliptical, colourless conidia. The mycelium of the conidial form present in the tissues of the host eventually forms numerous small black scerstia

These sclerotia, after a period of rest, produce either the conidial form of fruit, or the higher, ascigerous form.

On the other hand, the spores of the ascigerous stage, on germination form a mycelium, from which either the Botrytis or the ascigerous form may eventually develop, depending on conditions at present unknown.

Preventive Means.-Spraying with dilute Bordeaux mixture, or with potassium sulphide, destroys the conidia, and thus checks the spread of the disease. Leaves and fruit attacked by the fungus should be collected and burned; otherwise, if allowed to remain lying about, the sclerotia present in their tissues will eventually produce spores, which will again infect the young foliage.

De Bary, Morp. and Phys. Fungi (Engl. ed.), p. 224.

Pirotto, Nuovo Giorn. Bot. Ital., vol. xiii. p. I30 (I88 I).

Viala, Les Maladies de la Vigne, p. 352, figs.

\section{SCLEROTIUM DISEASE}

(Sclerotinia sclerotiorum, Massee.

= Sclerotinia libertiana, Fuckel.)

Probably no other parasitic fungus attacks and kills so many plants of different species, and belonging to widely 
separated Orders. Among others may be enumerated potato, chrysanthemum, hemp, haricot beans, petunias, zinnias, cucumbers, swedes, turnips, etc. The stem is the part most frequently attacked, but, according to Potter, stored swedes and turnips are also destroyed, the disease first showing itself just above the ground-line as a delicate white mould encircling the stem. The mycelium also

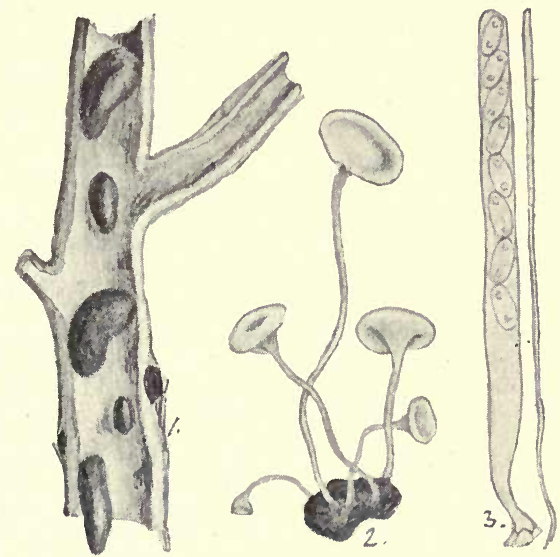

Fig. 32.-Sclerotinia sclerotiorum. I, portion of a chrysanthemum stem containing the black sclerotia of the fungus, nat. size; 2 , a sclerotium bearing five ascospores, nat. size; 3 , an ascus with spores, and a paraphysis, $\times 300$.

penetrates into the interior, and gradually extends upwards. Finally the stem becomes dry and brittle, and falls down. If such diseased and fallen stems are cut open, a considerable number of black sclerotia of very variable size and shape are met with in the pith, surrounded by mycelium.

When the stems decay, the sclerotia are set free and lie 
on the ground until the following spring, when they give origin to usually several more or less funnel-shaped, brown ascophores supported on long, slender, crooked, darkcoloured stems.

The spores are ejected from the asci at maturity, and germinate at once, soon forming a vigorous mycelium amongst dead organic matter, which afterwards becomes parasitic, attacking the stems of annual plants near the ground-line, and acting as already described. It was shown by De Bary that the earliest mycelium formed after germination cannot penetrate living tissues as a parasite, but must first live for some time as a saprophyte.

In addition to attacking the stems of living plants, this fungus often proves very destructive to tubers and roots stored for the winter, as dahlias, artichokes, beetroot, and more especially carrots, surrounding the tubers with a white cottony mycelium which rapidly causes rotting and decay, the mycelium of the fungus becoming studded with black sclerotia, varying from I line to half an inch or more in length. The rapidity of the disease is much intensified if there is any tendency to 'sweating' in the stored roots.

De Bary states that this species does not possess a Botrytis stage; other later observers, however, incline to the idea that this condition is sometimes produced.

Preventive Means.-A difficult fungus to combat. Disease stems containing sclerotia should be collected and burned, as should also diseased tubers and roots.

Where the disease has previously existed, and there is a probability of the presence of sclerotia in the soil, it would be well to sprinkle the surface with soot or quicklime, which would destroy the mycelium during its period of saprophytic existence, previous to attacking the young 
stems. Fresh stable manure on the surface of the soil greatly favours the spread of the disease.

De Bary, Bot. Ztg., p. 458, , 886.

Potter, Journ. Board Agric., vol. iii. No. 2, figs.

\section{COWBERRY SCLEROTINIA}

(Sclerotinia urnula, Rehm.

= Sclerotinia vaccinii, Wor.)

During the early part of summer the leaves and young stems of the cowberry (Vaccinium vitis-idaea) often show dark-brown patches or stains, which soon become covered with a snow-white delicate mildew, which often assumes a yellowish tinge when old. This mildew, the conidial or summer form of fruit of Sclerotinia urnula, when examined under the microscope, is seen to consist of simple or branched chains of conidia, arranged like a string of beads. As the conidia become mature, the narrow neck connecting adjoining conidia undergoes a peculiar change in form and structure, which results in the conidia assuming a lemonshaped form, and becoming free from each other. The mature conidia have a strong smell, resembling almonds, that proves very attractive to insects, who, along with wind, convey the conidia on to the stigmas of the Vaccinium flowers. These conidia germinate, the germ-tubes passing down the style into the ovary, where the hyphae forms a sclerotium in the interior of the fruit. Such diseased fruits fall prematurely, lie on the ground throughout the winter, and in the spring one or more dark brown, wineglassshaped ascophores grow from the sclerotium contained within the mummified Vaccinium fruits. 
The ascospores produced in the spring germinate and penetrate the young shoots and leaves of the cowberry, producing the brown spots previously alluded to, from the

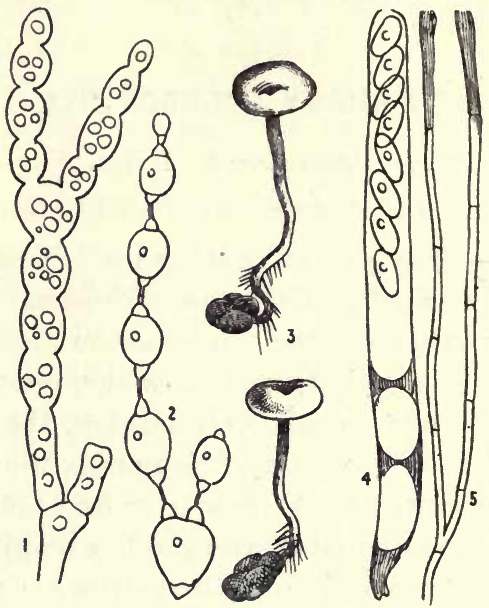

Fig. 33.- Sclerotinia urnula. I, conidial condition in young stage, $\times 250 ; 2$, conidial form of fruit ; at maturity, the narrow portions, or disjunctors, deliquesce, and set the conidia at liberty, $\times 250$; 3 , ascospores springing from mummified fruits filled with sclerotia, $\times 3 ; 4$, ascus containing eight spores, $\times 250 ; 5$, paraphyses, $\times 250$ (after Woronin).

surface of which the summer or conidial form of fruit is produced in less than three weeks.

The following species of Sclerotinia also form sclerotia in the fruit of different species of Vaccinium:-

Sclerotinia oxycocci, Wor., on Vaccinium oxycoccos.

Sclerotinia baccarum, Schröter, on Vaccinium myrtillus. 
Sclerotinia megalospora, Wor., on Vaccinium uliginosum.

Woronin, Mem. Acad. Imp. St. Petersburg, ser. viI., vol. xxxvi., ı 888 , го pl.

\section{CLOVER SCLEROTINIA}

(Sclerotinia trifoliorum, Eriksson.)

During certain seasons this fungus is very destructive to the different kinds of cultivated clover (Trifolium). It also attacks Sainfoin (Onobrychis sativa), Lucerne (Medicago sativa), Fenu-grec (Trigonella foenum-graecum), and Medicago lupulina.

The leaves are first attacked, and if the weather is sufficiently moist a delicate white mycelium appears on the surface, and extends to adjacent plants; finally the leaves shrivel and decay. Numerous minute, blackish sclerotia are formed during winter on the dead leaves and roots remaining in the ground. During the summer these sclerotia produce one or two ascophores of the usual Sclerotinia type, brown in colour, quite smooth, stem long and slender, hymenium or disc concave or saucer-shaped, thus differing from $S$. sclerotiorum. The spores of the ascophore form directly inoculate the leaves. Conidial condition unknown.

Preventive Means.-This disease has only been recorded as present in Britain quite recently, and may fortunately still be considered as rare. Where clover fields are attacked, it is necessary to abstain from cultivating this crop for several years. I have noticed this disease in a plot of Trifolium incarnatum once near Sheire, Surrey. Wherever the disease appears it should be promptly dealt 
with, otherwise the green fodder supply for our towns may suffer to the same extent as the sainfoin crop in some parts of France.

Eriksson, Kongl. Landthbr.-Akad. Handl. o. Tidskr., I 880, No. I.

- Prillieux, Malad. des Plantes Agric, vol. ii. p. 4I3, figs.

\section{ONION SCLEROTINIA}

\section{(Sclerotinia bulborum, Wakker.)}

Onions, hyacinths, and probably also other bulbs, are often destroyed in immense numbers by this fungus. Yellowish blotches appear on the foliage in spring or early summer. These blotches are soon covered with a velvety olive-brown mould. The mycelium passes down the tissues into the bulb, where blackish sclerotia, varying in size from a rape-seed to a small pea, are formed, more especially in the outermost scales of the bulb, in some instances in such quantities that the surface of the bulb is almost completely covered. During the following spring small, brown, cup-shaped ascophores, supported on a slender, wavy stem, spring from the sclerotia.

Preventive Means.-Spraying with potassium sulphide solution or with dilute Bordeaux mixture on the first symptoms of the disease will check its spread by diffusion of the Botrytis spores. Diseased bulbs should be collected and burned. It is advisable not to plant bulbs where the disease has existed for at least three years, as the sclerotia have been shown to be capable of germination when two years old. 
Wakker, Allgem. Vereen. voor Bloembollen-cultur, I883-84.

Massee, Gard. Chron., vol. xvi., I 894, p. I60; fig. of Botrytis and ascophore.

\section{ANEMONE SCLEROTINIA}

(Scierotinia tuberosa, Fckl.)

This fungus is very destructive to the wood anemone (Anemone nemorosa), also cultivated species of Anemones. The blackish sclerotium varies in form and size, half to three-quarters of an inch long, and attacks the rhizomes of the anemone. In the spring numerous long-stemmed, smooth, dark-brown ascophores are produced. The fertile portion is at first pear-shaped and closed, then funnelshaped, and at maturity expanding until almost flat.

Preventive Means.-Collecting the ascophores in the spring checks the spread of the disease.

\section{DROOPING DISEASE OF PAEONIES}

(Sclerotinia paeoniae, Massee.

= Botrytis paeoniae, Oud.)

Unsightly gaps often appear in beds of paeonies, caused by this fungus. Healthy-looking plants some time before the period of blooming suddenly become limp, the stem droops, and within a few days the plant dies. If the stem of a diseased plant is examined, a very delicate white mould will be seen on its somewhat blackened and shrivelled surface, just above the ground; and at a later stage, numerous minute black sclerotia are formed in the tissues, both above and below ground. 
The white mould is a Botrytis, producing myriads of conidia, which, carried by wind, inoculate other plants in the vicinity. The sclerotia remain in the soil until the following season, when they produce conidia which inoculate the stem near the ground.

Preventive Means.-Drooping stems should be removed at once to prevent the continued formation of conidia and sclerotia. Gardeners have observed that the application of green manure as a top-dressing causes paeonies and other plants to become diseased, and this is undoubtedly true. The manure, even if it does not contain spores, affords a congenial matrix for spores and sclerotia present in the ground, in which they reproduce themselves rapidly, and in the spring, when the young stems push through the manure, inoculation is almost certain to take place.

Where the disease has previously existed, the surface soil should be removed, and replaced with soil mixed with lime.

Massee, Gard. Chron., Aug. 13, 1898, fig. 32.

\section{TULIP MOULD}

(Sclerotinia parasitica, Massee.

$$
\text { = Botrytis parasitica, Cavara.) }
$$

Cultivated tulips are often killed by a mould which forms olive-brown, minutely velvety patches on the stem, leaves, and flowers. At a later stage smooth lentil-shaped sclerotia, at first grey, then black, appear, mostly in the outer parts of the bulb, sometimes being so numerous as to form black crusts. 
Preventive Means.-When the mould is observed, the plant should be taken up and burned to prevent the formation of the sclerotia, some of which are often formed in the soil close to the bulb, and thus endanger subsequent crops.

Cavara, App. Pat. Veg., ıо, tab. vi. figs. I-4.

\section{SNOWDROP MILDEW}

(Sclerotinia galanthina, Ludwig.

= Botrytis galanthina, Berk.)

The bulb is first attacked, and as the leaves and flowers appear above ground they are also seized upon by the fungus, the result being the plant does not bloom, neither do the leaves develop properly. A careful examination at this stage reveals the presence of a delicate whitish mould covering the leaves and flower spathes, and at a later stage numerous minute black sclerotia are formed in the tissues of the decaying leaves and in the outer bulbscales. The mould is of the usual Botrytis structure, but the conidia differ in form and size from those of any other known species, and the fact of producing sclerotia proves it to belong to the genus Sclerotinia, although the higher Peziza form of fruit is not yet known.

Preventive Means.-Experience has shown that diseased plants do not bloom, consequently all such should be removed on the first indication of the disease; by so doing, the formation of conidia and consequent spread of the disease is checked.

The sclerotia resemble small black grains sunk in the scales of the bulb; all diseased bulbs should be destroyed. 
Smith, Gard. Chron., March 2nd, I889, p. 2; 1889, p. 275 , figs.

Ludwig, Lehrbuch der niederen Kryptogamen, p. 335.

Oudemans, Verslag Gew. Verd. der Wis-en Nat. Afdeel., I 897 .

\section{DOUGLASS FIR BLIGHT}

(Sclerotinia douglassii, Massee.

= Botrytis douglassii, Tubeuf.)

Seedlings and young trees of the Douglass fir (Pscudotsuga douglassii, Carr.) and Wellingtonia (Sequoia gigantea, Lindl. and Gord.) sometimes have the lead and uppermost shoots destroyed by the Botrytis form of Sclerotinia douglassii. The same fungus appears to attack Juniperus communis. A brownish-grey mould appears on the branches, which soon become curved and finally die, the needles in the meantime falling off. The Botrytis continues to form conidia on the fallen leaves, and minute black sclerotia are formed on the dead branches. Several young plants of Sequoia gigantea were killed at Kew by this fungus.

Preventive Means.- - If detected at an early stage, spraying at intervals with Bordeaux mixture or potassium sulphide solution would destroy the conidia, and check the spread of the disease. Badly infected trees should be removed and burned.

Tubeuf, Beitr. z. Kenntniss d. Baumkr., 1888. 


\section{'A LILY DISEASE'}

(Sclerotinia, sp. )

Professor Marshall Ward has described the Botrytis form of a Sclerotinia which forms orange-brown and buff specks on the stem, pedicels, leaves, and buds of the white lily (Lilium candidum). The ascigerous condition is not yet known, and this is mentioned more especially for the purpose of directing attention to the very elaborate account of the fungus under consideration, which deals in a masterly manner with the mode of life of the parasite, and indicates the method by which the mycelium is enabled to pass through the living tissues of a host-plant.

Marshall Ward, Annals of Botany, vol. ii. p. 319, pl. xx.-xxiv. (r889).

Several other species of Sclerotinia attack cultivated and wild plants. In those cases where injury is experienced, the only means of prevention is to destroy diseased plants, and desist from cultivating susceptible plants in soil containing sclerotia.

Peziza vesiculosa, Bull.- Tubeuf gives an account of this fungus, which is so common as a saprophyte on old manureheaps and on richly manured ground. It attacks species of Balsamina, Hyacinthus, Sidalcea, etc.; in gardens. Plants supposed to have been killed by the fungus were placed under a bell jar, and were soon covered with the conidial form of Peziza vesiculosa, as described by De Bary. 
The fungus is one of the largest of the Pezizeae, growing in clusters; cups bladderlike, with a very small aperture at first, but expanding when old; substance fleshy, watery, brittle, pale brown, one to two inches across.

Ludwig, Zeitschr. für Pfanzenkr., 1895, p. I 2.

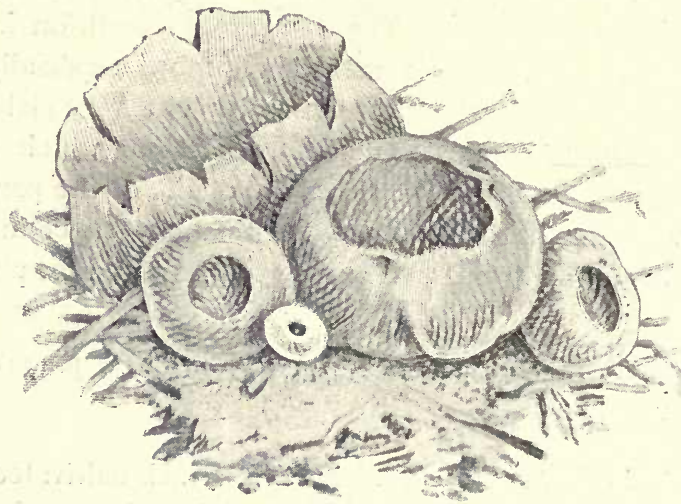

Fig. 34.-Peziza vesiculosa. A group of plants, nat. size.

Bulgaria polymorpha, Wetts.-This species has been recorded as growing on living oak trunks, and I have also seen it on living beech.

The fungus is usually densely gregarious, bursting through the bark as a soft, warty, rust-coloured knob, which gradually expands until it is half to one inch across, with a flat, black, highly polished disc or hymenium. Entire substance springy and soft.

Rhizina inflata, Quélet = Rhizina undulata, Fries.This peculiar fungus, which is not uncommon as a sapro- 
phyte, growing on stumps, on the ground, and more especially peat, has been shown by Hartig to be capable of living as a true parasite, proving very destructive to various conifers-Abies pectinata, Tsuga mertensiana, Picca sitkaensis, Pinus strobus, and Larix europaea, also Castanea vesca.

The ascophore forms a thickish crust one to two inches across, almost flat or irregularly undulate or warted, of a dark brown colour, sticky or viscid in rainy. weather; the margin is paler and often irregularly lobed or wavy. There is no stem, but the crust or sporophore is attached to the ground by numerous pale rhizoids or strands of mycelium, which spread in the soil.

If a section through the sporophore is examined under the microscope, numerous long, cylindrical asci are seen, each containing eight large, pale brown, spindle-shaped spores.

The root of the tree is the part attacked; and if the root of a tree killed by the fungus is carefully removed, a dense mass of white mycelium is found surrounding and enclosing the entire root system. No outflow of resin is present.

Preventive Means. - The only thing that can be suggested is the collection and destruction of the sporophores of the fungus.

Hartig and Somerville, Diseases of Trees (Engl. ed.), p. I 23, figs.

\section{TREE MOREL}

(Cyttaria gunnii, Berk.)

Growing in dense clusters on living branches of the Tasmanian myrtle-tree (Fagus cunninghamii), in the dense 
shady forests to the west of Tasmania, in early summer. Was freely eaten by the aborigines in their wild state. The

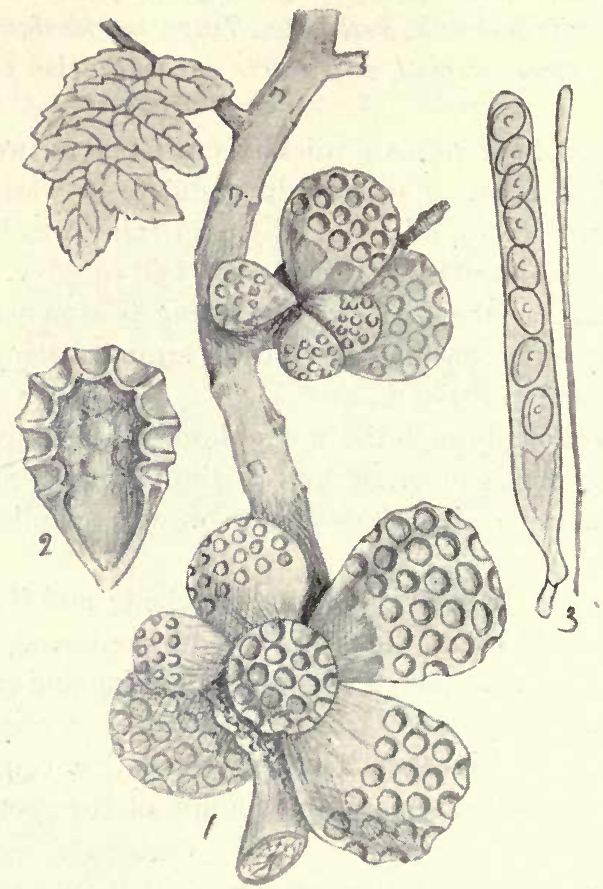

Fig. 35.-Cytuaria gunnii. I, groups of fungi on living branch of Fagus cunninghamii, somewhat reduced; 2 , section of fungus; 3 , ascus containing eight spores, $\times 300$.

fungus grows on rough, swollen knots on the branches, which sometimes reach a large size, and are due to the presence of mycelium. The sporocarp is pear-shaped, 
hollow, the thick end furnished with pits lined by the hymenium; colour whitish; about one inch long.

Cyttaria berteri, Berk.-Top-shaped, orange, up to one inch across. Edible, growing on living branches of Fagus obliqua, in Tierra del Fuego, Patagonia, and Chili.

Cyttaria darwinii, Berk.-Subglobose, solid, whitish. Edible. On living branches of Fagus antarctica and $F$. betuloides. Tierra del Fuego, Patagonia, Chili. First collected by Darwin.

Cyttaria hookeri, Berk.-Obovate or clavate, umbonate, yellowish cinnamon, half to three-quarters of an inch long. Edible. On living branches of Fagus obliqua and $F$. antartica. Tierra del Fuego, Patagonia, and Hermite Island, Cape Horn.

Fischer, Bot. Ztg., г888, p. 816, t. xii.

\section{HEMI-BASIDIOMYCETES}

'Jew's Ears' Fungus

(Hirneola auricula-judae, Berk.)

Enumerated by Prillieux and Delacroix (Bull. du Ministère de l'Agric., xii., No. 5, Sept. 1893) as a wound-parasite, attacking the mulberry-tree.

The fungus is very thin, and flexible like indiarubber, more or less shaped like a human ear, flesh-coloured or lurid, the sterile side minutely velvety. Common in Britain on living branches of elder (Sambucus nigra), which it kills. 


\section{MULBERRY ROOT DISEASE}

\section{(Helicobasidium mompa, Tanaka.)}

Nobujirō Tanaka has described a disease of the mulberry tree, which is extensively cultivated in Japan for rearing silkworms. The fungus first attacks the root of the living tree, and after about two months, above-ground symptoms are evident, the growth of shoots is arrested; and the leaves become gradually smaller, and at length die; the shoots also die as the disease advances. The lowest roots are killed first, and the tree pushes out others higher up, which in turn are destroyed, the tree sometimes keeping itself alive for three years by the successive formation of new roots. The diseased roots are covered with an irregular network of purplish-brown strands of mycelium ०.5-1 mn. thick; some of these radiate into the soil. As the disease proceeds, the fungus creeps above ground, forming at first a thin effused mass of mycelium of a dark purple-brown colour, which more or less covers the base of the stem and branches; the surface of this felty mass is smooth and velvety, and the definite margin paler in colour. Extraneous matter, as dead leaves, branches, soil, etc., are often enclosed in the rapidly spreading felt. As growth proceeds, a portion usually develops at right angles to the branch, and also extends laterally on one or both sides. The hymenium is produced on every portion of the free surface of the felt, and is whitish, with a tinge of violet. The basidia are curved, I-3 septate, fourspored.

Numerous sclerotia are formed in the decaying tissues of dead roots. No remedial measures are given, but the 
fungus probably belongs to the category known as rootparasites, travelling in the soil by means of mycelial strands or rhizomorphs.

Tanaka, Journ. Coll. Sci. Imp. Univ. Japan, vol. iv. pt. I, p. I93, pl. xxiv.-xxvii. (I 891).

\section{BASIDIOMYCETES}

\section{THELEPHORACEAE}

\section{RHODODENDRON GaLlS}

\section{(Exobasidium rhododendri, Cram.)}

The presence of this fungus is indicated by the occurrence of gall-like swellings on the leaves of Rhododendron hirsutum and $R$. ferrugineum. The galls vary in size from that of a pea to a marble, are at first of a pale yellowishgreen colour, becoming red on the side exposed to sunlight. During the summer the entire surface of the galls becomes covered with a very delicate bloom, due to the presence of basidia, or spore-bearing organs. The mycelium of the fungus remains in the tissues of the gall.

Preventive Means. - Collect and burn diseased leaves before the fruit of the fungus is produced. I have observed that when infested leaves have been removed sufficiently early, the disease does not appear the following year on the same plant; hence probably there is no permanent mycelium in the tissues, and the only means of infection is by spores.

Several other species of Exobasidium form galls on plants belonging to the following genera:-Rhododendron, 
Vaccinium, Andromeda, Ledum, Arctostaphylos, Cassandra, Saxifraga, Symplocus, Bromus, Arrhenatherum. The treatment is in all instances the same as that given under $E$. rhododendri.

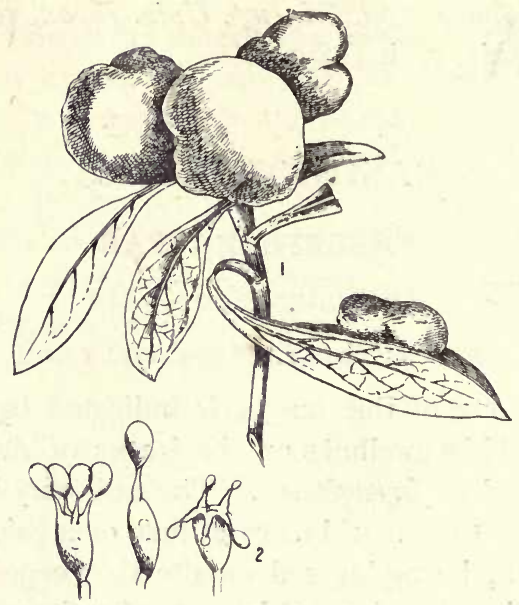

Fig. 36.-Exobasidium rhododendri. I, galls formed by the fungus on leaves of Rhododendron ferrugineum, about nat. size; 2, basidia bearing a variable number of spores, $\times 350$.

Exobasidium lauri, Geyl., forms club- or horn-shaped outgrowths up to one foot long, growing from the leaves of Laurus nobilis and L. canariensis in Italy and the Canaries.

\section{'BLISTER BLIGHT' OF TEA PLANT}

(Exobasidium vexans, Massee.)

Dr. Watt, who investigated the pests and blights of the tea plant in Assam under instructions from the Govern- 
ment of India, says of the present parasite: 'One of the very worst blights on tea is known to the planters as Blister blight. I have seen hundreds of acres completely ruined by it.'

The fungus attacks the leaves, first appearing as a minute pink spot, which continues to increase in size; the upper surface of the leaf at this point becomes depressed, forming a circular pit, a corresponding bulging out appearing on the under surface of the leaf at the same point. Several of these warts or blisters frequently form on a leaf. The convex surface of the blister eventually presents a minutely velvety or woolly appearance, due to the formation of the fruit of the fungus on the surface of the blister. The first fruit consists of small, one-septate conidia, which often commence germination in situ. These are followed by basidia, usually bearing two spores each. Sometimes fruit is also produced on the concave side of the blister.

When the disease has gained a foothold on the leaves, it also frequently attacks young shoots.

Preventive Means.-Dr. Watt states that the disease ' invariably appears on tea that has not been pruned in the autumn. About April it extends to the pruned tea, which has by then come into leaf.' As to whether it would not be wise under the circumstances to prune all plants, lack of practical knowledge prevents me saying; however, the statement suggests that the mycelium is perennial in the branches, and produces the first crop of spores the following season, which are carried by wind to the pruned trees. In addition to collecting and burning diseased leaves, it is absolutely necessary to cut off all diseased branches. 
Ascertain that the fungus is not also present on wild plants in the neighbourhood of the tea plantations.

Watt, The Pests and Blights of the Tea Plant, p. 4rg.

Massee, Kew Bulletin, 1898, p. I09, figs.

\section{GRAPE FLECK}

(Exobasidium vitis, Prill. and Del.

Aureobasidium vitis, Viala and Boy.)

Attention was first called to this disease by Dr. Viala, who observed it on vines, especially Frankenthal and Chasselas, in France.

On the fruit a little dingy speck first appears. This gradually increases in size, and becomes livid, afterwards depressed, with the skin wrinkled and dry. The diseased portion eventually becomes sprinkled with minute pale golden or yellow velvety tufts consisting of the fruiting portion of the fungus, which originate from the copious mycelium present in the tissue of the grape. This mycelium is very slender, branched, white towards the middle of the fruit, but becoming clear yellow just under the skin. This fungus illustrates one of the most reduced or primitive types of the Basidiomycetes at present known. The velvety tufts on the surface of the fruit consist of basidia bearing a variable number of spores-2 to 9 -at or near the apex.

Prillieux has observed this parasite also on the leaves of the vine, where it forms little white patches.

Var. album, Montem.-Dr. Montemartini has created 
this variety for a whitish form of the fungus found on the leaves and fruit-stalks of vines growing at Trieste, Austria.

Var. tuberculatum, M'Alpine. - This variety appears mainly to depend on the presence of a more or less evident stroma, which, however, may sometimes be absent. The differences observable in spore or other measurements are of no value, specific or varietal, when the same are admittedly so variable as in the present species. The fungus appears to be widely diffused in Victoria. This fungus was considered as the type of a new genusAureobasidium-by Viala, who was only acquainted with the autumn form produced on the fruit of the vine. Prillieux has shown that it also occurs on the leaves of the vine under the white form in spring, and correctly states that it conforms in all important points with the genus Exobasidium. Further, the amount of variation presented by the typical form overlaps those peculiarities considered as characterising the two varieties enumerated above.

Neither of the authors quoted has suggested remedial measures.

Viala and Boyer, Une Maladie des Raisins produite par l'Aureobasidium vitis, I pl.

Prillieux, Malad. des Plantes Agricoles, vol. i. p. 298, fig.

M'Alpine, Additions to the Fungi on the Vine in Australia, p. 16 , figs.

Hypochnus cucumeris, Frank.--This spreads as a delicate grey film over the stems of cucumbers close to the ground, 
causing rot and death of the plant affected. It also occurs on Lupines and Clover.

Hypochnus solani, Prill. and Del.-Forming greyish-white patches on the lower parts of living potato stems, but doing no appreciable damage.

Corticium comedens, Fries.-This species is stated by Rostrup to be a wound-parasite on the younger branches of the oak. The fungus originates below the bark, which eventually becomes torn and recurved, exposing the hymenium, which is at first purplish, becoming almost white; slightly viscid when moist. Not uncommon as a saprophyte on fallen branches, especially hazel.

\section{PARTRIDGE WOOD}

(Stereum frustulosum, Fries.) .

This fungus is sometimes a saprophyte, at others a parasite, attacking various forest trees, but especially oak. It differs from Stereum hirsutum in having no portion free from the wood on which it is growing, its entire substance forming a thickish, much cracked, very hard crust, firmly attached to the wood. The fungus is perennial, forming a new hymenium or spore-bearing surface each year, on the surface of the hymenium of the previous year. Hence the fungus continues to increase in thickness, and on section presents a distinctly stratified appearance, a character by which it is readily distinguished from various other fungi presenting a similar superficial appearance. The surface of the fungus is cinnamon colour when in active growth, becoming greyish and minutely primrose 
when old. The flesh is brown. Each portion of the cracked patch is an independent fungus, and these troops of crowded individuals often form large patches. The

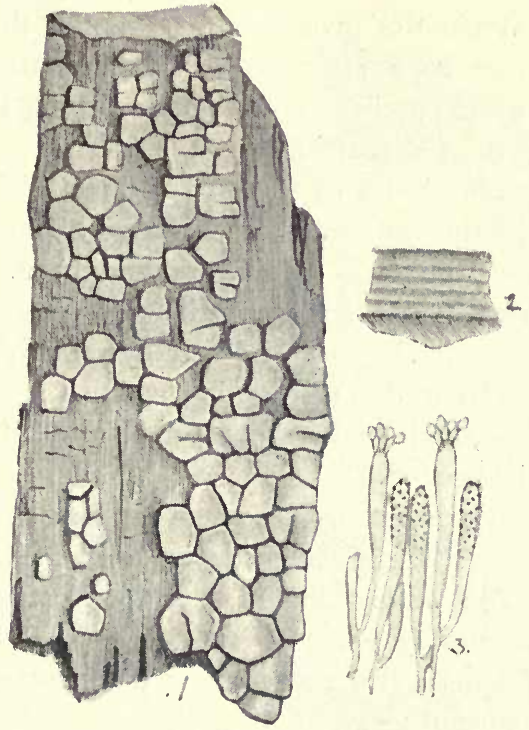

Fig. 37.-Stereum frustulosum. I, a dense group of individuals growing on a piece of oak wood, rather smaller than nat. size; 2 , section through portion of a fungus, showing five zones or layers; 3 , section through the hymenium, showing two basidia, each bearing four spores, also three paraphyses rough on the surface with minute particle 3 of oxalate of lime, $\times 300$.

basidia are club-shaped and bear four spores at the tip. The basidia are accompanied by numerous club-shaped sterile bodies or paraphyses, rough with small particles of oxalate of lime. 
Dr. Hartig, who has studied the action of this fungus on oak wood, states that the peculiar effect produced on the wood by the parasite is quite characteristic and distinct in appearance from that produced by any other fungous parasite. When the mycelium first attacks the wood, the latter changes to a clear brown colour, variegated with numerous white patches, somewhat resembling the plumage of the breast of a partridge. At a later stage the white patches become holes in the wood, lined with the white mycelium of the fungus. The remaining portions of the wood become darker in colour, and very hard.

At this stage the diseased portions of wood present the appearance of having been riddled by some boring insect. Eventually the walls of adjoining cavities are pierced by the mycelium, and finally the wood is more or less completely disintegrated.

Preventive Means.-Diseased patches should be removed, the surface being cut away until healthy wood is reached. The wound should then be protected against further infection by a coat of tar.

As the fungus is also a saprophyte, dead and fallen timber should be cleared away.

Hartig, Zersetz. des Holzes, p. 1०3, pl. xiii.

Prillieux, Malad. des Plantes Agric., vol. i. p. 307, figs. I 2 II 27.

\section{STEREUM WOOD-ROT}

(Stereum hirsutum, Fries.)

A fungus of very variable form, consistency tough and leathery, thin, sometimes forming irregularly shaped patches, lying flat on the bark or wood on which it grows; most 
frequently, however, the uppermost portion of the thin flap is free from the wood, and spreads at right angles to the fixed portion. The upper surface of the free portion is coarsely velvety, at first dingy yellow, and marked with

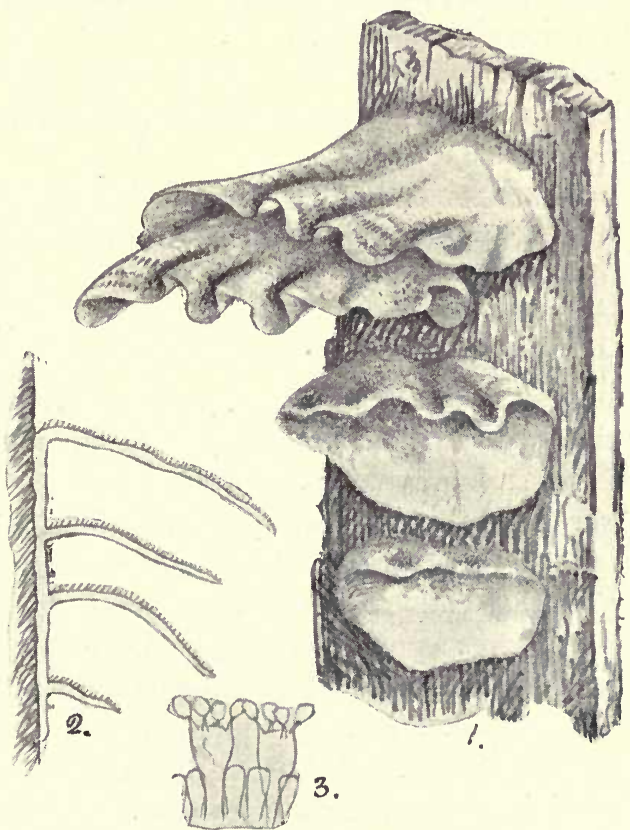

Fig. 38.-Stereum hirsutum. $\mathrm{x}$, fungus about half nat. size; 2 , section through same; 3 , basidia, bearing four spores each, $\times 35$.

concentric zones, becoming grey or whitish when old. The margin is often wavy or crisped. The under surface, which is the hymenium, is smooth, and of a clear ochraceous buff 
colour. As a rule the plants are imbricated or growing in tiers, often almost covering branches, stumps, etc.

The fungus is exceedingly common as a saprophyte, growing on dead wood; but Hartig has proved that not unfrequently it acts as a true and very destructive parasite, attacking various broad-leaved trees.

Being a wound-parasite, the spores germinate first on a wounded surface, the mycelium gradually attacking the sound wood, which it destroys.

The mycelium is perennial, and, having once gained access to a living tissue, continues to extend until the whole is destroyed.

The wood attacked becomes pale brown first, afterwards yellowish white.

The thickening of the cell-walls is first dissolved and used by the fungus, the intercellular plates alone remaining, and even these are eventually dissolved.

Professor Marshall Ward has quite recently studied this parasite, and added considerably to the previous account given by Hartig; and has furthermore succeeded in producing sporophores as pure cultures, commencing with the spore, and passing through all its phases, the first time this has been accomplished for a Basidiomycete.

Preventive Means. - Wherever the fungus is found growing on living trees it should be cut away, the wound washed with paraffin, or corrosive sublimate in water, and afterwards painted with tar. As already stated, when the mycelium has once entered the living wood it is very difficult to eradicate. I have more than once seen the fruit of the fungus emerge from such wood, and grow on a wound that had been treated with paraffin and afterwards tarred.

Decayed wood should not be allowed to accumulate, as 
it is almost certain to become covered with Stereum, the spores of which might alight on the wounded surface of a living tree.

Hartig, Die Zersetz. des Holzes, p. I 29, tab. xviii.

Prillieux, Malad. des Plantes Agric., vol. i. p. 3 I 4.

Marshall Ward, Trans. Roy. Soc., vol. clxxxix. p. I 23 , pl. I 7-2 I (I898).

\section{HYDNACEAE}

Apple-Tree Hydnum

(Hydnum schiedermayeri, Heufler.)

According to Thümen this fungus is very frequently destructive to apple-trees, developing under the bark, which is killed, often extending for several feet as a fleshy, irregular mass, and bursting through cracks here and there to form its sporocarps on the surface of the bark.

The fungus is often very large, fleshy, irregularly nodulose, the nodules or pilei producing long spines on their under surface; flesh yellow, externally yellow or pileus tinged flesh-colour. Smell spicy.

Preventive Means.-Badly diseased trees should be felled and used for firewood. The sporocarps of the fungus should not be allowed to develop.

Thümen, Zeitsch. f. Pflanzenkr., vol. i. p. I32.

Hydnum diversidens, Fries.-Very shortly stalked, pileus variable in form, whitish, upper surface densely covered with erect, variable, incised teeth; spines more or- less 
clavate on the margin, while on the under surface the spines are awl-shaped, and bear the hymenium. A wound-parasite on oak, beech, elm, and birch.

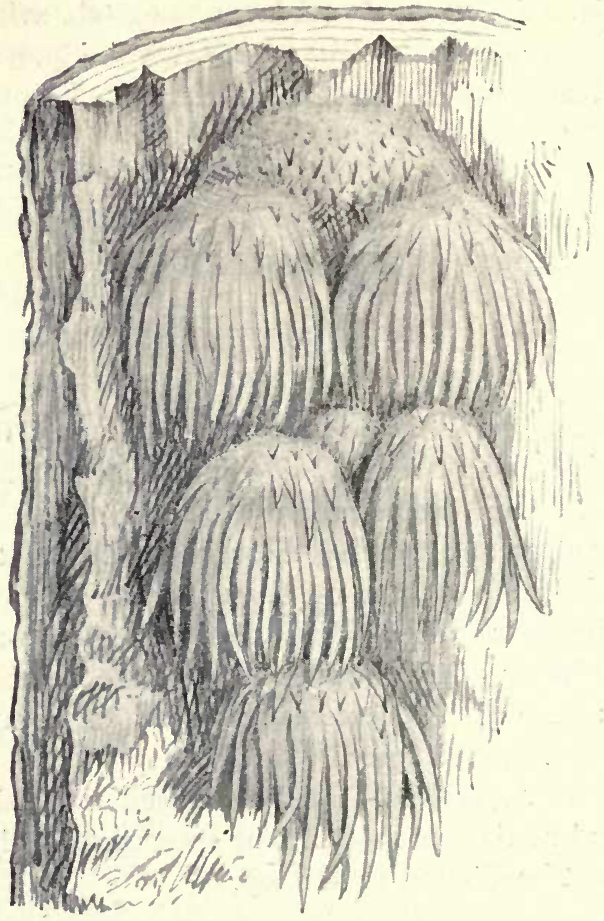

Fig. 39.-Hydnum sihiedermaycri. Entire fungus; about one-quarter nat. size.

During decay the colour of the wood is grey, with a tinge of yellow, alternating with pale brown stripes. The ferment secreted by the mycelium causes the inner layers 
of the cell-walls to swell into a gelatinous mass without being changed into cellulose before they are completely dissolved.

Hartig, Die Zersetzungserscheinungen des Holzes, p. 97, pl. xii.

\section{POLYPORACEAE}

\section{(Trametes pini, Fries.)}

Very hard, forming an irregular, thick, projecting mass, often almost triangular in section; pileus dark brown, concentrically grooved, rough, margin strigose ; flesh rusty; tubes long, stratified, rusty; smell pleasant; two to four inches across. Hartig, who has given a very elaborate account of the effect produced by this parasite on the wood, states that the sporophores sometimes live for fifty years. The fungus is a wound-parasite, attacking various coniferous trees, and as a rule does not develop on trees under fifty years of age, as up to that period wounds are quickly protected by turpentine, whereas later in life turpentine in the heart-wood is scanty, and thus the wounds caused by broken branches are not so quickly protected against floating spores.

Sporophores are only produced after a luxurious formation of mycelium is present in the living tissues. Diseased wood assumes a reddish-brown colour, afterwards white blotches, and finally holes appear here and there.

The fungus is very abundant in the pine woods of North Germany, less so in the spruce woods of South Germany, It is everywhere rare in Britain. 
Preventive Means.-When a tree once produces sporophores of the fungus, cure is hopeless, and it is not even worth while taking the trouble to remove the sporophores, as another crop would soon be produced by the vigorous mycelium present in the tissues. The best thing to do is to fell diseased trees, and thus save the bulk of the timber, for if allowed to stand, the great bulk of the wood is rendered useless; besides which, the sporophores liberate spores that in turn inoculate other trees.

Hartig, Wichtige Krankh. der Waldbäume, p. 43 ; Zersetzungs. des Holzes, p. $3^{2}$, pl. v. and viii.

Hartig and Somerville, Diseases of Trees (Engl. ed.), p. I9I, figs.

Tubeuf and Smith, Diseases of Plants (Engl. ed.), p. 453, figs.

Trametes suaveoleus, Fr., occurs as a parasite on willows. Bracket-shaped, pileus whitish, downy; flesh white, rather soft and corky; pores white, then brownish. Smell, especially when vigorously growing, fragrant, resembling aniseed.

\section{PORIA WOOD-ROT}

\section{(Poria vaporaria, Fries.)}

One of the commonest and most widely distributed of British fungi, and as a saprophyte occurring on almost every fallen branch to be found lying on the ground. Every part of the fungus is inseparably attached to the matrix, forming a thin crust, white at first, becoming dingy with age. The entire surface except the extreme margin 
is covered with irregularly shaped, minute pores, which are often slightly curved or inclined to become elongated. The walls or dissepiments separating the pores are very minutely toothed when seen under a pocket lens.

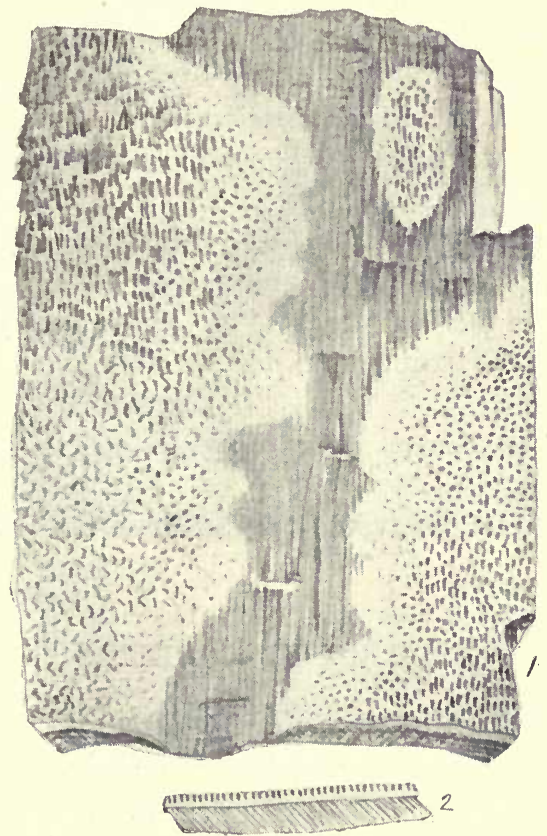

Fig. 40.-Poria vaporaria. I, portion of a fungus, nat. size; 2 , section of same.

Hartig states that this fungus is very common on spruces and pines as a parasite, attacking roots or parts above ground as a wound-parasite. The mycelium often forms white, branched, floccose strands, somewhat like those of 
the 'dry rot' fungus (Merulius lacrymans) in chinks, or between the dead wood and bark.

This fungus also proves very destructive to worked timber, forming snow-white expansions and long strands of mycelium on the surface of beams, etc.

Hartig suspects that the white strands of mycelium may travel underground from a diseased centre, and attack adjoining trees, but is not certain on this point.

Preventive Means.-When worked timber is attacked, the only hope of success turns on being able to dry the timber as quickly as possible by admitting air, otherwise the fungus spreads rapidly, and quickly destroys the wood after the manner of 'dry rot,' for which it is sometimes mistaken in the barren condition.

Hartig, Die Zersetzungserscheinungen des Holzes, p. 45, tab. viii.

Hartig and Somerville, Diseases of Trees, pp. I98 and 2 I 3.

\section{ROOT-ROT OF CONIFERS}

(Fomes annosus, Fries.

$=$ Trametes radiciperda, Hartig.)

Probably the most destructive of fungi attacking coniferous trees, occurring on species belonging to Pinus, Picea, and Abies; has also been noted as attacking Juniperus communis. Hartig has also seen it on the roots of old stumps of Betula and Fagus, but doubts its occurrence as a parasite on Dicotyledons.

The fungus is a true parasite, germinating spores gaining an entrance to the living tissues of the root, and forming a 
very thin, white felt of mycelium between the bark and the wood, hyphae from which attack the wood. The contents of the living cells change to a brown colour, and finally.

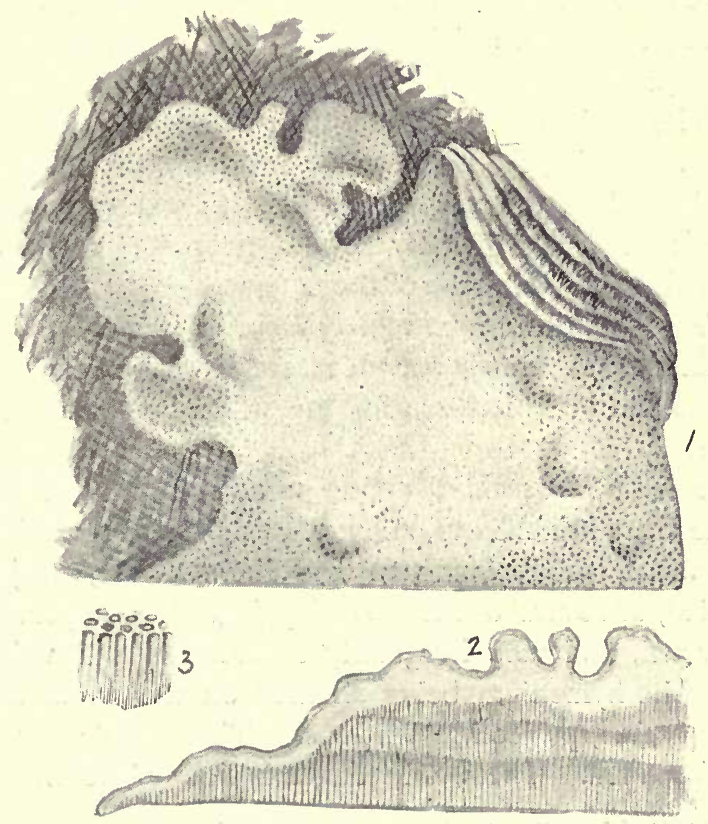

Fig. 4I.-Fomes annosus. I, portion of fungus, half nat. size; 2, section of same, showing the stratified tubes in three layers, nat. size; 3 , portion of hymenium showing the tubes and their openings or pores, slightly mag.

almost disappear ; the wood next assumes a pale, yellowishbrown colour with scattered white patches, each having a black spot in the centre. Finally the cell-walls are 
converted into cellulose and used by the fungus as food. Hartig states that in the Scots fir the disease does not pass from the root up into the trunk; this is considered to be due to the abundance of resin, more especially in the lower part of the stem, which prevents the upward extension of the mycelium, whereas in the spruce and Weymouth pine, which contain but little resin, the rot extends high up the trunk. During the progress of the disease flat sporophores are formed on the underground roots; whereas, after the tree is dead, more highly developed sporophores develop on and around the base of the stump.

The sporophore is extremely variable in size and form ; sometimes, as already stated, resembling a thin white cake, half to one inch across, with the white hymenium uppermost.

In the above-ground condition the fungus resembles a white crust attached to, and following the irregularities of, the wood, producing here and there a free, projecting portion, or several of these overlapping. The upper surface is brown, and very irregularly tuberculose and wrinkled, the white hymenium being situated on the under surface of such free, projecting portions. The pores are minute and rounded. The whole fungus is woody and hard, and sometimes reaches to six inches across.

Preventive Means. - Diseased trees should be removed at once, and the site isolated by a narrow trench, taking care to include within the trench all roots of the diseased tree, as Hartig has demonstrated that where the root of a healthy tree is in contact with a diseased root, the fungus can pass from one to the other.

The sporophores should be collected and burned whenever they appear, as their frequent occurrence on roots 
present in the burrows of mice or other animals suggested the idea to Hartig that the spores might be carried by the fur of animals-mice, etc.-from one locality to another, and thus spread the disease. Brefeld has shown that a conidial form of reproduction is also possessed by this fungus, which may be a further means of diffusing the fungus.

Hartig, Zersetzungserscheinungen des Holzes, p. I4, pl. i.-iv. Marshall Ward, Timber and some of its Diseases, p. 142.

Brefeld, Unters. aus dem Gessamtgeb. der Mykol., vol. viii. (called Heterobasidion annosum).

\section{GOOSEBERRY POLYPORUS}

(Fomes ribis, Fries.)

A parasite not uncommon on the stems of old gooseberry and currant bushes, growing in an imbricated manner; that is, several specimens growing above each other on the stem of the host.

The pileus is woody, thin, and horizontal, upper surface yellowish-brown, minutely velvety when young, becoming almost bald with age, usually with concentric zones. Pores very short, hymenium brownish-grey; flesh thin, rather soft, rusty brown.

Preventive Means.-The fungus is perennial, and only, as a rule, grows on old plants, which from every point of view should be replaced by young trees.

\section{TINDER FUNGUS}

(Fomes fomentarius, Fries.)

This fungus is a very destructive wouncl-parasite, attacking the beech (Fagus sylvatica) more especially, although 
it also occurs on the elm (Ulmus campestris), and on various fruit trees, etc. The sporophore resembles a horse's hoof or an inverted bracket, and varies from three to seven inches across, or sometimes even more. The upper, convex,

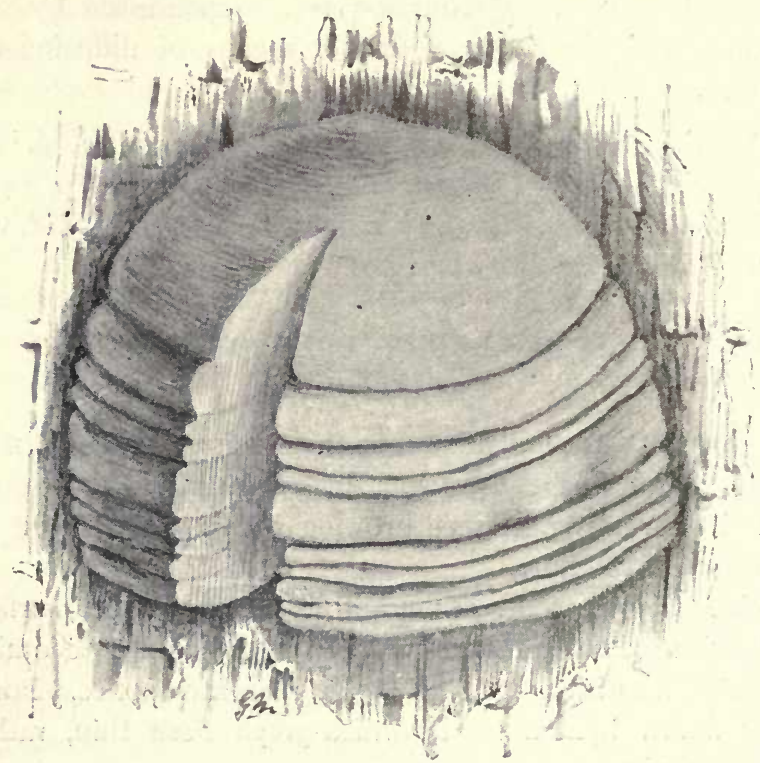

Fig. +2.-Fomes fomentarius. Entire fungus with a portion cut out to show the stratified pores, about onequarter nat. size.

sterile surface is dingy brown, and marked with concentric ridges; when in full vigour the entire upper surface is covered with a brown powder resembling snuff, a character by which this fungus can be distinguished from allied species. The edge is white at first, but finally becomes dark-coloured like the rest. The hymenium, situated on 
the under surface, is almost flat, powdered with white meal when young, afterwards rusty brown, and covered with very minute holes, the openings of tubes which bear the spores on their walls. The spores are oval and brown. A slice or section through the entire fungus is more or less triangular, the upper portion or flesh is rust-colour and rather soft; the tubes are arranged in layers, or stratose, and coloured like the flesh.

This fungus resembles in general appearance the 'False Tinder Fungus' (Fomes igniarius), from which it is distinguished by the softer flesh, and more especially by the brown spores. In the last-named fungus the spores are colourless.

After gaining access to the living tissues of the tree through some wound, the heart-wood is first attacked, which assumes a white colour and becomes broken up into square pieces by the action of the mycelium, which forms thin, tough white sheets, spreading from the wood towards the bark.

According to Tubeuf, the more or less evident groove or channel, so often present on the trunk above and below a sporophore of the fungus, is caused by the mycelium having killed the cambium, and thus prevented the growth of wood at these parts.

At one time the flesh of this fungus was used for tinder, and at the present day, after being beaten and converted into pliant, felt-like sheets, is made into a variety of articles, fancy and useful, as bedroom slippers, chest-preservers, purses, smoking-caps, bags, etc. A series of articles manufactured from this material are exhibited in No. 2 Museum, Kew Gardens.

Preventive Means. - When the fungus appears on a 
living tree it should be cut out, and the wound dressed with tar. As a rule the fungus attacks the lower part of the trunk, gaining an entrance very frequently at those irregularities of the surface which are kept constantly wet by rain or dew trickling down the trunk. All dead trees and fallen timber should be removed, as these serve as a nursery for the present and numerous other species of fungi, which live as saprophytes until an opportunity for attacking living trees presents itself.

\section{FALSE TINDER FUNGUS}

(Fomes igniarius, Fries.)

A wound-parasite, destructive more especially to oaktrees, but attacking also apple, willow, alder, and various other trees, exclusive of conifers. The fungus is perennial, first appearing as a roundish knob, which eventually develops into a hoof or bracket-shaped structure, four to eight inches across, which usually remains thinner than in the typical form of Fomes fomentarius. The upper surface is minutely velvety when young, finally becoming bald, reddish-brown, and at length blackish, very hard, and more or less cracked and broken up into ridges. The hymenium is cinnamon colour, the tubes minute, and in old plants are stratose or arranged in layers. The flesh is very hard, rusty brown, and zoned. Spores colourless and almost globose.

The present fungus superficially resembles Fomes fomentarius, but is readily distinguished by the colourless globose spores and very hard flesh, which is useless for making tinder or fungus-felt.

The wood of the host becomes brown during the first 
stage of attack, and afterwards white, or with a slight tinge of yellow, and quite soft. The inner layers of the walls of the cells are first absorbed by the mycelium, the middle lamellae being afterwards converted into cellulose and used as food by the fungus. In this way the whole of the heart-wood is absorbed.

Preventive Means. - The parasite gains an entrance into the host through wounds, broken branches, holes made by woodpeckers, etc. If the sporophores are cut out on their first appearance, and the wounds protected by tar, the life of the tree may be considerably prolonged; but it must be remembered that the mycelium having gained access to the living tissues of the host, it continues to spread, and the most certain method is to reduce the possibility of infection to a minimum by destroying the fungus wherever and whenever it appears, and also to remove old and useless trees, which favour its growth.

Hartig, Zersetzungserscheinungen des Holzes, p. II4, pl. xv. and xvi.

Prillieux, Malad. des Plantes Agric., vol. i. p. 359.

\section{BIRCH POLYPORUS}

(Polyporus betulinus, Fries.)

This fungus is unfortunately too common on the trunks of birch trees, and has such marked features that it cannot be confounded with any other species. The general shape is that of a horse's hoof. The upper surface is perfectly smooth, white, or often brownish, the brown skin often cracking and peeling off. The margin is thick and in 
curved; flesh very thick, soft, pure white; pores on the under surface very minute, white. Varying in size from three to eight inches across.

When the fungus first attacks the living wood it pro-

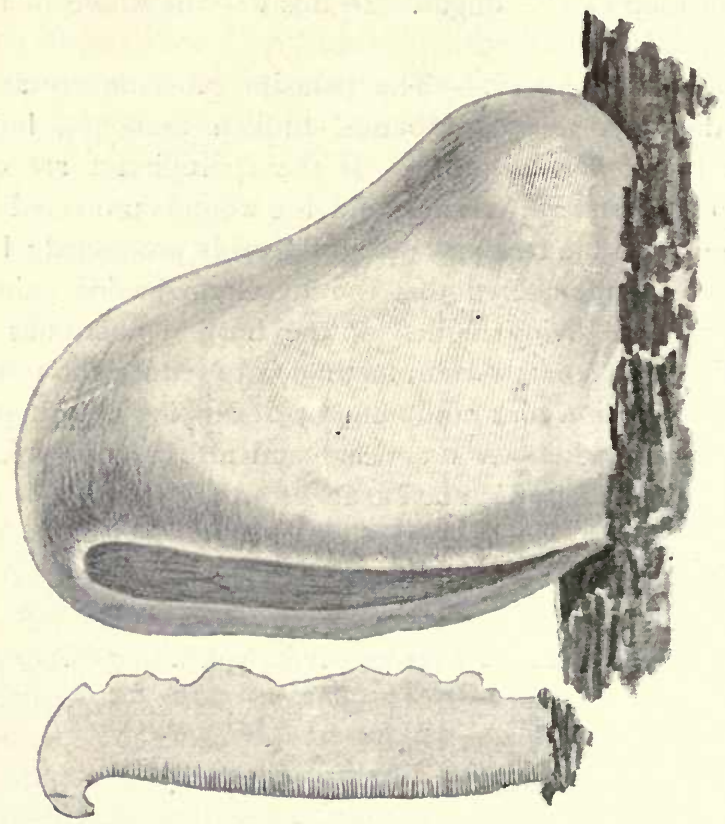

Fig. 43.-Polyporus betulinus. Fungus about oile-quarter nat. size; section of same.

duces a brown discoloration, due to a ferment present in the mycelium; by means of this substance the thickening layers of the cell-walls are dissolved and absorbed, the middle lamellae of the cells alone remaining. Finally cracks are formed in the soft, decayed wood, containing 
white strands of mycelium. The liber and bark are also attacked, and the fruit of the fungus first appears under the form of small white knobs in cracks of the bark, each knob developing into a pileus or spore-producing structure. Although the pileus is an annual production, it is probable that the mycelium is perennial in the wood, gradually encroaching on sound portions of the trunk, and producing new pilei every season.

Preventive Means.- - Healthy trees are first inoculated at some broken surface by means of floating spores; hence, to prevent the diffusion of spores, the fungi must be systematically destroyed. An old birch-tree having the trunk ornamented with numerous well-developed pilei of Polyporus betulinus is certainly an artistic object, and numerous such can be seen in the woods at Birklands, in Sherwood Forest ; but where the trees are grown for other purposes, such diseased examples. should be promptly removed, otherwise they form a centre from which myriads of spores are being liberated annually, and the spread of the disease under such favourable circumstances is certain.

Prillieux, Malad. des Plantes Agric., vol. i. p. 367.

\section{HEART-WOOD ROT}

(Polyporus hispidus, Fries.)

This fungus attacks the majority of broad-leaved trees; in orchards the apple is most frequently attacked. The parasite is readily recognised by its coarsely velvety, dark brown pileus or upper surface, thick, dark-coloured, fibrous flesh, and long, yellowish-brown pores. Large specimens 
are almost semicircular in shape, fixed to the trunk by a broad base, and measure six inches to a foot across. When actively growing the tubes exude water, which drips away in considerable quantities, even in very dry weather.

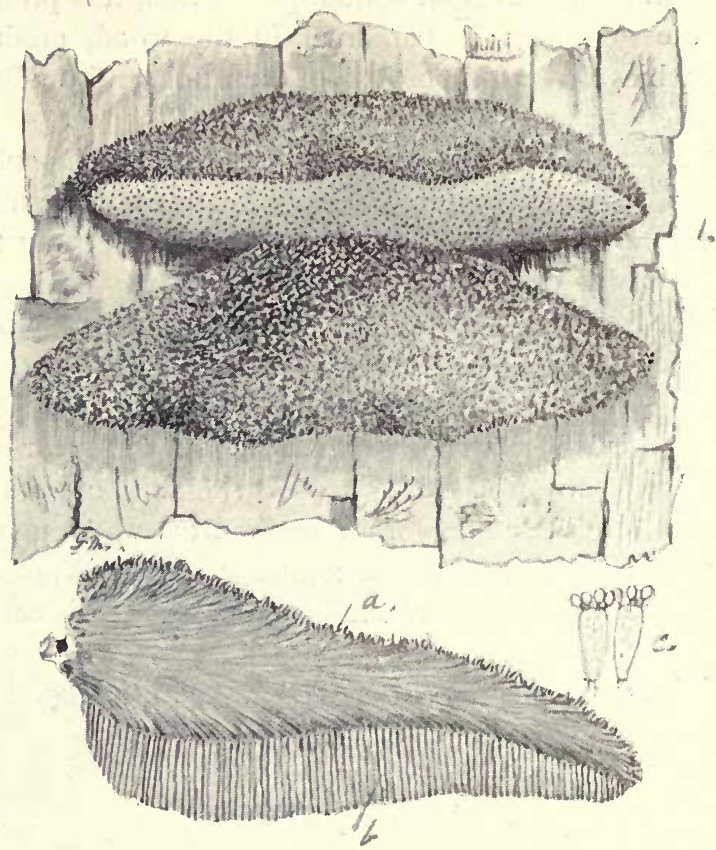

Fig. 44.-Polyporus hispidus. I, two plants much reduced; 2 , section through a fungus showing the pileus, $a$, and the tubes, $b ; 3$, two basidia bearing spores, $\times 300$.

Every part of the fungus yields a deep yellow colour when soaked in spirit or in an alkaline solution.

Being a wound-parasite, the mycelium can only gain 
access to living tissues through a wound. The heart-wood is first attacked, the trunk eventually becoming hollow, but frequently continuing to live for some years, until the outermost and youngest layers of wood are destroyed. The disorganised heart-wood is of a yellowish-white colour, and very soft, and there is a narrow band of a dark brown colour, which indicates the outward point of progress of the mycelium, which is most vigorous in the region of this band of colour, and pushing thence into the younger, still sound wood.

Preventive Means.-Same as for other species of Polyporus.

Prillieux, Malad. des Plantes Agric., vol. i. p. $35^{2}$.

\section{HEART-WOOD ROT}

\section{(Polyporus sulphureus, Fries.)}

This showy fungus is not uncommon as a parasite on the trunk of various trees, as oak, alder, willow, poplar, pear, apple, Robinia, and larch. When quite young it is a roundish, fleshy knob, which grows into an irregularly flattened body, the margin being often crisped or wavy, and bearing the very short, minute pores or hymenium on its under surface. In vigorous specimens there are several such overlapping portions or pilei, the whole frequently weighing several pounds, and measuring six inches to a foot across, or sometimes even much more. The upper surface is smooth, and varies in colour from pale yellow to orange, becoming bleached and pale when old. The under surface is bright sulphur-yellow. The flesh is white, 
rather soft, and easily broken. The entire fungus is brittle, has a very disagreeable smell, and is poisonous.

In addition to the usual means of reproduction by spores, two other methods of reproduction are known; one by means of sporelike bodies called conidia, which are produced in great abundance from the mycelium growing in cavities in the wood destroyed by the fungus, or sometimes in receptacles in the flesh of the fungus itself. The second form of reproduction in addition to that of the spores also consists of conidia produced in the interior of special receptacles, which resemble the young stage of the ordinary spore-bearing pileus, from which they differ in not producing pores bearing basidia. These last-named structures were at one time considered to be an independent fungus belonging to a genus called Ptychogaster, and the form we now know as forming a link in the life-history of Polyporus sulphureus was called Ptychogaster aurantiacus.

The fungus is an annual, grows rapidly, and decays in the autumn. It is a wound-parasite, gaining access to the living part of the trunk by means of mycelium which originates from the germination of a spore or conidium on the surface of a wound, such as a broken branch, or an imperfectly protected surface exposed by pruning. The heart-wood is first attacked, the mycelium gradually extending towards the sap-wood. During decay the wood changes to a clear reddish-brown colour, cracks, patches of white mycelium appearing in the crevices.

Preventive Means.-From what has been described respecting the mode of attack of the fungus, it will be seen how important it is to trim the ends of broken branches, and to protect cut surfaces with some fungicide. If the fungus has gained a footing on the trunk, it should be 


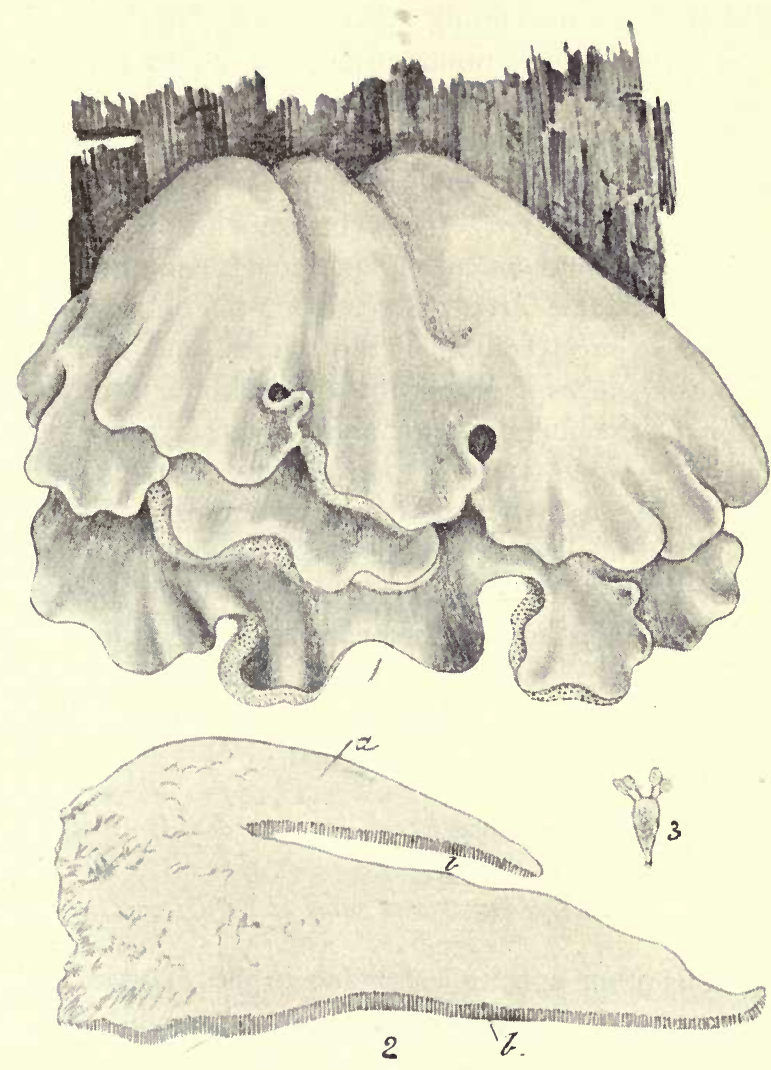

Fig. 45.-Polyporus sulphureus. 1, an entire fungus about onequarter nat. size; 2 , section through the same, showing the thick, fleshy pileus at $a$, and the tubes, which have the cavity lined with the hymenium, or spore-bearing surface, at $b ; 3$, a basidium bearing four spores, $\times 300$. 
removed, the surrounding wood cut away to the depth of an inch round the wound formed, so as to remove the mycelium and conidia that may be present. The cut surface of the wood should then be washed with a saturated solution of corrosive sublimate in spirit, and afterwards painted over with tar. If the broken end of a branch is attacked, it should be cut off far enough behind the point of attack to make certain of removing the portion of wood containing the mycelium of the fungus, and this should include six inches if practicable; for, although the fruiting portion of the fungus is an annual, its mycelium, when once in the wood, appears to extend its ravages from year to year. As a matter of course the fungus should be destroyed whenever it appears, as its spores and conidia are carried to a considerable distance by wind. By destroying the fungus is not simply meant removing it from a tree and crushing it under foot, which only in reality means spreading its spores; it should be either burned or buried, the first remedy being most effectual.

Hartig, Die Zersetzungserscheinungen des Holzes, p. I०9, tab. xiv.

Marshall Ward, Timber and some of its Diseases, p. I65.

Various other species belonging to the Polyporeae have been proved to be parasites, or are suspected of being such.

Polyporus schweinitzii, Fr.-A large brown fungus with a coarsely velvety pileus and soft brown flesh, pores large, irregular. Superficially resembling $P$. hispidus, but distinguished by the short central stem. It attacks the larch, Scots fir, and Weymouth pine. 
Polyporus borealis, Fr.-Bracket-shaped, or sometimes kidney-shaped and narrowed at the point of attachment, often imbricated; pileus whitish, hairy; flesh rather soft, whitish; pores irregular in form, edges toothed. Allied to $P$. betulinus. Attacks spruce more especially, causing a white rot of the wood.

Polyporus squamosus, Fries.-Clustered; pileus broad, thin, rather soft, upper surface whitish and scaly; pores short, becoming irregularly torn; stem short, black at the base, not central. Common on many kinds of broadleaved trees.

Polyporus dryadeus, Fr.-Bracket-shaped, thick, attached by a broad base, six to ten inches across, brown, rugged, margin paler and exuding drops of water; flesh rusty, velvety, fibrous. Attacks the oak; the heart-wood is striped with white or yellowish bands.

Fomes fulvus, Fr.-Very hard, convex above and below; pileus even, downy, tawny, then greyish; flesh rusty; pores minute, two to four inches across. Occurs on plum, poplar, hornbeam.

Fomes hartigii, Allesch. - Hard, irregularly bracketshaped; pileus reddish-brown, smooth; flesh tawny, stratose; tubes not distinctly stratified. Occurs on silver fir and spruce, causing a white rot of the wood.

Fomes pinicola, Schweinitz.-Bracket-shaped, thick behind; pileus grey, margin thickened, reddish; hymenium yellowish-white; flesh white. Occurs on living trunks of 
various conifers, and also on some broad-leaved trees in the United States.

Poria laevigata, Fries, forms hard rusty-brown crusts on the bark of birch trunks. A true parasite, destroying the last-formed wood of each year, hence the annual rings of wood become free from each other.

Polyporus giganteus, Fr., often forms dense masses of overlapping flaps or pilei, two to four feet across. The pilei are thin, pliant, brownish, slightly zoned; pores minute, very short, becoming dark-coloured at once when bruised, a character by which this species can be recognised from allies. Often springs in dense masses from the roots of living trees, and is probably parasitic.

Fistulina hepatica, Fries.-The beefsteak fungus; resembling overlapping flaps of liver in shape, colour, and consistency; grows on living oaks.

Dedaelea quercina, Fries, is very common as a saprophyte on oak stumps, and is also said to attack living oaks. It is a bracket-shaped fungus, six to ten inches across; the entire substance is tough and corky; pileus dingy white, marked with concentric grooves. The hymenium consists of thick, flexible plates, branching and anastomosing to form long, wavy, irregular pits.

\section{DRY ROT}

(Merulius lacrymans, Fr.)

Although not destructive to living trees, 'dry rot' is so well known that a few observations culled from the 


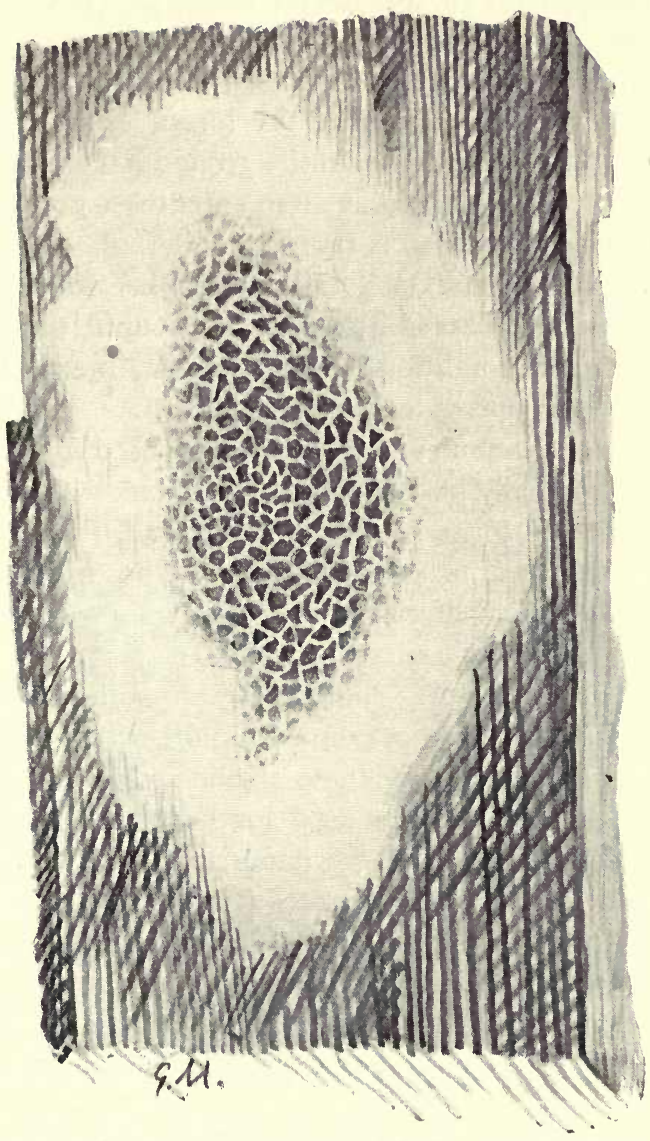

Fig. 46.-Merulius lacrymans. 'Dry rot' growing on a beam ; nat. size of a young specimen. 
luminous account of this fungus given by Hartig will be of value.

Wood that is perfectly sound when felled may become diseased even before leaving the forest, especially in the case of peeled trees lying on the ground. During drying, the wood cracks, and spores often enter these cracks, which close up when the wood is thoroughly wetted, enclosing the spores. These germinate and attack the woody tissues, and too frequently continue their work until the wood is used, when, if conditions are favourable, the well-known 'dry rot' soon makes its presence evident.

If fungus mycelium is present in wood used for structural purposes, and any portion comes in contact with moisture, as the ends of joists joining a damp wall, the mycelium soon commences to grow actively. The use of damp sound-deadening material is very productive of 'dry rot'; clean dry gravel or coarse dry sand is best; and on no account use coal-dust, cinders, or any other substance capable of forming an alkaline solution with moisture, as the spores only germinate in an alkaline solution.

If 'red-stripe' wood is used for beams, etc., the ends likely to come in contact with damp walls, etc., it should be thoroughly treated with creosote. 'Red-stripe' is the early stage of an attack by the mycelium of 'dry rot,' and it is far better not to use such in buildings; but as this is constantly done, the next best thing is to use creosote or some other material that will prevent the spread of the disease.

The fungus first appears as a thin white film of mycelium, and gradually becomes thicker at the centre, where it assumes an irregularly porous structure, and changes to a rich rusty-brown colour; the substance is soft, and the 
white mycelium at the margin gradually encroaches on the surrounding parts, being especially favoured by a damp, stuffy locality.

Hartig, Der ächte Hausschwamm (Merulius lacrymans), I 885 .

Hartig and Somerville, Diseases of Trees, p. 2 I 2.

\section{AGARICACEAE}

Tree Root Rot

(Armillaria mellea, Vahl.)

This very destructive fungus is probably the commonest and most generally distributed of British 'toadstools.' In addition to attacking nearly all kinds of orchard trees, it destroys various species of forest trees, including conifers.

The fungus commonly grows in dense clusters round the roots of growing trees; it also frequently occurs on dead stumps and trunks. Sometimes it appears to be growing in the naked ground, but in such instances it originates from buried wood, roots, etc.

The cap or pileus is two to three inches across when expanded, of a pale honey-yellow or wax-yellow colour, and is generally ornamented with minute, darker scales; the stem is three to six inches long, smooth, and coloured like the cap, often deeper honey-colour near the base; the gills are white when young, becoming cream-colour, and during the young stage are hidden by a membrane stretching from the stem to the edge of the cap; as the cap expands, this membrane breaks away from its edge, and 
forms a frill or ring round the stem; the spores are white, and are produced in great profusion, settling on objects near in the form of a dense white powder.

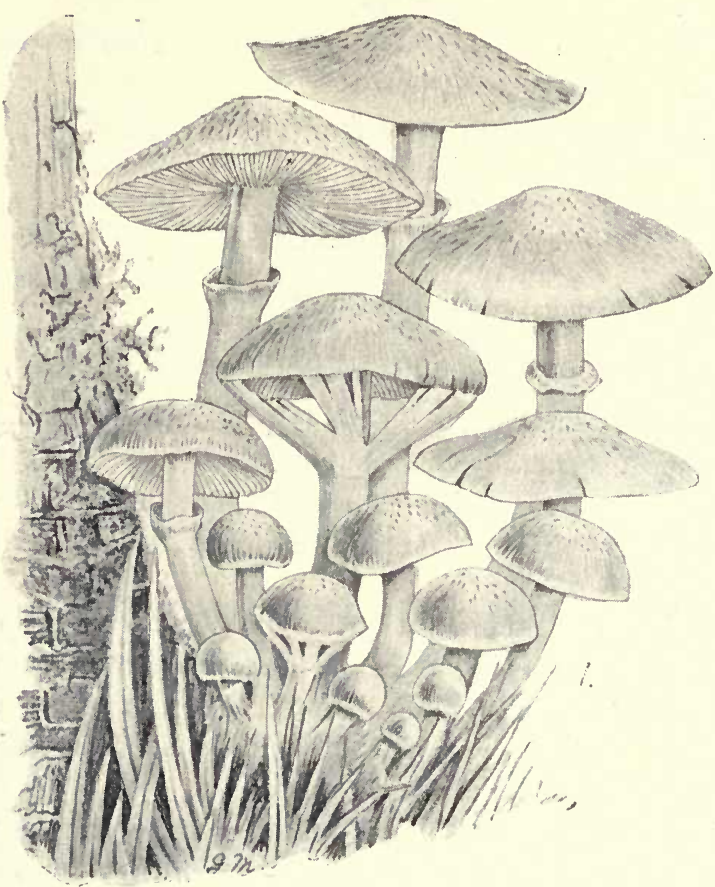

Fig. 47.-Armillaria mellea. Group of plants about one-quarter nat. size.

The roots of trees are attacked first, the mycelium of the fungus gradually passing up into the base of the trunk. The wood is not penetrated to any great depth; but as the 
portions attacked are vital parts, the young wood, cambium, and bark, and as the trunk is attacked simultaneously all round, the tree soon succumbs to its enemy. The mycelium of $A$. mellea is so thoroughly characteristic that it can be recognised with certainty, even when the fructification is absent. On examining roots attacked by this fungus, its mycelium is seen under the form of blackish, cordlike strands of the thickness of fine twine, which creep over the surface of the roots and the base of the trunk close to the ground, and in addition radiate in the ground on every side, where they continue to grow and increase in length until they come in contact with the roots of neighbouring trees, which are attacked, and become in turn centres from which the mycelium spreads in the ground as before, in search of new victims.

The black, cordlike strands of mycelium, known as rhizomorphs, do not penetrate the roots, but give off irregularly arranged delicate branches at intervals; these branchlets enter the roots and form thin white sheets of mycelium running between the bark and the wood, and are known as subcortical rhizomorphs. Hyphae from these latter penetrate the wood for a short distance, mostly following the medullary rays, branches of hyphae passing into the vessels of the wood, which soon become choked with a dense mass of mycelium. In conifers the mycelium fills the resin canals, and destroys the cells forming their walls, the resin exuding through the bark in large masses at the base of the trunk.

Preventive Means.-In orchards, etc., where only few trees are attacked, it is advisable, as suggested by Hartig, to isolate such trees, by digging a narrow trench about a foot deep round each, at some distance from the trunk; 
thus preventing, to a great extent, the spreading of the underground rhizomorphs to adjoining trees.

Armillaria mellea is edible; hence if the fungus appears it may be eaten, and, although rather devoid of flavour, if properly cooked forms by no means a despisable dish. However, apart from this, the fungus should always be collected and burned when it appears in the neighbourhood of fruit or ornamental trees, as, if the spores are allowed to disperse, they germinate and produce the creeping rhizomorphs. A fertile source of infection consists in the careless manner in which the base of the trunk or partly exposed roots of trees are often wounded by the spade, cart-wheels, and perhaps more especially by grass-cutting machines; such wounds forming a starting-point for the attack of various kinds of injurious parasitic fungi. All such wounds should be at once protected by painting over the broken surface with tar, which prevents decay and also the germination of the spores of fungi on the wound.

Hartig, Die Zersetzung. des Holzes, p. 59, tab. xi., figs. i.-v. Hartig, The Diseases of Trees (Engl. ed.), p. 207, with figs. Prillieux, Malad. des Plantes Agric., vol. i. p. 377.

Marshall Ward, Timber and some of its Diseases, p. 155 , figs.

\section{BEECH AGARIC}

(Armillaria mucida, Schrad.)

This fungus is a wound-parasite on the beech. At High Beech, Epping Forest, where this fungus is abundant on decaying beeches, a healthy branch of a beech having been broken off, the wound was inoculated with the spores of 


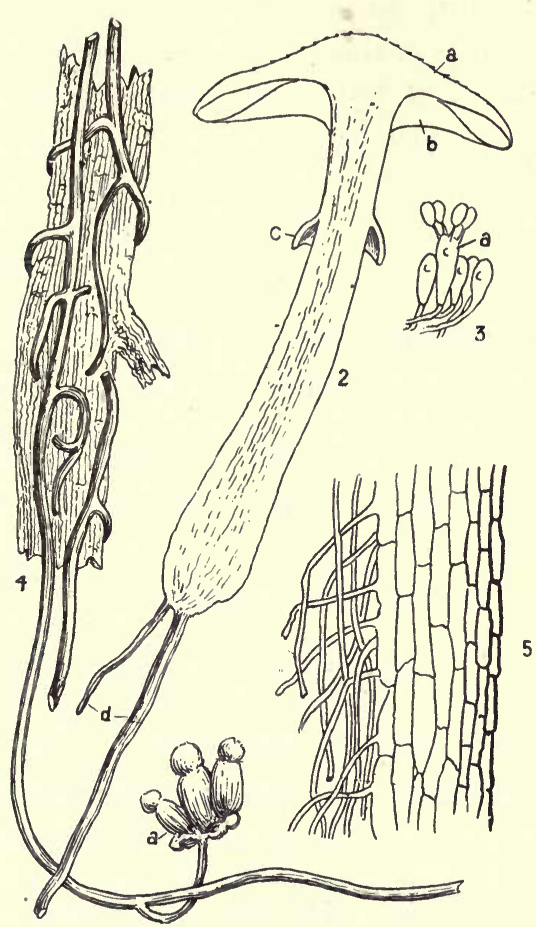

Fig. 48.-Armillaria mellea. 2, section through a plant, $a$, pileus ; $b$, gills ; $c$, ring ; $d$, black cordlike strands of mycelium; 3 , portion of hymenium or spore-bearing surface of the gills ; $a$, basidium bearing four spores, $\times 300 ; 4$, portion of a root with branching strands of the mycelium surrounding it; at $a$, a cluster of young fungi are springing from the mycelium; 5 , section through the black rhizomorph or mycelium, showing the thick-walled cells forming the outer black rind, and the thin-walled, colourless cells forming the inner portion, $\times 400$. 
A. mucida." At the end of the second season after inoculation, the branch was killed for a considerable distance, and the sporophores of the fungus appeared in abundance. The spores also germinate readily on very small wounds made in the bark. A reddish-brown zone indicates the point reached by the mycelium of the fungus in the wood. The decayed wood is quite white, and very tender.

The fungus often grows in clusters, and is readily recognised by being white, and everywhere exceedingly glutinous, as if smeared with thick gum. There is a ring on the stem, which is sometimes greyish, as is also the cap. The fungus is edible, and has a very pleasant flavour.

Preventive Means.-Destroy the fungus, and protect wounded parts with tar, filling up cavities used for nesting by birds.

\section{BANANA DISEASE}

(Marasmius semiustus, Berk. and Curt.)

In Trinidad and other islands in the West Indies a banana disease is not uncommon, due to the presence of a small agaric having the pileus half to one inch across, very thin, and yellowish-brown; gills rather wide apart, thin, dirty white, stem about half to three-quarters of an inch long, very thin, with a flattish foot of attachment.

These fungi grow in immense numbers on the stem of the banana plant, and the mycelium permeates the tissues and attacks the inflorescence or the flower-stalk as it grows up the centre of the leaf-sheaths forming the 'stem.' In old or dead plants immense numbers of minute whitish sclerotia, usually not larger than the head of a pin, are present in the tissue of the leaf-sheaths. 
Preventive Means.-Diseased stems should not be allowed to lie and rot on the ground, otherwise the sclerotia present will, in some form or other, reproduce the pest; burning is the only safe method of dispensing with such diseased material. The fungus should be removed from stems as early after its appearance as possible.

Marasmius sacchari, Wakker. - Infection experiments have proved this agaric to be a true parasite on living stems of sugar-cane in Java.

Wakker and Went, Zeikten van het Sinkerriet op Java, p. 194, pl. 5 .

\section{SUGAR-CANE AGARIC}

(Schizophyllum commune, Fr.)

This fungus is said to be parasitic on stems of cultivated sugar-cane in the West Indies. It has also been recorded as a parasite on the mulberry-tree by Prillieux.

The pileus is fan-shaped, without a stalk, very thin and pliant; upper surface whitish or grey, very hairy, gills. radiating from the point of attachment, forked, pale brown, margin split.

Prillieux and Delacroix, Bull. du Ministère de l'Agric., No. 5, Sept. I 893 .

\section{SLIMY TREE AGARIC}

(Pholiota adiposa, Fries.)

This is a very showy fungus usually growing in clusters; when fully expanded the cap is two to four inches across, 
and the curved stem three to six inches long; the colour of every part is clear yellow. The cap is covered with a glutinous liquid, and like the stem is ornamented with rust-coloured scales arranged in irregular circles; these scales, along with the glutinous substance, are usually washed off by rain as the fungus becomes old. The gills are at first pale yellow, then rusty orange.

This fungus is not uncommon as a saprophyte, growing on decaying timber, stumps, trunks, etc.; but Tubeuf has shown that not unfrequently it becomes a wound-parasite, growing on living trunks of silver fir, beech, plum, etc. The white wood of the fir becomes yellow or honeycolour with scattered patches of light brown, and eventually breaks up into irregular pieces under the influence of the mycelium of the fungus.

Preventive Means. - The only known mode of reproduction of the fungus is by means of spores; hence all fungi should be collected and either burned or buried. Protect all wounds by applying a coat of tar.

The following Agarics also sometimes grow on living trees :-

Pholiota aurivella (Batsch) resembles Pholiota adiposa (Fries) in general appearance, but the stem is always dry, not sticky. Often solitary.

Pholiota squarrosa (Müll.), densely tufted, dry, yellowishbrown; pileus and stem, up to the ring, ornamented with projècting brown scales. Smell strong.

Pholiota destruens (Brond.). - Pileus dingy white or yellowish, floccosely squamulose; stem whitish, squamulose. On poplars. 


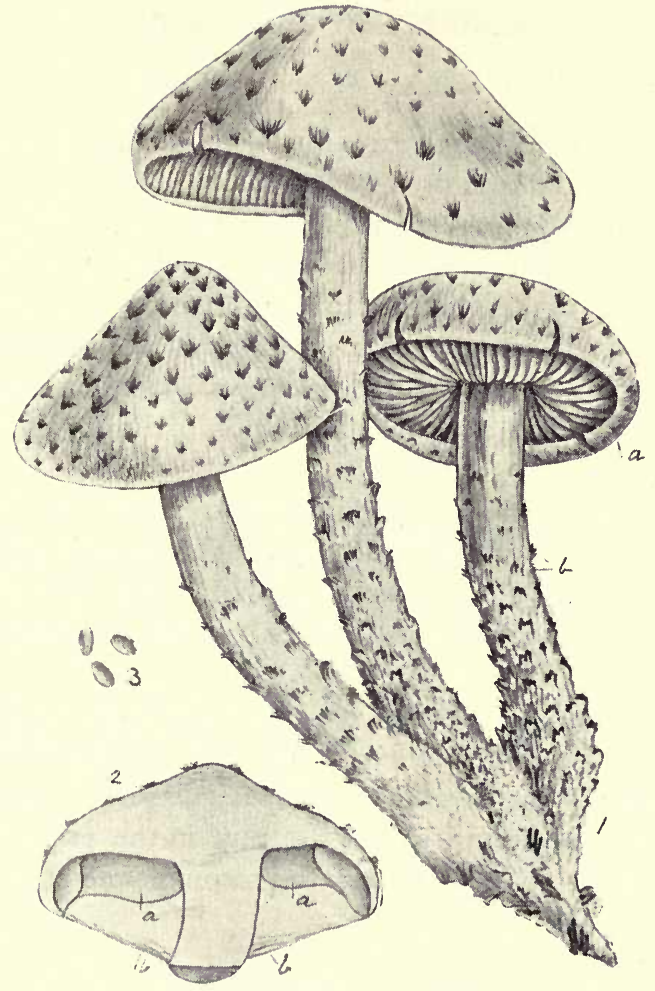

Fig. 49.-Pholiota adiposa. I, cluster of fungi, $a$, pileus, $b$, stem; about half nat. size; 2 , section of pileus, $a, a$, lamellae or gills, $b, b$, the veil, which when young extends as a membrane from the stem to the margin of the pileus, and afterwards shrinks and forms a more or less perfect ring round the stem, almost obsolete in the present species ; 3 , spores, $\times 300$. 


\section{RASPBERRY ROOT ROT}

\section{(Hypholoma fasiculare, Fries.)}

This fungus, although exceedingly abundant, has not been notified as a parasite in Europe. However, quite recently Mr. D. M‘Alpine, Government Vegetable Pathologist, Melbourne, has announced that this species is very destructive to raspberries in Victoria, forming a dense white mycelium round the roots after the manner followed by Armillaria mellea. Sour, damp soil favours the disease, whereas drainage and the application of lime prevents its spread.

The fungus grows in dense clusters on and around rotten trunks, stumps, posts, etc. The general colour is dingy yellow. The gills are yellowish-green, then clouded with the dark-coloured spores. Taste very bitter, smell acrid.

Preventive Means. - M'Alpine says drainage and liming of the soil, together with the removal and burning of diseased plants, are the principal measures to be relied on. The addition of salt to the lime in the proportion of two of lime to one of salt may be recommended.

\section{USTILAGINACEAE}

Loose Smut of Oats

(Ustilago avenae, Jensen.)

Popularly known as 'smut' or 'slean,' this disease is known wherever oats are cultivated; and before the simple but certain preventive methods were discovered, 
Swingle estimates the annual loss at not less than $\$ 18,000,000$ for the United States alone.

The smut or mass of spores is produced in the ovary,

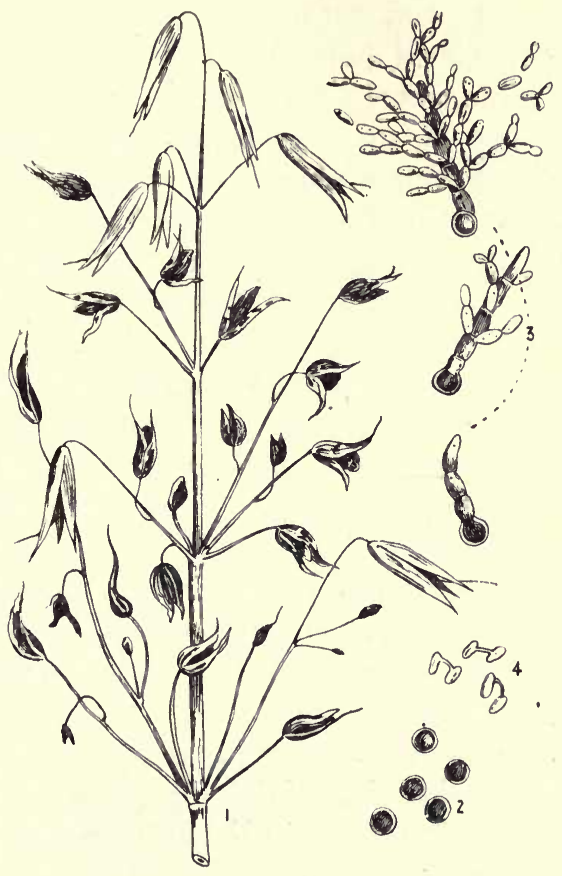

Fig. 50.-Ustilago avenae. I, a 'smutted' ear of oats ; 2 , spores, $\times 300 ; 3$, germinating spores, $\times 300 ; 4$, secondary spores conjugating, $\times 300$.

and matures when the oat is in flower, and is dispersed by wind or rain before harvest.

A form of this species called laevis, on account of the smooth spores, has been recorded from America, growing 
along with the typical form. In this hidden form the chaff is not destroyed, and the spore-mass is concealed in the grain.

Brefeld has proved that inoculation can only be effected when the oat plant is quite in the seedling stage, immediately after germination. Smut spores adhering to the oat seed germinate at this period, produce a promycelium, which bears secondary spores, and these latter inoculate the young oat plant, the germ-tubes entering its delicate tissues, and grow along with the oat plant until its flower is produced, when the fungus produces its spores under the form of 'smut.'

Preventive Means. - The hot-water method is effective, as is also steeping the seed in a solution of potassium sulphide- $\mathrm{I} \frac{1}{2}$ pounds in 25 gallons of water-for twentyfour hours, stirring thoroughly at intervals. A wooden vessel should be used.

It has been definitely proved that by using either of the above methods, a much greater increase in the yield is obtained than would result by merely replacing the smutted by sound grain.

Close has recently conducted an extensive series of experiments, proving that sprinkling the seed grain with a one per cent. solution of either lysol or formalin entirely prevented the smut.

Brefeld, Nachrichten aus dem Klub der Landwirthen zu Berlin, I888, No. 220 et seq.

Jensen, Journ. Roy. Agric. Soc. England, vol. xxiv. pt. 2, I 888 .

Rostrup, Nogle Undersogelser angaande Ustilago Carbo, I 890 . 
Swingle, Year Book, U.S. Dept. Agric., I894, p. 4 I 4.

Close, N. York State Stat. Bul. I3 I, p. 44 I.

\section{LOOSE SMUT OF WHEAT}

(Ustilago tritici, Jensen.)

This fungus attacks the grain and also the chaff, destroying the whole, and forming a loose black, dirty mass, which usually disappears before harvest-time, leaving only the stalk of the ear. The powder is not fotid.

Var. folicola (P. Henn.) develops on the leaf and leafsheath of wheat, and is not uncommon in Egypt.

Preventive Means. - A difficult disease to combat, the ordinary hot-water method not being effective, neither is the bluestone method. Kellerman and Swingle state that certain forms of hot-water treatment are effective, but these injure the germinative power of the seed. The safest method is to obtain seed from a locality free from the disease.

\section{MAIZE SMUT}

\section{(Ustilago mays zeae, Magnus.)}

This disease appears to occur wherever maize or Indian corn is cultivated, and has received attention from scientists for a long time past, Brefeld, however, having contributed most towards a correct knowledge of its life- , history. The disease usually appears first on the leaves, and not before the plant is about a yard high ; afterwards at the junction of leaf-sheath and blade ; finally the ear of corn is attacked. In some instances one or other alone 
of these parts is diseased. On the leaf the first evidence of disease is the appearance of whitish wrinkled blisters, usually surrounded by a reddish tinge of colour; at a later stage the blisters burst and expose the mass of spores. On the ear large, whitish, polished swellings appear, reaching in size that of a walnut, and Brefeld states that in an artificially infected ear the swelling reached the size of a child's head. As the spores mature the swellings become darker in colour, and the enclosing membrane finally ruptures, exposing the dark olive-green mass of spores.

The spores germinate readily at maturity, and produce numerous very minute secondary spores; and it is mostly by means of these secondary spores that the disease spreads so rapidly, inoculation taking place in the first instance from spores that have remained over year in the soil, or from secondary spores that have continued to propagate themselves by germination. Unlike most other cereals, maize can be inoculated at any age, so long as young growing tissue is present at any point.

Preventive Means. - It has been observed that smut is most abundant where fresh manure has been used, the spores probably germinating in the manure, and the secondary spores continuing to reproduce themselves until the maize is susceptible of infection.

Brefeld, Unters. aus dem Gesammtgebiete der Mykol., Hefte iv., xi., numerous figs.

Norton, Kansas State Agric. Coll., Bull. No. 62, 1o pl.

Ustilago hordei, Jensen.-Attacks ears of cultivated barley; the spore-mass is very hard and persistent, being 
surrounded by the unbroken walls of the ovary, and frequently remains intact after harvest. Steeping the seed in

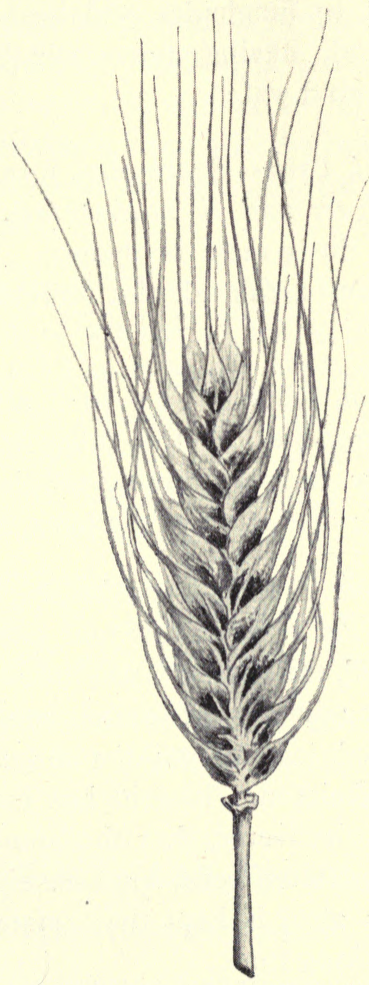

Fig. 51.-Ear of barley attacked by Ustilago hordei.

a half per cent. copper solution prevents the disease, as also does the hot-water treatment.

Ustilago nuda, Jensen.-This species also attacks culti- 
vated barley, but differs from the last in the spore-mass becoming pulverent and dispersed as soon as mature.

Very resistent to fungicides, and best treated with the hot-water method, having previously been soaked for several hours in cold water.

Ustilago sorghi, Pass. - Spore-mass forming in the ovary of Sorghum vulgare and $S$. saccharatum, and completely filling it with a dusty mass of spores. The anthers are also attacked. As a rule all the flowers forming a head are attacked.

Ustilago cruenta, Kühn.-This smut attacks the top of the culm and branches of the inflorescence, rarely the ovary of Sorghum vulgare, forming reddish-brown patches and causing much distortion of the parts attacked.

Ustilago reiliana, Kühn.-Attacks Sorghum vulgare and $S$. halepense, and Zea mays in different parts of the world. The ear is attacked, the spore-masses roundish or elongated, at first enclosed in a silvery white membrane, then pulverulent and soon dispersed, leaving only the more persistent parts of the ear as a skeleton. Brefeld has experimented with this species, and discovered that the spores germinate in a nutritive solution after being kept for eight years. The secondary spores also, if kept dry, retain the power of germinating for a long time.

Ustilago emodensis, Berk. = Ustilago treubii, Solms.Professor Solms Laubach has given an interesting account of this parasite-Ann. Jard. Bot. Buitenzorg, vol. vi. p. 79, pl. ix. (1887) -but has overlooked the fact that it was previously described by Berkeley-Hook. Journ. Bot., vol. 
iii. p. 202 (185I). Clustered outgrowths up to one inch long, longitudinally wrinkled, and capitate, are produced, the violet spore-mass being formed in the swollen head or apex of the outgrowths. Much hypertrophy and modification of anatomical structure occurs at the diseased points. Galls are also sometimes formed in the inflorescence.

The host is Polygonum chinense, and the disease is known from India and Java.

Ustilago esculenta, P. Henn.-This fungus causes considerable distortion or swelling of the stem of Zizania latifolia, and the diseased portions are sold as a vegetable in the market of Hanoi, Tonkin. In Japan it is sold in the apothecaries' shops under the name of Zizania_root-charcoal ; the dark spores are used by those having thin eyelashes to make them look darker, and mixed with oil they are used by women having thin or grey hair. The spores are also much used in Japan in the lacquer industry, to produce rust-coloured ware when mixed with lac.

Miyabe, Bot. Mag., vol. ix. No. 99, I895.

Hennings, Hedre, vol. xxxiv. p. Iо, I895.

\section{SUGAR-CANE BRAND}

(Ustilago sacchari, Rabenh.)

The leaves are attacked, more especially the upper ones, while yet unexpanded and embracing each other, the whole being converted into a projecting, discoloured, tendril-like production.

Wakker and Went, De Zeikten van Het Suikerriet op Java, p. 24, pl. 2. 


\section{STINKING SMUT OF WHEAT}

(Tilletia tritici, Winter.

= Tilletia caries, Tulasne.)

A destructive fungus to the wheat crop, inoculating the young plantlet, and growing along with it without producing any external evidence of its existence, except perhaps just a deeper tinge of green in the leaves, until the wheat is in bloom, when the rigid, erect ear and spreading florets and scales betray the presence of the parasite. The spores are produced in the ovary or grain, and, as a rule, every grain in the ear is diseased. When mature the mass of spores liberated on crushing a diseased grain between the fingers is black, with a tinge of olive, and possesses a very strong, disagreeable smell, somewhat resembling rotten fish, especially when moistened.

The spores are always produced at the tips of branchlets of mycelium, which do not become gelatinised. The epispore, or outer wall of the spore, is furnished with thin raised ribs, which are so arranged as to form a network on the surface of the spore. Germination takes place readily when the spores are placed on a damp surface, an elongated promycelium being produced in the air, which bears a tuft of 7 to 22 narrow, elongated, secondary spores at its apex. These secondary spores usually become connected in pairs by the outgrowth of a narrow neck from one to the other, and when completed resemble the letter $\mathrm{H}$. The secondary spores that fuse in pairs germinate at once, some producing a very slender thread or branch of mycelium; others give origin to curved sporidia, which in turn emit a delicate germ-tube. Both these conditions 
are capable of entering the tissues of a very young wheat plant.

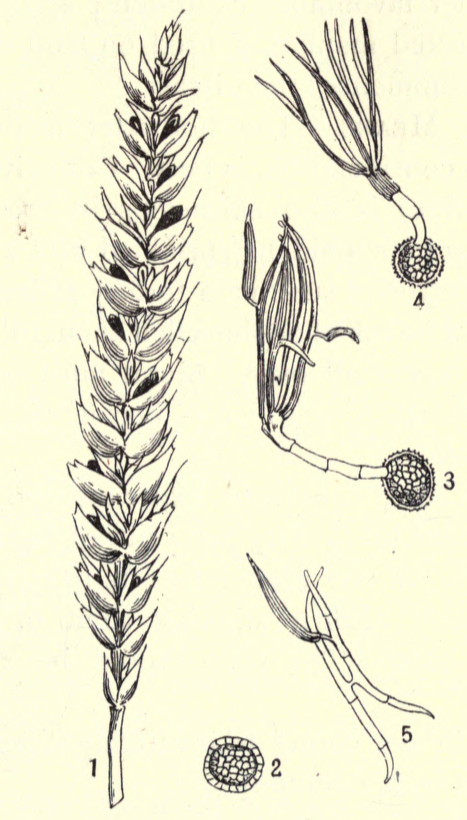

Fig. 52.-Tilletia tritici. I, ear of wheat diseased; 2, spore, $\times 300 ; 3,4$, spores germinating and producing a germ-tube bearing a cluster of secondary spores at the tip, $\times 300 ; 5$, two secondary spores that have conjugated or become united by a short, transverse neck; one of the secondary spores has produced a conidium, $\times 300$ (3-5 after Brefeld).

The secondary spores produced in the air germinate readily in a nutritive solution as saprophytes, forming a 
copious mycelium and numerous conidia. This mode of reproduction is capable of developing and increasing for some time under favourable conditions, as in a manureheap; such infected manure, if used on land where wheat is to be sown, commences the disease.

Preventive Means. - The hot-water method, taking everything into consideration, is best. Corrosive sublimate (mercuric chloride) is also efficacious in preventing the disease. The grain should be sprinkled with a solution of one pound of corrosive sublimate to fifty gallons of water; the wheat should be raked or shovelled about till the surface of every grain is wet all over. Metal must not come in contact with the solution, which is poisonous, and should be used with care.

Bolley and Close, American experimenters, have discovered that formalin (a forty per cent. of formaldehyde), used at the rate of one pound to fifty to sixty gallons of water, is effective against stinking smut of wheat and loose smut of oats. The seed should be soaked two hours.

Wheat sown in the spring is invariably more 'smutted' than when sown in the autumn.

Brefeld, Unters. aus dem Gesammt. der Mykol., v. Heft, p. I46, Taf. xii.-xiii., figs. 25-52 (1883).

Tilletia levis, Kühn = Tilletia foetens, Arthur. - Developed in the grain of wheat, like $T$. tritici, which it resembles in appearance and smell, but differs in the perfectly smooth spores. This species appears to be most abundant of the two in the United States, whereas it is rare in Europe. Treatment same as for Tilletia tritici. 
Tilletia decipiens, Winter = Tilletia secalis, Kühn.Spore-mass blackish-brown, formed in the ovary in rye, also in several wild grasses. The Agrostis pumila of Linnæus is nothing more than Agrostis vulgaris dwarfed by this Tilletia.

\section{RYE SMUT.}

\section{(Urocystis occulta, Rabenh.)}

This smut is most abundant on rye, but also occurs less frequently on oats and barley, and has been met with on wheat in Australia, according to Wolff.

It forms long grey lines on the leaf-sheaths, leaves, and upper part of the culm. When the epidermis, which for some time covers the spores, is ruptured, the streaks are black and powdery. In diseased plants the tissues are more or less destroyed and deformed, the ear is arrested in its development, and the culm often bends over at the point attacked.

The spores are in small clusters, two to three central ones, thick-walled, dark-coloured, and fertile, surrounded by several pale, sterile cells. On germination a germ-tube is formed, which bears at its tip a whorl of cylindrical, secondary spores, each of which on germination gives origin to a slender germ-tube from its basal end. These germtubes inoculate the host-plant by penetrating its tissues when in the youngest condition, soon after sprouting. Inoculation cannot be effected at a later stage of growth of the host.

Preventive Means.-Jensen considers that this smut 
can be prevented by immersing the seed for five minutes in hot water at $127^{\circ} \mathrm{F}$.

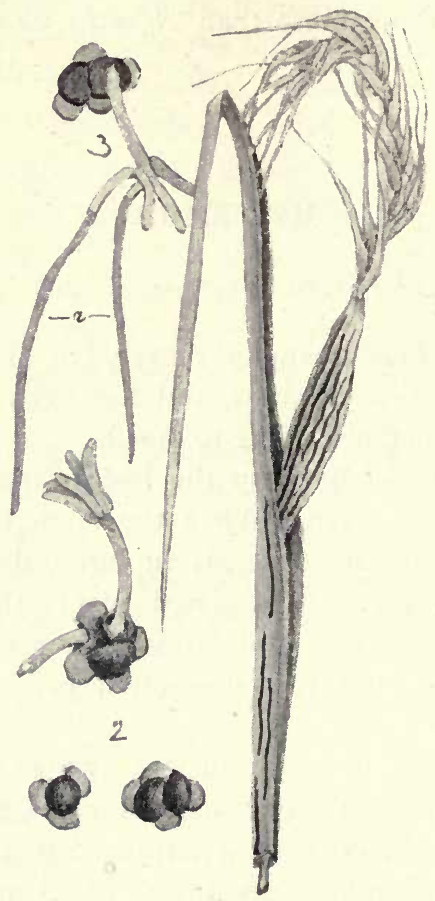

Fig. 53.-Urocystis occulta. I, upper part of a rye plant diseased; 2, spores, one of which has germinated and produced a cluster of secondary spores at the apex of the germ-tube, $\times 300 ; 3$, a spore that has germinated and produced secondary spores, two of which have germinated, $a, \times 300$.

Prillieux, Malad. des Plantes Agric., vol. i. p. I87, figs. 


\section{ONION SMUT}

\section{(Urocystis cepulae, Frost.)}

This disease is up to the present only known to attack the cultivated onion, and develops during the seedling stage of the host. As a rule, the first leaf shows the disease before the second leaf is developed, generally appearing on successive leaves in the order of their development ; the outer tunic of the bulb eventually becomes infected. When the fungus is mature, the epidermis is ruptured and the spores appear on the surface under the form of large, black, powdery streaks.

Sometimes the first leaf alone is attacked, when the plant continues to grow; if more leaves are attacked, the seedling soon perishes.

White varieties of onion appear to be most susceptible to the disease.

Preventive Means.-The spores are shed on the ground in immense numbers, and great care should be taken not to transport such infected soil to new and uninfected localities by means of tools, shoes, etc. It is highly probable that the seedlings are infected by smut spores present in the soil at the earliest stage of growth, and cannot be infected at a later stage; hence it is recommended that onions should be transplanted, for even if planted in ground containing smut, the plants remain free from the disease owing to the period of possible inoculation having been passed. Furthermore, apart from the disease, it is maintained that transplanted onions yield a better crop and mature earlier than onions that have not been transplanted. All diseased plants should be collected when the onions are being weeded and thinned. Where soil has become infected with smut-spores, onions should 
not be sown for some years. The disease appeared in one instance after a period of twelve years' rest, due presumably to smut-spores still present in the soil.

Thaxter, Ann. Rep. Conn. Agric. Expt. Station, p. I 29, pl. 2 (1 890 ).

Weed, Fungi and Fungicides, p. I52.

\section{COLCHICUM SMUT}

(Urocystis colchici, Rab.)

This smut often forms long rows of black, powdery streaks on the leaves of Colchicum (Colchicum autumnale),
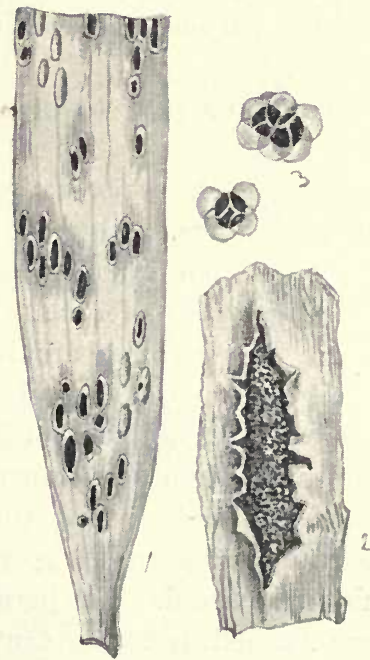

Fig. 54.-Urocystis colchici. I, Portion of a diseased leaf, nat. size; 2 , a single sorus, slightly mag. ; 3 , spores, $\times 300$.

Muscari racemosum, $M$. comosum, Scilla bifolia, Allium rotundum, A. cepa, A. magicum, and Paris quadrifoïa. 


\section{POTATO SCAB}

(Sorosporium scabies, Fisch. de W.)

This disease forms large olive scabs or rough patches on the surface of nearly full-grown potatoes. It is not very injurious, and in fact is often considered as a sign that the potato attacked is good and floury. When present in large quantity the market value is depreciated. Adding lime to the soil is said to prevent the disease.

\section{BEETROOT TUMOUR}

(Oedomyces leproides, Trabut.

= Urophlyctis leproides, P. Magnus.)

Beetroot-Beta vulgaris, var. rapacea-growing in the grounds of the School of Agriculture, Rouiba, near Algiers, was attacked by a disease not previously recorded. Large nodulose or brainlike outgrowths develop near the apex of the root, and may consist of modified leaves or rootlets; the tumours are fleshy, attached to the root by a short, narrow neck, and in the substance are numerous cavities filled with dark-coloured spores. The spores are subglobose, produced at the apex of a hypha, which bears a large vesicular swelling just below the spore.

Preventive Means.-As resting-spores are formed, all diseased material should be removed from the soil and burned.

Trabut, Rev. Générale de Bot., vol. vi. p. 409, I pl. (1894). Saccardo and Mattirolo, Malpighia, vol. x. (1895).

Magnus, Ann. Bot., 1897, p. 87, 2 pl. 


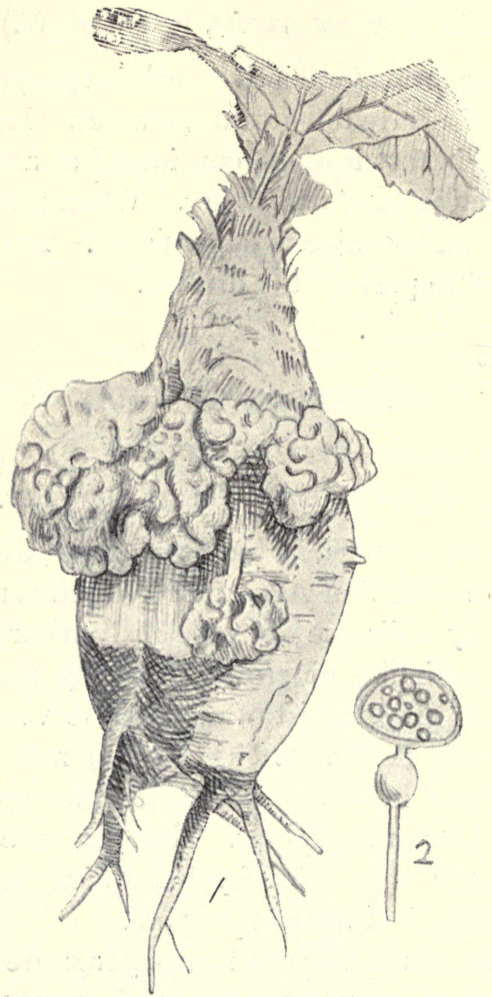

Fig. 55.-Oedomyces leproides. I, a diseased beetroot ; 2, a spore, $\times 300$ (after Trabut). 


\section{U R EDIN A C E A E}

\section{Colchicum Smut \\ (Uromyces colchici, Massee.)}

For three successive seasons the foliage of a bed of Colchicum speciosum was completely destroyed by this fungus, and during the third season plants of Colchicum bavaricum and $C$. autumnale growing on either side of the

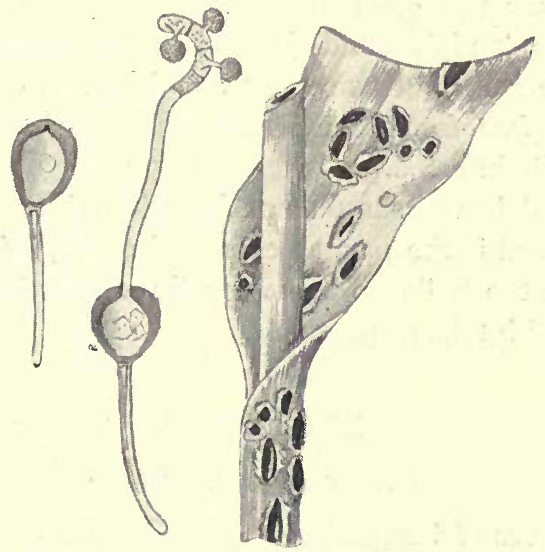

Fig. 56.-Uromyces colchici. $\mathrm{x}$, portion of a diseased Colchicum leaf; 2, a sorus or cluster of spores which has ruptured the epidermis of the host-plant, $\times$ ro ; 3 , teleutospores, consisting of several cells united in a cluster; the central dark cells are fertile, the pale, peripheral cells are sterile, $\times 300$.

diseased patch were also attacked, although escaping for the first two seasons. The parasite attacks the leaves only, commencing at the base of the leaf-sheath and gradually extending towards the tip of the leaf. The lowest and oldest leaf is first attacked.

The sori or spore-clusters are very much larger than is 
usual in the genus, often elongated when growing on the leaf-sheath, whereas on the leaf the spots are usually arranged in circular groups. The sori remain for a long time covered by the epidermis of the leaf, which is finally ruptured, exposing the conspicuous black spore-masses. Teleutospores are alone known, and these remain dormant during the winter, germinating the following spring.

Preventive Means.-A portion of the plants sprayed with a deep rose-coloured solution of potassium permanganate (=Condy's Fluid) just when the leaves appeared above the soil, and twice later, at intervals of ten days, remained free from disease, adjoining unsprayed plants being badly infected.

Diseased leaves should not be allowed to rot on the ground; and if the plants become diseased, it is advisable to remove the bulbs to some locality where the soil is not infected with teleutospores.

\section{BEET RUST}

(Uromyces betae, Kühn.)

The leaves of beetroot and mangold are often infested with rust to such an extent that the value of the crop is very considerably reduced. The cluster-cup or aecidium stage is the first to show itself ; the cups have whitish, torn edges, and occur in groups on yellowish spots. These are followed in June by the uredo stage. Finally, the crowded, blackishbrown pustules of teleutospores follow in August, and continue to develop until the leaves fade in the autumn.

Preventive Means. - Spraying early in the season with dilute Bordeaux mixture or solution of potassium sulphide will arrest the spread of the disease.

The usual difficulties attend an attempt to avoid a re- 
petition of the disease. When the crop is lifted, the leaves, covered with teleutospores, often find their way into the piggery or cattle-fold, whence many of the teleutospores eventually find their way back to the field along with

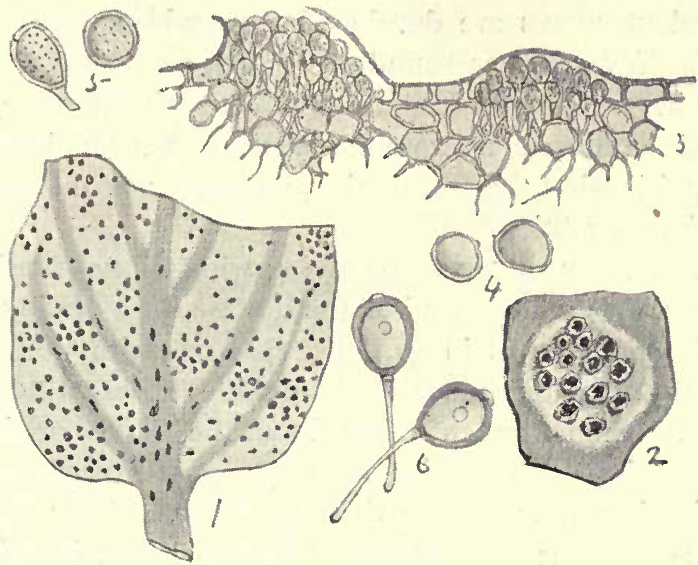

Fig. 57.-Uromyces betae. I, portion of a mangel leaf, spotted with the teleutospore stage; 2 , portion of a leaf showing a white patch crowded with aecidia, $\times 6 ; 3$, section of portion of a leaf showing two clusters or sori of uredospores, $\times 70 ; 4$, aecidiospores, $\times 300 ; 5$, uredospores, $\times 300 ; 6$, teleutospores, $\times 300$.

manure. If the leaves are left to rot in the field the case is no better.

The fungus also occurs on wild beet, and from thence has been proved to pass on to cultivated crops.

\section{BROAD BEAN RUST}

(Uromyces fabae, De Bary.)

This parasite is very common on the leaves and stems of broad beans, peas, also on several wild leguminous plants, as vetches, etc. The aecidium stage is the first to 
appear in the spring; the cups are grouped on conspicuous, thickened, whitish spots on the stem and leaves. The uredo stage follows under the form of minute brown spots, often thickly scattered over the surface of the leaf. Finally, the teleutospores are developed from midsummer to the end of November as roundish or elongated spots on stem and leaves. The uredospores germinate when mature, and spread the disease, whereas the teleutospores germinate the spring following their formation, and produce the first or aecidium condition.

Preventive Means.-Spraying with dilute Bordeaux mixture arrests the spread of the disease. In dealing with small quantities, as in gardens, spraying with potassium permanganate or potassium sulphide effects the same object. It must be remembered that the disease originates in the spring from floating secondary spores produced by germinating teleutospores that passed the winter on the leaves or stems; hence infected plants should be burned as soon as the fruit is gathered, and not allowed to stand or lie on the ground throughout the winter. In the case of field crops these facts also apply, although it is difficult to suggest a practical remedy; but it is almost certain that if the straw eventually finds its way to the manure-heap, many of the teleutospores will survive until the manure is used, and if this happens to be in a field sown with beans or peas, infection of the crop will follow.

Wild vetches should not be allowed to grow in hedges or waste places.

\section{HARICOT BEAN RUST}

(Uromyces appendiculatus, Link.)

Haricot beans or 'scarlet-runners' are often much injured by this pest. All three stages-aecidia, uredo, and teleuto- 
spores-develop on the leaves. The two latter often form myriads of little pustules which cause the leaves to fall early, and thus the development of fruit is checked.

Preventive Means.-Spraying with potassium sulphide solution, if commenced sufficiently early, might be beneficial, although I am not aware of its having been tested. Fallen leaves bearing teleutospores should be gathered and burned.

\section{COFFEE LEAF DISEASE}

(Hemileia vastatrix, Berk. and Broome.)

This terrible scourge, which was first observed in small quantity on a single estate in the Mandulsima district, which occupies the south-western portion of the hilly country of Ceylon, is now widely distributed - India, China, Malay Peninsula, East Indies, Philippines, Natal, German East Africa, and probably wherever coffee is cultivated in the Old World.

The leaves are most frequently attacked, spots being also sometimes present on young shoots and even on the fruit.

On the leaves the earliest stage of the disease is indicated by the presence of more or less circular, discoloured spots. These continue to increase in size for some time, retaining their irregularly circular outline, become pale yellow, and studded with bright yellow clusters of spores, which soon change to a bright orange colour. The patches show on both surfaces of the leaf, but the spores are confined to the under surface.

The spores are produced in dense clusters on the tips of hyphae which come to the surface of the leaf through the stomata. Those surfaces of the spore that are in con- 
tact when the spores are growing are smooth, whereas the outer, free portion of the surface is coarsely warted.

Preventive Means.-Very little success in this respect attended the efforts of those investigators of the disease, whose primary object was to discover, if possible, some

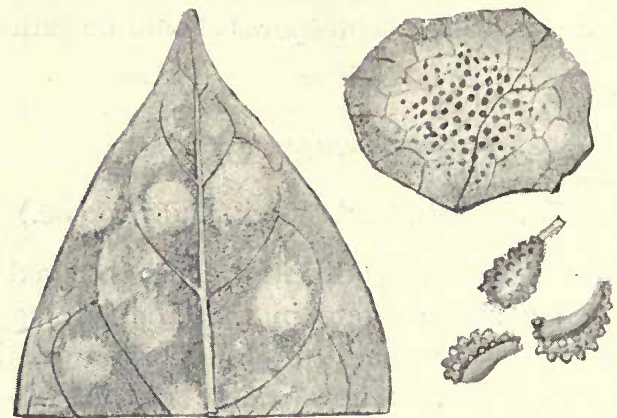

Fig. 58.-Hemileia vastatrix. I, portion of a coffee leaf showing diseased patches; 2, a patch showing sori or clusters of spores, slightly mag.; 3 , spores, $\times 350$.

means of checking the epidemic. Probably some of the modern fungicides, as Bordeaux mixture, etc., might prove more effective. Diseased leaves should be collected and burned on all occasions.

Full notes respecting the distribution of the different species of Hemileia, along with the dangers arising from want of discrimination in the selection of 'shade trees,' will be found on p. 27 of this book.

Berkeley, Gard. Chron., p. II 57 (1869).

Morris, The Coffee Leaf Disease of Ceylon and Southern India. 
Marshall Ward, Sessional Papers, xvii., Colombo, Ceylon, I88I.

\section{WEYMOUTH PINE RUST}

(Cronartium ribicolum, Deitr.

=Peridermium strobi, Kleb.)

The aecidium stage of this fungus occurs on living bark of the Weymouth pine (Pinus strobus), and has also been recorded as occurring on Pinus lambertiana and $P$. cembro. The large aecidia burst through the bark in considerable numbers, are pale yellow, and contain minutely warted, subglobose, orange spores. These spores when placed on living leaves of the black currant (Ribes nigrum), also $R$. aureum and $R$. alpinum, germinate and produce, in the first instance, crowded pustules of uredospores ; afterwards, from the centre of each uredo pustule, a very slender, hairlike body about one line long springs up, composed of a mass of teleutospores, which germinate without falling away; each teleutospore gives origin to one germ-tube which bears three or four minute secondaryspores near its tip. These secondary spores in turn give origin to the aecidium stage on pine bark. Spermogonia alone are formed the first year after infection, the aecidia the following year. The stage on currant leaves was at one time considered as an independent fungus called Cronartium ribicolum.

It is somewhat remarkable that, so far as at present known, this fungus is absent from America, the home of the Weymouth pine.

Preventive Means. - Requiring the two hosts for its 
continuance, the only course is to remove the one considered as of least value.

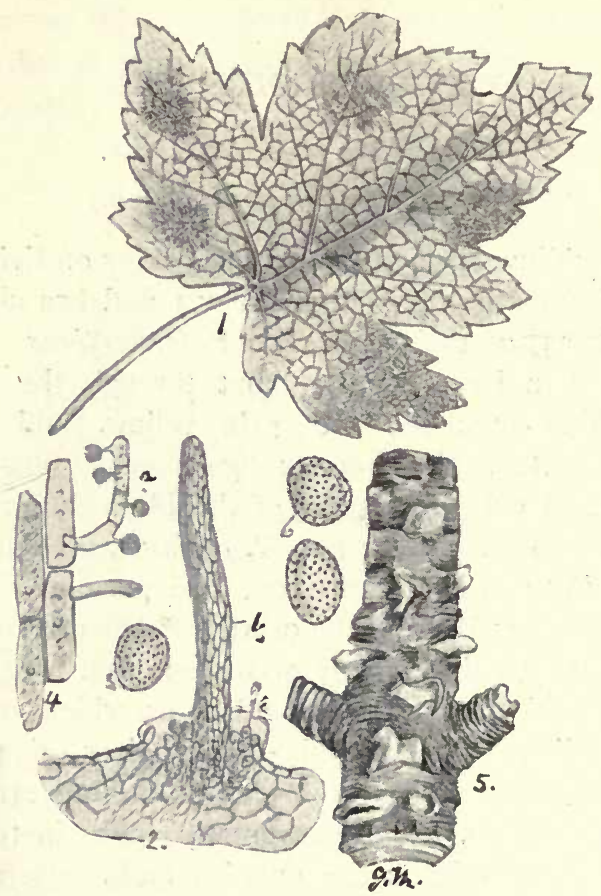

Fig. 59.-Cronartium ribicolum. I, uredo and teleutospore stages on leaf of black currant ; 2, uredospores, $a$, and teleutospores, $b$, cemented together to form an erect, hairlike structure, $\times 50 ; 3$, uredospore, $\times 300$; 4 , four teleutospores, two of which are germinating, and one of the germ-tubes has produced four promycelium or secondary spores, $\times 300 ; 5$, aecidia on bark of Weymouth pine $; 6$, aecidiospores, $\times 300$.

Rostrup, Bot. Centralb. xliii. p. 353.

Prillieux, Malad. des Plantes Agric., vol. i. p. 275. 


\section{PINE BLISTER-BLIGHT}

(Cronartium asclepiadeum, Fr.

=Peridermium cornui, Rostr. and Kleb.)

The aecidia occur on the bark of Scots fir (Pinus silvestris), and produce effects very similar to those described under Peridermium pini.

The hairlike bundles of teleutospores and uredospores grow on the under surface of the leaves of Cynanchum vincetoxicum.

Supposed varieties of this species occur on oaks (Quercus nigra and Q. tinctoria), also on Comandra umbellata and $C$. pallida in the United States, also on leaves of Asclepia speciosa in France.

Prillieux, Malad. des Plantes Agric., vol. i. p. 27 I, figs.

Cronartium flaccidum, Winter.-Uredospores and teleutospores on the under surface of leaves of cultivated paeonies. Aecidial condition unknown. Other species are also known, in which the aecidia are not yet known.

\section{PINE BRANCH TWIST}

\section{(Melampsora pinitorqua, Rostrup.$$
\text { = Caeoma pinitorquum, A. Br.) }
$$

The aecidium condition of the present fungus has been proved by Hartig to be very destructive to young pines, seedlings being sometimes diseased when just appearing above ground, whereas at the age of about thirteen years the disease dies out, and plants that have not been too 
severely attacked up to that period recover. Plants that become diseased when quite young are usually killed, as the disease appears year after year, if the weather is damp in May and June, suggesting that the mycelium is permanent in the tissues of the host.

In a seed-bed or young plantation it is observed that the disease spreads centrifugally from a centre, infection being effected by wind-borne spores, which leads to the conviction that the aecidiospores can perpetuate the disease on pines. Spermogonia and aecidia appear on the leaves or young shoots, the cortex of the latter becoming orange-colour. Growth of the branch is checked at the part diseased, whereas it continues at other points; the result of this unequal growth resulting in a curvature of the branch, and as the tip of the branch tends to grow upwards, double curves are the result.

Rostrup demonstrated by experiment that the teleutospores of a fungus supposed at one time to be a distinct species called Melampsora tremulae, Tul., growing on dead leaves of the aspen (Populus tremula), when caused to germinate on the leaves or shoots of young pines, gave origin to the condition called Caeoma pinitorquum, also previously considered as an independent fungus. He also produced the uredospore and teleutospore stages on aspen leaves by inoculation with aecidiospores formed on the pine.

Preventive Means.-Badly diseased plants should be removed from seed-beds. Aspens should not be allowed to grow in the neighbourhood of nurseries or young plantations of pines.

During seasons favourable to the growth of the fungus on the aspen, its leaves are often quite yellow with the 
uredospores during the summer, and consequently fall off before the normal time. The flat, compact, crustlike patches of teleutospores develop on the fallen, dead leaves, and germinate the following spring.

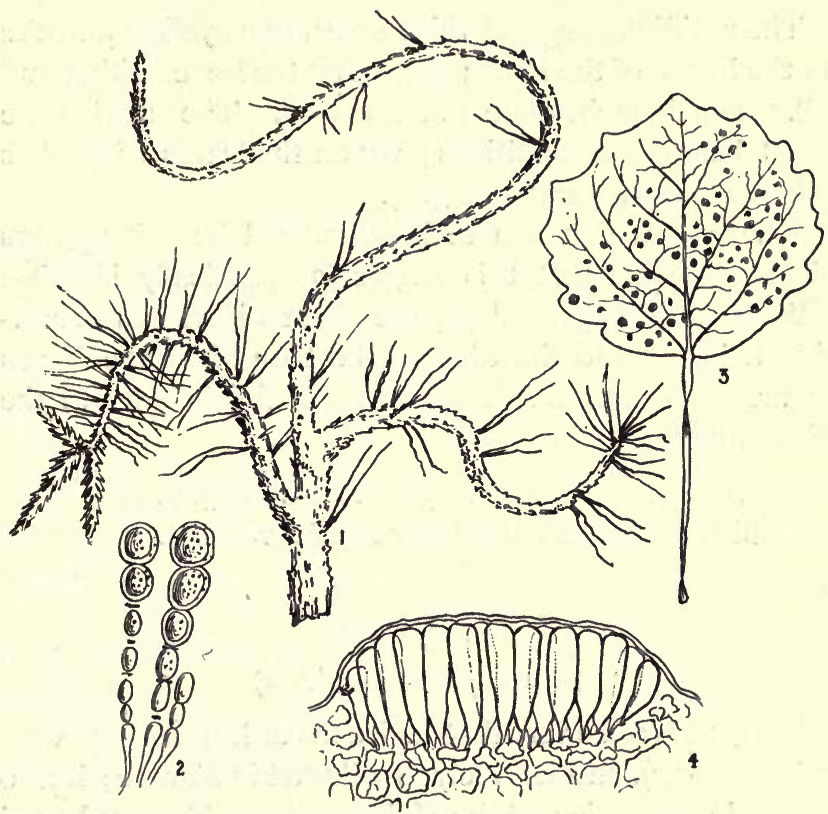

Fig. 6o.-Melampsora pinitorqua. I, top of a young pine attacked by the aecidium stage; 2 , two chains of aecidiospores, $\times 400 ; 3$, aspen leaf with pustules of teleutospores; 4 , section through a pustule of teleutospores still covered by the epidermis of the leaf, $\times 400$.

Hartig, Bot. Centralb., xxiii. p. 362 (I885).

Hartig and Somerville, Diseases of Trees, p. I66, figs.

Prillieux, Malad. des Plantes Agric., vol. i. p. 286, figs. 


\section{BRUNISSURE}

In Europe and North America a disease of the vine, characterised by the appearance of brown spots on the leaves, which eventually extend, and cover more or less the entire surface, has been considered by Viala and Sauvageau, as due to the presence of an amoeboid organism in the cells, to which they have given the name Plasmodiophora vitis, Viala and Sauv.

The California vine disease is also considered by these authors to be caused by an organism allied to the last, which they named Plasmodiophora californica, Viala and Sauv.

I have demonstrated elsewhere that Brunissure, also the disease on the leaves of cultivated orchids, known as 'spot disease,' is entirely due to physical causes.

Viala and Sauvageau, Journ. de Botanique, 1892, figs.

Viala, Malad. de la Vigne, ed. iii.

Massee, Ann. Bot., vol. ix. p. 42 I, I pl.

\section{BACTERIA}

\section{BACTERIOSIS OF TOMATOES}

Prillieux has described a bacterial disease of tomatoes, which is very destructive in the north and central parts of France; it has also occurred in England.

Inoculation is supposed to be effected through the style of the flower, and from this point a blackening of the fruit extends in circles until the whole is destroyed.

Prillieux, Malad. des Plantes Agric., vol. i. p. 19, fig. 


\section{HYACINTH BACTERIOSIS}

(Bacterium hyacinthi, Wakker.)

A destructive disease of hyacinths, well known in Holland, attacks the bulbs in the resting condition, and also shows itself in the foliage. The presence of the parasite is indicated by the appearance of yellow spots on the bulb or leaves, due to the presence of a yellow mucus teeming with bacteria, located in the vessels and intercellular spaces of the fundamental tissue. Infection of healthy plants with this mucilage produces the disease.

Wakker, Onderzoek der Zeikten van Hyacinthen, Haarlem, I 884 .

Prillieux, Malad. des Plantes Agric., vol. i. p. 22, fig.

\section{PINK BACTERIOSIS OF WHEAT}

(Micrococcus tritici, Prill.)

A bacterial disease of grains of wheat, indicated externally by a rose or purplish colour. The colour is brightest and most pronounced in the superficial layer consisting of proteids, less marked where starch predominates.

The starch is first attacked, causing the grain to become more or less hollow, afterwards the gluten, and finally the cell-walls.

The bacteria are globose or ovoid, depending on the phase of development, and form a thin, opaque, colourless, nodulose layer lining the cavity in diseased grains.

This is interesting as being the first account of a bacterial disease of cultivated plants causing real damage.

Prillieux, Ann. des Sci. Nat. Bot., 6th ser., vol. viii., I879; and in Malad. des Plantes Agric., vol. i. p. 7, figs. 
After the crop is gathered, the summer plants might be sprayed with Bordeaux mixture to keep the fungus in check ;

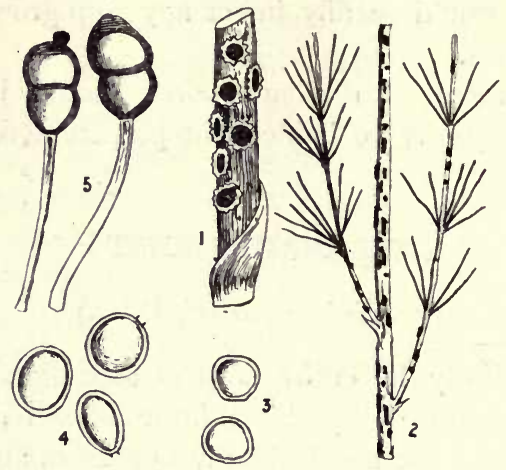

Fig. 6r.-Puccinia asparagi. $\mathrm{r}$, aecidium stage on a young shoot of asparagus; 2 , teleutospore condition on a summer plant ; 3 , aecidiospores, $\times 300 ; 4$, uredospores, $\times 300$; 5 , teleutospores, $\times 300$.

but the important point is to remove diseased plants, and so by degrees prevent the possibility of infection in the spring.

\section{MINT RUST}

\section{(Puccinia menthae, Pers.)}

Whole beds of garden mint, especially when growing in damp, shady situations, are often completely destroyed by this parasite, which also occurs on several species of wild mint, and other Labiate plants.

All three conditions of the fungus develop on the same host. The orange aecidia or cluster-cups appear first in the spring, and are most abundant on the stems, which become swollen and much twisted and distorted. 
The uredospores and teleutospores appear later in the season, mostly on the leaves, the former as pale brown pustules, which soon become powdery; the latter form blackish-brown powdery pustules.

Preventive Means. - When plants are once attacked, cure is practically impossible, as the mycelium is perennial in the plant, passing the winter in the part below ground, and growing up, year by year, with the new stems.

If the disease appears, infected plants should be dug up at once, and burned, care being taken to remove all the underground parts, otherwise the disease will appear again with the new shoots.

\section{CHRYSANTHEMUM RUST}

\section{(Puccinia hieracii, Mart.)}

A specimen of a supposed new disease of cultivated chrysanthemums was sent to Kew for examination by the editor of the Gardeners' Chronicle in 1897. During the remarkably dry summer of $\mathrm{i} 898$ this disease spread to such an alarming extent in the south of England and in parts of France that cultivators of this favourite flower, remembering the wave of fungous disease that rendered the successful cultivation of the hollyhock a matter of impossibility for some years, predicted for it a similar fate. Fortunately the exercise of prompt measures averted such a catastrophe.

The uredo or summer fruit forms minute, snuff-coloured clusters of spores on the under surface of the leaf. In badly diseased examples the pustules are often so numerous as to cover the greater part of the surface of the leaf. Unless checked, this stage of the fungus reproduces and 
extends itself throughout the summer months. When the leaves are fading, the teleutospore form of fruit is produced, which differs from the uredo form in the pustules being darker in colour, and not powdery. The aecidium stage is absent.

The teleutospore stage has not up to the present been observed on the chrysanthemum, and some observers consider the uredo as belonging to Puccinia tanaceti.

Preventive Means.-Spray at intervals, dating from the growth of new leaves, with potassium sulphide solution, which not only destroys the rust-spores, but also those of various other fungous pests that attack chrysanthemums. Remove plants showing the slightest trace of disease.

If the disease has existed, be careful to destroy all leaves that may be likely to produce teleutospores, otherwise a recurrence of the disease is practically certain. In the case of plants grown in houses, the uredo form will continue throughout the winter on the living leaves, therefore a constant watch for the fungus is necessary.

Finally, this fungus is by no means uncommon on a score or more wild species of plants belonging to the Compositae, and care should be taken not to allow the disease to be introduced by such outside sources; the fungus is especially common on wild species of hawkweed (Hieracium), hence its specific name.

There is no reason why this fungus should not, in course of time, attack other cultivated composite plants, as cinerarias, dahlias, etc.

Massee, in Gardeners' Chronicle, and Gardeners' Magazine, with figs., Oct. 8th, 1898. 


\section{GOOSEBERRY LEAF CLUSTER-CUPS}

(Puccinia pringsheimiana, Klebahn.)

During certain seasons the leaves, and sometimes also the fruit, of the gooseberry are studded with little groups of cluster-cups seated on a red or orange patch. When
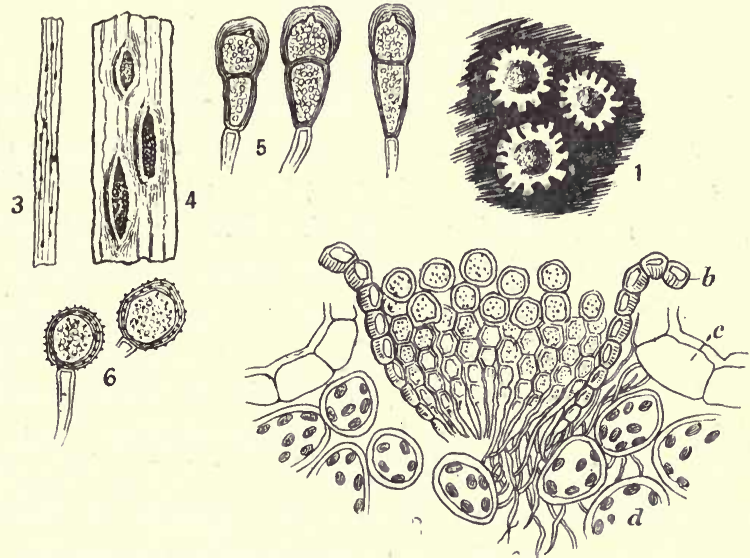

Fig. 62.-Puccinia pringsheimiana. I, portion of a gooseberry leaf with three aecidia or 'cluster-cups ' fully expanded, $\times \mathrm{I}_{5} ; 2$, section through a single cluster-cup showing, at $a$, the spores, produced in chains, which afterwards separate into single spores, filling the cup with a yellow powder ; $b$, the protective wall or peridium ; $c$, epidermal cells of the leaf; $d$, the middle cells of the leaf; $e$, the mycelium of the fungus running between the cells of the leaf, $\times 300 ; 3$, portion of the leaf of a sedge, bearing the sori or minute clusters of uredospores and teleutospores; 4 , a portion of fig. $3, \times I_{5}$ times ; 5 , teleutospores, $\times 300 ; 6$, uredospores, $\times 300$.

mature the cups have white, torn edges, and are filled with orange spores. The uredo and puccinia forms of the fungus have only quite recently been identified; they grow on the leaves of sedges (Carex).

Preventive Means.-As a rule the fungus does not 
appear in sufficient quantity to do any harm. Removing the infected sedges will prevent its appearance.

Klebahn, Zeitschr. f. Pflanzenkr., vol. v. p. 76 (I895).

Smith, Gard. Chron., vol. xvi. p. 76, I88 I, figs.

\section{GRAIN RUSTS}

Notwithstanding the combined efforts of scientists and practical men in various countries to devise some method for preventing the enormous amount of damage to our cereals caused by fungi belonging to the genus Puccinia, the problem yet remains unsolved. Nevertheless, a large amount of valuable information has been acquired, and it is generally acknowledged that we are now in possession of two general principles bearing on the subject: (I) that from the present standpoint of knowledge, spraying with fungicides is of no practical value in preventing rust; (2) that the production of rust-resisting varieties of wheat should be aimed at, the results of experiments already accomplished in this direction being most encouraging.

The essential points that collectively contribute to form rust-proof varieties are: toughness of the epidermis of the leaf; leaf narrow, fairly rigid, and erect, or nearly so.

Early sown and early ripening varieties escape rust best.

Top-dressings of nitrate of soda (Chili saltpetre) make the foliage soft and broad, and consequently more susceptible to rust. Nitrate of soda retards ripening, and thus favours rust.

The following is from Dr. Eriksson's latest résumé of his researches on the grain rusts. There are at least ten kinds of fungus which cause rust in cereals, partly species, partly 
specialised forms of species. In addition to growing on cereals, these fungi are also met with on numerous wild grasses; Puccinia graminis occurs on a hundred different grasses in Sweden. It was considered until quite recently that the cereals could be infected by the spores of a rust produced on any wild grass. This is not the case, but as a rule the various forms are almost exclusively confined to one host, and are unable to infect any other cereal but that one. Thus stems of oats bearing black rust can propagate black rust to oats, but not to rye, wheat, or barley; stems of rye bearing crown rust can propagate crown rust to rye, but not to wheat ; and so on. Plants of rye and barley attacked by black rust make an exception to this rule, as they are able to infect one another; in some cases also those of wheat propagate black rust to other cereals.

The propagation of rust is often slight between grasses capable of serving as a host to the same specialised form.

The germinating power of uredospores and aecidiospores is often small, or at best capricious. It was discovered that chilling the spores by putting them on ice or in cold water for several hours increased the power of germination.

The germinating power of teleutospores depends upon certain external conditions, and is restricted to a short period of time, and it appears that only the crop of teleutospores maturing during late autumn is able to germinate the following spring.

All the modes of propagation enumerated appeared inadequate to account for the enormous amount of rust usually present, and the following observations led Eriksson to formulate a theory of the occurrence of rust to another cause than that solely due to infection by spores :- 
a. The yellow rust appears in certain varieties of wheat and barley that are especially susceptible, uniformly four to five weeks after sowing.

b. The intensity has sometimes been stronger in sunny than in shady places in the same wheatfield.

c. Plants of a variety of barley extremely susceptible to yellow rust, grown in sterilised soil, and protected from external infection in isolated glass-houses, have sometimes become rusted.

'These results prove beyond doubt that the disease must come from internal germs inherited from the parent plant. But in what form are these internal germs of disease living? Is it easy to follow and identify them with the microscope? Not at all. They can only be detected just before the breaking-out of the young pustules. The microscope examination induces me to suppose that-

- The fungus lives for a long time a symbiotic life as a mycoplasma in the cells of the embryo and of the resulting plant, and that only a short time before the eruption of the pustules, when outer conditions are favourable, it develops into a visible state, assuming the form of a mycelium.'

Eriksson, Bot. Gaz., vol. xxv. p. 26 (1898).

It has been proved experimentally that rust-shrivelled wheat used as seed produces as good a crop, and one as free from rust, as when plump seed is used. If Eriksson's theory is correct, it is not wise to sow rust-shrivelled grain for seed, as probably the amount of rust produced may be due to the internal mycoplasma, consequently more grain is produced which presumably would contain mycoplasma, and if this should be used as seed the same thing would 
be repeated. There is also a danger of infection by spores produced by the crop; a condition accepted by Eriksson, if only to a limited extent.

The following literature may be consulted as bearing on the subject:-

De Bary, Mon.-Ber. der Akad. der Wiss. zu Berlin, Sitz. I 2 th Jan. 1865.

Cobb, Agric. Gaz. N.S. Wales, vol. i. No. 3 ; vol. iv. No. 6.

Eriksson and Henning, Die Getreideroste, 1896.

Marshall Ward, Ann. Bot., vol. ii. No. 6, I888.

M'Alpine, Dept. Agric. Victoria, Bull. г 4, 189r.

Farrer, Dept. Agric. N.S. Wales, No. 206 (1 898).

\section{BLACK RUST}

(Puccinia graminis, Pers.)

This universally distributed species is the one most injurious to cultivated cereals, attacking wheat, oats, barley, and rye, but is most general on wheat. It is also common on numerous wild grasses, occurring on one hundred different species in Sweden alone, according to Eriksson.

The aecidia occur in clusters seated on orange spots on living leaves, young shoots, flowers, and fruit of various species of barberry - Berberis - and the allied genus Mahonia. The uredo and teleutospore conditions form small streaks on the leaf-sheath, leaf, culm, and less frequently on the chaff of grasses. The uredo streaks are rusty orange; the teleutospore streaks, which appear later in the season, blackish. An account of the life-cycle of this species is to be found at p. Ir. 


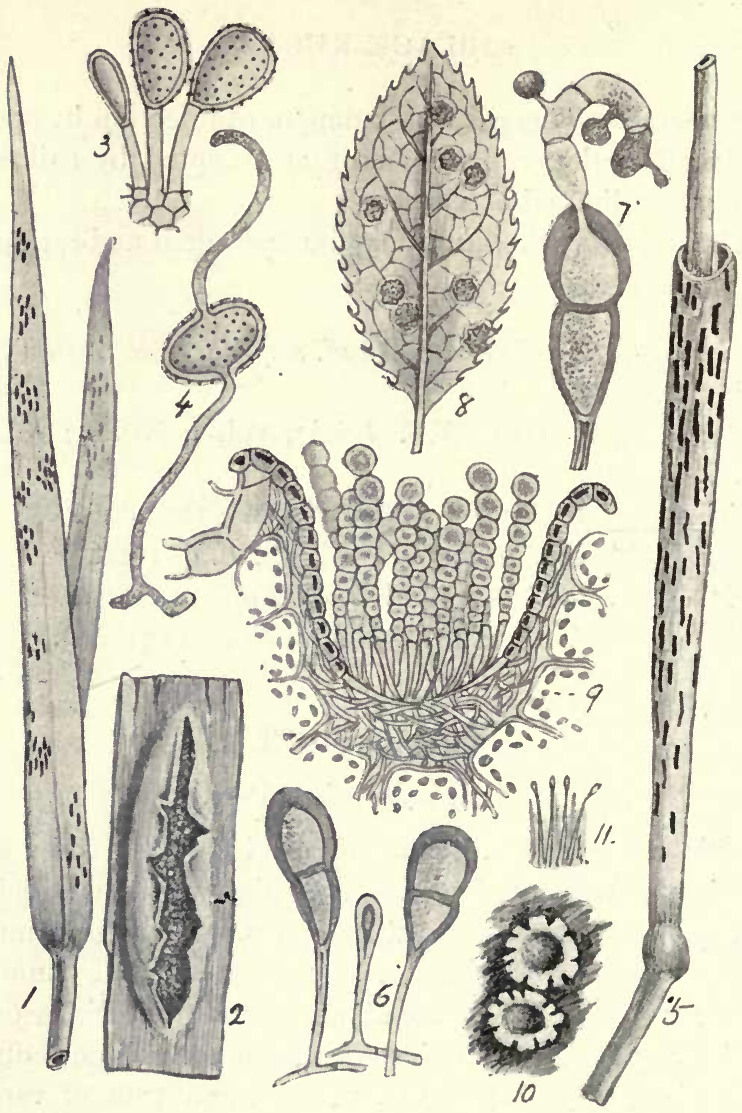

Fig. 63.-Puccinia graminis. I, leaves of wheat plant with rust pustules of the uredo stage ; 2 , a rust or uredo sorus, or group of spores, $\times$ Io ; 3 , uredospores in various stages of development, $\times 300 ; 4$, uredospore germinating, $\times 300 ; 5$, portion of culm of a wheat plant showing the dark streaks formed by the sori of the teleutospore stage on the sheath of a leaf; 6 , teleutospores in various stages of development, $\times 300 ; 7$, a teleutospore that has germinated and produced a germ-tube bearing three secondary spores, $\times 400 ; 8$, a barberry leaf bearing several clusters of aecidia ; 9 , section of an aecidium showing the pseudoperidium or external protective covering, $a$, enclosing numerous chains of aecidiospores, $\times 300$; Io, two aecidia seen from above, slightly mag. ; II, sporules on sterigmata from a spermogonium, $\times 300$. 


\section{CROWN RUST}

\section{(Puccinia coronata, Corda.)}

A widely distributed rust, characterised by the apex of the teleutospore being ornamented with a varying number of blunt projections. The aecidia form irregular yellow patches on the under surface of living leaves, also sometimes on the flowers and fruit of various species of buckthorn-Rhamnus.

The uredo and teleutospore stages occur on the upper surface of the leaves, less frequently on the leaf-sheath, culm, and chaff.

The minute black teleutospore sori often form irregular rings.

Met with on wheat, barley, rye, and many wild grasses.

Puccinia phlei-pratensis, Eriks. and Henn.-This species in a wild state occurs on Timothy grass-Phleum pratense - but artificial infection has proved that it can inoculate cultivated cereals. The aecidium stage is unknown.

Puccinia glumarum, Eriks. and Henn.=Puccinia rubigovera, D. C. - A widely distributed and destructive species, attacking wheat, barley, oats, and many wild grasses.

Aecidium stage unknown. Uredo and teleutospore conditions develop on the leaves and inner side of the chaff. Teleutospore sori accompanied by paraphyses.

Puccinia dispersa, Eriks. and Henn.-The aecidium forms irregularly elongated patches on living leaves, stems, flowers, and fruit of Alkanet-Anchusa arvensis and A. officinalis. Uredo and teleutospore stages on the leaves of wheat, rye, 
and wild grasses belonging to the genera Bromus, Trisetum, and Triticum. Paraphyses are present in the teleutospore sori.

Puccinia simplex, Eriks. and Henn.-Aecidium unknown. Uredo and teleutospore conditions on leaves of barley. Paraphyses are present in the teleutospore sori.

\section{CELERY LEAF RUST \\ (Puccinia bullata, Winter.)}

This fungus forms small warts on the leaves, which are brown when the spores rupture the epidermis and are exposed. It occurs on celery, parsley, and dill, also on various wild umbelliferous plants, and proves destructive when present in quantity.

Preventive Means.-Spraying with dilute Bordeaux mixture checks the spread. Diseased leaves should be cleared and burned.

Zimmermann, Atlas der Pfanzenkrankheiten, Heft 3 (I 886).

Smith, Gard. Chron., r886, Dec. I I, figs.

\section{SUNFLOWER RUST}

\section{(Puccinia tanaceti, D. C.)}

This rust forms brown pustules on the leaves of the common sunflower (Helianthus annuus), which are sometimes so abundant that the leaf is destroyed; and as all the leaves on a plant are usually attacked, the plant is prevented from producing fruit.

Preventive Means.-Repeated spraying with Bordeaux mixture holds the disease in check. 
The fungus grows on tansy (Tanacetum), and care should be taken that this host is not allowed to harbour the parasite in the neighbourhood of sunflowers.

\section{PLUM LEAF RUST \\ (Puccinia pruni, Pers.)}

This rust is very common on the leaves of cultivated plum-trees, cherry, peach, apricot, and almond, and occurs wherever these plants are cultivated. The aecidium stage is absent. The uredo and puccinia stages form small brown spots on the under surface of the leaves, and are
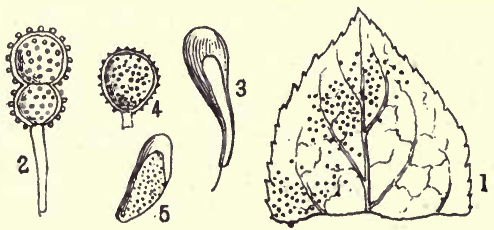

Fig. 64.-Puccinia pruni. I, portion of a diseased plum leaf; 2 , teleutospore, $\times 300$; 3 , paraphysis accompanying teleutospores, $\times 300 ; 4$, uredospore, $\times 300$; 5 , paraphysis accompanying uredospores, $\times 300$.

so abundant that they almost cover the entire surface. The uredospores are globose, brown, and minutely warted. The puccinia-spores or teleutospores consist of two superposed globose cells, the uppermost one usually largest, with a deep constriction where the two join, clear brown, and warted.

When the leaves are attacked they fall early, consequently the fruit is poor in quality, and the wood not sufficiently hardened to resist frost.

Preventive Means. - Spray with dilute Bordeaux 
mixture when the leaves are expanding, and again at intervals if the rust appears. Fallen diseased leaves should be thoroughly cleaned up and burned.

The fungus is often common on the leaves of the blackthorn, and care should be taken not to allow this plant to act as a nurse to the fungus, and thus constitute a centre of infection.

Prillieux, Malad. des Plantes Agric., vol. i. p. 24 I.

\section{HOLLYHOCK RUST}

\section{(Puccinia malvacearum, Mont.)}

This rust is a native of Chili, and first appeared as a pest in Australia, soon afterwards entering Europe through France, and at the present day is to be met with wherever the hollyhock is cultivated, and in addition having victimised the wild mallows and allied plants during its distribution. This disease, at the time of its first appearance, rendered almost impossible the successful cultivation of the hollyhock; but with the progress made during recent years in the methods of arresting plant diseases, it can now be cultivated with success.

The teleutospore phase is the only one formed, and this appears on the leaves under the form of minute, hard, pale brown warts; in many instances the stem, also the calyx and fruit, are studded with pustules. These teleutospores germinate without a period of rest, the secondary spores produced continuing the disease. It has been stated that the teleutospores formed late in the season act as resting-spores, not germinating until the following season.

Preventive Means.-Spraying with Bordeaux mixture 
is effective. I have ascertained that - without sprayingwhen first year plants are diseased, if the fading leaves are collected, the plants are not diseased the second season, whereas if the leaves are allowed to decay on the ground under the plants, they are invariably attacked the second season; an observation tending to prove that resting-spores survive the winter and germinate the following spring. I have also ascertained that when the carpels are attacked by the fruit, the seeds produce diseased seedlings, the cotyledons usually bearing pustules.

\section{PINK RUST}

\section{(Puccinia arenariae, Wint.)}

During certain seasons this fungus proves very destructive to pinks and carnations. Teleutospores only are produced, the small blackish spots being scattered or arranged in circles on the under surface of the leaves and the stem. The spores germinate quickly when mature, hence the disease spreads rapidly.

Preventive Means. - Dilute Bordeaux mixture has proved effective. I have also seen the disease checked by sponging with a rose-red solution of potassium permanganate. The fungus is very common on many wild Caryophyllaceous plants, as chickweed, stitchwort, lychnis, spurrey, etc.; therefore all such should be kept aloof from cultivated plants.

\section{HAWTHORN CLUSTER-CUPS}

(Gymnosporangium clavariaeforme, Jacq.)

This destructive parasite is a typical representative of the group of fungi called Uredineae, the members of which 
not only present a very dissimilar appearance, but also grow as parasites on different plants at different periods during the completion of their life-cycle. The fungus under consideration causes spindle-shaped swellings on the branches of Juniperus communis, and during the months of April and May numerous flattened, gelatinous masses of a pale orange colour, and about half an inch in length, ooze out of these swollen places. The gelatinous outgrowths consist of myriads of reproductive bodies called teleutospores, imbedded in mucilage. When the teleutospores are mature, they commence to germinate at once, without falling away.

Each spore produces two long, slender branches or germ-tubes, each of which bears two or three very minute secondary spores near its tip. The mycelium of the fungus is perennial in the juniper branches ; consequently, when a branch is once infected, a crop of spores is produced each spring, the diseased patch becoming larger each succeeding year, as the mycelium spreads in the branch. This is as far as the development of the fungus proceeds on the juniper. The minute secondary spores, when mature, are scattered by wind, insects, etc., and those that happen to alight on the damp surface of a living leaf, young shoot, or fruit of the hawthorn, or on the leaves of the pear or the whitebeam, germinate at once, the germ-tube enters the tissue of the living leaf, and in about three weeks' time from the period of inoculation produces the second form of fruit of the fungus, known as the aecidium stage, which bursts through the tissue of the leaf under the form of clusters of minute, horn-shaped bodies. These bodies are hollow, open, and slightly fringed at the tip, and are filled with minute round bodies capable of germination, called aecidiospores. Finally, the aecidiospores only germinate 
and form a mycelium on branches of juniper, where they give origin to the first or teleutospore stage of the fungus.

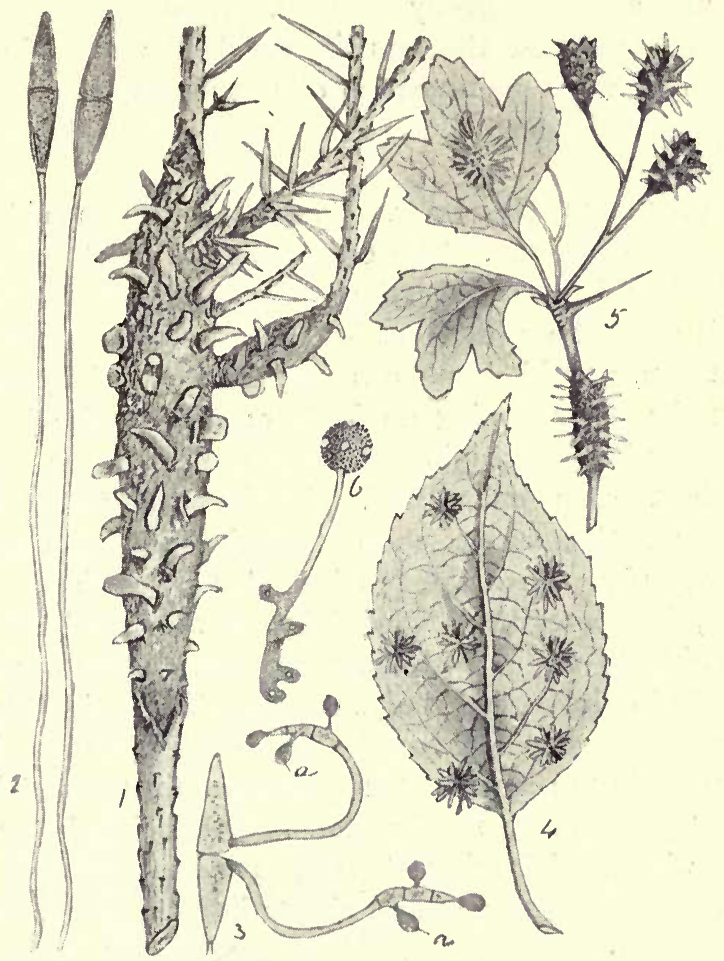

Fig. 65.-Gymnosporangium clavariaeforme. I, teleutospore stage on branch of juniper; 2 , teleutospores, $\times 300 ; 3$, teleutospores germinating and producing secondary spores $a a, \times 300$; 4 , aecidium stage on pear leaf; 5 , aecidium stage on branch, leaves, and fruit of hawthorn ; 6, aecidiospore germinating, $\times 300$.

The aecidium stage of the fungus is often very injurious to nursery stock, frequently nearly every leaf on the tree being 
attacked, the consequence being that the leaves fall quite early in the season, and the new growth is small in quantity and imperfectly matured. In the case of fullgrown pear trees, the loss of the leaves early in the season prevents the formation of a good supply of reserve material, and consequently a poor crop of fruit the following season.

Preventive Measures.-Spraying with fungicides is of no practical use. The one important point to clearly understand is the fact that the fungus produces two different kinds of fruit on different host-plants. The plum tree, hawthorn, or whitebeam can only be infected by spores from the stage growing on juniper; whereas the juniper can only be infected by aecidiospores formed on one of the host-plants enumerated. Abolish one of the hostplants and the mischief ends. Infection has been known to take place when the two host-plants were half a mile apart, the spores being carried by the wind. When it is desirable to retain both trees concerned, then spare no trouble in discovering the juniper producing the teleutospores, the gelatinous orange masses being quite conspicuous in the spring. The most certain method is to completely remove the infected branches, if this can be done without disfiguring the tree, as the mycelium of the fungus is perennial and extends far into the wood, and is with difficulty destroyed. If it is not desirable to cut out the diseased juniper branches, remove the bark from the diseased portion, wash with a strong solution of sulphate of copper or corrosive sublimate, and afterwards cover the wound with grafting wax, or paint over with tar. Even after this treatment a strict watch should be kept on the branches each spring, otherwise the mycelium present in 
the branch might extend and produce fruit beyond the portion treated.

The preventive treatment for arresting the ravages of the species of Gymnosporangium described hereafter is identical with that given above, some species of juniper being in every instance one of the two host-plants upon which the fungus lives and produces its teleutospores.

Plowright, Brit. Ured. and Ustilag., p. 233.

\section{PEAR LEAF CLUSTER-CUPS}

(Gymnosporangium sabinae, Winter.)

The teleutospore condition of this fungus grows on Juniperus communis, J. oxycedrus, J. virginiana, and J.phoenicea. The gelatinous masses of spores are formed in the spring, and are flattened and about half an inch in length, blackish at first, then reddish-brown. So far as at present known, the aecidium stage grows only on living pear leaves. The aecidiospores in turn germinate on young leaves of the juniper, from whence the mycelium passes into the branch, where it forms a perennial mycelium, from which a crop of teleutospores is produced every spring.

Plowright, Brit. Ured. and Ustilag., p. 230.

Prillieux, Malad. des Plantes Agric., vol. i. p. 258.

Fischer, Zeitschr. f. Pflanzenkr., vol. i. pp. 193 and 283.

\section{MEDLAR CLUSTER-CUPS}

(Gymnosporangium confusum, Plowr.)

This fungus closely resembles in general appearance and structure Gymnosporangium sabinae, but differs in its lifehistory. The secondary spores will not germinate and 
produce the aecidium condition on pear leaves, but do so readily on leaves of the medlar, quince, and hawthorn. The aecidia, or cluster-cups, are cylindrical and soon split into shreds; they appear on roundish, thickened, orange spots, which are often bounded by a reddish or purple line.

Plowright, Brit. Ured. and Ustilag., p. 232.

Fischer, Zeitschr.f. Pfanzenkr., vol. i. pp. 193 and 283.

\section{MOUNTAIN ASH CLUSTER-CUPS}

(Gymnosporangium juniperinum, Winter.)

This is the fourth species having its teleutospore stage parasitic on Juniperus communis and $J$. nanus. It is recognised by the subglobose shape of the soft, gelatinous spore-masses formed in spring, which are dark brown at first, changing to orange at maturity. The aecidium stage grows on living leaves of the mountain ash, and is also said to have been found on apple leaves. The aecidia are cylindrical and curved, soon becoming torn into shreds at the tip. They occur in small clusters on orange-red, roundish spots.

Plowright, Brit. Ured. and Ustilag., p. 235.

\section{RASPBERRY RUST}

(Phragmidium rubi-idaei, Winter.)

This fungus produces its three forms of fruit on the same host-plant. The aecidium stage is the first to appear, and may be found in June under the form of small yellow or greenish-yellow pustules, usually arranged in circles on the 
upper surface of the leaves, less frequently forming elongated patches on the leaf stalks or stems. Next follows the uredo stage, which differs but little from the aecidium as seen with the naked eye; the pustules are small, pale orange,
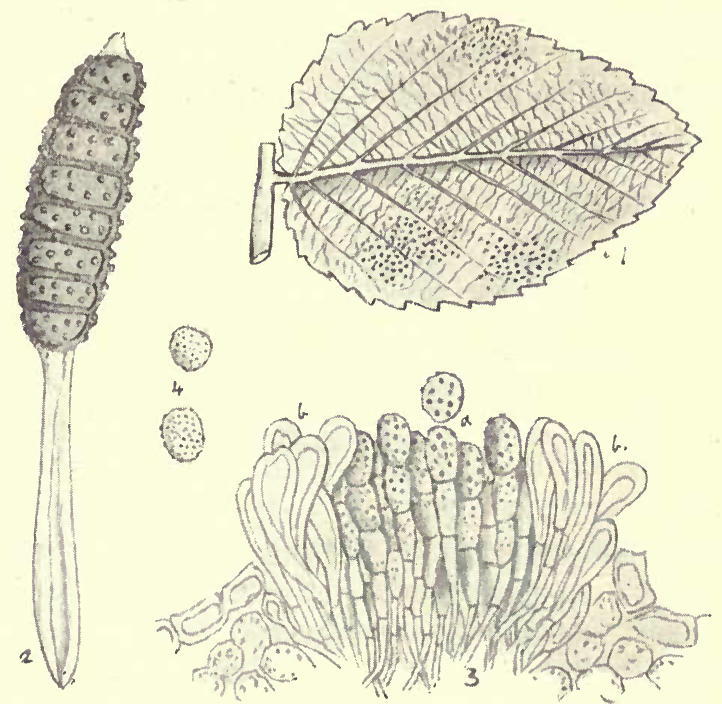

Fig. 66.-Phragmidium rubi-idaei. I, under surface of a raspberry leaflet showing pustules of teleutospores ; 2 , teleutospore, $\times 350 ; 3$, section through an aecidium; $a$, chains of warted spores; $b, b$, large club-shaped sterile cells forming the covering of the aecidium, $\times 300 ; 4$, uredospores, $\times 300$.

and scattered, not arranged in circles. Later in the season, the numerous small black clusters of teleutospores are produced on the under surface of the leaves.

The teleutospores are very beautiful objects seen under the microscope, each spore consisting of a single row of 
seven to ten cells, dark brown, and minutely warted; stalk long, colourless, swollen near the free end.

Preventive Means.- Spraying with potassium sulphide solution checks the extension of the rust. If Bordeaux mixture is used it should be very much diluted, otherwise the foliage will be injured. If the disease has run its course, the fallen leaves should be gathered and burned to prevent a recurrence of the disease.

Prillieux, Malad. des Plantes Agric., vol. i. p. 25 I.

\section{ROSE RUST}

\section{(Phragmidium subcorticatum, Winter.)}

A troublesome pest to cultivators of roses, attacking more especially hardy hybrid varieties. All three forms of the fungus are produced on the same host. The aecidia appear in late spring on the leaves and young shoots, forming powdery, orange patches, and often cause distortion of the shoots. About midsummer the patches become deeper in colour, owing to the formation of uredospores. Finally the teleutospores or resting-spores are produced as minute black dots on the under surface of the leaves.

Preventive Means.-The appearance of the disease in spring depends entirely on the presence of teleutospores in the neighbourhood; it is therefore necessary to collect and burn all fallen leaves in the autumn. Plants that have been attacked the previous season should be thoroughly drenched with a solution of sulphate of copper in water -2 ounces in 3 gallons -in early spring before the buds expand. The soil round the plants may also be sprayed with the same solution. Dilute Bordeaux mixture, or ammoniated car- 
bonate of copper solution checks the aecidium and uredo stages.

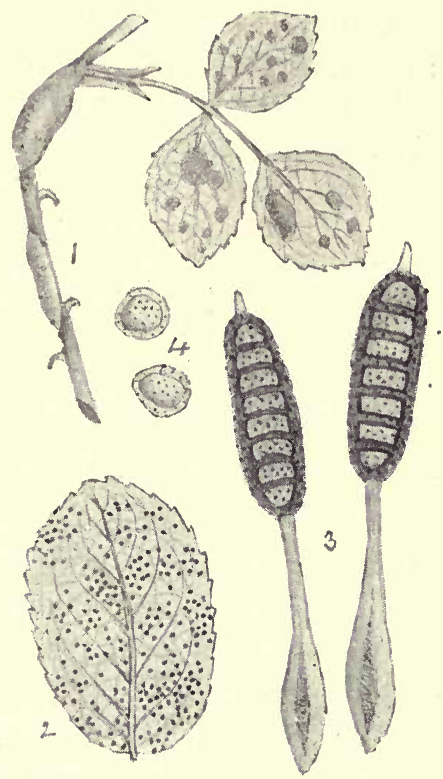

Fig. 67.-Phragmidium subcorticatum. I, rose branch and leaves infected with aecidium stage of disease; 2 , leaf with clusters of teleutospores; 3 , teleutospores, $\times 300$; 4 , uredospores, $\times 300$.

The fungus also grows on wild roses, and these may become a source of infection unless precautions are taken.

\section{PINE CLUSTER-CUPS}

(Coleosporium senecionis, Fries.

$$
\text { =Peridermium pini, Wallr.) }
$$

One of the heteroecious parasites, the uredo and teleutospore stages forming orange patches on the under surface 
of living leaves of groundsel (Senecio vulgaris), ragwort (Senecio jacobea), and various other species of Senecio. The aecidia are of two forms, one cylindrical and slender, formed on the leaves; the other much larger and inflated, growing in crevices of the bark of Pinus silvestris, $P$. maritima, $P$. insignis, and $P$. strobus.

Preventive Means.-The injury done is slight, mostly amounting to a discoloration of the leaves, which, however, do not fall before the normal time. The removal of species of Senecio from the neighbourhood arrests the disease.

\section{RHODODENDRON RUST}

(Chry'somyxa rhododendri, De Bary.)

This fungus is heteroecious, the uredo and teleutospore stages occurring as small pustules on the leaves of species of Rhododendron, $R$. hirsutum, and others; whereas the aecidium stage grows on the young shoots and leaves of the spruce. Yellow spots appear on the spruce leaves, and about August the spermogonia of the fungus appears on these spots; at a later period numerous peridia are produced, and contain such a quantity of spores that when a diseased tree is shaken the air is filled with a dense cloud of spores. Diseased leaves die and fall the same season.

In the present genus the teleutospores consist of a row of superposed cells. Not a dangerous parasite. The removal of either of the hosts from the vicinity of each other checks the disease.

De Bary, Bot. Ztg., I 879.

Hartig and Somerville, Diseases of Trees, p. I.77. 
Chrysomyxa abietis, Unger.-The teleutospore condition is alone known, forming pale yellow spots on spruce leaves. The formation of teleutospore pustules commences during the year of infection, reaches a certain stage of development, and passes into a resting condition until the following season, when the development is completed, the teleutospores germinating in situ during the month of May, when the secondary spores produced are conveyed to young larch leaves, which become infected. Hartig states that as a rule little injury is caused by the parasite.

\section{PINE CONE FUNGUS}

\section{(Aecidium strobilinum, Reess.)}

The aecidia are formed on the inner surface of the carpellary scales or bracts of cones of the Norway spruce (Abies excelsa); a few aecidia also sometimes develop on the outer surface of the scales. The mycelium of the fungus destroys the inflorescence. The aecidia are subglobose, or often angular from lateral pressure when crowded, brown, and opening by an irregular crack.

Hartig states that the diseased fallen cones can be readily distinguished by opening even in damp weather, under which condition sound cones remain closed.

Reess, Die Rostpilzformen der Deutschen Coniferen, p. Iоo.

Aecidium pseudo-columnare, Kühn. - The elongated aecidia grow in two rows on the under surface of the leaves of Abies pectinata and other species of Abies.

Aecidium magelhaenicum, Berk.-Grows on species of Berberis. The perennial mycelium distorts the buds of the host, and causes the formation of 'witches' brooms.' 
Aecidium esculentum, Barcl.-The young shoots of Acacia eburnea are, in India, distorted and rendered succulent by the action of this fungus, and such are used as food.

Aecidium ornamentale, Kalchbr.-This aecidium sometimes appears in enormous numbers on branches and spines of Acacia horrida, at the Cape of Good Hope. The entire structure and general appearance is completely altered, the branches forming fantastic curves.

Peridermium harknessi, Moore $=P$. filamentosum, Peck. -The following account accompanied specimens of this fungus, sent to Kew to Dr. Harkness, from Sacramente, California :-

'Fungus found growing upon Pinus ponderosa, Dougl., up the Sierra Nevada mountains. It attacks the young tree trunks, and arrests further growth.'

In all the specimens I have had an opportunity of examining, the fungus has first attacked the stem when two or three years of age, and in one instance had continued to grow year by year until the tree was thirteen years of age, when the specimen had been collected. During this period of growth, the fungus had caused the stem at the point of attack to assume a barrel shape, four inches long, and three inches in diameter. The stem just below the swelling was one and a half inches across.

The fungus also attacks the following North American trees: Pinus insignis, Dougl., P. sabiniana, Dougl., P. contorta, Dougl.

Peridermium pini, Wallr. - A well-known parasite, attacking various pines in Europe and the United States. The mycelium is perennial in the bark, bast, and wood, and continues to extend year by year. As a rule the cambium is not destroyed all round the branch at one 
point, therefore it continues to grow and yields very eccentric sections, owing to growth being checked by

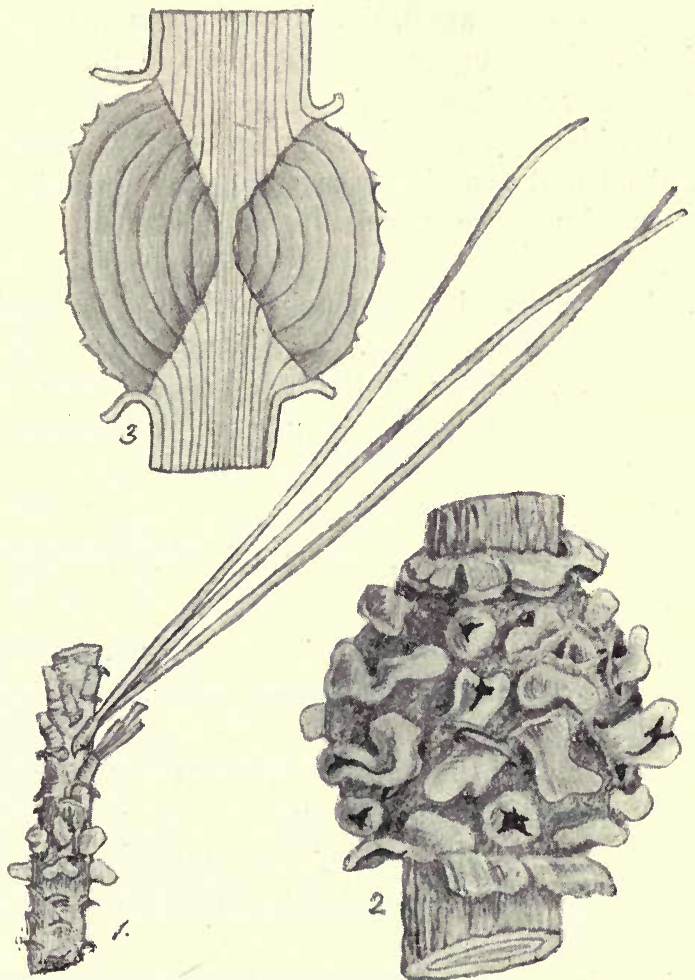

Fig. 68.-Peridermium harknessi. I, young stem of Pinus ponderosa, three years old, showing the Peridermium, two-thirds nat. size; 2 , appearance of a stem eight years old, attacked by the fungus, the swollen portion being thickly studded with aecidia, two-thirds nat. size; 3 , section through No. 2, the shaded portion indicates the darkened portion of wood containing mycelium of the fungus, two-thirds nat. size.

destruction of the cambium on different sides at different levels. Cells attacked by haustoria lose their contents 
and afterwards secrete turpentine in considerable quantity, which escapes through cracks in the bark. As the disease encroaches on the wood, the upward passage of water is checked, and the upper branches die, and are known as 'resin top' or ' resin leader.'

The aecidia appear in late spring, bursting through the outer dead cortex as irregularly shaped, pale yellow sacs, which open by an irregular fissure, and liberate the powdery spores.

Hartig considers that the trunk cannot be infected after the age of twenty-five years. How inoculation is effected is not known, neither is the teleutospore form of the fungus; consequently the only remedial measure that can be suggested is the removal of diseased trees.

Hartig, Wichtige Krankh. d. Waldbäumen.

Tubeuf and Smith, Diseases of Plants (Engl. ed.), p. 4Ir, figs.

Peridermium coruscans, Fr.-This fungus is common on spruces in Northern Europe, and I have seen it on Abies pinsapo in England. The whole of the leaves on a young shoot are attacked, becoming shorter and succulent, and such branches are eaten in Sweden.

The peridia usually occupy the whole length of the leaf, rupturing irregularly and exposing the bright yellow, powdery spores.

Peridermium conorum, Thum. = Aecidium conorum-piceae, Reess.-The aecidia are large, appearing on the outer surface of cone bracts of the spruce, few in number (but not constantly two).

Peridermium elatinum, Wallr.-This species grows on silver firs, forming cankered swellings on the trunk and 
branches. From these swollen spots abnormal branches, 'witches' brooms,' often spring, and are readily recognised at a distance by growing quite erect, and in the much smaller yellowish leaves which fall off about the end of August, the 'witches' broom' being deciduous.

Aecidia are only formed on the 'witches' broom' leaves, and not on the swollen portions of the branch, as in other species.

The bark is ruptured and thrown off at the cankered swellings, which consequently often serve as a startingpoint for wound-parasites, especially Polyporus hartigii and Flammula adiposa.

Hartig and Somerville, Diseases of Trees (Engl. ed.), p. 17 , figs.

Peridermium cerebrum, Peck. - Forms barrel-shaped swellings on the trunk of Pinus ponderosus, Dougl., in America.

Peridermium siganteum, Mayr. - Also forms barrelshaped swellings on the trunk of Pinus densiflora, Sieb. and Zacc., and P. thunberyii, Parl., in Japan.

Peridermium thomsoni, Berk. = Aecidium thomsoni, Berk., Gard. Chron., I852, p. 627, with fig.-Forms large, elongated aecidia on the leaves of Picea morunda, Link., in Sikkim.

Peridermium orientale, Cooke.-Also an Indian species from the neighbourhood of Simla, growing on leaves of Pinus longifolia and $P$. excelsa. The American forms referred to this species are distinct.

Several other species of Peridermium are parasitic on the bark or leaves of conifers. 


\section{VINE LEAF RUST}

(Uredo vitis, Thumen.

= Uredo vialae, Lagerh.)

This fungus forms small, yellowish, powdery pustules on cultivated vine leaves, and has been recorded from the United States and some of the West Indian Islands.

Preventive Means.-The parasite has hitherto occurred in small quantity, and little or no injury done. Spraying with a fungicide would probably check its spread, if inclined to be troublesome.

Lagerheim, Compt. Rend., 1890, p. 728.

Massee, Grevillea, vol. xxi. p. I 99 (1893).

\section{CANNA DISEASE}

\section{(Uredo cannae, Winter.)}

A destructive pest to cultivated cannas in the West Indies and other parts of the New World, but has not yet been recorded as doing damage in Europe.

The fungus forms numerous small, orange-coloured spots on the leaves, which become discoloured and die in consequence. The summer spores enable the disease to spread rapidly when once present. Destroying diseased leaves is to be recommended, also spraying with a fungicide.

\section{SPHAEROPSIDIACEAE}

\section{Australian 'Shot-Hole Fungus'}

(Phyllosticta prunicola, Sacc.)

This fungus attacks living leaves of apple, pear, plum, cherry, apricot, etc. Small brownish spots first appear on 
the upper surface of the leaves, which become dry and brittle, and eventually drop out, giving to the leaf the appearance of having been riddled with small shot. Tiny perithecia are produced on the diseased portions. It has been suggested that the present fungus is a stage of Leptosphaeria pomona, Sacc.

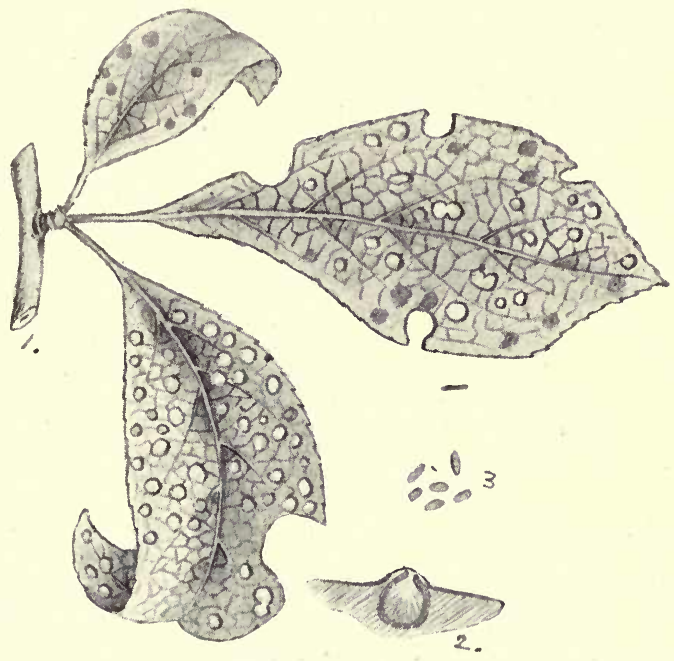

Fig. 69.-Phyllosticta prunicola. I, apple leaves showing the holes formed by the falling away of portions of the tissue killed by the fungus; 2 , section through a perithecium imbedded in the substance of the leaf, $\times 18 ; 3$, spores, $\times 300$.

Preventive Mrans. - Not very destructive, unless especially numerous on the leaves, when spraying with dilute Bordeaux mixture is recommended.

Superficially resembles the 'shot-hole fungus'-Cercospora circumscissa, - but the fruit is very different. 


\section{CELERY LEAF SPOT (Phyllosticta apii, Hals.)}

Dr. Halsted discovered this disease on celery in the United States. It differs from Cercospora apii in the spots on the leaf being dull brown, never pale coloured.

It is described and figured in the $N$. Jersey Agric. Expt. Station Report, 189i, p. 253.

Septoria petroselini, Desm., Var. Apii, B. and C.-Causes celery leaves to become brown and studded with small black dots over the entire surface.

\section{CARROT DISEASE}

\section{(Phoma sanguinolenta, Rostr.)}

Forming greyish-brown, sunken, cankerlike spots on the root; the mycelium during subsequent growth extends into the stem, where depressed areas are formed which prevent the umbel from being fully developed, hence no seed is produced. Numerous minute, dark-coloured perithecia are present on the diseased patches, the conidia escaping in long, flesh-red or blood-red strings or tendrils; a character by which this fungus can be readily distinguished.

Preventive Means.- It is useless planting diseased roots with the object of procuring seed, as the bloom is always destroyed. Great care should be exercised in storing not to include diseased carrots, otherwise the pest spreads by contact. 
Rostrup, Zeitschrift für Pfanzenkrankh., 1894, p. 195, pl. iv.

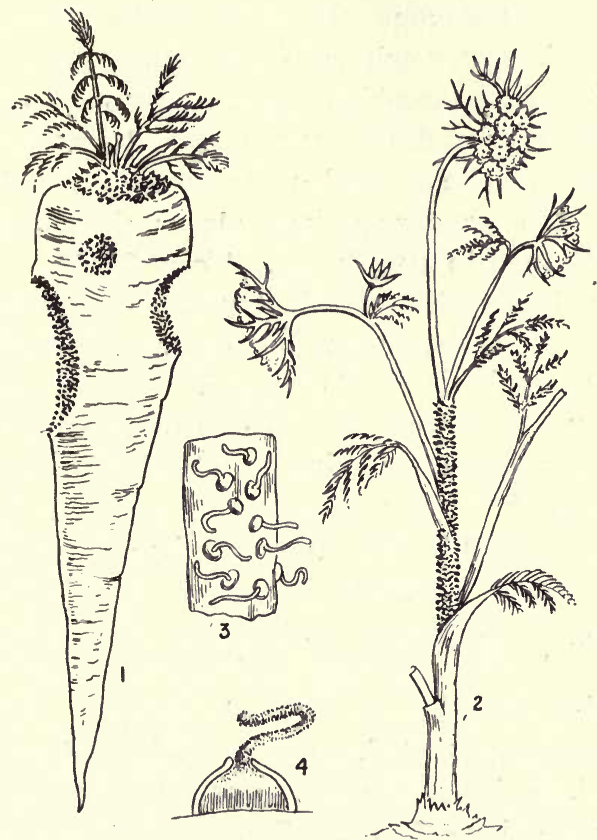

Fig. 70.-Phoma sanguinolenta. I, a diseased carrot root ; 2, a diseased carrot stem ; 3, portion of a disease spot, showing perithecia with the conidia escaping in the form of a mucilaginous tendril, slightly mag. ; 4, section of a perithecium with the conidia oozing out in a tendril, highly mag.(Zeitschr. für Pfanzenkr.)

\section{SQUIRT BERRY}

\section{(Phoma tuberculata, M'Alp.)}

An Australian grape disease, described by Professor M'Alpine of the Victoria Department of Agriculture. 
The fruit is the part attacked, and when gently pressed between finger and thumb readily squirts out its contents, hence the popular name adopted. Berries attacked show at first a circular patch from ashy-grey to slaty-blue in colour, dotted and speckled with very numerous gregarious and confluent tubercles or pustules, for a long time covered by epidermis. The affected surface usually occupies about a third of the grape, sometimes almost the whole, and is somewhat rough in appearance. Towards the end of the season the berries dry partially, but are always pliable.

The stroma of the fungus is more or less columnar, and bears the perithecia on its surface. Conidia, oblong or oval, minute. Various other forms of vegetative bodies, supposed by the author to be reproductive in function, are produced on the stroma.

No experiments relating to preventive means have been tried.

M'Alpine, Add. to Fungi on the Vine in Australia, p. 23, pl. iv.

Phoma solani, Halsted.-Dr. Halsted has described and illustrated, in the $N$. Jersey Agric. Expt. Station Report, r89 r, a 'damping off' of seedling egg-plants caused by a Phoma. The disease attacks the seedlings at the base of the stem, the fruit of the fungus appearing as exceedingly minute black dots on the diseased parts.

Phoma hennebergii, Kuhn.-Often proves very destructive to the wheat crop, attacking the glumes and causing the ears to shrivel. The fungus sometimes also appears on the leaves.

Frank, Zeitsch. für Pflanzenkr., vol. iii. 1893, p. 28. 


\section{ONION SCAB}

\section{(Vermicularia circinans, Berk.)}

This is an erratic parasite, being very abundant during certain seasons, and entirely absent at others. As a rule but little injury is done to the bulbs, which are the only part attacked, so long as they remain in the ground; nevertheless the unsightly black blotches on the outermost scales considerably reduce their market value.

The fungus usually appears when the bulbs are nearly full-grown, under the form of scattered black patches, formed of minute black, velvety tufts, arranged in concentric circles, or irregular, wavy lines. If one of these mature velvety tufts is examined under the microscope, it is found to consist of myriads of erect threads, each bearing a long, slender, slightly curved, colourless spore at its tip, and in addition the tuft is thickly studded with long, black, projecting spines, which give to it the velvety appearance when seen through a pocket-lens.

Preventive Means.-Bulbs showing the least signs of the disease should not be mixed with healthy ones, and the bulbs should be thoroughly dry before storing, otherwise the disease will spread quickly; as, notwithstanding great care, a few very slightly tainted bulbs are liable to be passed; and if there is the least indication of sweating, the resulting moisture and heat greatly facilitate the growth of the fungus, which often spreads with startling rapidity. Diseased bulbs should not be allowed to decay on the ground, but should be carefully collected and burned, otherwise the spores remain in the soil for some time in a condition ready for germinating; and it must be borne in mind it is only necessary that a single onion should be 
inoculated, to secure for the fungus a foothold from which it can attack neighbouring plants, and, in the course of the season, victimise most or all the plants in the neighbourhood.

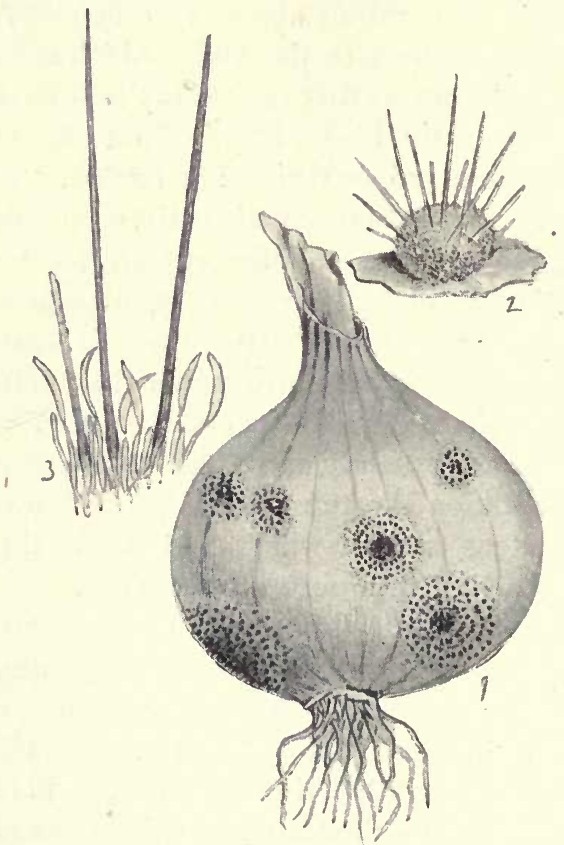

Fig. 71.-Vermicularia circinans. I, onion attacked by Vermicularia; 2, one of the black tufts of the fungus, $\times 50 ; 3$, portion of a tuft showing the curved conidia borne at the tips of slender threads or conidiophores, also the long black spines, $\times 250$.

Berkeley, Gard. Chron., I851, p. 595, figs. Stoneman, Bot. Gaz., I898, p. 98, fig. r6. 


\section{GIRDLING OF SILVER FIR}

\section{(Fusicoccum abietinum, Sacc. = Phoma abietina, Hartig.)}

Hartig called attention to a disease of the silver fir, which, although previously undescribed, is very common in the Bavarian Forest, Black Forest, etc. The disease is characterised by usually killing the bark all the way round both small and large branches. If the bark is only killed on one side of the branch, it is shed, and a callus forms along the uninjured margin.

Numerous minute black stromata containing cavities bearing small fusiform conidia are developed in the dead cortex, and rupturing the tissues appear on its surface.

Hartig and Somerville, Diseases of Trees, p. 138, figs. Prillieux, Malad. des Plantes Agric., vol. i. p. 285 , figs. Mer., Journ. de Bot., I893, p. $3^{64}$.

\section{PEA SPOT}

\section{(Ascochyta pisi, Libert.)}

Sometimes injurious to cultivated peas (Pisum sativum), haricot beans (Phaseolus vulgaris), and species of Vicia, and Cercis. Pale spots are formed on the pods which cause them to become stunted and deformed. The leaves and stem are also attacked.

Preventive Means.-None recorded. Probably spray- 
ing with Bordeaux mixture would prove beneficial. Diseased portions should be burned.

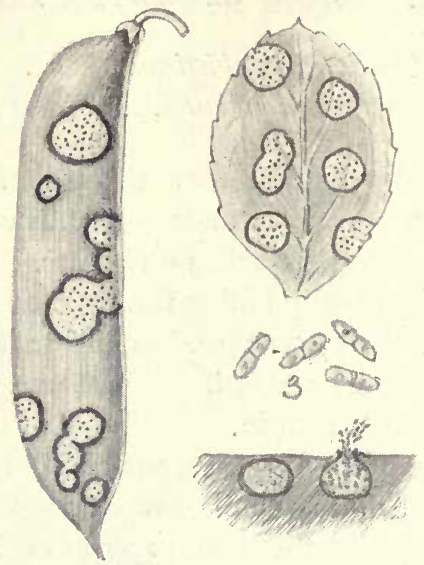

Fig. 72.-Ascochyta pisi. I, pod and leaflet of garden pea diseased; 2 , section through two conceptacles of the fungus, slightly mag. ; 3 , conidia, $\times 300$.

\section{LEAF SCALD}

(Entomosporium maculatum, Lév.)

A very destructive fungus to pear, apple, peach, quince, cherry, and other rosaceous fruit-trees. Diseased leaves fall early in the year, and as all the leaves on a tree are usually attacked, defoliation results; not unfrequently a second growth of leaves takes place, and these suffer in the same way, consequently the tree is much weakened, and in the case of nursery stock the trees are frequently killed outright, or are so enfeebled that grafting becomes a difficult matter. In bad cases the fungus also attacks the 
young shoots, and has been considered as causing the spottiness and cracking of fruit, pears more especially. Small red spots appear on the upper surface of leaves when still young; these increase in size and become brown, having one or more minute black spots-the fruit of the fungus-slightly projecting above the general surface. If the spots are numerous, as is usually the case, and the leaf

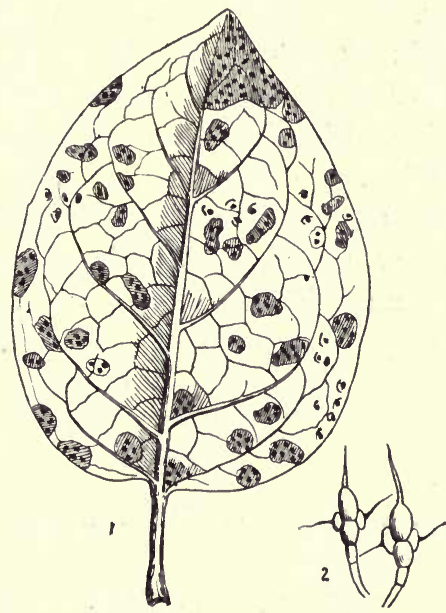

Fig. 73.-Entomosporium maculatum. I, quince leaf diseased ; 2 , spores of the fungus, $\times 300$.

young, it becomes altogether brown, shrivels, and falls off. If the leaf is older, with rigid tissues, it retains its shape, but falls to the ground. The spores, as shown in the accompanying figure, have a very characteristic shape. On the branches the spots are at first reddish and circular, elongating, becoming slightly sunken with a central elevation, and blackish in colour; these often coalesce to form 
irregular patches encircling the branch, in which case the portion above the diseased area dies.

Dr. Sorauer considers that an ascigerous fungus, called by him Stigmatea mespili, which occurs on the diseased spots on fallen leaves previously occupied by the Entomosporium, is really the higher condition of that fungus; this idea has not, however, as yet been corroborated by cultures.

Preventive Means.-Spraying with Bordeaux mixture holds the disease completely in check; the first spraying should be applied, using a very dilute solution, as the leaves are expanding.

Dead leaves should be collected and burned. Diseased branches should be removed, as it is probable that the disease first originates as an epidemic in the spring, from spores produced by the mycelium permanent in the branches.

Léveille, Bull. Soc. Bot. France, vol. iii. p. 3 I.

Sorauer, Handb. der Pfanzenkrankheiten, vol. i. p. 372, pl. xvi., figs. 6-9.

Galloway, Rep. Commiss. Agric. U.S., r 889 , p. 357, pl. viii., ix.

Entomosporium thumeni, Sacc.-Somewhat similar in appearance to $E$. maculatum; occurs on living leaves of species of Crataegus.

\section{MELANCONIACEAE}

Grape Rot

(Gloeosporium ampelophagum, Sacc.)

This minute fungus is one of the scourges of European vineyards, where its ravages have repeatedly proved most disastrous. In Britain, however, it is not common, and 
with the exercise of ordinary intelligence and care can be readily stamped out when it occurs, as but comparatively few vines have to be dealt with in any one locality. Since

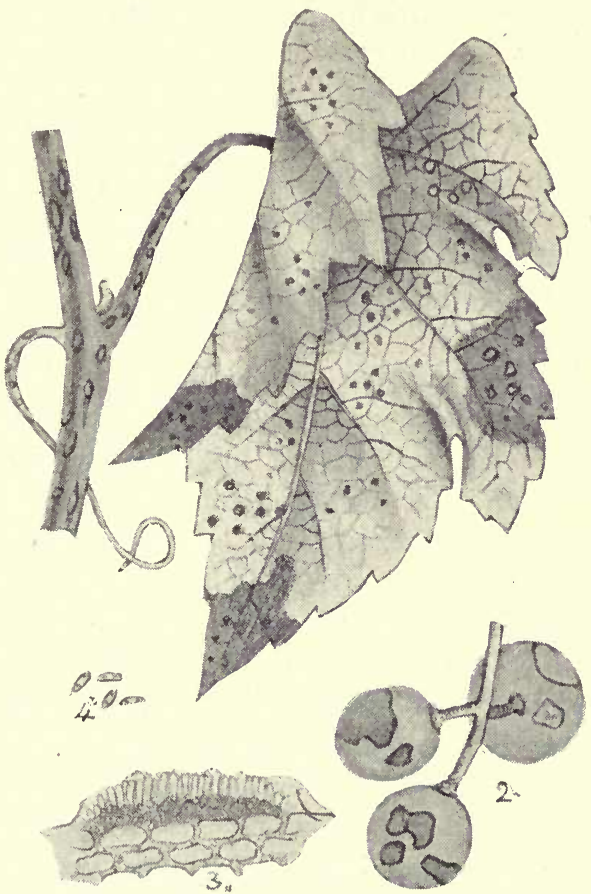

Fig. 74.-Gloeosporium ampelophagum. I, appearance of the disease on the leaves, stem, and tendrils of the vine; 2, diseased grapes; 3 , section through a fruit pustule formed on a young grape, $\times 300 ; 4$, conidia, $\times 400$.

I $88 \mathrm{I}$ it has also caused considerable anxiety and loss to American viticulturalists, having in all probability been imported to that country from Europe. 
The young shoots, leaves, and fruit are attacked, the disease often appearing in the spring and continuing till the cessation of active growth of the host. On the leaves the fungus forms small, irregularly scattered, greyish spots, bordered by a dark line; sometimes the central portion of the spots becomes dry, brittle, and eventually falls out, forming holes in the leaf. On the young shoots, tendrils, and leaf-stalks the spots at first resemble those on the leaves, but soon become elongated; the central portion sinks owing to the decay of the tissues, the bark and under- lying wood, sometimes down to the pith, being destroyed by the fungus. The spots on the fruit usually retain a circular outline and become larger than those on the leaves, and not unfrequently run into each other, forming irregular blotches, and have a bright red ring inside the blackish border, hence the American name, 'Bird's-eye rot.'

The growth of diseased fruit is arrested, and finally it shrinks and dries up, still remaining hanging. As a rule all the grapes in a cluster become diseased, one infecting another. The grey central portion of the patch becomes studded with black points when mature, which when examined under the microscope are seen to consist of dense tufts of upright, slender branches or conidiophores, each bearing a minute, colourless conidium at its tip.

These conidia germinate quickly in water, and are washed by rain and dew, or carried by insects or birds from one tree to another, and thus spread the disease.

Preventive Means. - This disease is undoubtedly very difficult to combat successfully. Dredging with flowers of sulphur may be practised on the shoots and leaves, repeating at intervals of ten days if the disease continues to spread. A small quantity of quicklime should be mixed 
with the sulphur on the second application, and the quantity of lime should be increased on each successive application, until the proportions of lime and sulphur are nearly equal, always keeping just a little more sulphur than lime. It has been found of service to thoroughly wet the branches with a solution of sulphate of iron when the vine is resting.

The use of rich stable manure is stated to make vines more susceptible to this disease.

Diseased leaves and shoots should be collected and burned, and diseased fruit should also be removed as speedily as possible.

Viala, Malad. de la Vigne, ed. iii. p. 204, pl. v. and figs. Arcangeli, Nuovo Giorn. Bot. Ital. vol. ix. p. 74, pl. ii.

Massee, Gard. Chron., Feb. 2, 1895, figs.

\section{APPLE ROT}

(Gloeosporium fructigenum, Berk.)

This disease, first investigated by Berkeley, is very destructive to ripe apples, causing the too familiar brown, sunken patches, the diseased portion having a very bitter taste.

The disease usually first appears as minute spots when the fruit is about half-grown, and continues to enlarge, retaining a rounded form, but frequently increasing in size so much that several originally distinct spots blend together, and form a large irregular patch, and not unfrequently the entire surface is eventually covered. Black, slightly raised, minute points, often arranged in irregular circles, form on the diseased parts; these represent the fruit of the fungus, consisting of numerous closely 
packed conidiophores, each bearing a single conidium at its tip. Eventually the epidermis of the apple is split at the apex of each pustule, and the spores escape in the form of a slender tendril, held together by mucus. In the case of stored fruit, if these spores come in contact with
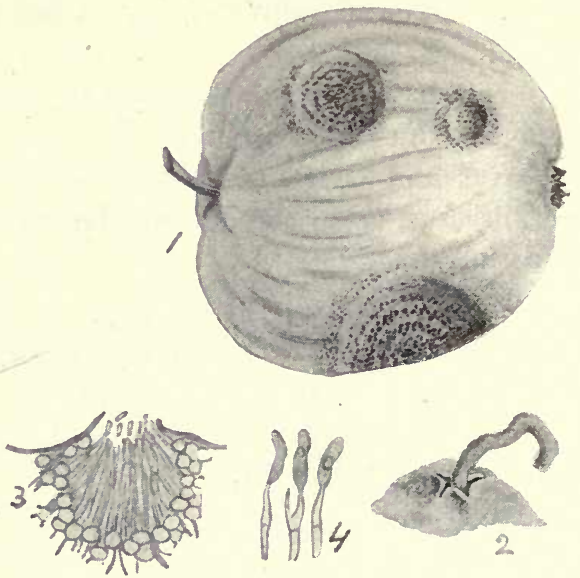

Fig. 75.-Gloeosporium fructigenum. I, appearance of the disease on an apple; 2 , showing the apex of one of the black pustules or fruit of the fungus; the spores are escaping stuck together into a thread or tendril, through a rupture in the epidermis of the apple, $\times 50$; 3 . section through one of the pustules showing the conidiophores bearing conidia at their tip, $\times 50 ; 4$, three conidiophores, each bearing a conidium at its tip, $\times 300$.

healthy apples, the disease is communicated, and in a very short time the disease spreads through the entire stock. A second and higher form of fruit is suspected, but the genetic connection is not yet proved.

It has been proved in the United States that this fungus also attacks grapes, pears, peaches, etc. 
Preventive Means.-If apples are large when attacked, they usually soon fall; such should not be allowed to remain on the ground, as the fungus present continues to form spores if the winter is mild, and proves a source of infection the following season.

On the other hand, if young fruit becomes diseased, it usually remains hanging on the tree; such mummified fruit should also be removed and burned. Do not throw diseased fruit into the pigsty or on the manure-heap, but burn it.

When storing, all fruit exhibiting the slightest trace of disease should be picked out.

The following quotation shows how the Americans treat this disease :-

'Mr. Curtiss has repeatedly lost all of certain varieties [of apples] by this fungus, and his orchard offered a good field for experiment. In order to make the value of the remedies used perfectly clear, he left some of the trees unsprayed, and in one case he only sprayed half a tree, leaving the other half unsprayed as a check. The remedies used were potassium sulphide-one half-ounce to a gallon of water-and the ammoniacal copper carbonate. The sprayings were not begun until August the I8th for the potassium sulphide, and August 27 th for the copper carbonate, too late in both cases for the best results, as the disease had already made considerable progress. But even under these unfavourable conditions the result was very marked. The apples that were not diseased at the time of spraying were perfectly protected, while the unsprayed trees dropped all their fruit. On the tree that was half sprayed the difference between the two sides was as marked as between the sprayed and unsprayed trees. 
If the spraying had been done a month earlier, it is reasonable to suppose that with proper care in application the rot could have been almost entirely prevented.

'Where copper remedies are used for black rot or mildew, it is not unlikely that the grapes are in danger from the ripe rot [=apple rot], and in cases where no remedies have been used, two or three sprayings will probably protect the grapes. For this it will not be necessary to go to the expense of preparing the Bordeaux mixture, but the ammoniacal solution, or even the potassium sulphide solution, will probably be satisfactory.'

Galloway, U.S. Dept. of Agriculture, Bull. No. 8, p. 6r ; and in Ann. Rep. U.S. Dept. Agric., I889, p. 4 I 2, figs.

Southworth, Journ. Mycol., vol. vi. p. I64.

\section{PLANE LEAF SCORCH}

\section{(Gloeosporium nervisequum, Sacc.)}

A destructive fungus, causing defoliation of planes in Europe and the United States. When the leaves are just full-grown, scattered brown spots appear, often following the veins; sometimes the patches become very large, from the meeting and blending of originally distinct areas of disease. The mycelium passes from the veins into the leaf-stalk, when the leaf soon falls before it is dead; by this means trees are often destitute of leaves at midsummer. Minute blackish pustules containing the spores are formed on the veins on the under surface of the leaf. At maturity the spores ooze to the surface in a mass, held together by mucilage, are dispersed by rain, and, being capable of germinating at once, infect fresh leaves.

Platanus occidentalis, L., and $P$. orientalis, L., suffer severely, $P$. occidentalis, the American species, being most 
susceptible to the disease, both at home and in Europe. Platanus racemosa, Nutt., the sycamore of the United

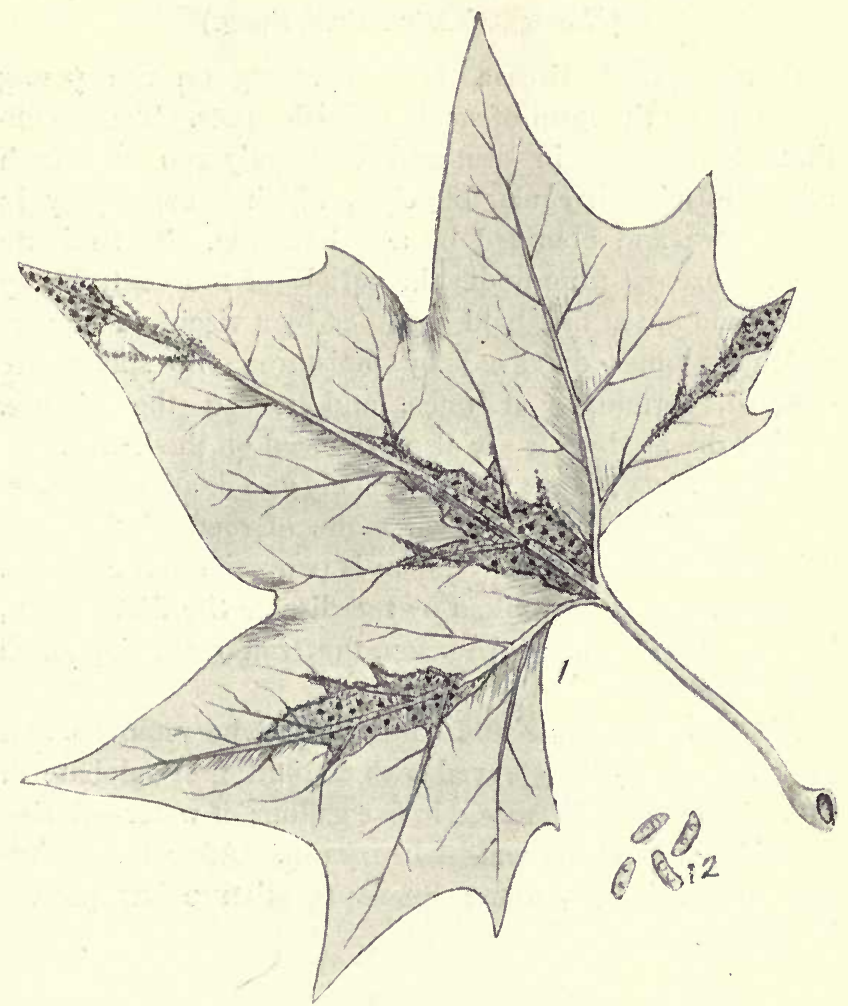

Fig. 76.-Gloeosporium nervisequum, Sacc. I, a diseased leaf of plane, reduced ; 2 , spores, $\times 300$.

States, is also attacked. It has also been recorded as occurring on oak leaves in America.

Prillieux, Malad. des Plantes Agric., vol. ii. p. 320 , figs. Stoneman, Bot. Gaz., vol. xxvi. p. 70, figs. 


\section{RASPBERRY SPOT \\ (Glocosporium venetum, Speg.)}

A widespread disease, first appearing on the young canes under the form of small reddish spots. These continue to increase in size, and frequently run into each other, forming irregular blotches, which become grey in the centre, and bounded by a red margin. The minute spores ooze out from under the cuticle of the central grey spots, and are at first held together by a viscid substance, which becomes dissolved by moisture; the spores are diffused, germinate at once, and spread the disease. Similar diseased spots are also produced on the leaves.

Preventive Means. - The quickly germinating summerspore form is the only known mode of reproduction, and it is supposed that the mycelium is perennial in the tissues. Young canes are not killed by the disease the first season, but succumb the second season, the fruit remaining small and shrivelled.

All diseased leaves and canes should be removed, and the canes should be sprayed with a solution of sulphate of iron-two pounds dissolved in five gallons of water-during the winter before the leaf-buds expand. After the expansion of the foliage, dilute Bordeaux mixture has proved beneficial.

\section{CURRANT LEAF SPOT}

(Gloeosporium ribis, Mont.)

The leaves of red and black currants and gooseberries are often attacked by this fungus, and when this occurs to 
a serious extent the leaves fall early, and the fruit does not ripen properly, if at all. Further, such trees are unable to accumulate the necessary amount of reserve material, and consequently do not produce a good crop of fruit the following season.

The disease usually appears when the leaves are just full-grown, appearing as minute blackish spots, chiefly on the upper surface. These spots are caused by dense tufts of mycelium in the tissues of the leaf, which increase in size and eventually rupture the epidermis, the minute spores escaping in the form of a tendril, being stuck together by mucus. When on the surface, these strings of spores are washed apart by dew or rain, and find their way to other leaves, where they germinate, and thus spread the disease.

Preventive Means.-Very dilute Bordeaux mixture, or potassium sulphide solution, if applied sufficiently early, checks the disease.

Dudley, Cornell Expt. Station, U.S., No. 15.

\section{BANANA ANTHRACNOSE}

(Gloeosporium musarum, Cke. and Massee.)

Forming blackish spots which gradually spread over the entire surface of the fruit, causing rotting to take place. The black spots are suffused with a roseate tint when the spores are extruded.

First described as occurring on ripe bananas at Brisbane; afterwards met with in the United States on the same host.

Diseased fruit should be removed as soon as the small 
black spots are noticed, to prevent the spread of the fungus.

Stoneman, Bot. Gaz., vol. xxvi. p. 69, fig.

Gloeosporium rhododendri, Briosi and Cavara.-This fungus forms large yellowish blotches on the leaves. The minute black pustules containing the spores are arranged in irregular concentric circles on the bleached spots.

Briosi e Cavara, Fung. Parassiti delle Piante Coltiv. od Utili, No. 198 , fig.

Gloeosporium bicolor, M'Alp. - Forming wax-yellow, then brown pustules on ripe grapes in Australia. Differs from allies in the conidia being colourless, even in the mass. No bitter taste is imparted to the fruit attacked.

M'Alpine, Add. to Fungi on the Vine in Australia, p. $3^{8 .}$

\section{ANTHRACNOSE OF SCARLET RUNNER}

\section{(Colletotrichum lindemuthianum, Briosi and Cavara.)}

A disease commonly attacking the pods of scarlet runners, less frequently those of French beans, sometimes also present on the stem and leaves.

On the pods the disease appears first as small dark spots, bounded by a reddish line. These spots continue to increase in size and often run into each other, forming irregular blotches, which become sunk below the general level of the surface. On the stem the patches corrode the tissues and kill the part above the wound. 
When pods are badly diseased, they are often contorted; the beans are also sometimes attacked.

Professor Halsted states that this fungus is parasitic on the living rind of cucumbers, pumpkins, water-melons, and muskmelons.

Preventive Means. - Spray with Bordeaux mixture when the disease first appears on the stem or leaves, which will prevent its passing on to the pods. Badly diseased plants should be removed. Seed obtained from plants where the disease has existed should not be used. Plants grown in damp situations are most liable to the disease.

Voglino, Fungi Dannosi alle Piante Coltivate, pl. 8.

Halsted, Bull. Torr. Bot., vol. xx. p. 246, figs.

Beach, N. Y. Expt. St., Bull. No. 48 , figs.

Massee, Gard. Chron., May 7, I 898, figs.

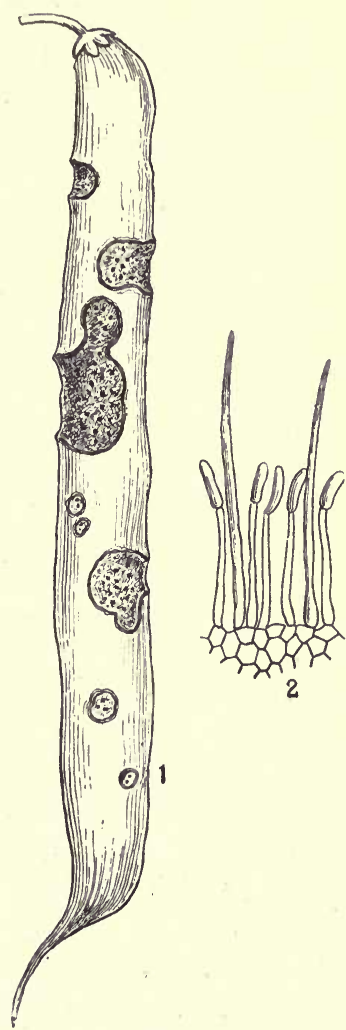

Fig. 77. Colletotrichum lindemuthianum. I, diseased pod of scarlet runner; 2, portion of fruitbearing surface, showing the spores borne singly at the tips of long sporophores, also two long spines projecting above the mass of the spores, $\times 300$. 


\section{COTTON ANTHRACNOSE}

\section{(Colletotrichum gossypii, Southw.)}

Either alone, or accompanying the fungus causing 'black rust' (Cercospora gossypina, Cke.), this fungus does considerable injury to the cotton crop in the southern United States. On the 'bolls' or fruit the fungus causes depressed, blackish spots, which ultimately assume a reddish tint, due to the formation of spores. The leaves and stem are also attacked, soon looking as if killed by frost; the stems blacken, and the plant usually dies.

Atkinson, Journ. Mycol., vol. vi. No. 4, p. I 73, 2 pl.

\section{HOLLYHOCK ANTHRACNOSE}

(Colletotrichum althaeae, Southw.)

A fungus that has caused considerable trouble in America to hollyhocks grown in greenhouses, and has quadrupled their value in New York. Any part of the plant may be attacked; on the leaves brown spots are formed, which may increase in size until the whole leaf is diseased or withered. The spots vary from light yellowishbrown to black.

Preventive Means.-Spraying with dilute Bordeaux mixture at intervals, commencing as soon as the leaves appear, although not effecting all that could be wished, proved to be the best fungicide experimented with. Diseased plants should be removed at once.

Southworth, Journ. Mycol., vol. vi. No. 2, p. 45, I pl. 


\section{SPINACH ANTHRACNOSE}

(Colletotrichum spinaceae, Ellis and Hals.)

This disease has proved especially destructive to spinach in the United States. The spots formed on the leaves are at first minute, and present a moist appearance. These gradually increase in size, become grey, dry, and studded with numerous dark points, often on both surfaces of the patch. The fruit comes to the surface through the stomata.

Halsted, N. Jersey Agric. Coll. Expt. Station, Bull. 70, figs.

\section{CHERRY AND PLUM LEAF BLIGHT}

(Cylindrosporium padi, Karsten.)

According to Fairchild, nursery stock of cherries and plums are often severely attacked, the leaves falling so early as to render the first year's growth of stocks almost insignificant. Plum trees suffer more than cherries, as the leaves fall while yet green, whereas in the latter the leaves often assume autumnal tints before falling. Great variation exists as to the susceptibility of different varieties, the English Morello cherry being especially victimised.

The disease appears under the form of small, round, purple spots on the leaf, these eventually become brown, dry up, and drop out, leaving holes in the leaf.

Preventive Means. - Bordeaux mixture arrests the disease. Spray first when the leaves are expanding, and again after an interval of three weeks.

Fairchild, Journ. Mycol., vol. vii. p. 249, pl. xxi.-xxix. (1893). 


\section{CHRYSANTHEMUM LEAF BLIGHT}

(Cylindrosporium Chrysanthemi, Ellis and Dearn.)

Mr. J. Dearness has described a chrysanthemum leaf blight which proved destructive to cultivated plants in Ontario, Canada. Large dark blotches appear on the leaves, which turn yellow, and shrivel. When attacked the flower-buds do not expand.

Numerous fruiting pustules are formed on the diseased patches; these produce myriads of long, narrowly spindleor club-shaped, colourless, septate conidia, which rupture the epidermis of the host, become diffused, and spread the disease rapidly.

The diseased leaves hang down and lie close to the stem.

Preventive Means.- 'The owners sprayed the plants with all their fungicides, but without any apparent effect on the disease. Doubtless the best course is to burn the affected leaves, or destroy the plant as soon as the disease is observed.'

\section{FIG TREE DISEASE}

\section{(Libertella ulcerata, Massee.)}

This parasite causes the bark to become cankered and cracked, large patches completely disappearing as the disease progresses. When a branch is girdled, the portion above the wound dies, and then produces the fruit of the fungus in minute cavities in the bark, the very minute conidia oozing to the surface in the form of fine hairs, composed of conidia stuck together by a viscid substance, which is dissolved by wet. The conidia are not capable 
of inserting a germ-tube into the unbroken surface of the bark, but gain an entrance through wounds. A knife used for cutting out a diseased portion was afterwards used for making a slight incision in the branch of a healthy plant, and the disease followed.

Preventive Means.-All wounded surfaces should be coated with tar at once, and care should be exercised in pruning or trimming not to cut sound branches with a knife that has been used for cutting out diseased parts, until it is disinfected.

Massee, Gard. Mag., July 23, I 898, fig.

\section{PANDANUS DISEASE}

(Melanconium pandani, Lév.)

The surface of the trunk, aërial roots, and adventitious branches of cultivated species of Screwpine (Pandanus) are sometimes attacked by a fungus which forms small black pustules, bursting through the epidermis, and at maturity extruding black, subgelatinous tendrils, consisting of minute conidia held together by a mucilaginous substance. These pustules are often produced in immense numbers, and blacken the parts attacked.

An ascigerous form-Nectria pandani, Tul.-frequently appears on the Melanconium pustules, and the two are considered as phases of one fungus, but this has not yet been proved.

Preventive Means.-If the diseased parts are cut out, and the wounds covered with a fungicide as soon as the disease is observed, it may be arrested; if neglected, the plant invariably dies. 


\section{CHERRY LEAF SPOT}

\section{(Coryneum beyerinckii, Oud.)}

This fungus attacks not only the cherry but also the peach, apricot, almond, and plum. Not unfrequently in spring the young leaves show red or rosy spots on the under surface; such are also often present on the young shoots. At a later stage the tissue at diseased points becomes brown, and dies, and the conidia of the fungus are produced in minute black spots grouped on the dead portions, which finally as a rule fall away, leaving the leaf perforated. The diseased spots on the twigs are usually elongated. When the fruit is attacked the flesh dries up to the stone.

Late in the season a second form of fruit-pycnidiaappears on the diseased patches on the twigs, and on mummified cherries an ascigerous condition has been detected the following spring. These are supposed to belong to the Coryneum, but the point has not yet been definitely settled. The ascigerous condition has received the name of Ascospora beijerinckii, Vuill. A certain amount of gumming sometimes takes place on branches attacked by the fungus, but whether caused by the parasite is not known with certainty; Vuillemin thinks not.

Preventive Means.-No methods have been recorded, but probably spraying at the time when the leaf-buds are expanding would prove beneficial.

Oudemans, Hedru., I883, p. II 3 .

Vuillemin, Journ. de Bot., vol. ii. p. 255.

Prillieux, Malad. des Plantes Agric., vol. ii. p. 337, figs. 


\section{'GREY BLIGHT' OF TEA PLANT' \\ (Pestalozzia guepini, Desmaz.)}

Said by Dr. Watt to be one of the most destructive and dangerous of parasitic fungi to which the tea plant is liable. It occurs in Assam and Cachar, and probably in all the
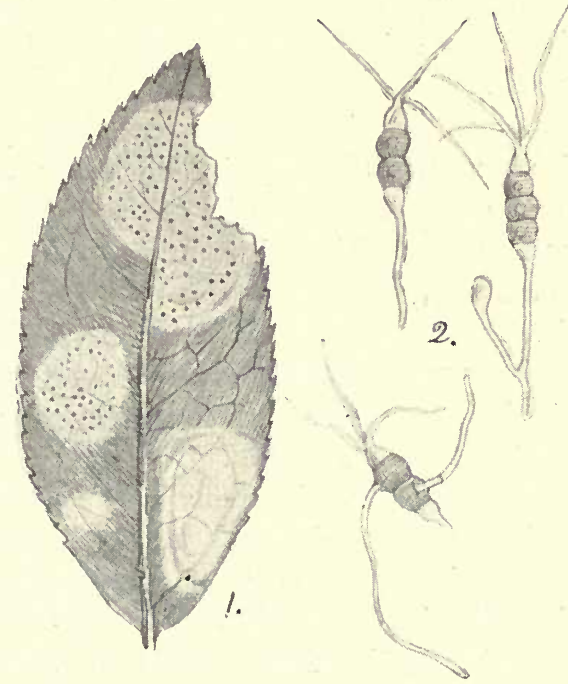

Fig. 78.-Pestalozzia guepini. I, blotches caused by the fungus on a tea leaf, slightly reduced; 2 , spores of the fungus, $\times 350$.

tea districts of India, also in Ceylon. The disease first appears as minute, brownish-grey spots on the upper surface of the leaves. These spots gradually increase in size and coalesce, forming large, irregular blotches, which finally become grey and sprinkled with minute black points, the fruit of the fungus. During the increase in size the 
blotches are often bordered by a dark, slightly raised line. Diseased leaves are not at all blistered or swollen; in fact, the grey patches are thinner than the uninjured portion of the leaf, owing to collapse of the tissues.

Dr. Watt states that the disease commences for the most part on one side of a bush, very often on the same side of all the bushes over an affected plot-a circumstance that may be taken as indicative of the germs having been wind-conveyed.

In addition to growing on the tea plant, Pestalozzia guepini also occurs as a parasite on other species of Camellia and on Rhododendron in India; in Europe it is not uncommon on cultivated camellias and rhododendrons. In the United States it also occurs on introduced species of Camellia and Citrus, from whence it possibly passed on to the native Magnolia. Finally, it is known to occur on indigenous plants (Niphobolus) in New Zealand, and on Alphitonia in Queensland.

Preventive Means.-The remarks I offered in the Kew Bulletin are repeated here. If the diseased leaves were collected with the amount of care and intelligence exercised in collecting sound leaves, and burned at once after being collected, the disease would soon be stamped out, as the mycelium of the fungus is not perennial in the tea plant; consequently infection and a recurrence of the parasite depends entirely on inoculation by the numerous conidia or reproductive bodies of the fungus present on diseased leaves. Remembering the very different kinds of plants on which the fungus is known to be parasitic, it is very probable that it also occurs on wild plants growing in the vicinity of the tea-gardens. If such proves to be the case, all such plants should be removed if practicable, as 
the conidia of fungi are carried considerable distances by wind, birds, and insects, and no amount of attention in the way of removing the parasite from the tea plants would avail if the supply of conidia requisite for inoculating the tea plants were formed on other plants growing in the neighbourhood.

Watt, The Pests and Blights of the Tea Plant.

Massee, Kerv Bulletin, I898, p. Io6, figs.

\section{CONIFER SEEDLING DISEASE}

(Pestalozzia hartigii, Tubeuf.)

Seedlings of spruce and silver fir are frequently destroyed in large numbers, due to the injuries caused by this Pestalozzia. In summer young plants lose their colour and die. On examination it is found that the cortex just above ground is destroyed, and closer search reveals the presence of numerous minute masses of fungus mycelium or stromata bearing those peculiar conidia characteristic of the genus Pestalozzia.

Preventive Means.-Remove and burn all diseased seedlings.

Tubeuf, Beitr. zur Kenntniss der Baumkrankheiten, p. 40, pl. v., I 888 .

Hartig and Somerville, Diseases of Trees, p. I36, figs.

\section{MAPLE BLIGHT}

(Septogloeum hartigianum, Sacc.)

The year-old branches of maple (Acer campestre), especially those forming the crown of the tree, are often 
destroyed by the pest named above. Two-year-old shoots are only very rarely infected. In the month of May the periderm of diseased shoots is ruptured at intervals longitudinally, exposing the conidial layer of the parasite as a greyish-green cushion, bounded by the upraised periderm. Young shoots are infected in May and June by the conidia before the periderm is formed, and such usually perish the following season.

Preventive Means.-Hartig states that the disease can be prevented by removing the diseased shoots from the crown in the beginning of May.

Hartig and Somerville, Diseases of Trees, p. I4 I, fig. 80.

\section{HYPHOMYCET ACEAE}

\section{MUCEDINEAE}

\section{(Oospora abietum, Oud.)}

Defoliation of various conifers-Abies excelsa, A. pinsapo, $A$. nordmanniana, and $A$. douglasii-results from the injury done by an inconspicuous fungus called Oospora abietum. A single row of minute greenish-grey fluffy tufts on each side of the nerve, and on both surfaces of the leaf, come to the surface through the stomata; the delicate hyphae composing these tufts produce minute, colourless $_{2}$ elliptical conidia, which, being scattered by wind or rain, alight on other healthy leaves and spread the disease.

Preventive Means. - It is advised that all fallen leaves should be collected and burned.

Oudemans, Compt. Rend. de l'Acad. Roy. d. Sci. des PaysBas, séance de Jan. 1897 . 


\section{AMERICAN POTATO SCAB}

(Oospora scabies, Thaxter.)

This troublesome disease, although so generally distributed, has only quite recently been thoroughly investigated by an American-Dr. Thaxter. The parasite usually attacks the tubers while young, forming rough patches on the surface, known as 'scab.'

When just dug up, a very delicate greyish mould is present on young diseased patches, which however soon entirely dries up and disappears. Beet, swede turnips, carrots, and cabbages also appear to be susceptible to the same disease, and should not follow a crop of potatoes, as the germs remain in the soil for some years.

This parasite has nothing in common with potato scab, as understood in Britain.

Preventive Means.-Professor Bolley recommends the following treatment :-Immerse potatoes intended for planting-contained in a sack of open texture-for an hour and a half in a solution consisting of two and a quarter ounces of corrosive sublimate (bichloride of mercury) to fifteen gallons of water, after which they may be cut and planted as usual after being spread out to dry. First dissolve the corrosive sublimate in a few gallons of hot water, and place the solution in a cask or wooden vessel, as the mixture corrodes metal. The solution is poisonous, and care should be used.

It has recently been proved by Professor Arthur that steeping potatoes in a solution of half a pint of formalin in fifteen gallons of water for two hours is a complete specific.

Thaxter, Ann. Rep. Conn. Agric. Expt. Station, I89o, p. 84 . 
Bolley, Bull. No. 4 and No. 9, N. Dakotu Agric. Expt. Station.

Arthur, Indiana St., Bull. No. 65, pp. 19-36.

\section{BROWN ROT OF FRUIT}

\section{(Monilia fructigena, Pers.)}

One of the commonest and most widely distributed of moulds against which the fruit-grower has to contend. It attacks apples, plums, cherries, and other kinds of orchard fruit, and is also common on various wild fruits belonging to the Order Rosaceae.

In Britain it is most frequently seen on apples, and although best known to the casual observer on the fruit, occurs also on the young shoots, leaves, and even the flowers.

On the leaves, where the fungus usually appears in the spring, it forms thin, velvety, olive-brown patches, consisting of chains of barrel-shaped spores, originating from the mycelium present in the tissues of the leaf. At maturity the spores become free, and are carried by rain, wind, insects, or birds on to the surface of healthy leaves or young fruit, where, if conditions are favourable, a new diseasespot is formed.

On the fruit the first indication of disease is indicated by the appearance of brownish scattered patches on the skin. This is followed by the appearance on the surface of small tufts composed of chains of spores. As the disease extends, the tufts of spores are usually arranged in irregular circles round a central starting-point. 
Fruit attacked by the fungus does not readily rot, but remains in a mummified condition throughout the winter, either lying on the ground, or frequently hanging on the tree. During the winter, the mycelium, which permeates every portion of diseased fruit, forms numerous minute, blackish sclerotia. $\checkmark$ On the return of spring, these sclerotia bear a crop of spores, which are carried on to the young leaves, and a recurrence of the disease ensues.

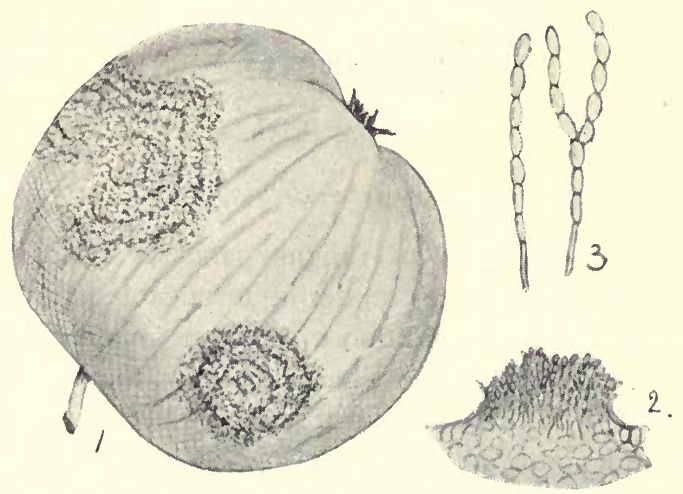

Fig. 79.-Monilia fructigena. $\mathrm{x}$, an apple badly diseased; 2, a pustule of the fungus, $\times 50 ; 3$, chains of Monilia spores, $\times 200$.

Preventive Means.-The mycelium is not permanent in any part of the host ; consequently every spring the trees are perfectly free from disease, and would remain so if not inoculated by spores derived from the diseased fruit of the previous season; hence all diseased fruit should be collected and burned. Where the disease has already existed, the trees should be thoroughly drenched with a solution of sulphate of iron in early spring before the buds expand; 
and after the buds have expanded, with dilute Bordeaux mixture at intervals of ten days.

Smith, Gard. Chron., vol. xxiv. p. 51, figs.

Massee, Brit. Fungus-Flora, vol. iv. p. $28 \mathrm{I}$.

Smith, Journ. Mycol., vol. v. p. I 23.

Arthur, Fourth Ann. Rep. N. York Agric. Expt. Station, p. 254 (1885).

\section{DEMATIEAE}

\section{Apple Scab}

\section{(Fusicladium dendriticum, Fuckel.)}

The most injurious of fungus parasites attacking the apple, in many instances rendering unsaleable half or more of the entire crop, in addition to doing permanent injury to the trees. It was at one time considered that the disease was confined to the fruit, but it is now well known that the leaves and young shoots are also attacked; in fact, as a rule the fungus first appears on the leaves under the form of small, roundish, dark spots, mostly on the upper surface. These spots soon increase in size, and run into each other, forming large, irregularly shaped, blackish blotches; and when conditions are favourable for the growth of the parasite, the leaves are frequently killed while quite young.

The dark-coloured mycelium spreads in the leaf or fruit between the cuticle and the epidermis, the cuticle being eventually ruptured, and myriads of very short branches protrude, each bearing a conidium at its tip. The disease is extended throughout the season by means of these conidia. 
The disease is tided over the winter by means of the mycelium present in fallen fruit. Goethe, a German observer, states that an ascigerous form of fruit is produced

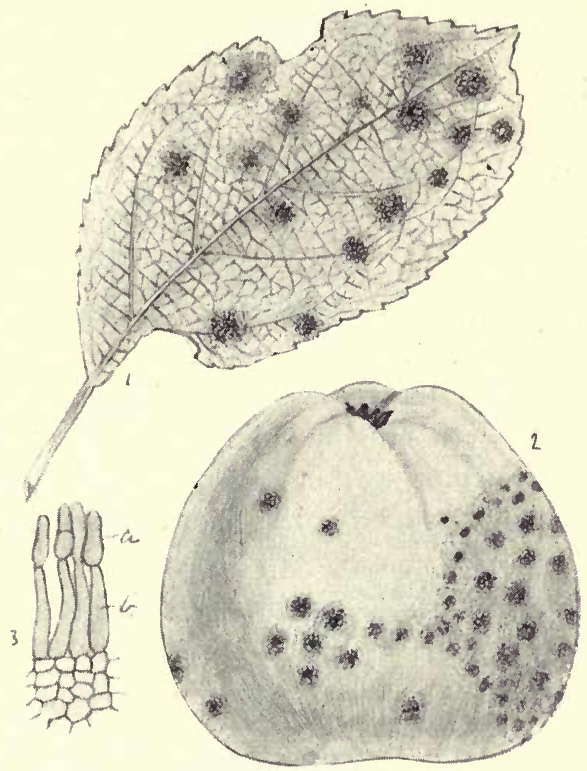

Fig. 80.-Fusicladium dendriticum. I, appearance of fungus on the upper surface of an apple leaf; 2 , the fungus on an apple; 3 , conidia, $a$, borne on the tips of conidiophores, $b, \times 300$.

on the diseased patches, which matures the following spring.

Preventive Means.-The following method for combating the disease is recommended by Professor Galloway :'Spray with Bordeaux mixture: first, just as the flower-buds 
begin to open; second, when the petals of the flowers are falling; and third, when the fruit is the size of peas or slightly larger. If the season be rainy a fourth treatment should be given twelve days after the third. Four ounces of Paris green added to each fifty gallons of the mixture at the time of the third spraying will hold the codlin moth in check. The Paris green should first be made into a thin paste by adding a little water. This paste readily unites with the mixture, and does not seem to decrease its value in any way.'

Experience has shown that ordinary Bordeaux mixture is apt to scorch the foliage, especially when young, hence it is advisable to use the dilute form.

In cases where the disease has existed previously, the trees should be thoroughly drenched with a solution of sulphate of iron during the winter, commencing with the Bordeaux mixture when the leaf-buds are just expanding.

Galloway, Rep. U.S. Dept. Agric., r887, p. 34 I, figs. Goethe, Gartenflora, I 5 .Mai 1887.

\section{PEAR SCAB}

(Fusicladium pirinum, Libert.)

This parasite closely resembles in structure and habit apple scab (Fusicladium dendriticum), and by some mycologists is considered as a form of the last-named. Others, however, look upon the two as distinct, but closely allied. At all events, the injury done to the foliage and fruit of the pear is sometimes very severe, especially during a cool, damp season. 
Preventive Means.--Similar to those recommended under 'Apple Scab.'

Goethe, Gartenflora, I5 Mai I887.

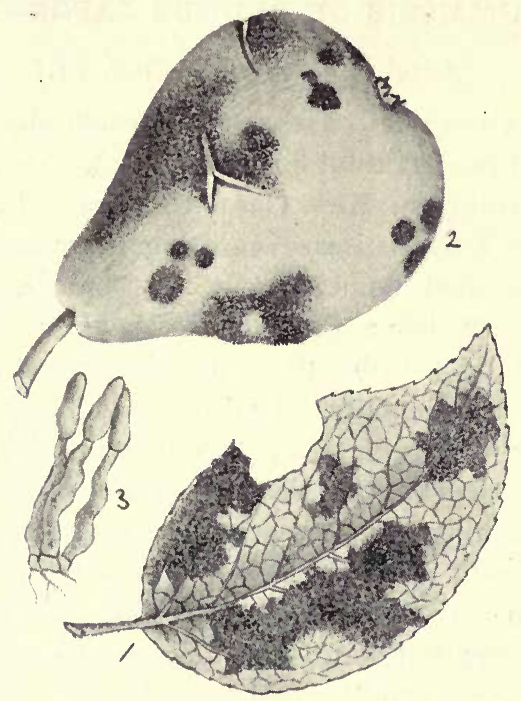

Fig. 8I.-Fusicladium pirinum. I, fungus on the upper side of a pear leaf; 2, fungus on a pear; 3 , conidia, $a$, borne on the tips of conidiophores, $b, \times 300$.

\section{SWEET-CHESTNUT DISEASE}

\section{(Acrospeira mirabilis, Berk.)}

The ripe fruit of the sweet-chestnut (Castanea vesca, Gaertn.) is sometimes filled with a dense blackish-olive felt belonging to the fungus named above. Nothing as to the life-history of the parasite is known. The disease 
appears first at the apex of the fruit, and inoculation probably takes place through the stigma.

\section{GUMMOSIS OF PRUNUS JAPONICA}

(Cladosporium epiphyllum, Fr.)

During two successive seasons a considerable number of examples of the beautiful flowering shrub, Prunus japonica, Thunb., growing in Kew Gardens, were either killed or much injured by a disease agreeing in nature with what has been termed gummosis. Stout branches are most frequently attacked; the disease is indicated by the appearance of tearlike drops of almost colourless gum oozing from the branches. The drops are solitary or crowded, and rapidly increase in size, eventually forming irregularly nodulose masses varying in size from a marble to that of a walnut. During damp weather the masses are soft and gelatinous, with just sufficient consistency to hold together, whereas in dry weather they shrink considerably and become horny. Finally the masses are dissolved and washed to the ground by rain.

As already stated, the small drops are colourless, gradually changing from grey to black as they increase in size. If a large black mass is hardened by placing it in methylated spirit, and then cut through, it will be seen that the surface alone is black, the colour gradually becoming lighter inwards, and white at the centre.

This extrusion of gum is entirely due to the action of a minute fungus which does not differ structurally from the exceedingly common Cladosporium epiphyllum. Repeated experiments prove that the fungus is a wound-parasite, gaining an entrance into the tissues through small wounds 
in the bark, broken branchlets, and more especially at those points where leaf-buds or flower-buds have been broken off by birds. An olive patch of Cladosporium first appears at the diseased point, and after the conidia are dispersed the drop of gum appears, and into this gum the hyphae of the fungus extend, keeping pace with its increase in size, but not projecting beyond the surface of the gum-mass. The hyphae at first are colourless and very slender, but as the mass increases in size the tips of the hyphae nearest the circumference become tinged olive, and broken up into short, irregularly shaped chains of cells. When the mass has reached its full size, the peripheral portion is densely crowded with the coloured chains of cells, many of which produce dense masses of cells or micro-sclerotia with thick, dark-brown walls. When this stage of development has been reached, if the mass remains damp and distended, the large brown cells and micro-sclerotia give origin to myriads of very minute hyaline conidia which are contained in the dense gum-mass, and have been produced in the absence of oxygen, or in an anaerobic manner. If conditions remain unchanged, the minute conidia, when liberated from the mother-cell, increase at a rapid rate by germination, or in a yeastlike manner, until finally the originally black surface of the mass becomes white and opalescent. Eventually the mass is washed to the ground by rain, and there the conidia continue to reproduce themselves by gemmation.

After a gum-mass has been removed, a large cankered wound, sometimes extending to the pith, is revealed.

On the other hand, if the black masses are washed to the ground by rain, and dissolved before the commencement of the production of conidia, the large brown cells and 


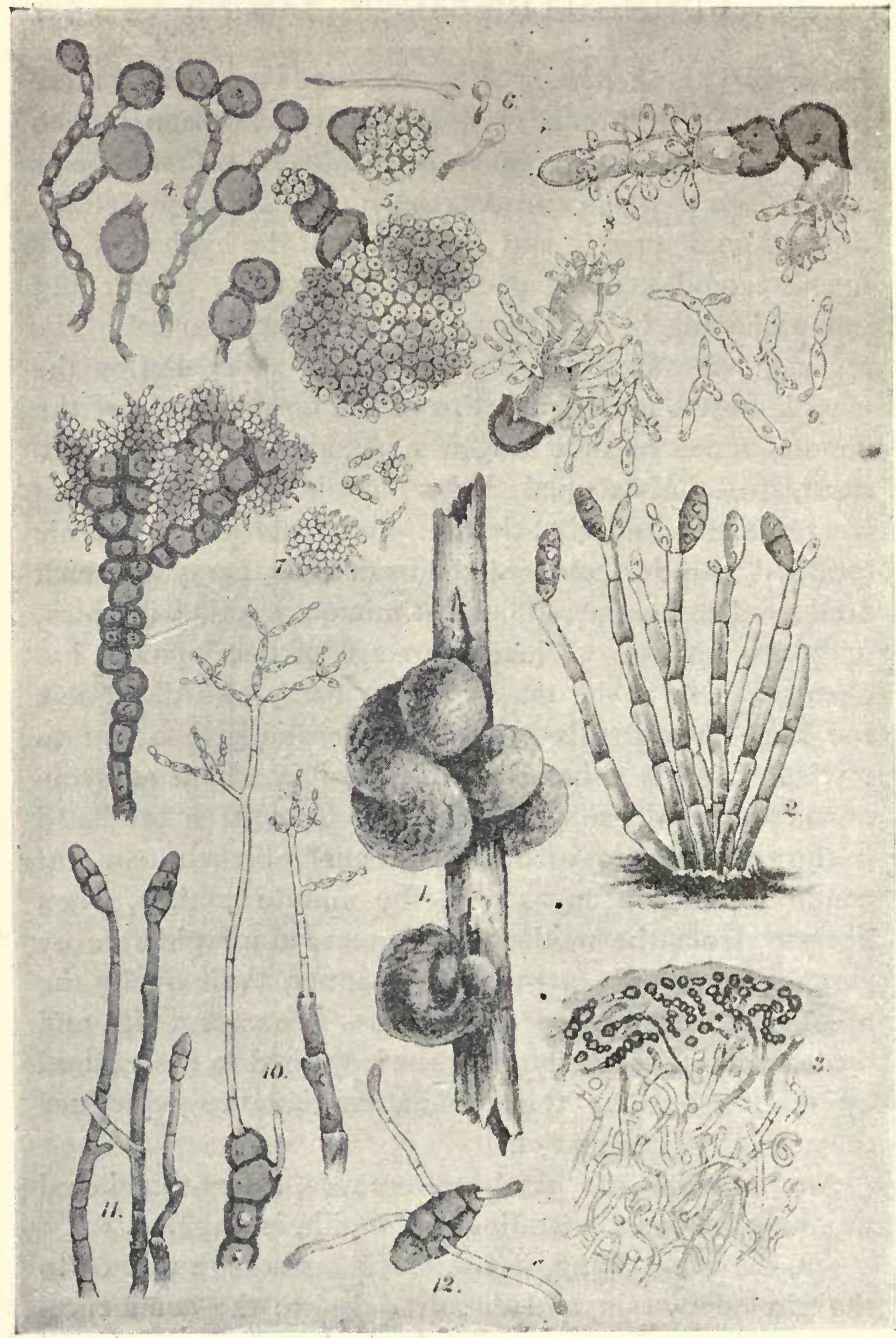

[For description see p. 309. 
micro-sclerotia, fully exposed to the air, produce a chain of two or three very large, colourless cells, and these in turn bear numerous smaller, elliptical conidia. When mature the conidia become free and reproduce themselves quickly by gemmation. This condition of conidia formation corresponds to the stage known as Dematium pullulans, De Bary, and is the aerobic mode of reproduction of the Cladosporium.

Numerous pure cultures of the various phases described above were made, and inoculations with the olive conidia of the ordinary condition of Cladosporium, and also with the conidia of the aerobic stage, produced the disease. Inoculation with conidia of the anaerobic condition gave no result.

This is the first instance where gummosis has been directly proved to be caused by a fungus.

Preventive Means.-Diseased branches should be removed, or, better still, collar-pruning should be resorted

Fig. 82.-Cladosporium epiphyllum. I, portion of a branch of Prunus japonica, bearing two masses of gum, half nat. size ; 2, Cladosporium form of fruit, $\times 250 ; 3$, section of a portion of the periphery of a black gummass, showing the hyphae of the Cladosporium, $\times 50 ; 4$, dark-coloured tips of hyphae from the periphery of a gum-mass, bearing large, thickwalled, brown cells, $\times 250 ; 5$, large thick-walled cells germinating in a nutrient solution in the absence of air, and producing yeastlike cells, which reproduce themselves by gemmation, $\times 250 ; 6$, stray cells emitting a germ-tube, seen in the material described under $5 ; 7$, micro-sclerotia germinating under conditions similar to those described under 5 , and producing similar conidia, $\times 400 ; 8$, large, brown, thick-walled cells germinating in a nutrient solution, with free access of air, and producing the form of fruit known as Dematium pullulans, $\times 250 ; 9$, conidia of the Dematium increasing by germination, $\times 250$; xo, fragments of sporophores of Cladosporium producing a slender form of Dematium pullulans, $\times 250$; Ir, a form of Macrosporium often appearing on old canker-spots caused by the Cladosporium: no genetic connection between the two could be established, $\times 300$; 12, spore of Macrosporium germinating, $\times 400$. (From Kew Bulletin.) 
to; and to prevent a recurrence of the disease from conidia present in the soil, the surface soil should be removed and fresh soil added, with a layer of quicklime on the surface.

Massee, Kew Bulletin, I899, p. I, I pl.

\section{PLUM SCAB}

(Cladosporium carpophilum, Thümen.)

This disease has received the name of ' $\mathrm{scab}$ ' in the United States. It attacks the fruit of cultivated plums, cherries, and almonds. On half-grown fruit the fungus forms greyish or olive-brown spots, which extend radially; when numerous the fruit shrivels, and often cracks.

Preventive Means.-Bordeaux mixture has been suggested for checking the disease; it should contain a little treacle or soap to secure adhesion. Spraying should cease when the fruit commences to ripen.

Pammel, Iozera Agric. Coll. Expt. Station, Bull. No. 23, p. 9I 8, 2 figs. (I894).

\section{LEMON AND ORANGE SCAB}

\section{(Cladosporium citri-pro tem.)}

This disease, so fully described and illustrated by Swingle and Webber, proves very injurious to lemon and orange trees in Florida and Louisiana. The disease is indicated by the presence of numerous small warts or excrescences on the leaves and fruit. When the fruit is attacked quite young, the warts are often numerous, and measure up to $\frac{1}{4}$-inch high and across, although often smaller. The disease is caused by a minute fungus, which covers the warts with a delicate mould, grey at first, then 
dusky, finally black. Trees growing in low, moist situations are most subject to scab; in fact, the spread and development of the fungus requires the almost constant presence of moisture in the air. The sour orange (Citrus bigaradia) is especially susceptible to this disease.

Preventive Means.-Spraying with ammoniacal solution of copper carbonate is effectual; so is Bordeaux mixture, but the latter is more or less injurious to the foliage and fruit. Spraying should commence when the fruit is just set, and continued at intervals.

All diseased fruit, whether on the ground or still on the tree, should be collected and burned.

Sour orange-trees should be cut down, also all shoots from sour stocks.

In planting avoid low-lying, damp situations.

The fungus causing this disease has been referred to by the authors as Cladosporium sp. I have added the specific name citri, not for purposes of priority, but for convenience of reference to the diagnosis in the systematic appendix.

This Cladosporium species is evidently quite distinct from Cladosporium elegans, Penzig, which forms arid, brown spots on living leaves of oranges in Italy.

Lamson-Scribner, Bull. Torrey Bot. Club, vol. xiii. p. I 8 I.

Swingle and Webber, U.S. Dept. Agric., Bull. No. 8.

\section{TOMATO LEAF RUST}

(Cladosporium fulvum, Cke.)

This disease often proves destructive to tomatoes both in Europe and the United States, especially where the plants are grown under glass. The leaf is the part most 
frequently attacked, although the fungus sometimes passes on to the young fruit also. Small brown spots appear first on the young leaves, which gradually increase in size until the greater part of the surface is covered; the leaves gradually become blackish-brown, shrivel, and die. The

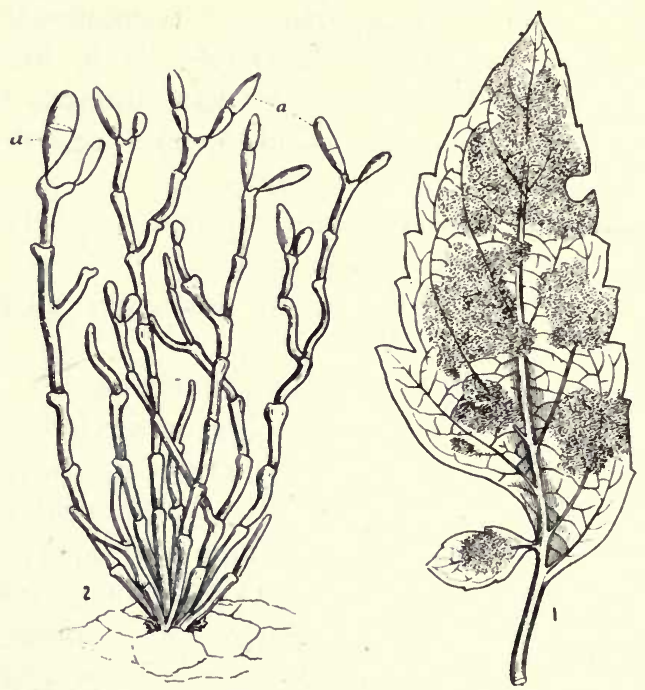

Fig. 83.-Cladosporium fulvum. I, under surfacc of a diseased tomato leaf; 2 , a tuft of conidiophores bearing conidia, $\times 300$.

under surface of the leaf corresponding to the dark patches is covered with a short felt of a rusty-brown colour. This felt consists of closely packed, sparingly branched clusters of coloured conidiophores bearing elliptical, one-septate conidia at their tips. The sporophores are knotted or swollen at the joints. Blackish stripes are often present on the stems of diseased plants. 
Preventive Means.-Spraying with dilute potassium sulphide solution, or with dilute Bordeaux mixture, will check the disease if resorted to sufficiently early, and repeated at short intervals. If the disease has previously existed, spraying should be commenced before the disease appears. Diseased plants should be removed to prevent an epidemic.

Plowright, Gard. Chron., Oct. 29, 1887, figs.

Galloway, Ann. Rep. U.S. Dept. Agric., 1888, p. 347, I $\mathrm{pl}$.

Cladosporium elegans, Penzig.-This fungus appears as minute blackish tufts seated on arid spots on living orange leaves in Italy. The specific diagnosis proves this to be distinct from the United States species, causing 'scab' on leaves and fruit of the lemon. To which species the fungus causing a somewhat similar disease in Japan and Australia belongs, cannot be determined in the absence of specimens.

\section{MAIZE BLIGHT}

(Helminthosporium turcicum, Pass.

=Helminthosporium inconspicuum, Cke. and Ellis.)

This fungus often proves destructive to maize or Indian corn (Zea mays), and has been recorded from Southern Europe, Queensland, and the United States. Small pale patches appear on the leaves, and continue to increase in size and run into each other, forming large patches, until finally the greater portion of the blade is covered, the midrib alone remaining rigid. The spots finally change to a pale brown, often with a darker border, and are more or less covered at this stage with a very delicate dusky mould, 
which when magnified is seen to consist of pale olive upright conidiophores, each bearing at its apex or tip a large spindle-shaped, many-septate, pale olive conidium.

In some cases the blotches become much elongated, and do not run into each other. The mycelium spreads in the

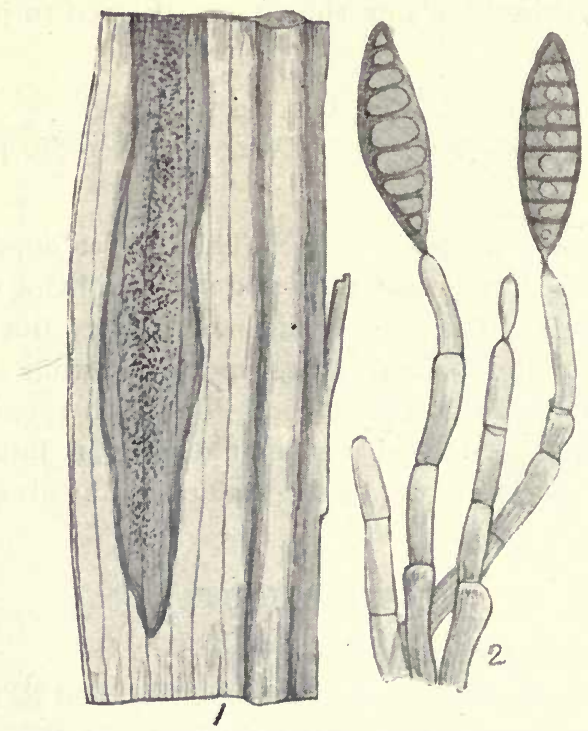

Fig. 84.-Helminthosporium turcicum. I, portion of an Indian corn leaf, diseased; 2, a tuft of conidiophores bearing two conidia, $\times 300$.

tissue, which finally becomes dry and brittle. The appearance of the fruiting condition on the surface of the leaf depends much on climatic conditions; if uninterruptedly warm and moist, the leaves often become brittle, and fall to the ground in fragments before the conidia are formed; these however do develop on the pieces lying on the ground. 
On the other hand, if warm weather is suddenly followed by a chill, fruit is usually formed in abundance. The disease may appear during any period of growth of the host.

Preventive Means.-A difficult disease to combat; perhaps burning after the corn has been gathered would be to a certain extent effective in preventing a return of the disease the following season. The most certain means of effecting this, however, would be by the rotation of crops ; and as maize impoverishes the soil to a very marked extent, this course is, under all circumstances, advisable.

Bancroft, Proc. Roy. Soc. Queensland, vol. iii. p. Io8.

Helminthosporium gramineum, Erikss.-Forms elongated olive blotches on leaves of barley, the injury done being in proportion to amount of fungus present.

Helminthosporium teres, Sacc.-Also attacks the leaves of barley, forming long olive blotches, and causing the leaves to shrivel.

A form of this species-Forma Avenae sativae, Briosi e Cavara-forms numerous narrow, elongated, dry patches on the leaves of oats, and when in profusion arrests the maturing of the fruit.

\section{SEEDLING PEA BLIGHT}

\section{(Brachysporium pisi, Oud.)}

Oudemans has described a disease which proves destructive to young pea plants (Pisum sativum).

The leaves show blackish mouldy patches, become yellow, and soon die. The dark patches consist of myriads of upright dark threads, each bearing a coloured, elliptical, three-septate conidium at its tip.

Preventive measures are not given, but probably dilute 
Bordeaux mixture, or potassium sulphide solution, which has proved effective against allied fungi, would arrest the spread of the disease.

Oudemans, Nederl. Bot. Ven., 1898, p. 527.

\section{CELERY LEAF BLIGHT}

(Cercospora apii, Fr.)

During a damp season celery leaves often show pale spots which rapidly increase in size and often cover the greater portion of the leaf. The portion not attacked

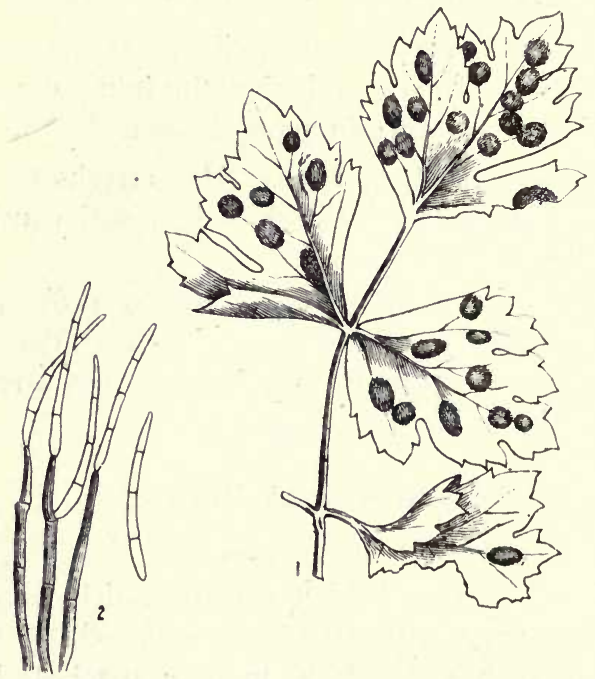

Fig. 85.-Cercospora apii. I, celery leaf attacked by the fungus ;

2 , fruit of fungus, $\times 300$.

turns yellow, and the leaf dies. As a rule the disease spreads rapidly unless checked by a spell of dry weather, 
which prevents the spores germinating on the leaves. The fruit-bearing branches of the fungus come through the stomata of the leaf and produce spores on the surface. When the greater part of the foliage is thus destroyed, the crop is a failure.

Preventive Means. - Spraying with an ammoniacal carbonate of copper solution has been proved to be effectual in checking disease, but it is very important to commence quite early, as the plants are most susceptible to the disease when quite young.

Professor Galloway states that spores found on fragments late in spring germinated readily, hence all diseased leaves should be collected and destroyed.

Galloway, Ann. Rep. Commis. of Agric., U.S., I886, I pl. ; also in Rep. I 888, p. 398.

Halsted, $N$. Jersey State Ag. Expt. St. Rep. I89г, p. 250 , fig.

\section{'SHOT-HOLE FUNGUS'}

(Cercospora circumscissa, Sacc.)

This well-known pest attacks the leaves of peach, apricot, cherry, almond, and nectarine. Small circular patches of the leaf, bearing conidia on one or both surfaces, become dry, contract, and drop away, leaving a hole in the leaf; numerous such holes are often present on a single leaf, giving it the appearance of having been riddled with small shot. Such diseased leaves fall early in the season before the formation of wood has been completed, consequently there is a poor crop of fruit the following season. The young branches, and even the fruit of the peach, are sometimes attacked. The disease often spreads quickly, being 
favoured by the dispersion of the dropped-out portions of the leaf bearing conidia.

Preventive Means.-Spray with ammoniacal solution of copper carbonate, the first time just when the leaves

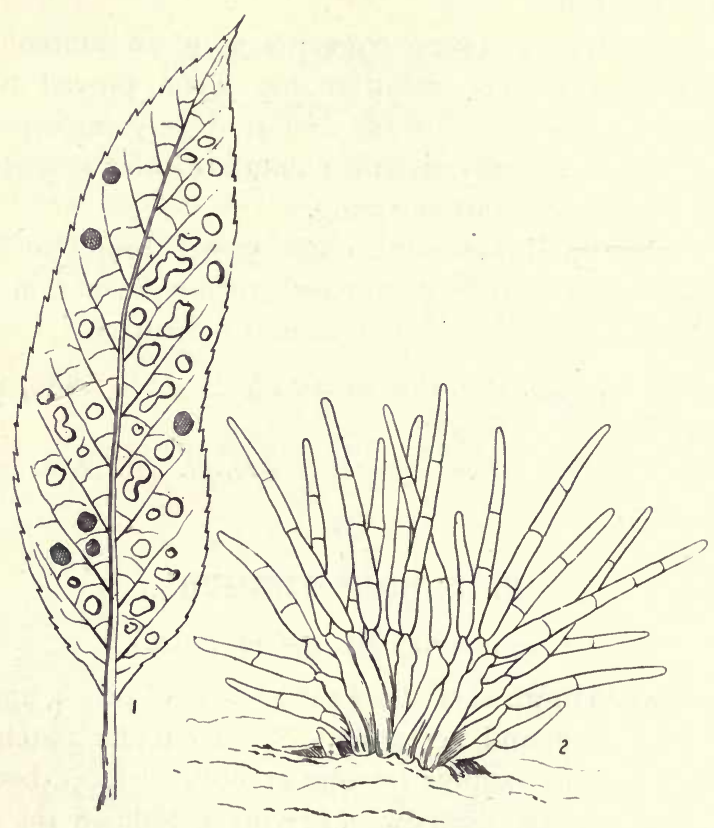

Fig. 86.-Cercospora circumscissa. I, peach leaf diseased; 2, cluster of conidiophores bearing conidia, $\times 400$.

are expanding, and repeating at intervals. Bordeaux mixture should not be used for peach or almond, as the leaves, and even young shoots, are injured by dilute solutions.

Pierce and Galloway, Journ. Mycol., vol. vii. p. 66, 4 pl. (I894). 
Cercospora viticola, Sacc.-Forms irregular, dry, brown spots on vine leaves, and is most abundant during a damp season. The discoloration extends through the leaf. Most abundant on the lower, shaded leaves.

Cercospora beticola, Sacc.-Forms irregular, dry, pallid blotches on leaves of beet (Beta vulgaris). Can be held in check by spraying with Bordeaux mixture.

\section{MIGNONETTE DISEASE}

(Cercospora resedae, Fuckel)

This fungus often proves destructive to cultivated mignonette, especially when grown under glass, causing dry brownish spots to appear on the leaves. It can be controlled by spraying with Bordeaux mixture.

Cercospora violae, Sacc.-This species causes dry, pallid spots to form on the leaves of Viola odorata, the sweet violet, and often proves troublesome when the plants are grown under glass. Spray with dilute Bordeaux mixture.

\section{FAIRY-RING OF CARNATIONS}

\section{(Heterosporium echinulatum, Cke.)}

This disease often proves destructive to cultivated carnations and pinks, especially when the plants are exposed to a chill, or when a moist, warm period in spring is followed by a sudden lowering of temperature.

The characteristic arrangement of the small black clusters of the fruit of the fungus in irregular circles, seated on pale spots on the leaf, resembling the 'fairyrings' formed in pastures by Marasmius oreades, renders the determination of this disease quite certain, even without microscopic examination. 
Numerous minute sclerotia are formed in the dying leaves; these remain in a passive condition until the

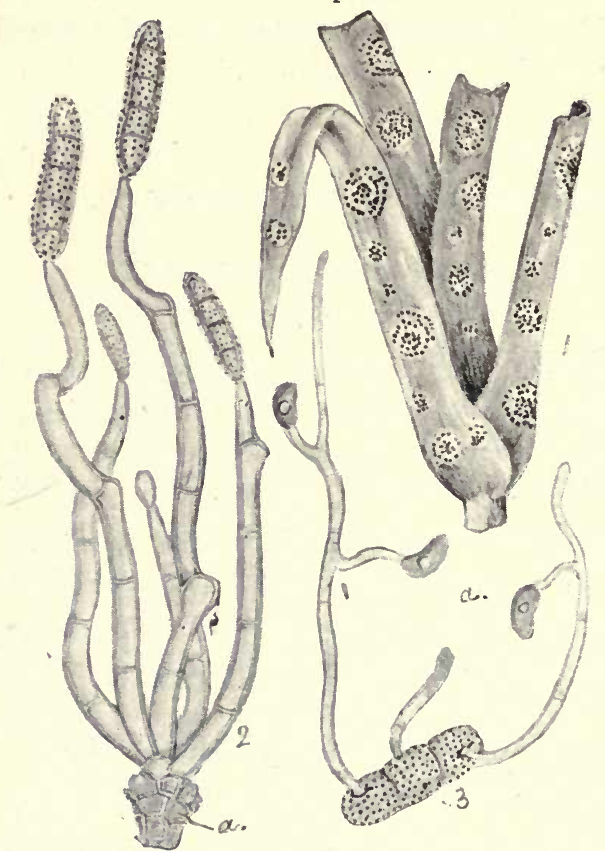

Fig. 87.-Heterosporium echinulatum. I, portion of a

- diseased carnation; 2, a small tuft of fungus fruit, showing the large, minutely warted, septate spores borne singly at the tips of crooked sporophores; $a$, portion of a compact mass of mycelium from which the cluster of conidiophores spring, and which eventually forms a sclerotium, $\times 300 ; 3$, a spore that has germinated in water; the germ-tubes bear short branchlets, each of which produces a dark-coloured secondary spore at its tip, $\times 300$.

following season, when they produce minute conidia, which, when placed on living leaves of carnation, give origin to the first patches of disease. 
Preventive Means.-Spraying with potassium sulphide checks the disease. All diseased leaves should be picked off and burned. By consistently attending to this point, the disease does not spread, and the danger of a reappearance of the disease the following season is much diminished.

When plants are grown under glass, the foliage should be kept as free from moisture as possible, as, if the surface is dry, floating spores alighting on the leaves do not germinate. Secure good ventilation, and avoid watering the foliage.

Smith, Gard. Chron., r 886, p. 244, fig.

Heterosporium gracile, Sacc.-Often disfigures or kills the leaves of cultivated species of Iris, Freesia, Antholyza, and Hemerocallis.

The mycelium is localised, but as the diseased spotselliptical, pale brown, with a darker margin-are often abundant, and also large, up to half an inch long, attacked leaves soon die. The pale spots eventually become studded with the minute olive-brown tufts of conidiophores, bearing the large, warted conidia at their tip.

Damage has been done to members of one or other of the above-named genera in Europe, Cape of Good Hope, New Zealand, and United States.

Preventive Means.-Spraying with ammoniacal copper carbonate solution checks the disease-at least, when present on Freesia recurva. I have not experimented in the case of other genera. Clear away diseased leaves, and do not disperse the conidia in so doing. 


\section{CARNATION MACROSPORIUM}

\section{(Macrosporium nobile, Vize.)}

As seen with the naked eye, this fungus forms minute, dark-coloured spots on the stem and both surfaces of the leaves of cultivated carnations. The spots are irregularly

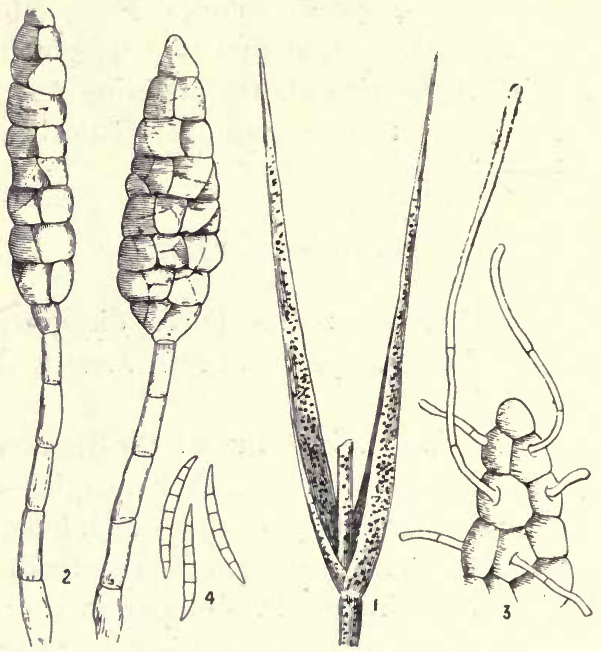

Fig. 88.-Macrosporium nobile. I, portion of a carnation showing the disease ; 2 , two conidia, $\times 300 ; 3$, portion of a conidium germinating, $\times 300 ; 4$, Fus arium spores, $\times 400$.

scattered, and the mycelium is widely diffused in the tissues before these spots or clusters of conidia appear and burst through the epidermis. The conidia are large, pale olive-brown, and consist of many cells joined together. Later in the season numerous minute black sclerotia are imbedded in the diseased parts of the plant. 
Preventive Means. - Spraying with a solution of ammoniacal copper carbonate, or of potassium sulphide, arrests the spread of the fungus. The wisest plan is to remove diseased plants before the conidia diffuse, and by picking off the leaves the formation of sclerotia is prevented. If stems are also attacked they should be cut off.

\section{POTATO LEAF CURL}

\section{(Macrosporium solani, Cooke.)}

The well-known disease of the foliage of potatoes known as 'leaf curl' attacks the stem, usually close to the ground at first, and gradually creeps up, first causing the leaves to curl, and finally the stem also collapses. When the leaves first curl, there is usually no external sign of the fungus, but at a later stage the stem and leaves become more or less studded with blackish, minutely velvety patches.

These dark patches are due to the production of innumerable conidia on the surface of the host. The conidia are large, olive-brown, and divided into numerous cells by septa crossing at right angles.

This fungus is closely allied to, if not identical with, the Macrosporium causing 'black stripe' or blotch on the tomato.

Preventive Means.-The spores persist through the winter on fragments of leaves and stems ; hence, to prevent a repetition of the disease, it is essential the potato 'tops' should be carefully collected and burnt in the autumn.

Spraying with dilute Bordeaux mixture, if commenced sufficiently early, prevents the disease from doing serious mischief. 


\section{TOMATO BLACK ROT}

\section{(Macrosporium tomato, Cooke.)}

This disease appears to be present wherever the tomato is cultivated. The fruit is most frequently attacked, but the fungus is also often present on the stem and leaves. The fungus is a wound-parasite, and on the fruit most frequently effects an entrance through minute cracks round

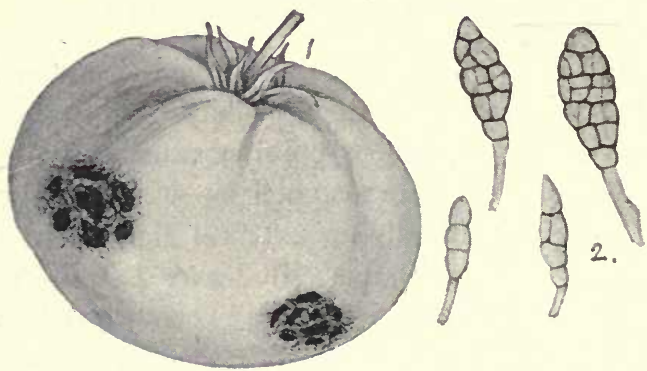

Fig. 89.-Macrosporium tomato. I, a diseased tomato;

2 , conidia of the fungus in various stages of development, $\times 300$.

the style, or at the point of insertion of the stem, but may appear on any part of the fruit where a puncture of the skin large enough to admit of the entrance of the germ-tube of a spore is present. A dark-coloured mycelium forms in the tissues, and rapidly destroys the cells, consequently the area occupied by the fungus sinks a little below the general surface of the healthy part of the fruit. At a later stage the sunken surface of a diseased spot becomes covered with a delicate, velvety pile of a brownish or blackish-olive colour. Microscopic examination shows this pile to consist 
of closely packed, dark-coloured conidiophores, each bearing a dark, many-celled conidium at its tip.

When mature, the conidia germinate quickly in water, each cell of the spore producing a germ-tube capable of inoculating a tomato if placed on a wounded surface. The present fungus is suspected of being a condition of some higher form, but this has not yet been definitely proved.

Preventive Means. - Thorough spraying with potassium sulphide solution at frequent intervals. All diseased parts should be cleared away and burned, otherwise they continue to grow on shrivelled fruit, stems, and leaves. The use of green stable manure is considered to favour the disease, and also causes the fruit to crack, thus rendering it susceptible to a high degree.

Smith, Gard. Chron., Oct. I, I 887, fig. 89.

Plowright, Gard. Chron., Nov.' 12, 1881, figs. I18, I19, I 22.

Galloway, Ann. Rep. U.S. Dept. Agric., 1888, p. 339, pl. iii.

\section{IRIS BULB SCAB}

(Mystrosporium adustum, Massee.)

Bulbs of Iris reticulata are frequently destroyed by a fungus which forms black crustaceous patches on the outer sheath, the hyphae gradually extending to every part. The conidia are very large, dark brown, and divided into a number of cells by cross-walls or septa.

Preventive Means. - If only slightly attacked, soaking the bulbs for two hours in a solution of one part of formalin to three hundred parts water will destroy the fungus before it enters the deeper parts of the bulb. 
Diseased bulbs should be collected and burned to prevent the dispersion of conidia.

Mystrosporium alliorum, Berk.-This species sometimes forms dark patches on onion bulbs.

Mystrosporium abrodens, Neumann.--Said to be destructive to the wheat crop in some districts in France. Dark patches are formed in the leaves and nodes, the latter becoming weak. The plant bends over. The ears are imperfectly developed.

Neumann, Soc. Biol. Toulouse, 1892.

\section{THREAD BLIGHT OF TEA PLANT}

(Stilbum nanum, Massee.)

Indian tea-planters have known this most destructive fungus for at least the last thirty years. The name 'thread blight' is given on account of the very thin strands or films of white mycelium that are firmly attached to the branches and under surface of the leaves of the tea plant. The mycelium also runs under the surface of the branches, living in the tissues of the bark, and coming to the surface here and there to spread over the outside of leaves and twigs.

The fruit only appears to be formed on very old, rotten branches that have fallen to the ground and become decayed, and resembles pins in miniature-a very slender stem and a round head, the whole not half a line high. Repeated observation proves the fruit to be very rare, and infection from spores may be left out of consideration, except in the case of reclaimed ground, where the trees have been neglected for some time. 
The amount of evidence forthcoming seems to suggest that the mycelium travels underground, and first attacks the root, afterwards passing up the stem, either externally or internally, always finally coming to the surface.

Preventive Means.-It seems to be generally admitted that thread blight is common in the jungle on various plants; and to prevent its spread to the tea plants, narrow trenches should be kept open. These need not be very deep, as underground mycelium runs near the surface. By similar means, diseased patches in the plats should be isolated. Prunings should be burned and not buried, as each buried mass may prove a centre of infection. If quicklime is available, and not in other respects injurious to the tea plant, a shallow trench should be made round the stem, filled with lime, or lime mixed with sulphur, and covered over with soil.

Spraying with Bordeaux mixture or with potassium sulphide would check the external spread of the mycelium on the plant.

Watt, Pests and Blights of the Tea Plant, p. 433.

Cunningham, Scientific Mem. Med. Officers of Army of India, pt. x. p. 20.

Massee, Kew Bulletin, I898, p. I I I, figs.

\section{COFFEE TWIG DISEASE}

\section{(Necator decretus, Massee.)}

Bursting through the epidermis of young shoots as minute white spots, which soon become orange-red and gelatinous. Said to be a destructive parasite on coffee trees at Singapore. Commencing at the tips of young 
branches and extending downwards. Removing diseased branches checks the spread of the disease.

Massee, Kew Bulletin, I898, p. I 9.

\section{SLEEPING DISEASE OF TOMATO}

(Fusarium lycopersici, Sacc.)

This disease was first recorded from Guernsey, where the culture of tomatoes constitutes at present the principal source of revenue. It has also been recorded quite lately from widely separated localities in Britain. In some instances where only a small area is under cultivation, the annual loss has amounted to $£ 300$, and in some instances an average-sized house containing tomatoes will, if attacked by the disease, mean the loss of $£_{100}$ to $£_{200}$ in a season.

The disease is indicated by the dull colour of the leaves, which commence to droop; this is quickly followed by a collapse of the stem, hence the name 'sleeping disease.' If the plants are not attacked until the fruit is present, this frequently ripens, and to the naked eye, or even when examined microscopically, appears to be free from disease ; nevertheless it is well known that seed obtained from diseased plants produces diseased seedlings.

The root is invariably attacked first, the fungus gaining an entrance through the rootlets, gradually extending to the taproot and lower portion of the stem. Its presence is indicated to the naked eye by a brown discoloration of the vascular bundles, and when this stage is reached the plant droops, or 'sleeps.' Shortly after the sleeping stage has been reached, the portion of stem just above ground is more or less covered with a very delicate white 
mould. This mould consists of fruiting branches or conidiophores which bear conidia at the tips of their whorled branches. The conidia fall to the ground, where they
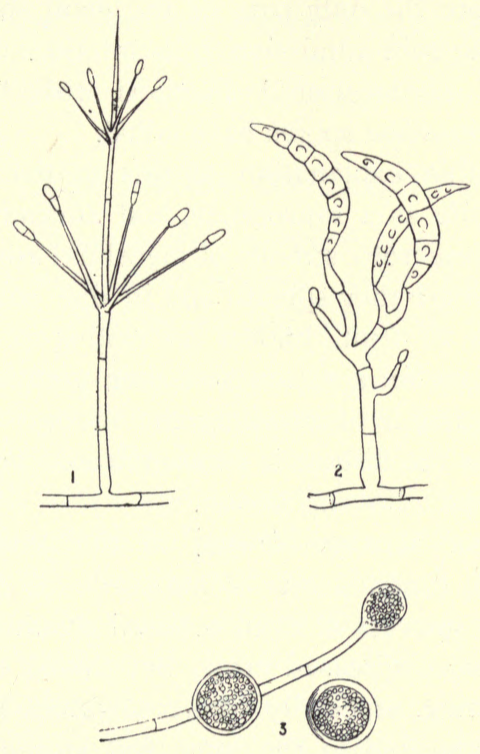

Fig. 90.-Fusarium lycopersici. I, Diplocladium stage, $\times 300 ; 2$, Fusarium stage, $\times 300 ; 3$, restingspores, $\times 300$.

germinate, producing a mycelium which attacks the rootlets of tomato, and continue the disease.

This is the first, or Diplocladium stage of the fungus, which is quickly followed by the second, or Fusarium condition, which forms from the same mycelium that previously produced the Diplocladium. The spindle-shaped, curved spores of the Fusarium stage are produced in 
immense numbers and germinate quickly, hence the very rapid spread of the disease can be readily understood.

It is somewhat remarkable that the young rootlets of the tomato are the only part of the plant through which the fungus can gain admission to its interior. All attempts to inoculate above-ground portions with either Diplocladium or Fusarium spores have failed.

The probable explanation of this is that the fungus commences life as a saprophyte, and afterwards becomes parasitic. Numerous strands of mycelium are also present in the soil, where they spread, and in due course produce a third form of fruit, known as resting-spores. These remain dormant for a season and then germinate, forming a mycelium capable of attacking the rootlets of tomatoes. By this means the disease is communicated to a new crop of tomatoes the following season.

Preventive Means.-Owing to the mode of attack, spraying with fungicides is of no avail. It is considered fortunate by growers if even a small quantity of fruit is obtained from a diseased crop; but this is obviously unsound reasoning, especially where tomatoes are grown in the same house and in the same soil year after year, for the simple reason that when a diseased crop is allowed to stand and mature its fruit, resting-spores innumerable are produced in the soil, ready to attack the succeeding crop, which in turn can only yield a very small quantity of fruit.

Plants should be removed on the first symptoms of disease, and the soil mixed with quicklime. Where the plants in a house have been badly diseased, all the soil should be removed, and the walls, etc., drenched with a solution of iron sulphate. 
Seed obtained from diseased plants, or from a neighbourhood where the disease prevails, should not be used.

Massee, Gard. Chron., June 8th, I895; also repeated in Journ. Roy. Hort. Soc., vol. xix. pt. I, figs. (1895).

Collenette, Journ. Roy. Hort. Soc., vol. xix. pt. I (1895).

\section{RED MOULD OF BARLEY}

(Fusarium heterosporum, Nees.

=Fusisporium hordei, W. G. Sm.

=Fusisporium lolii, W. G. Sm.)

Not uncommon on barley and rye, also occurring on maize and on several other grasses, as rye grass (Lolium) Holcus, Paspalum, Panicum, and Molinia. Met with in Europe, South Africa, and United States. The grain is the part attacked, and this is distorted and swollen by the dense tufts of sporophores which burst through the pericarp, and form an orange, crimson, or deep red subgelatinous mass on the surface of the fruit. The sporophores are branched, each branchlet bearing at its tip a slender, colourless, sickle-shaped spore, which usually becomes fiveseptate at maturity. Barley attacked by the fungus becomes valueless for malting purposes. A pure culture of the mould placed in sterilised beer-wort of specific gravity 1.057 gave rise to a peculiar ferment, producing alcohol and carbonic acid gas.

Preventive Means.-Use healthy seed not obtained from a district where the disease is known to occur, and be especially careful to prevent contamination from the fungus living on wild grasses growing in ditches or hedgerows. 
Matthews, Journ. Roy. Microscop. Soc., I883, p. 32 I, $2 \mathrm{pl}$.

Smith, Disexses of Field and Garden Crops, p. 209, figs. Frank, Jahrb. d. Deutsch. Landwirth. Gesell., I 892.

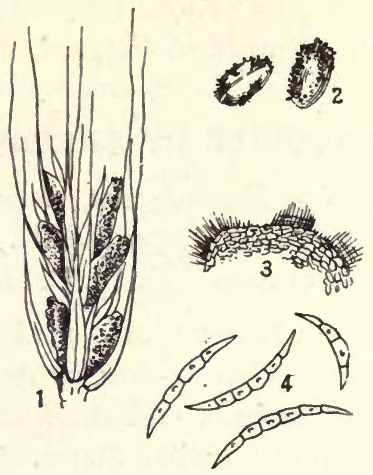

Fig. 91.-Fusarium heterosporum. I, portion of an ear of rye showing diseased grains; 2, diseased grains; 3 , portion of a diseased grain showing the dense clusters of sporophores on its surface, slightly $\times$; 4, spores, $\times 350$.

\section{FOOT-ROT OF ORANGE AND LEMON}

(Fusarium limonis, Briosi.)

A fungus causing considerable injury to orange and lemon trees in Europe and the United States. Its presence is indicated by the exudation of masses of gum near the base of the trunk. The diseased patches are small at first, but gradually increase in size, spreading round the trunk and passing into the roots, extending through the bark and cambium into the wood, killing the tissues. At the same time the leaves are few in number, small, and yellowish, and many of the smaller branches die. 
This disease is known as 'mal-di-gomma' in Italy, and 'foot-rot' in Florida.

Preventive Means. - Remove the soil from the base of the trunk, and cut away the diseased patches, painting the wounds with some fungicide. Good drainage is essential.

Briosi, Men. della R. Acad. Lincei, 1878.

Webber and Swingle, U.S. Americ. Dept. Agric., Bull. No. 8 (1896).

\section{RED MOULD OF WHEAT}

(Fusarium culmorum, W. G. Sm.)

This fungus attacks wheat, forming cream-coloured, yellow, or orange subgelatinous expansions on the ear, gluing the spikelets together, and arresting the growth of the grain. The spores are larger than those of $F$. heterosporum, fusiform, 3-5-septate, orange, soon breaking up at the septa.

Smith, Diseases of Field and Garden Crops, p. 208, figs.

Fusarium solani, Sacc., is said to cause the rotting of potato tubers, but the matter requires further investigation.

Fusarium pannosum, Massee.-This remarkable fungus forms broadly effused, felty, gelatinous expansions of a clear vermilion colour on the living trunk of Cornus macrophylla, Wall., in the Punjab.

\section{CLIVIA LEAF BLOTCH}

(Chaetostroma cliviae, Oud.)

Yellow blotches of large size and varied form appear on the leaves of Clivia nobilis, at first towards the margin, 
and finally scattered over the entire surface. At a later stage these blotches are studded with minute black spots or stromata, which on being magnified are seen to be bordered with a fringe of black, pointed hairs. The conidia are long, narrowly cylindrical, and colourless. No preventive measures appear to have been tried, but probably the spread of the disease could be checked by cautious spraying with a fungicide, very dilute, to commence with, until its action on the foliage is observed.

Oudemans, Comp. Rend. Acad. Roy. Sci. Pays-Bas, ı 896, p. 226 .

\section{MYXOGASTRES}

'FINGER-AND-TOE'

(Plasmodiophora brassicae, Woronin.)

This destructive disease, known in different parts as ' finger-and-toe,' 'club-root,' and 'anbury,' attacks the various kinds of cabbage, turnips, radishes, wallflowers, in fact most cultivated plants, as well as weeds belonging to the Order Cruciferae.

The root is the part most frequently attacked, the presence of the parasite being indicated by the formation of numerous nodules, or wartlike outgrowths, or the entire root becomes swollen and clubbed, eventually rotting and emitting a very disagreeable smell.

The disease also exists in the leaves, at least in the case of cabbages, but no distortion occurs, as in the root.

Berkeley appears to have been the first to investigate the disease; and, although he failed to determine the true cause, was convinced, as the result of microscopic 

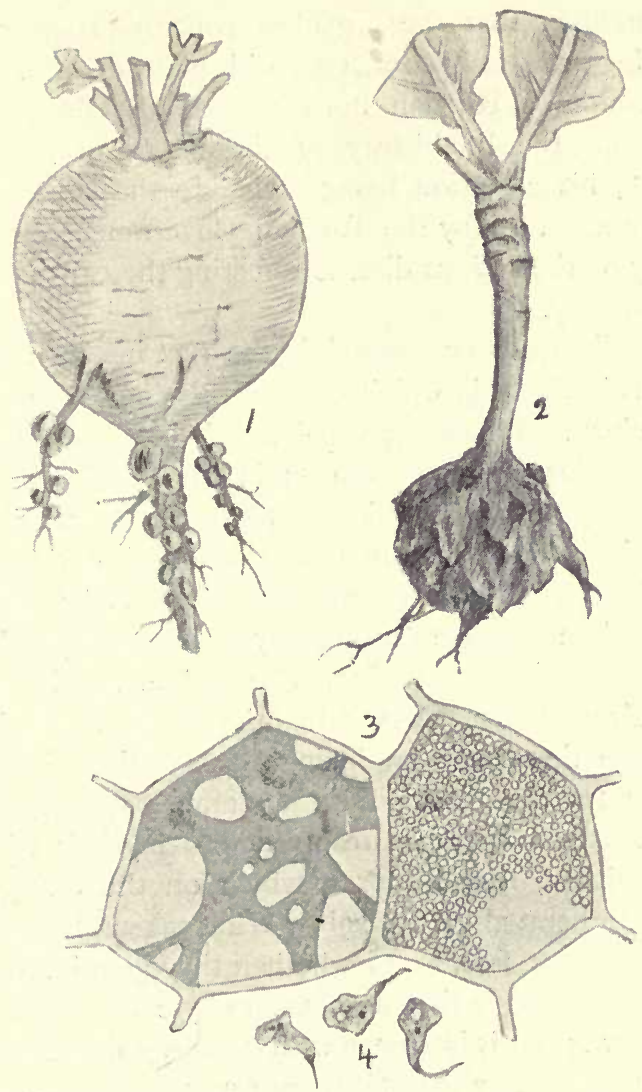

Fig. 92.-Plasmodiophora brassicae. I, a young turnip showing the early stage of the disease; 2 , a cabbage plant with clubbed root; 3 , two diseased cells from the root of a cabbage, one contains plasmodium, the other is crowded with the minute spores of the parasite; 4 , three myxamoebae or motile bodies produced by the spores on germination, very highly mag. 
examination, that the organism concerned differed from anything previously connected with plant disease.

Woronin, a Russian botanist, was the first to clearly work out the life-history of the organism causing the disease, his attention being called to the subject by the offer of a reward by the Russian Government for the discovery of the serious disease affecting the cabbage crop in that country.

The disease is contracted in the first instance by spores present in the soil, which enter the living cells of the root of the host. When once inside a living cell, the parasite does not form a mycelium as in the fungi, but a glairy mass of protoplasm called a plasmodium, which slowly alters its form from time to time, and constitutes the vegetative condition of the parasite. Cells containing plasmodium increase enormously in size, and furthermore the plasmodium passes from one cell to another, devouring their contents. After remaining in the vegetative state for some time, and producing the swellings in the root alluded to, the plasmodium undergoes certain changes, and eventually becomes resolved into myriads of exceedingly minute, round spores, which on the decay of the root are liberated in the soil. What takes place after the spores are set free, as to whether they germinate, form a plasmodium that exists as a saprophyte for some time, is not known; but it is known with certainty that if cabbages, turnips, or other allied plants are sown or planted in soil that has produced diseased plants the previous season, or even two or three years previously, such plants will become diseased.

Preventive Means.-From what has been stated, it will be seen that it is simply courting disaster sowing or 
planting cabbages, turnips, etc., in diseased soil; on the other hand, repeated experiments have proved that the application of quicklime destroys the germs in the soil. In the New Jersey Agricultural Coll. Experiment Station, Bulletin No. 98, devoted to the subject, it is stated: 'Lime is an effective preventive of the club-root, and, by its constant use, at the rate of seventy-five bushels or so per acre each year, cabbages have been grown at frequent intervals-almost yearly-upon the same soil.'

The use of artificial manures containing acids, phosphates, and sulphates, favours the spread of the disease. It has been demonstrated that soil from an infected locality, carried by means of cart-wheels, tools, etc., is sufficient to start the disease in a new locality.

Weeds such as shepherd's-purse, charlock, garlicmustard, and other crucifers should not be allowed to grow in places where cultivated plants belonging to the same Order are grown.

Do not throw diseased plants on to the manure-heap, but burn them.

Dr. Halsted states that the plants are most susceptible to the disease during the first three weeks after germination, and that thirty-five bushels of lime per acre is sufficient to arrest the disease.

Woronin, Pringsh. Jahrb., vol. xi., 1878, 6 pl.

Marshall Ward, Diseases of Plants, p. 47, figs.

Eycleshymer, Journ. Mycol., vol. viii. p. 79, 2 pl.

Massee, Proc. Roy. Soc., vol. lvii., I 895.

Halsted, American Gard., vol. xix. p. 373 (1898). 


\section{BRUNISSURE}

In Europe and North America a disease of the vine, characterised by the appearance of brown spots on the leaves, which eventually extend, and cover more or less the entire surface, has been considered by Viala and Sauvageau, as due to the presence of an amoeboid organism in the cells, to which they have given the name Plasmodiophora vitis, Viala and Sauv.

The California vine disease is also considered by these authors to be caused by an organism allied to the last, which they named Plasmodiophora californica, Viala and Sauv.

I have demonstrated elsewhere that Brunissure, also the disease on the leaves of cultivated orchids, known as 'spot disease,' is entirely due to physical causes.

Viala and Sauvageau, Journ. de Botanique, 1892, figs.

Viala, Malad. de la Vigne, ed. iii.

Massee, Ann. Bot., vol. ix. p. 42 I, I pl.

\section{BACTERIA}

\section{BACTERIOSIS OF TOMATOES}

Prillieux has described a bacterial disease of tomatoes, which is very destructive in the north and central parts of France; it has also occurred in England.

Inoculation is supposed to be effected through the style of the flower, and from this point a blackening of the fruit extends in circles until the whole is destroyed.

Prillieux, Malad. des Plantes Agric., vol. i. p. 19, fig. 


\section{HYACINTH BACTERIOSIS}

(Bacterium hyacinthi, Wakker.)

A destructive disease of hyacinths, well known in Holland, attacks the bulbs in the resting condition, and also shows itself in the foliage. The presence of the parasite is indicated by the appearance of yellow spots on the bulb or leaves, due to the presence of a yellow mucus teeming with bacteria, located in the vessels and intercellular spaces of the fundamental tissue. Infection of healthy plants with this mucilage produces the disease.

Wakker, Onderzoek der Zeikten van Hyacinthen, Haarlem, I 884 .

Prillieux, Malad. des Plantes Agric., vol. i. p. 22, fig.

\section{PINK BACTERIOSIS OF WHEAT}

\section{(Micrococcus tritici, Prill.)}

A bacterial disease of grains of wheat, indicated externally by a rose or purplish colour. The colour is brightest and most pronounced in the superficial layer consisting of proteids, less marked where starch predominates.

The starch is first attacked, causing the grain to become more or less hollow, afterwards the gluten, and finally the cell-walls.

The bacteria are globose or ovoid, depending on the phase of development, and form a thin, opaque, colourless, nodulose layer lining the cavity in diseased grains.

This is interesting as being the first account of a bacterial disease of cultivated plants causing real damage.

Prillieux, Ann. des Sci. Nat. Bot., 6th ser., vol. viii., I879; and in Malad. des Plantes Agric., vol. i. p. 7, figs. 


\section{BLACK ROT OF CABBAGE}

\section{(Pseudomonas campestris, E. F. Smith)}

A disease of cabbages and other Cruciferous plants, known in the United States for the last dozen years, and also recently detected in England, is diagnosed as follows by Dr. Erwin F. Smith :-

'This disease may appear on the plant at any stage of growth, and is characterised by the following symptoms: Dwarfing, or one-sided growth of the heads, or, if the disease is very severe and has begun early in the season, by the entire absence of any heads, and in extreme cases by the death of the plant. Occasionally the heads rot and fall off, but this is not a necessary consequence, the soft, bad-smelling rot being due to the entrance of other organisms. If the stumps of affected plants are broken or cut across, a brown or black ring will be observed corresponding to the woody part of the stem, this being the part of the stem specially subject to the disease. In bad cases this blackening may be easily traced upwards into the centre of the head, and is generally worst on one side. In the leaves the symptoms usually begin at the margins, and consist in yellowing of all affected parts except the veins, which become decidedly brown or black. The leaves appear to have "burnt edges."

The disease is caused by a yellow bacterium which enters the plant above ground, and usually at the margin of the leaves, through minute openings called water-pores, situated on the teeth of the margin of the leaf.

Slugs and caterpillars also spread the disease by gnawing alternately diseased and healthy plants, or by carrying the 
germs on their body, and, in crawling, depositing them in the region of the water-pores.

Preventive Means.-Rotation of crops is the best means of ridding the soil of the pest. Care should be taken not to allow Cruciferous weeds to flourish, otherwise the benefit of rotation of crops is lost, as the weeds may continue the disease. Slugs and cabbage-feeding caterpillars should be kept in check. Removal of infected leaves in the early stages of the disease should prove beneficial, as the disease passes down the leaf to gain access to the stem. Finally, it has been shown that when diseased cabbages have been converted into manure, the cabbages manured with this material have shown the disease.

Smith, in U.S. Dept. of Agric., Farmers' Bulletin No. 68 ; also in Centralh. fïr Bakter. Parasitenk. u. Infektionkrankheiten, 2 Abt., Bd. iii. pp. 284, 408, 478, pl. I.

\section{OLIVE TUBERCULOSIS}

(Bacillus oleae, Trev.)

In Italy and other portions of the Mediterranean region, olive trees are subject to a peculiar disease caused by a Bacillus, which causes the formation of irregularly nodulose tubercles on the branches. These tubercles vary in size from one-quarter of an inch to an inch in diameter, and superficially resemble galls of insect origin.

Preventive Means. - Removal of affected branches checks the spread of the disease.

Savastano, Annuario R. Scuola Sup. d'Agric. in Portici, vol. v. fasc. 4, I 887 .

Voglino, I Fungi Dannosi alle Piante Coltivate, I pl.

Pierce, Journ. Mycol., vol. vi. No. 4, p. I48, 2 pl. 


\section{BACTERIAL DISEASE OF TOMATO, EGG PLANT, AND IRISH POTATO}

\section{(Bacillus solanacearum, E. F. Smith)}

Dr. Erwin F. Smith has described in detail a bacterial disease of the above-named plants in the United States. Plants belonging to Physalis and Petunia were also proved to be susceptible to the disease. The disease first causes the foliage to wilt; at a later stage the stem and branches become discoloured and die. On cutting across a branch in the early stage of the disease the woody cylinder shows a brownish discoloration, and the vessels are filled with bacteria, which ooze out at the cut surface in tiny dirtywhite or yellowish drops.

In potatoes the disease passes down the stem and into the tubers, causing a brown or black rot.

In the egg plant (Solanum melongena) the symptoms are similar to those in the tomato and potato.

Preventive Means. - The disease has been proved to be transmitted by leaf-eating insects, the Colorado potato beetle (Doryphora decemlineata) being used for experimenting on the potato ; consequently leaf-eating and leafpuncturing insects should be kept in check. Diseased plants should be removed on the first indication of wilting. Rotation of crops should be resorted to where the disease has been present.

Smith, E. F., U.S. Dept. of Agric., Bulletin No. I2, $2 \mathrm{pl}$.

\section{LICHENES}

The larger foliaceous lichens are not parasitic; as to whether the smaller crustaceous forms that appear to be 
immersed in the bark, or the numerous species present on persistent, coriaceous leaves in the tropics, are more or less parasitic is yet an unsettled question. Apart from this, it is known that lichens are often injurious to trees when present on the trunk and branches in quantity, and this is more especially the case with nursery stock.

It has been shown by Waite that spraying with Bordeaux mixture of full strength kills the lichens present on pear trees. This method would, as a matter of course, prove equally effective in the case of other kinds of trees.

Finely powdered lime sprinkled on the branches during damp weather is also said to remove lichens.

Cephaleurus mycoide،, Karsten $=$ Cephaleurus virescens, Künze; Mycoidea parasitica, Cunningham.-This lichen is abundant on the polished, coriaceous leaves of many kinds of plants in tropical regions; among genera of economic importance may be mentioned Coffea, Citrus, Camellia, Anona, Cinnamomum, and Quassia. Dr. Watt states that in Assam it may be said to occur on any tree or bush the leaves of which have, like the tea plant, a fairly hard and polished epidermis on the upper surface.

On leaves the plant first appears as circular orange patches; at a later stage the patches change to green, or greyish-green, finally becoming white and polished like porcelain, and are circular or irregularly branched. Minute black spots are usually present on the white patches, corresponding to the ascigerous form of the fungus.

So far as the tea plant is concerned, it appears that so long as the disease is confined to the leaves but little injury results, whereas, according to Cunningham, when it 
attacks branches it becomes an undoubted parasite, and kills the parts attacked. As the disease on branches in all probability in many instances originates from infection by reproductive bodies formed on leaves in the first instance, its presence under any circumstances should be regarded with suspicion. Dr. Watt states that in the present state of knowledge regarding this blight the following remedial measures seem worthy of consideration :-

rst. Where shade trees are found to cause the leaves of tea underneath to be coated with the grey lichenoid formation and the orange-red algal patches, the trees in question should be removed.

2nd. Where the leaves of any plot of tea are found to be abnormally attacked by the alga, they should be plucked off and destroyed, or washed with Bordeaux mixture. In neighbourhoods liable to the form that invades the stem, every orange-red spotted leaf should be carefully removed and destroyed.

3 rd. The seedlings in the nursery, if found to manifest the orange-red spots, should be washed with the abovementioned fungicide, and in districts liable to the stem invasion they should be dipped into a tub of that fluid at the time of transplantation.

Cunningham, Trans. Linn. Soc. (Bot.), ser. II. vol. i. p. 30I, pl. xlii. xliii. (1879).

Marshall Ward, Trans. Linn. Soc. (Bot.), ser. II. vol. ii. p. 87 , pl. xviii. xxi. (I884).

Karsten, Ann. Jard. Bot. Buitenzorg, i 89i, pl. iv.-vi.

Cephaleurus parasiticus, Karsten.-Common on leaves of Calathea and Pandanus at Buitenzorg, Java. The epider- 
mal cells contain the alga, which spreads over the leaf, blackening and killing it.

Karsten, Ann. Jard. Bot. Buiten., vol. x., I pl. (I891).

Cephaleurus minus, Karsten, destroys the leaves of Zizyphus jujuba in Java.

Karsten, l.c.

\section{DISEASES OF UNCERTAIN ORIGIN}

(Rhizoctinia violacea, Tul.)

This remarkable fungous parasite, the fruit of which is not yet known with certainty, is too well known as being most destructive to saffron (Crocus sativus). The roots of many other plants are also attacked, including beetroot, potato, lucerne, carrot, asparagus; also many wild plants. The tubers or roots are invested by a more or less dense violet or brownish mycelium, which gives off violet rhizomorphs that anastomose irregularly, and traverse the soil, attacking adjacent roots. By this method the disease extends rapidly from a diseased centre, unless very prompt measures are adopted. Two forms of sclerotia are also developed, one kind being often as large as a hazel-nut, and minutely velvety, the other small, glabrous, and often densely crowded, resembling the perithecia of some Rosellinia in general appearance.

An ascigerous form of fruit-Leptosphaeria circinans, Sacc.-found on dead roots of lucerne (Medicago sativa) killed by the Rhizoctinia, may prove to be the perfect form of fruit, but this point is as yet undecided.

Preventive Means. - If the disease appears, the area should be isolated by a trench, throwing the removed soil 
into the diseased part, and all plants included should be carefully removed and burned. When a field has once become thoroughly infested, it has been proved that after an interval of twenty years saffron has been attacked at once, the fungus having lived in the meantime on the roots of various weeds.

Cereals which are not attacked by the Rhizoctinia should be sown on infected ground, and all weeds should be kept down; by these means alone can the fungus be destroyed.

Prillieux, Malad. des Plantes Agric., vol. ii. p. I44, figs.

\section{COTTON ROOT-ROT}

\section{(Ozonium auricomum)}

Bulletin No. 7 of the Texas Agricultural Experimental Station is devoted to an account of the above disease.

Ozonium was by the older mycologists considered as a true genus of Fungi; it is now known to consist only of sterile mycelium, usually of a brown or orange colour. Opinion differs as to the perfect or fruiting condition of Ozonium mycelium, which is probably a name covering the mycelium of many distinct species. The cotton rot has not yet been connected with any fruiting stage. It attacks the roots, more especially the taproot, which is surrounded by a weft of brown strands of mycelium. When this stage has been reached, the cotton plant wilts, then blackens and dies. The disease travels in the soil, spreading irregularly in all directions from the point first attacked.

Numerous forest and orchard trees, excepting the genus Prunus, also suffer from root-rot caused by this fungus, as do also the tubers of the sweet potato. Wet seasons, and 
especially rain followed by heat, favour the spread of the disease, which is always worst on badly drained land.

Preventive Means. - Rotation of crops appears to be the only known means of holding the pest in check. Members of the grass family should be used as the alternating crop, as these are not attacked by the fungus.

\section{THE PEACH ROSETTE}

A peculiar and very destructive disease attacking peach, plum, and almond trees is described by Dr. Erwin F. Smith as being very prevalent in Georgia. It agrees in some important points with the disease known as peach yellows, which has been investigated by the same author, but differs in the following particulars, which may be considered as furnishing the characteristics of peach rosette :-

(I) The entire tree is more apt to be attacked all at once, and the disease is more quickly fatal. Trees often die the first year, and I have not heard of any cases living beyond the second season. What corresponds to the first stage of yellows seems to be wanting.

(2) On the parts attacked many obscure buds and all or most of the winter buds push into diseased growths suddenly in early spring. The primary shoot-axes grow only an inch or two, but send out many short branches. This gives to each growth a compact, tufted form, and to the affected tree a very peculiar appearance, unlike anything heretofore described, and much resembling the work of insects. These stunted, green or yellowish rosettes often form the only foliage of large trees, projecting from the ends of long, naked twigs like leafy galls, or like house leeks tied to the ends of sticks. 
(3) The lower leaves on these tufts or rosettes roll and curl, turn yellow, dry up at the ends and edges, and fall early. They begin to drop before midsummer, and a slight jar shakes them off by the hundred.

(4) On the trunk and base of the main limbs it is rare to find anything more than rosettes, and often these are also wanting, the diseased growths being confined to the extremities of the branches.

(5) Diseased trees seldom bear fruit of any sort.

The following is Dr. Smith's summary:-The Scolytus rugulosus does not cause this disease, nor do I think it due to any other insect. Whatever be its cause, the disease is evidently increasing, and peach-growers should be on the alert to destroy it as soon as it appears. The affected trees should be dug out and burned as soon as discovered. The contagious nature of the disease is now beyond dispute, and it is not wise to let them remain a single day.

Smith, Journ. Mycol., vol. vi. p. 143, pl. viii.-xiii. (1891).

\section{SLIME-FLUX}

Weeping wounds, the liquid portion of which consists of various micro-organisms mixed with water, forming a glairy, repulsive mixture trickling down the trunk, are not uncommon on many fruit and forest trees. Such represent the 'Schleimfluss' of the Germans, and the 'Écoulement blanc, rouge, musqué,' etc., of the French. There is at present a difference of opinion as to whether such outflows originate the disintegration of tissue at the point from which the mucus originates, or otherwise.

L'écoulement blanc, viscid and alcoholic, is frequent on oaks, but occurs also on other trees. It is the result of the fermentation of all the elements of bark and cortex, down 
to the cambium zone, the agents in these pathological processes being Endomyces magnusii, Ludw.; Saccharomyces ludwigii, Hansen; and Leuconostoc lagerheimi, Ludwig.

A very full abstract of all that has been done in this particular branch of vegetable pathology, accompanied by copious references, is contained in Revue Mycologique, ı 896, by Professor Ludwig.

\section{F U N G I}

\section{PHYCOMYCETES}

Vegetative mycelium not forming a compact mass, but ramifying in the living tissues of plants or animals, rarely saprophytic. Asexual mode of reproduction by conidia produced on the surface of the host, which on germination produce zoospores or germ-tubes. Sexual reproduction by zygospores or oospores, produced in the matrix, which germinate only after a period of rest.

Chytridiaceae.-Parasitic on aquatic or aerial plants or animals. Mycelium absent or very rudimentary; asexual reproduction by zoospores; sexual reproduction by conjugation.

Olpidium, A. Braun.-Vegetative condition passive naked protoplasm, the product of one spore. This becomes enclosed in a thin cellulose wall, and forms the zoosporangium, the uniciliate swarmspores escaping through a beak, or the wall becomes very thick, and a resting-spore is formed, which gives origin to zoospores. Sexual reproduction absent.

Parasitic in living cells of plants or animals.

Olpidium brassicae, Dang., Ann. Sci. Nat., 1886, p. 327 (Chytridium brassicae, Wor., Prings. Jahrb., vol. xi. p. 557). 
Sporangia scattered, or several in a cell, globose, with a thin, colourless wall and a long, slender tube, which often passes through four or five layers of cells to reach the surface of the host. Swarmspores globose, oneciliate, with a glistening oildrop, and a vacuole. Resting-spores colourless or yellowish, solitary or clustered, thick-walled, warted. Germination unknown.

Saprolegniaceae.-Asexual reproduction by zoospores formed in zoosporangia borne on the hyphae; sexual reproduction by antheridia and oospheres, producing oospores.

Pythium, Pringsh.-Mycelium parasitic in living plants, intra- and intercellular; zoosporangia usually terminal, wall thin; zoospores always naked; resting conidia interstitial or terminal, often produced in large numbers; oogonia monosporous; wall of oospore colourless, smooth or ornamented.

Pythium de baryanum, Hesse, Ueber Pythium, etc., Hallenser Dissertat, I874.-Mycelium branched, septa rare; resting conidia spherical, thin-walled, terminating short branches, or interstitial, $20-25 \mu$ diam. Zoosporangia globose or broadly elliptical, often shortly papillate, terminal or intercalary; oogonia globose, membrane not perforated ; oospores globose, wall colourless, smooth, I 5I8 $\mu$ diam., forming a mycelium, and not zoospores, on germination. Antheridia clavate, on very short branches immediately below the oogonia, or on distinct branches.

Pythium intermedium, De Bary, Bot. Ztg., r88 r, p. 554, tab. v., f. I4-r6.-Conidia terminal, globose, in chains of $2-5$, terminal one largest, $18-24 \mu$ diam., on germination 
producing either a germ-tube or zoospores. Sexual reproduction unknown.

Mucoraceae.-Mycelium and sporangiophores hyaline or coloured; asexual reproduction by spores and chlamydospores; sexually by zygospores. Aërial.

Rhizopus, Ehrh.-Vegetative hyphae creeping, producing fasciculate rhizoids that penetrate the substratum; sporangiophores usually fasciculate, erect, coloured; sporangia globose, with a columella, many-spored, dark-coloured at maturity. Zygospores formed in the substratum, conjugating branches straight; suspensors very short and stout, without branchlets. Germination unknown.

Rhizopus nigricans, Ehrenb., Nova Acta Acad. Leop., x. I, 198, tab. xi., f. I-7.- Sporangiferous hyphae erect, in fascicles of 3-10, springing from stoloniferous hyphae that give off rhizoids at corresponding points; sporangia globose, blackish-olive, granular, $100-300 \mu$ diam., columella hemispherical; spores broadly elliptical or globose, grey, variable in size, 8-1 $4 \mu$ diam. Zygospore subglobose or tun-shaped, $150-200 \mu$. Epispore brown, with rounded warts.

Rhizopus necans, Massee, Kerw Bulletin, 1897, p. 87, I pl.--Sterile hyphae, creeping, forming a thin white felt; sporangiferous hyphae fasciculate, simple or forked, coloured, about $2 \mathrm{~mm}$. high, $20-25 \mu$ thick, springing from long, creeping stolons, which give off fasciculate rhizoids; sporangia globose, blackish-brown, smooth, about $250 \mu$ diam., columella large, subglobose; spores subglobose, minutely striate, pale olive-brown, $5-6 \mu$; zygosore tunshaped, 100-120 $\mu$ diam., blackish, covered with spinous warts. 
Peronosporaceae. - Conidiophores usually branched; conidia generally producing zoospores; sometimes directly forming a germ-tube; sexual reproduction by antheridia and oosphores producing oospores.

Cystopus, Lév.-Conidia concatenate, chains vertical, numerous, forming a sorus, which remains covered by the epidermis of the host until the conidia are mature, and then bursts through. Conidia all alike, producing zoospores; or the terminal conidium thicker walled, giving origin to a germ-tube, or sterile and protective in function. Oospores globose, epispore usually ornamented.

Cystopus candidus, Lév., Ann. Sci. Nat., ser. III. vol. viii. p. 371.-Sori white, shining, then powdery, often large and confluent, conidia all similar, globose, smooth, 15-17 $\mu$ diam. Oospore subglobose, 28-50 $\mu$, epispore yellowish-brown, with blunt warts, which sometimes pass into short, crooked ridges.

Cystopus tragopogonis, Schröet., Krypt.-Flor. Schles., III. i. p. 234.--Sori white, globose or oblong, flat, often concentrically arranged; terminal conidium largest, thickwalled, sterile, remainder shortly cylindrical, thin-walled, with an equatorial thickened ring, I6-22 $\mu$. Oospores globose, $45-65 \mu$, brown, with large, hollow warts, which are themselves minutely warted.

Phytophthora, De Bary.-Mycelium spreading in the tissues of the host, haustoria few or wanting; gonidiophores generally sparingly branched, gonidia at first terminal on the branches, then apparently lateral also, owing to continuation of growth of apex of conidiophore beyond the point of origin of the first conidium, elliptical, apex papillate, usually producing zoogonidia on germination. Oospores globose, epispore smooth, rather thin, brown. 
Phytophthora phaseoli, Thaxter, Bot.Gaz., vol. xiv. p. 273 (I889).-Mycelial hyphae branched, rarely penetrating the cells of the host by irregular haustoria. Conidiophores strongly swollen at their point of exit through the stomata, arising singly, or one to several in a cluster; simple, or once dichotomously branched, and once to several times successively inflated below the apices; conidia oval or elliptical, with truncate base and papillate apex, $35-5 \circ \times$ 20-24 $\mu$. Germination by zoospores, usually fifteen in number, or rarely by a simple hypha of germination. Oospores unknown.

Phytophthora'infestans, De Bary, Journ. Bot., n. ser. vol. v. p. I49 (I876).-Mycelium slender, haustoria absent; conidiophores solitary, or in clusters of 2-5, emerging through the stomata, simple or sparingly branched upwards, tapering upwards, above with scattered, swollen portions, corresponding to the points of origin of conidia, up to $\mathrm{I} \mathrm{mm}$. high, ro-I $2 \mu$ thick below, hyaline, forming a very delicate mould on the leaf; conidia lemon-shaped, colourless, with a prominent papilla, $25-30 \times 15-20 \mu$, procuring on germination 6-16 swarmspores; oospores unknown.

Phytophthora cactorum, Schroeter, Krypt. Fl. Schles., p. 236=Phytophthora omnivora, De Bary.-Hyphae variously branched, haustoria absent; conidiophores slender, simple, or sparingly unilaterally branched, often nodulose at intervals below the apex; conidia lemon-shaped, $50-60 \times 35-40 \mu$, liberating on germination up to 50 zoospores; oospore globose, smooth, yellowish-brown, 24-30 $\mu$ diam., often conglomerated.

Plasmopara, Schroeter.-Mycelium stout, furnished with 
small, entire, ovate haustoria. Conidiophores erect, sparingly branched; conidia generally papillate. Oospores globose, epispore thin, smooth, brownish.

Plasmopara viticola, Berl. et De Toni, Sacc., Syll., vii. p. $239($ 1888) = Peronospora viticola, De Bary.-Mycelial hyphae thick, often constricted and varicose, haustoria minute, spherical ; conidiophores fasciculate, coming to the surface through the stomata, slender, $250-850 \mu$ high, branched near the apex; primary branches $3-5$, alternate, secondary branches short, 3-4-furcate, ultimate branchlets pointed, straight, short, usually 4 , bearing the ovoid, smooth, colourless, not papillate, very variable in size, smallest $8 \times \mathrm{I} 2 \mu$, the largest $\mathrm{I} 7 \times 30 \mu$; oospores subglobose, 30-35 $\mu$ diam., wall thin, brownish, smooth or slightly wrinkled epispore, often very numerous in dead portions of the host plant.

Bremia, Regel.-Mycelium with vesicular or clavate, simple haustoria ; conidiophores repeatedly dichotomously branched, tips of ultimate branchlets vesicular and bearing several short, subulate sterigmata; conidia sphaeroid, papillate; oospores globose, minute, epispore yellowishbrown, subrugulose.

Bremia lactucae, Regel, Bot. Ztg., I 843, p. 665, tab. iii., f. B.-Mycelium stout, often contorted; haustoria clavate, simple; conidiophores 2-6 times dichotomously, or sometimes trichotomously branched, ultimate branchlets inflated at the tips, the inflated portion bearing several conical, short spicules, each bearing a subglobose conidium with a broad, depressed apical papilla, I6-23 $\mu$; oospores globose yellowish-brown, pellucid, epispore rugulose, 25-35 $\mu$.

Peronospora, Corda.-Mycelium generally bearing fili- 
form, branched haustoria; conidiophores solitary or fasciculate, emerging through the stoma of the host, dichotomously branched, ultimate branchlets often acute and curved; conidia ovate or elliptical, not papillate at the apex, giving off a lateral germ-tube on germination; oospores globose or subglobose, epispore smooth or variously ornamented.

\section{Epispore of oospore rugulose or netted.}

Peronospora trichotoma, Massee, Journ. Linn. Soc. (Bot.), xxiv. 45, 2 figs. (r 888).-Mycelium thick, haustoria clavate; conidiophores fasciculate, 2-3 times trichotomously divided; conidia small, obovate, or subglobose, 1 $2 \times$ 1० $\mu$; oospore globose, epispore brown, with ridges anastomosing to form an irregular network, 35-40 $\mu$.

Peronospora parasitica, De Bary, Ann. Sci. Nat., ser. IV. vol. xx. p. I Io (1863).-Mycelium thick, much branched, haustoria numerous, branched; conidiophores stout, flaccid, irregularly 5-8 times dichotomous or trichotomous, branches always repeatedly bifurcate, the last two orders of branches slender and curved; conidia broadly elliptical, 20-22 $\times 16-20 \mu$, apex very blunt, pure white; oospores globose, 26-43, smooth or slightly rugulose, pale yellowishbrown.

Peronospora effusa, Rabenh., Herb. Myc., Ed. i., I880. -Forming effused, greyish spots; conidiophores fasciculate, emerging through the stomata, short, thick, 2-7 times dichotomously branched above, ultimate branchlets thick, shortly subulate, curved downwards; conidia elliptical, pedicellate, pale dingy lilac, $25-35 \times 15-24 \mu$; oospores globose, epispore clear brown, more or less irregularly wrinkled, $25-40 \mu$. 
Epispore of oospore smooth.

Peronospora schleideni, Unger., Bot. Ztg., I 847 , p. 3 I 5. -Forming greyish-lilac tufts; conidiophores erect, $250-$ $400 \mu$ high, branched alternately, or in a dichotomous manner, ultimate and penultimate branches strongly curved; conidia obovate, apex obtuse or subacute, pale dingy violet, $44-52 \times 22-25 \mu$; oospores broadly elliptical or globose, epispore thin, smooth.

Peronospora trifoliorum, De Bary, Ann. Sci. Nat., ser. Iv. vol. xx. p. I I 7 (i863).--Conidiophores 350-450 $\mu$ high, forming broadly effused tufts, equally or irregularly 6-7 times dichotomous, rarely trichotomous, primary branches 4-5 times dichotomous; ultimate branchlets pointed, slightly curved; conidia ellipsoid, about 2 I $\mu$ diam., wall, pale violet; oospores globose, epispore thick, smooth, brown, 25-34 $\mu$ diam.

Peronospora schachtii, Fuckel, Symb. Myc., p. 7 I (1869-70).- Forming dense grey tufts; conidiophores erect, 6-8 times dichotomous, primary branches $2-5$, short, ultimate branchlets generally unequal, short, straight, wide-spreading, obtuse; conidia ovate, pale umber, 20-24 $\times$ I5-1 $8 \mu$; oospores globose, wall thick, smooth. Very closely allied to $P$. effusa.

Peronospora violae, De Bary, Ann. Sci. Nat., ser. IV. vol. xx. p. 125. - Forming somewhat dense, clear, pale violet tufts; hyphae rather short, about $300 \mu$, 4-7 times dichotomously branched, ultimate branchlets short, acute, deflexed; conidia elliptical, blunt, shortly apiculate, averaging $25 \times 18 \mu$, pale violet; oospore with a golden-brown epispore.

Peronospora cubensis, Berk. and Curt., Tourn. Linn. Soc 
(Bot.), vol. x. p. $3^{6} 3$ (1869).-Forming very delicate white patches on the under surface of the leaf; conidiophores repeatedly dichotomously branched, branches spreading, ultimate branchlets acute, straight, spreading; conidia hyaline, elliptical, 25-32 $\times$ i 8-20 $\mu$.

Peronospora hyoscyami, De Bary, Ann. Sci. Nat., ser. IV. vol. xx. p. I 23.-Forming dirty greyish-violet tufts of the under surface of the leaf, sometimes small, at others effused over the greater portion of the surface; conidiophores 300-500 $\mu$ high, averaging $300 \mu, 5-8$ times dichotomously branched near the apex, branches spreading, ultimate ones very divergent, short, awl-shaped; conidia small, elliptical, ends obtuse, pale dingy violet, I5-24X I3-1 $8 \mu$; oospore unknown.

Peronospora maydis, Raciborski, Ber. Deutschen Bot. Gesell., xv. p. 475, 4 figs. (I897).-Conidia emerging through the stomata, $0^{\circ} 3 \mathrm{~mm}$. high, and up to $25 \mu$ thick, with I-3 main dichotomous branches, which are divided at the tip into 3-6 conical, pointed branchlets, each bearing a smooth, hyaline, globose conidium I5-18 $\mu$ diam.; oospores globose, membrane smooth, I 4-24 $\mu$ diam.

\section{ASCOMYCETES}

Spores produced in large mother-cells or asci; asci either naked, or more frequently produced within an excipulum, or a perithecium; perithecium either with a distinct opening through which the asci escape at maturity, or rupturing in an irregular manner, but never exposing the disc or hymenium ; excipulum expanding and exposing the hymenium at maturity.

Gymnoasaceae. - Perithecium and excipulum absent, 
hence the asci are naked, and almost free on the surface of the host, I-4-8-spored, the asci frequently becoming crowded with myriads of secondary spores produced by germination of the ascospores within the ascus; paraphyses rare.

Exoascus, Fuckel.-Mycelium perennial in the hostplant, in some species much reduced, and located between the cuticle and the epidermis, in others more abundant, intercellular in the tissues below the epidermis, and causing malformations, as 'witches' brooms,' etc. Asci formed in a series below the cuticle through which they emerge to the surface at maturity, sometimes furnished with a stem-cell which is cut off from the ascus by a septum; stem-cell or base of ascus usually penetrating between the epidermal cells of the host. The asci at first contain 8 spores, but these often produce secondary spores of small size which completely fill the ascus.

Exoascus deformans, Fuckel, Symb. Myc., 1869, p. $25^{2}$. -Asci cylindrical, apex rounded, $35-40 \times 9$-10 $\mu$, stem-cell 6-8 $\times 6-9 \mu$, base somewhat pointed, and penetrating between the epidermal cells.

Exoascus pruni, Fuckel, Enum. Fung. Nassoviae, r86r, p. 29, fig. 26. -The asci are 40-55 $\times 8$-1 $5 \mu$, stem-cell ro-16 $\mu$ high, and about $5 \mu$ broad at the base, which is seated upon the epidermal cells, but not penetrating between them; spores averaging 4-5 $\mu$ diam.

Exoascus cerasi, Sadeb., Jahrb. der Hamburgischen Wissensch. Anstalten, x. 2, 48 (I 893).-Asci slender, clavate, apex rounded, 30-50 $\times 7$-10 $\mu$, stem-cell 10-16 $65^{-8} \mu$, occasionally only about $3-5 \mu$ thick; spores $6-9 \times 5-7 \mu$. 
Exoascus amentorum, Sadeb., Sitz.-Ber. d. Ges.f. Bot. z. Hamburg, iv., I888, p. 90.-Asci subcylindrical, base more or less pointed, often immersed for one-third of its length between the epidermal cells, $40-45 \times$ 10 $\mu$, stem-cell absent; ascospores usually $8,5 \mu$ diam.

Exoascus turgidus, Sadeb., Jahrb. der Hamburgischen Wissensch. Anstalten, x. 2, 59 (1893).-Asci 46-50 $\mu$ long, apex rounded or more or less narrowed, widening below to about $\mathrm{I}_{5} \mu$ wide; stem-cell conical, up to $30 \mu$ long, the pointed end passing between the cells of the host.

Taphrina, Fries.-Mycelium not perennial in the host plant. Asci as in Exoascus, but the original 8 ascospores produce quite early a large number of secondary spores, consequently the ascus is crowded with minute spores as soon as mature.

Taphrina bullata, Sadeb., Jahrb. der Hamburgischen Wissensch. Anstalten, viii. 29, tab. 4, f. 4 (1890).-Asci 36-40 $\times 8-9 \mu$, stem-cell 10-1 $5 \times 8-9 \mu$, not entering between the epidermal cells, and not narrowed at the point; ascospores $5 \mu$ diam.

Taphrina sadebeckii, Johans., Öfvers. af $K$. Vet.-Akad. Förh., I885, p. 38.- Asci varying in length between $4 \mathrm{I}-55 \mu$, and up to $15 \mu$ broad, stem-cell I8-22 $\mu$ high, and fairly thick, base rounded and but little, if at all, passing between the epidermal cells; ascospores $6 \mu$ diam., secondary conidia more frequently present in the asci.

Taphrina ulmi, Johans., Öfvers. af $K$. Vet.-Akad. Förh., I885.-Asci very variable, for the most part short, cylindrical, apex rounded, I2-20 $\times 8$-10 $\mu$, stem-cell $3^{-6} \mu$ high, and I $^{-1} 7 \mu$ broad; ascospores 3-5 $\mu$ diam.

Taphrina johansonii, Sadeb., Jahrb. der Hamburgischen 
Wissensch. Anstalten, x, 2, 74 (I893).-Asci subclavate, apex mostly rounded, 92-105 $\mu$ long, I6-25 $\mu$ thick at the free part, portion between the epidermal cells $30-50 \mu$ long, base about $8 \mu$ wide; ascospores about $4 \mu$ diam.

Taphrina aurea, Fries, Obs. Myc., pt. i. p. 217 (ISI5).Asci very variable, sometimes slender and deeply sunk in the leaf, 80-11 $2 \times 20-27 \mu$; others are stouter, rounded below, and entering but little between the epidermal cells, measuring $80 \times 30-40 \mu$; ascospores about $4 \mu$ diam.

Perisporiaceae.-Perithecia distinct, not produced on a stroma, coriaceous or subcarbonaceous, not provided with a distinct mouth, hence splitting irregularly to allow of the escape of the asci; mycelium superficial.

Microsphaera, Lév.-Perithecia containing many asci; asci ovoid or oblong, 4-8 spored; appendages branched at the tip.

Mierosphaera grossulariae, Lév., Ann. Sci. Nat., 1851, vol. xw. p. I60, tab. 9, f. 25--Mycelium cobweblike, greyish-white, on both surfaces of leaves; perithecia scattered, 75-I20 $\mu$, appendages $10-20$, once to twice as long as diameter of perithecium, 4-6 times dichotomously forked at the tips; asci $3-5$ : ovoid; spores 4-6, variable in size, i5-30 $\mu$ long.

Uncinula, Lér.-Perithecium containing several asci, which are 2-8-spored; appendages free from the mycelium, curled at the undivided tips.

Uncinula spiralis, Berk., Crypt. Bot., p. 268, f. 64.Mycelium arachnoid, amphigenous, often evanescent; perithecia minute, scattered, globose, blackish-brown, appendages $10-20$, variable in length, septate, occasionally forked, tips loosely and spirally twisted, basal portion 
coloured; asci ovate, pedicellate; spores 4-6, elliptical, ends rounded, $20 \times 8-10 \mu$.

Oidusm stage ( $=$ Oidum fuckeri).

Phyllactinia, Lév.-Perithecia globoso-depressed, containing many asci, large, appendiculate, seated on arachnoid mycelium; asci 2-4-spored; appendages acicular, straight, radiating, base inflated into a vesicle.

Phyllactinia suffulta, Sacc, Mich., ii. p. 50-Amphigenous or often most abundant on the under surface of leaves, cobweblike, often evanescent; perithecia scattered, hemispherical, at length depressed, large; asci 4-20, ovate, pedicellate, $80 \times 50 \mu, 2$, seldom $3-4$, spored, spores ovate, variable in size, $40-52 \times 22-25 \mu$.

Sphaerotheca, Lév.-Perithecia containing one ascus only; ascus subglobose, octosporous; spores elliptical, continuous, hyaline; appendages of the perithecium filamentous, tips not branched, mixed with the mycelium.

Sphaerotheca pannosa, Lév., Amr. Sä. Nat, i85 I, vol. sv. p. I 38 , pl. 6, f. 8.-Mycelium cottony then densely felted, white, then tinged ochraceous, persistent; perithecia minute, globose, scattered; appendages, floccose, hyaline, short; asci subglobose; spores 8, elliptical, 22-25X $13-16 \mu$

Conidia in chains, terminal one the oldest, elliptical, hraline, $20-30 \times 13-16$ pr-

Sphaerotheca castagnei, Lế, Ann. Sri. Not, I85I, vol. xv. p. I 39, pl. 6, f. 9, 1a-Forming a white, cobweblike, often evanescent mycelium on both surfaces of leaves or on inflorescence; perithecia scattered, spherical, minute; appendages numerous, short, brownish appendages with 
flexuous tips, mixed with the mycelium; asci globose or broadly ovate, $55^{-68} \times 4^{2-54} \mu$; spores up to 8 , broadly elliptic, hyaline, 15-20 12 12-1 $5 \mu$.

Sphaerotheca mors-uvae, Berk. and Curt., Grev., iv. p. I58.-Mycelium dense, thickish, margin white, centre brownish; perithecia minute, closely gregarious, black, globoso-depressed, rugose, left prominent by the collapsing mycelium, spores I $5 \mu$ long.

Erysiphe, Hedw.-Perithecia superficial, spherical or hemispherical, submembranaceous, yellow then blackish; appendages simple or vaguely branched, never dichotomous, intermixed with the mycelium, often undifferentiated or absent; asci, many in a perithecium; spores hyaline; conidia Oidium erysiphoides.

Erysiphe communis, Fries, Summa Veg. Scand., p. 406. - Mycelium effused, arachnoid, persistent, or evanescent, on both surfaces of the leaf; haustoria lobed; perithecia minute, scattered, or gregarious; appendages short; asci subglobose, 4-8-spored, $4-8$ in a perithecium, I I $\times 72$ $80 \mu$; spores elliptical, 40-42, 20-22 $\mu$.

Asterula, Sacc.--Perithecia seated on blackish, radiating, subsuperficial mycelium, lenticular or globoso-depressed, almost mouthless, membranaceous ; asci generally octosporous; spores continuous, hyaline.

Asterula beijerinckii, Sacc., Syll., ix. $376=$ Ascospora beijerinckii, Vuill., Journ. de Bot., I888, p. 255 figs.Mycelium plentiful, crustaceous ; perithecia globosodepressed; mouth very minute or absent, I00-I30 $\mu$ diam., black, carbonaceous, erumpent; asci numerous (up to 40), obovate, then cylindrical, I I० $\times 20 \mu$; spores elliptical, ends obtuse, continuous, hyaline, $17 \times 5^{-7} \mu$. 
Pycnidia $=$ Phyllosticta beijerinckii, Vuill. - Perithecia globose, pierced, surrounded by septate hyphae, ${ }_{5} \circ \mu$ diam., conidia elliptical, $6 \times 5 \mu$, extended in a viscid tendril. Considered by Vuillemin as the higher form of Coryneum beyerinckii.

Dimerosporium, Fuckel.-Perithecia superficial, mouthless, membranaceo-carbonaceous; asci short, 8-spored; spores I-septate, hyaline or fuscous ; mycelium copious, black, subcrustaceous, often bearing conidia.

Dimerosporium mangiferum, Sacc., Syll., i. p. $53=C a p$ nodium mangiferum, Cke. and Broome, Grev. iv. p. Ir 7.Effused, sometimes almost covering the entire surface of the leaf, amphigenous, velvety, intense black; perithecia narrowly ovate, elongated; asci broadly piriform, 48-50X 3० $\mu$; spores 8 , hyaline, I-septate, elliptical, slightly constricted at the septum, I 2-I $5 \times 5^{-6} \mu$.

Meliola, Fries.-Perithecia seated on superficial spots or effused patches of black, radiating mycelium, globose, mouthless, membranaceous, often surrounded by specialised bristles or appendages; asci often short and broad, 2-8spored; spores typically oblong, 2-5-septate, fuscous; sometimes truly continuous or muriform, hyaline, or fuscous.

Meliola penzigii, Sacc., Syll., i. 70.-Mycelium crustaceous, effused, black, readily peeling off; perithecia subglobose, superficial, glabrous, springing from threads of mycelium, umbilicate, black, I50-I60 $\mu$ diam.; asci obovate, apex rounded, sessile, 8-spored ; spores distichous or irregularly grouped, ovate-oblong, 3 -septate with one or more vertical septa also, constricted, I I-I $2 \times 4-5 \mu$, hyaline 
then tinged brown. Secondary fruit, Coniothecium Heterobotrys, Chaetophoma, Capnodium, etc.

Capnodium, Mont.-Mycelium effused, black, spreading over leaves, branches, and fruit ; perithecia rather fleshy or carbonaceous, simple or branched, vertically elongated, often torn at the mouth ; asci obovoid or oblong; spores 8 , ovoid-oblong, typically 3-4-septate, sometimes muriform, fuscous.

Capnodium citricolum, M'Alpine, Proc. Linn. Soc. N.S. Wales, 1896, pt. 4, pl. xxiii.-xxxiv. - Forming black, sootlike incrustations, peeling off as a thin membrane, often covering entire surface of leaf. Perithecia intermixed with spermogonia, antennaria, ceratopycnidia, and pycnidia, sea-green to sage-green appearing black, oblong to oval or variously shaped, rounded and smooth at free end, with netlike surface, II 2-250 $\times 5^{2-\text { I } 2 ~} \mu$; asci cylindric-clavate, subsessile, apex rounded, 8-6 or 4-spored, 70-80 $\times 1$ 9-20 $\mu$; spores brown, oblong, sometimes a little fusoid, generally obtuse at both ends, constricted about the middle, 5-6septate, often with longitudinal or oblique septa, arranged mostly in two ranks, but occasionally in three, averaging $2 \mathrm{I}-24 \times 8.9 .5 \mu$; paraphyses hyaline, elongate-clavate, as long as the asci, $9{ }^{\circ} 5 \mu$ broad towards apex.

Torula, Coniothecium, and Heterobotrys stages occur.

Sphaeriaceae.-Perithecia distinct or produced in numbers in the substance of a stroma, membranaceous, coriaceous, or carbonaceous, distinct from the substance of the stroma (when the latter is present), blackish, furnished with a distinct mouth through which the ascospores escape. 
Spores continuous, hyaline.

Trichosphaeria, Fckl., Symb. Myc., p. I44.-Perithecia subglobose, superficial, sparsely or densely pilose, sometimes seated on a byssus; asci oblong or cylindrical, 8spored; spores continuous, ovate, oblong-ovate, or subcylindrical, very rarely appendiculate, always hyaline.

Trichosphaeria sacchari, Massee, Ann. Bot., I893, p. 5I5, pl. xxvii. - Perithecia broadly ovate, blackishbrown, sparsely clothed with long, dark, rigid hairs; asci cylindrical; spores 8 , obliquely $\mathbf{I}$-seriate, hyaline, continuous, elliptic-oblong, $8-9 \times 4 \mu$; paraphyses absent.

Melanconium stage; oozing out to the surface of dying canes in the form of black, curved tendrils ; conidia produced in conceptacles situated in a stroma formed under the epidermis, I-septate, pale-brown, cylindrical, straight or very slightly curved, I 4-I $5 \times 3.5-4 \mu$.

Macroconidia.-Forming an intensely black, velvety layer, lining cracks and cavities in decaying canes; conidia in chains originating within the ruptured apex of a hypha; terminal conidium globose, $20-25 \mu$ diam., the others barrelshaped, i $8-20 \times$ i $2 \mu$, blackish-brown.

Microconidia.-Similar in origin and structure to the Macroconidia, but smaller ; growing on the diseased surface of the cane, and forming black, velvety patches.

Guignardia, Viala and Ravaz.-Perithecia innate, lenticular, usually with a projecting mouth, membranaceous; asci 8-spored, usually subclavate; spores elongated, continuous, hyaline; paraphyses absent.

Guignardia bidwellii, Viala and Ravaz, Bull. Soc. Myc. France, viii. p. 63 (1892)-Spermogonia (= Haemaspora 
ampelicida Engelm.).-Conceptacles innate, subglobose, mouth piercing the matrix; spermatia hyaline, cylindrical, slightly constricted at the centre, $1{ }^{\cdot} 5 \times \cdot 5 \mu$, borne on very slender conidiophores. Germination unknown.

Pycnidia (=Phoma uvicola, Berk. and Curtis).-Conceptacles indistinguishable from those of the spermogonia; conidia hyaline, elliptical, variable in size, 6-9 $\times 3-4 \mu$.

Perithecia.-These are the conceptacles of the Phoma stage, which produce asci the following season; asci clavate, obtuse, narrowed below, straight or slightly curved, 65-70 X I0-I I $\mu$; spores 8 , continuous, hyaline, slightly obovate, I 2-I $5 \times 6-7 \mu$; paraphyses absent.

\section{Spores I-septate, hyaline.}

Sphaerella, Ces. and De Not.-Perithecia membranaceous, subglobose or depressed, covered by the epidermis or erumpent, mouth indented or shortly papillate; asci 8-spored; spores elongated, I-septate hyaline, or very slightly tinged; paraphyses absent.

Sphaerella fragariae, Sacc., Syll., ii. p. 505.-Perithecia gregarious, often circinating, globose, black, innato-erumpent, seated on pale spots surrounded by a purple ring previously occupied by the conidial form 90-I30 $\mu$ diam.; asci oblong, 8-spored, $40 \mu$ long; spores I-septate, slightly constricted, hyaline, $15 \times 3-4 \mu$.

Conidia (Ramularia tulasnei, Tul.). - Conidiophores springing in tufts from the whitish, bordered spots; conidia narrowly elliptic-oblong, continuous, or $1-3$-septate, variable in size, $20-50 \times 2 \cdot 5-4 \mu$, hyaline.

Spermogonia.-Conceptacles resembling the perithecia in form, rather smaller, and mixed with the latter, containing myriads of ovoid spermatia about $3 \mu$ long. 
Sphaerella tabifica, Prill. and Dell., Bull. Soc. Myc. France, vii. 23 , figs (1891).-Perithecia rotund, brown, erumpent, mouth papillate, $150 \mu \mathrm{diam}$.; asci oblongclavate, obtuse, stipitate, 60-I $2 \mu$; spores hyaline, 2 -celled, upper cell ovate-rotund, lower narrower, slightly attenuated, septum below the middle, constricted, $2 \mathrm{I} \times 7.5 \mu$, 2 -seriate ; paraphyses absent.

Conidial stage (Phyllosticta tabifica, Prill. and Dell., Phoma betae, Frank).-Conceptacles subglobose, pierced by a pore at the summit; conidia escaping in a mucilaginous tendril, elliptical, hyaline, 5-7 $\times 3-4 \mu$.

Gnomonia, Ces. and De Not.-Perithecia covered or erumpent, glabrous, submembranaceous, often scattered, ostiolum more or less elongated, cylindrical, central, or lateral; asci 4-8-spored, tunic often perforated at the apex ; spores elongated, I-septate, hyaline; paraphyses usually absent.

Gnomonia erythrostoma, Auersw., Myc. Eur. Pyren., p. 26, f. I 2 7.-Perithecia innate, erumpent, shortly rostellate, texture parenchymatous, rufescent ; asci cylindrical, shortly stipitate, apex obtuse, apical lumen bifoveolate, 8-spored, IоO-IIоXI $2-15 \mu$; spores distichous, cylindric-oblong, rounded at both ends, spuriously i-septate below the middle, not constricted, 4-guttulate, hyaline, furnished with a small curved appendage which soon disappears, $18 \times 5^{-6}$ $\mu$; paraphyses absent. Fuckel describes spermagonia as follows :- Resembling Septoria. Perithecia? subsuperficial, gregarious on large, discoloured spots; spermatia filiform, continuous, curved, elongated, hyaline.

Dipaorthe, Nits.-Perithecia membranaceous or subcoriaceous, often greyish within, most frequently furnished with 
a filiform, long ostiolum, rarely short ; asci fusoid, 8-spored. Spores fusoid or subellipsoid, I-septate, generally constricted at the septum, hyaline, with or without appendages.

Sub.-Gen. Chorostate, Sacc.-Perithecia aggregated in clusters in a Valsoid manner.

Diaporthe (Chorostate) taleola, Sacc., Fung. Ven., ser. iv. p. 1 2.-Aglaospora taleola, Tul.-Stroma cortical, perithecia numerous, small, crowded in the centre, disc white, ostiola punctiform-immersed, smooth; asci cylindrical, 8-spored, I $52 \times$ I $4 \mu$; spores obliquely I-seriate, oblong-ovate, ends obtuse, I-septate, constricted, hyaline, with I slender appendage at each end, and 3 appendages springing from the median septum, I 8-24 $\times$ 7-9 $\mu$.

Spores 2-many-septate, hyaline.

Calospora, Sacc.-Stroma immersed in the bark, valsoid, pustulate ; asci typically 8-spored; spores oblong or fusoid, 2-pluriseptate, hyaline, with or without appendages; paraphyses present.

Calospora vanillae, Massee, Kew Bulletin, I892, p. I I I, I pl.-Perithecia subglobose, narrowed above into a neck; asci cylindric-clavate, 90-100 X I 2-1 $4 \mu$; 8-spored; spores elliptical, 3 -septate, hyaline, I 5-I $6 \times 5 \mu$; paraphyses slender. Cytospora form; perithecia globose, conidia hyaline, elliptical, continuous, 14-16×6-7 $\mu$. Hainesia form. Dull red or amber-coloured, gelatinous pustules, conidia subhyaline, continuous, 9-10 $\times 3 \cdot 5-4 \mu$.

Herpotricha, Fckl.-Perithecia carbonaceous, globose, clothed with long, crisped, creeping hairs, vertex flattened, subglabrous, discoloured, mouth minute, papillate; asci oblong, stipitate, 8-spored; paraphyses usually present ; 
spores subdistichous, ovate-oblong, or fusoid, I- then manyseptate, both ends sometimes papillately-apiculate, hyaline.

Herpotricha nigra, Hartig, Hedw., I888, p. I3.-Mycelium blackish-brown, widely effused, slender, furnished with haustoria, attacking living leaves which it kills; perithecia subglobose, black, $0^{\circ} 3 \mathrm{~mm}$. diam., clothed with long deflexed hairs towards the base; asci 76-100 $\times 12 \mu$; spores distichous, I- soon 3 -septate, constricted at the middle, 4-guttulate.

Acanthostigma, De Not., Sfer. Ital., p. 85.-Perithecia free, spherical, fragile, clothed with setae or hairs, papillate, with a perforate mouth; asci 8-spored; spores elongatefusoid, I-5 septate, hyaline; paraphyses present in some, absent in other species.

Acanthostigma parasiticum, Sacc., Syll., vii. 855.Perithecia subglobose, minute, mouth distinct, the upper portion with rigid, divergent bristles, $0^{\circ} \mathrm{I}-0^{\circ} 25 \mathrm{~mm}$. diam., and with the bristles $0.7 \mathrm{~mm}$. diam.; asci $5 \circ \mu$ long, soon disappearing; spores fusoid, straight, or curved, smoky-grey, I 5-20 $\mu$ long, soon 2 -3-septate.

\section{Spores continuous, coloured.}

Rosellinia, De Not. - Perithecia subsuperficial, subglobose, papillate, subcarbonaceous, black, glabrous, or hairy, or seated on a byssus; asci cylindric or cylindricclavate, 8-spored, spores continuous, broadly ovate or elongated and cymbiform, brown, with or without appendages; paraphyses present.

Rosellinia quercina, Hartig, Baumkrankh., p. ıоo, pl. 8, 9.-Perithecia scattered or subgregarious, seated on a black byssus or subiculum, large, black, globose, obtusely 
papillate, about I mm. diam., smooth; asci cylindrical or subclavate, base narrowed, I60-170 8-10 $\mu$, 8-spored; spores obliquely I-seriate, fusoid, guttate, both ends acute, brown, $28 \times 6-7 \mu$.

Rosellinia ligniaria, Nits., Fuckel's Symb. Myc., I 50 (1 86970).-Perithecia gregarious, globoso-conic, superficial, black, sparingly covered with minute hairs, $\frac{1}{3} \mathrm{~mm}$. diam.; asci cylindrical, stipitate, 8-spored, 80-96 $\times$ ıо-1 $2 \mu$; spores obliquely I-seriate, ends obtuse, blackish-brown, continuous, I $6 \times 8 \mu$.

Rosellinia necatrix, Berl. = Dematophora necatrix, Hartig. -Perithecia densely gregarious, seated on a byssus or subiculum, obovate, blackish, nearly $2 \mathrm{~mm}$. diam., surrounded at the base by fascicles of conidiophores; asci cylindrical, 8-spored ; spores fusiform, often inaequilateral, continuous, brown, $4 \circ \times 7 \mu$; paraphyses filiform ; conidiophores springing from small black sclerotia, fasciculate, branched; conidia elliptical, hyaline, 2-3 $\mu$ long; pycnidia springing from sclerotia, black, subglobose; stylospores hyaline, elliptical, continuous, or I-3 celled, averaging $25 \times 8 \mu$.

Rosellinia radiciperda, Massee, Kew Bull., ı896, p. I, I pl.-Ascophores densely gregarious, seated on a black, velvety byssus, globoso-depressed, mamillate, black, glabrous, large; asci cylindrical, apex truncate; spores 8, I-seriate, elliptic-fusiform, slightly inaequilateral, continuous, brown, 40-45 $\times$ 12. $\mu$; paraphyses filiform; pycnidia globosodepressed, sparingly pilose, black, stylospores elliptic-oblong, continuous, hyaline, continuous, $7-8 \times 4-5 \mu$; conidiophores springing in fascicles from small black sclerotia, much branched at the apex; conidia terminal on the branchlets, hyaline, continuous, elliptic-oblong, $7 \times 4 \mu$. 


\section{Spores muriform.}

Pleospora, Rabenh.-Perithecia scattered or subgregarious, immersed, or erumpent through the epidermis, spherical, ostiolum generally papillate, glabrous, membranaceous, rarely hard (Scleroplea); asci clavate, 4-8-spored; spores elongated, yellowish, or fuliginous, rarely hyaline (Catharinia); conidia, pycnidia, and spermogonia sometimes present.

Pleospora gummipara, Oud., Hedw., r883, p. I62.Perithecia formed in the neighbourhood of the pycnidia and conidia, black, glabrous, globose, $\frac{1}{6}-\frac{1}{4} \mathrm{~mm}$. diam., membranaceous, sometimes bearing sessile Coryneum conidia on the surface; asci $90 \times 18-20 \mu$, 8-spored; spores biseriate, 3 -septate, constricted at the septa, then becoming muriform, dark brown, $24 \times 12 \mu$; paraphyses absent; pycnidia, conceptacles resembling the perithecia, conidia brown, continuous, then transversely septate, finally muriform, about $7 \mu$ diam.

Conidia $=$ Coryneum gummiparum, Oudem., Hedw., I883, p. I31. - Fruit clusters very minute, dotlike, black, gregarious; conidia springing from a brownish prosenchymatous cushion, oblong or oblong-ovate, pale smoky-olive, 3 -septate, slightly constricted at the septa, $14 \times 6 \mu$; conidiophores colourless, shorter than the conidia.

Hypocreaceae.-Perithecia free, or more or less immersed in a somewhat soft, fleshy, waxy, or rarely a byssoid stroma, somewhat fleshy, or waxy-membranaceous, generally reddish (rarely bluish, olive-yellow, or pallid), never carbonaceous, mouth distinct; asci 4-8-many-spored, usually containing 8 spores; secondary conditions of fruit frequent. 
Claviceps, Tul.-Stroma stipitate, erect, capitate, springing from a sclerotium; perithecia immersed in the stroma, very slightly protruding; asci cylindric-clavate; spores filiform, continuous, hyaline; spermogonia and conidia present in some species.

Claviceps purpurea, Tul., Ann. Sci. Nat., I 853, vol. xx. tab. 3.-Mycelium developing in the ovary of various grasses and forming first a whitish, minutely velvety body on the surface of the ovary, covered with conidiophores bearing very minute conidia (=Sphacelia segetum, Lév.). Next the sclerotium increases in size and becomes hornshaped or cylindrical, slightly curved, purple-black, and rugulose externally. After a period of rest the sclerotium gives origin to one or several stipitate, subglobose, purplish, warted stromata 2-4 mm. diam., stem often crooked, I-3 cm. long; asci narrow, 8-spored; spores filiform, hyaline, continuous, arranged in a parallel fascicle, $50-70 \times \mathrm{I}^{\circ} 5 \mu$.

Epichloe, Fries.-Stroma sessile, effused, girdling the culm in grasses, bright-coloured or blackish, at first bearing conidia; perithecia immersed, mouth scarcely prominent; asci 8-spored; spores filiform, almost as long as the ascus, hyaline or tinged yellow, continuous or multiseptate, in some species separating at the septa into numerous cells, arranged in a parallel fascicle in the ascus.

Epichloe typhina, Tul., Fung. Carp., iii. p. 24.--Stroma entirely encircling the culm of various grasses, up to 3 $\mathrm{cm}$. long, at first whitish and producing ovoid, hyaline conidia $4-5 \times 3 \mu$; then yellow and finally tawny orange, minutely granulose from the projecting mouths of the perithecia ; asci cylindrical, slightly constricted just below 
the truncate apex, I30-200 $\times$ 7-10 $\mu$; spores filiform, hyaline, very delicately multiseptate, I30-I 50X I-I'5 $\mu$.

Nectria, Fries.-Perithecia distinct, caespitose, or scattered, sometimes seated on a fleshy stroma that has previously borne conidia ; ostiolum usually papillate, fleshy, or submembranaceous, soft, glabrous, downy, squamulose, or byssoid, brightly coloured, usually red or orange; asci cylindric-clavate, 8-spored; spores elongated, hyaline, I-septate; paraphyses absent or indistinct.

Nectria cinnabarina, Fr.-Perithecia caespitose, crowded on a pulvinate hemispherical, fleshy pink stroma, which at first bears minute, hyaline conidia, $6-8 \times \mathrm{I}^{\cdot} 5^{-2} \mu(=$ Tubercularia vulgaris) ; perithecia spherical, corrugated, cinnabar, then reddish-brown, mouth papillate; asci cylindric-subclavate, apex slightly narrowed, 8-spored, 60-90 $\times 8$-г $2 \mu$; spores I-2-seriate, oblong, ends obtuse, straight or slightly curved, hyaline, I-septate, I 4-I6 6 5-7 $\mu$.

Nectria ditissima, Tul., Carp., iii. p. 73, tab. I3, f. I-4.Perithecia usually broadly effused in very dense clusters, globose, obtuse, then papillate, polished, bright blood-red; asci cylindric-clavate, $82 \times 8 \mu, 8$-spored; spores ovateoblong, I-septate, hyaline, I $4 \times 5^{-6} \mu$.

Conidial form, Tubercularia crassostipitata, Fckl., conidia ovate-oblong, continuous, $6-8 \times 3-4 \mu$.

Nectria cucurbitula, Fries, Summ. Veg. Scand., 388.Perithecia usually in numerous scattered, very dense clusters, globose, polished, vermilion, shortly and obtusely papillate, not collapsing; asci cylindrical, slightly constricted below the apex, shortly stipitate, 8-spored, IooI Iо $\times 9$-Iо $\mu$; spores I-seriate, oblong-biconoid, I-septate, constricted at the septum, hyaline, I4-I $8 \times 6-7 \mu$. 
Nectria ipomeae, Halst., Rep. N. Jersey. Agric. Expt. St., I891, p. 28I, figs.-Perithecia in little clusters, conicoglobose, acutely papillate, verrucosely squamulose, red; asci cylindric-clavate, 8-spored; spores hyaline, cylindricoblong, I-septate, slightly constricted at the septum.

A Fusarium condition is present with this species.

Nectria pandani, Tul., Fung. Carpol., iii. p. 7 I (as a footnote).-Perithecia crowded, globose-ovate, papillate, pallid ; asci cylindrical, $80 \times 6 \mu$; spores monostichous, shortly lanceolate, straight, $10 \times 4 \mu$, I-septate.

Often accompanied by a conidial form scarcely differing from Acrostalagmus cinnabarinus, except in its pale colour. The Nectria springs from pustules of Melanconium pandani, Lév., of which it is suspected as being the ascigerous condition.

Nectria vandae, Wahrl., Orchideenwurzelpilze, p. I I, f. $20,23,24$.- Perithecia solitary or $3-5$ or more in a cluster on a reddish, well-developed stroma, pear-shaped, red, very furfuraceous, substance thickish, white near the ostiolum; asci 8-spored; spores obliquely I-seriate, elliptical, 8-10 $\times 4.4 \mu$, I-septate, slightly constricted at the septum, hyaline.

Conidia cylindrical, ends rounded, $20-30 \times 3.3-4.4 \mu$, borne on long conidiophores, forming dense tufts.

Nectria goroshankiniana, Wahrl., Orchideenzurzelpilze, p. I I, f. I 7, 22, 25.-Perithecia solitary or 3-5, rarely more, in a cluster, seated on a reddish-brown, welldeveloped stroma, ovoid, apex subacute, deep red, squamulose; substance thin, deep-red; asci 8-spored; spores obliquely I-seriate, lanceolato-elongate, I-septate, slightly constricted at the septum, tinged brown, 12-1 $5 \times$ 
4-5 $\mu$; conidia same as in $N$. vandae, inserted in tufts at the apex of the sporophore.

Polystigma, Pers.-Stroma rather fleshy, parenchymatous, effused, innate on the leaf, ochraceous, tawny, or reddish ; perithecia immersed ; asci 8-spored ; spored ovoid continuous; spermogonia usually present.

Polystigma rubrum, D. C., Mem. Mus., p. 337, pl. 4, f. 7.-Hypophyllous, suborbicular, reddish, then reddishbrown, ostiola sunk; asci clavate, 8 -spored ; spores ovoid, obtuse, straight, subhyaline, г $\circ 6 \mu$.

Spermogonia (Libertella rubra, Bonor).-Spermatia filiform, curved, $30 \mu$ long.

Dothidiaceae.-Compound, stroma pulvinate, effused, or linear, coriaceous or carbonaceous (not fleshy), blackish (not brightly coloured); perithecia or loculi confluent and homogeneous with the substance of the stroma, but distinctly defined, mouth distinct; asci 4-8-spored; spores often hyaline, rarely brownish; secondary forms of fruit common.

Plowrightea, Sacc. - Stroma convex-pulvinate, often confluent, and form an extended crust, thickish, coriaceous, becoming black; asci elongated, 8-spored; spores ovoid or elliptical, I-septate, hyaline, or faintly tinged with yellowish green; conidia and pycnidia known in some species.

Plowrightia morbosa, Sacc., Syll., ii. 638 (I883).Stromata caestipose, forming large, elongated, nodulose, rigid, black incrustations on branches. Conidiophores bearing ovoid olive conidia, about I $6 \mu$ long, first covering young stromata with a blackish-olive velvety layer; peri- 
thecia crowded, variable in form; asci cylindric-clavate, I I0-I50 X I6-I $8 \mu$; spores obovate, hyaline, I-septate, basal cell much the smaller of the two, I5-20 $\times 8$-10 $\mu$; pycnidia resembling the perithecia, containing elliptical, pale yellow, 3-septate stylospores, I0-I $2 \times 6-7 \mu$; spermogonia also similar to perithecia, containing exceedingly minute spermatia.

Plowrightia ribesia, Sacc., Syll., ii. p. 635 (1883).Stroma transversely erumpent, convex, black, minutely granular with the ostiola, up to $2 \mathrm{~mm}$. long; loculi occupying the periphery, minute; asci 85-I00 $\times$ I2-I4 $\mu$; spores 8, distichous, elongato-fusoid, slightly curved, unequally I-septate, yellowish-white, I8-20 × 5-6 $\mu$.

Hysteriaceae.-Ascophore erumpent, innate, or superficial, elliptical or linear, or vertical and compressed, carbonaceous or membranaceous, dehiscing by a long, narrow slit, black or blackish-brown, disc not exposed at maturity; asci 4-8-spored; spores hyaline or coloured, continuous or septate; paraphyses usually present.

Lophodermium, Chev. - Perithecia innate, elongated, membranaceous, dehiscing by a longitudinal slit; asci clavate or cylindric-clavate, 8-spored; spores hyaline, filiform guttulate, almost as long as the ascus, arranged in a parallel fascicle; paraphyses filiform.

Lophodermium macrosporum, Rehm, Krypt.-Flora, p. 45.-Apothecia black, elliptical, arranged on either side of the nerve; asci clavate, apex narrowed, Io० $\times$ I 5-2I $\mu$; spores needle-shaped, continuous, $75 \times \mathrm{I}^{\circ} 5 \mu$; paraphyses filiform, apex hooked.

Lophodermium nervisequum, Rehm, Krypt.-Flora, 
p. 44.-Perithecia forming a single line on the nerve on the under side of the leaf; spermogonia a year earlier on the upper surface; asci clavate, apex narrowed, 70-100 $\times$ I 5-20 $\mu$; spores linear-clavate, continuous, 50-60 $\times 2-2.5 \mu$; paraphyses hooked at the tips.

Lophodermium pinastri, Chev., Flor. Paris, i. 430.Perithecia scattered, many usually surrounded by a black line, epiphyllous, innately immersed, elongated, black, glabrous, finally longitudinally split, disc livid; asci cylindric-clavate, apex narrowed, 8-spored, II 5-I65 $\times$ I4I $7 \mu$; spores in a parallel fascicle, filiform, apex thickened, guttulate, hyaline, I०0-I $40 \times \mathrm{I}^{\cdot} 5^{-2} \mu$; paraphyses slender, tips curved.

Discomycetaceae. - Excipulum fleshy, rarely subcarbonaceous, clear-coloured, rarely blackish, glabrous, downy, or hairy, closed at first, then expanding and exposing the disc at maturity, sessile or stipitate, sometimes springing from a sclerotium; asci 4-8-rarely-many-spored; spores hyaline, rarely coloured, continuous or septate; paraphyses present.

Rhytisma, Fries.-Ascophores crowded on a thin, broadly effused, black, crustlike stroma; elongated, often more or less wavy, finally gaping and exposing the pale disc; asci clavate, 8-spored; spores linear, hyaline, continuous, arranged in a parallel fascicle in the ascus; paraphyses slender, often curved at the tip.

Conidia are formed on the stroma before the ascospores in some species. By some considered as belonging to the Pyrenomycetae.

Rhytisma acerinum, Fries.-Stroma forming thin, black, crustlike patches on living leaves, $\frac{1}{2}$-I in. broad; ascophores 
appearing in the spring on fallen, dead leaves, elongated, wavy, gaping, disc pale ; asci clavate; spores needle-shaped, about $60-80 \times \mathrm{I}^{\cdot}{ }^{-2} \cdot{ }^{-2} 5 \mu$; paraphyses slender, curved at the tip; conidia cylindrical, hyaline, straight, or curved, 6-9 $\times$ I $\mu$.

Rhytisma punctatum, Fr.-Stroma black, broken up into small detached pieces, seated on a yellow spot on living leaves; ascophores circular or elongated; asci clavate, tip narrowed; spores 8 , needle-shaped, apex blunt, base pointed, arranged in a parallel bundle, $35-40 \times \mathrm{I}^{\cdot} 5^{-2} \mu$; paraphyses slender; conidia cylindrical, straight, hyaline, $5-6 \times{ }^{\circ} 5 \mu$.

Rhytisma salicinum, Fries, Vet. Akad. Handl., I819, p. 104.-Stroma forming circular or irregular, thickish, shining black patches on the upper surface of leaves; asci clavate, apex narrowed; spores 8, needle-shaped, pointed at both ends, curved, continuous, guttulate, hyaline, $65-95 \times \mathrm{I}^{\cdot} 5^{-2}{ }^{\circ} 5 \mu$; paraphyses slender, tips wavy.

Pseudopeziza, Fckl.-Parasites or saprophytes; ascophore erumpent, sessile, sometimes narrowed at the base, glabrous, minute; asci narrowly clavate, apex usually narrowed, 4-8 spored; spores hyaline, smooth, narrowly elliptical or fusiform, continuous or I-septate; paraphyses present.

Pseudopeziza trifolii, Fckl., Symb. Myc., p. 290.-Epiphyllous, sessile, gregarious, in small clusters on dark spots, erumpent, soon plane, dingy yellow, glabrous, about $\frac{1}{3}$ $\mathrm{mm}$. across; asci clavate, 8-spored, spores irregularly 2-seriate, hyaline, elliptic-oblong, or sometimes slightly broader at the apex, 10-1 $5 \times 5^{-6} \mu$; paraphyses hyaline, rather stout, sometimes branched. 
Dasyscypha, Fries.-Ascophore minute, shortly stipitate or sessile, closed at first, gradually expanding externally, and the margin pilose or downy; asci cylindric-clavate, 8 -spored; spores irregularly 2 -seriate, hyaline, smooth, narrow, and elongated, continuous or I-septate at maturity; paraphyses lanceolate or cylindrical, often longer than the asci.

Dasyscypha calycina, Fuckel.-Caespitose, gregarious, or scattered, narrowed into a short, stout, stemlike base, rather fleshy, up to I line broad; disc orange-yellow; externally white, villose ; asci subcylindrical ; spores hyaline, ellipticfusiform, continuous, $18-25 \times 6-8 \mu$; paraphyses slender, cylindrical.

Sclerotinia, Fuckel.-Ascophore solitary or gregarious, springing from a sclerotium, stipitate, at first closed, gradually expanding until saucer-shaped or plane, glabrous, brown; asci narrowly cylindrical, 8-spored; spores obliquely I-seriate, hyaline, continuous, and smooth; paraphyses slender.

Conidial form (=Botrytis and Monilia) often present; ascophore absent in some species, the conidial form absent in others.

* Ascigerous and conidial forms knonen.

Sclerotinia fuckeliana, Fuckel, Symb. Myc., p. 320.Ascophores I-3 springing from a small scleratium, soon plane, $0^{\circ} 5-3 \mathrm{~mm}$. broad, yellowish-brown; stem very slender, 5-10 $\mathrm{mm}$. high; asci cylindric clavate, I30XI 2-1 $3 \mu$; spores elliptical, hyaline, Io-I I $\times 6-7 \mu$.

Conidial form (=Botrytis cinerea, Pers.).-Sterile hyphae creeping, fertile, erect, gregarious, simple or sparingly 
branched, and with several short, simple, or divided branchlets near the apex, ultimate branchlets spinulose, septate, slightly constricted at the septa, smoky-brown, 200-300 $\times$ 1 2-1 $6 \mu$; conidia broadly elliptical or subglobose, apiculate, almost colourless, Iо-І $2 \mu$ diam., forming globose heads.

Sclerotinia bulborum, Rehm, Krypt.-Flora, p. 8ig.Ascophores I- 3 in number, springing from an irregularly elliptical sclerotium, blackish externally, 8-12 mm. diam.; at first closed, then expanding, brown, $3-5 \mathrm{~mm}$; stem slender, IO-I $5 \mathrm{~mm}$. long; asci narrowly cylindrical ; spores 8, elliptical, I4-16 6 7-8 $\mu$; paraphyses slender.

Botrytis form.-Compact, brownish-buff tufts, tips of fertile branchlets spinulose, each spine bearing a smooth, hyaline, elliptical, apiculate conidium, 9-1० $\times 7 \mu$.

Sclerotinia oxycocci, Wor., Mem. Acad. St. Petersb., I888, p. 28 , pl. vii.-Ascophore slenderer than in $S$. vaccinii, stem slender, crooked, $5 \mathrm{~mm}$. long, fixed to the ground by rhizoids, springing from a fruit sclerotium; asci cylindrical, spores 8 , of two different sizes, 4 measuring I $2-\mathrm{I} 4 \times 6 \mu$, and 4 measuring $8 \times 3^{-4} 4$; paraphyses clavate, tips brown.

Conidia Oidium-like, forming a whitish mould on leaves and slender branchlets; broadly elliptical, $25-28 \times 16-22 \mu$; disjunctors present.

Sclerotinia urnula, Rehm, Krypt.-Flora Disc., p. 804 (=S. vaccinii, Wor.).-Ascophore solitary, rarely two from a fruit-sclerotium, chestnut-brown, $5^{-1} 5 \mathrm{~mm}$. broad, stem usually crooked, slender, $2-10 \mathrm{~cm}$. long, fixed to the ground by rhizoids near the base; asci cylindrical, $150-$ I $80 \times 7-8 \mu, 8$-spored, spores of two sizes, elliptic-oblong, ends obtuse, the four largest I $_{2-1} 5 \times 5^{-6} \mu$, the other four 
slightly smaller; paraphyses slightly clavate, tips brownish. Conidia Oidium-like. Forming a delicate white mould on leaves and twigs. Conidia in chains, lemon-shaped, $3^{\text {I- }} 3^{2} \times 19^{-2} 5 \mu$; disjunctors present.

Sclerotinia baccarum, Rehm, Hedw., 1885, No. I.Ascophores usually 2-3, from a sclerotium, brown, 3-10 mm. broad, narrowed into an often crooked, dark stem $0^{\circ} 5-5 \mathrm{~cm}$. long; asci cylindrical, I 20-1 50 $\times$ I0-1 $2 \mu$, 8-spored, four of which are only perfect as a rule, elliptical, ends obtuse, I 8-2 I $\times$ 9-I I $\mu$; paraphyses septate, clavulate.

Conidial form Oidium-like, forming a white mould on the concave side of curved branches, concatenate, nearly globose, with disjunctors.

Sclerotinia megalospora, Woronin, Mem. Acad. St. Petersb., r888, vol. xxxvi. No. 6, p. 35, pl. 9, го.-Asco phore solitary, or sometimes two springing from the fruitsclerotium, dark brown, 3-7 $\mathrm{mm}$. broad; stem very slender, $2-4 \mathrm{~cm}$. long; asci cylindrical, very large, 8-spored; spores elliptical, I9-25 $\times$ I4-16 $\mu$; paraphyses stout, branched above, septate.

Conidia Oidium-like, forming a greyish hue on the nerve of the under side of the leaf, produced in chains, globose, 24-30 $\mu$ diam. ; disjunctors minute.

* Ascigerous form only known.

Sclerotinia sclerotiorum, Massee, Brit. Fungus-Flora, iv. p. 280.- Solitary or 2-4 ascophores springing from a black, usually elongated, often irregular sclerotium $\mathrm{I}-2 \mathrm{~cm}$. long; at first small and closed, expanding until almost plane, pale brown, 3-7 $\mathrm{mm}$. broad; stem slender, $\mathrm{I}-3 \mathrm{~cm}$. long; asci narrowly cylindrical; spores 8 , elliptical, $9^{-\mathrm{I}} 3 \times 4-6 \mu$; paraphyses slender. 
Sclerotinia tuberosa, Fckl., Symb. Myc., p. 331.Ascophores 2-6, springing from an irregularly elliptical sclerotium, up to $3 \times \mathrm{I}^{\circ} 5 \mathrm{~cm}$. buried in the ground, externally black, inside white ; ascophore at first pear-shaped and closed, then funnel-shaped, finally almost plane, bright brown, I-3 cm. across; stem slender, $2-7 \mathrm{~cm}$. long; ascus cylindrical; spores elliptical, I5-I $8 \times 6-7 \mu$; paraphyses septate, slightly thickened upwards.

Sclerotinia trifoliorum, Erik., Kgl. Landtbr. Ak. Handl., I880, No. I.-Apothecia usually solitary, springing from a small black sclerotium, at first closed, then expanding, yellowish-brown, I-Io mm. across; stem slender, 3-28 mm. long; asci cylindrical, I60-I80 $\times$ I2-I $4 \mu$; spores elliptical, ends obtuse, I 6-I $8 \times 8-9 \mu$; paraphyses slender, septate, up to $7 \mu$ thick at the enlarged apex.

\section{*** Conidial form only knozen.}

Sclerotinia galanthi, Ludw., Lehrb. d. nied. Krypt., p. 355.-Ascigerous condition unknown.

Conidial stage (Botrytis (Polyactis) galanthina, B. and Br.). Forming a grey mould on dying leaves and flowerspathes; hyphae shortly branched upwards, coloured, branchlets thickened at the tips; conidia obovate $5_{5-1} 8 \times$ IO-I I $\mu$, forming heads, springing from slender sterigmata. Numerous small black sclerotia are formed on the dead parts of the host, and in the bulb scales.

Sclerotinia douglasii, Massee; Botrytis douglasii, Tubeuf, Beitr. z. Baumkr., 4, tab. I ; Sacc., Syll. x. 536.Conidiophores brownish, passing through the stomata, solitary or fasciculate, branched towards the summit, alınost continuous, branchlets dilated and denticulate at the 
tips; conidia grouped in heads, almost colourless, about $9 \times 6 \mu$.

On living leaves and youngest internodes of seedling Abies douglasii and Sequoia gigantea.

Distr.-Germany, Holland, England.

Sclerotinia parasitica, Massee ; Botrytis parasitica, Cavara, App. Pat. Veg., ro, tab. vi. f. r-4; Sacc., Syll., x. 536.-Conidiophores grey, scattered, erect, basal joint inflated; conidia obovate, large, shortly pedicellate, on short umbellately arranged branchlets, hyaline or tinged grey, $16-2 x \times 10-13 \mu$; sclerotia formed in the parenchyma of the host, globoso-depressed, smooth, greyish, then black, 2-3 mm. diam., sometimes numerous, and forming black crusts.

Botrytis on leaves, stem, and flowers of cultivated tulips; sclerotia more especially on the bulbs.

Distr.-Holland, Britain.

Sclerotinia paeoniae, Massee; Botrytis (Phymatotrichum) paeoniae, Oud., Comptes Rendus de l'Acad. Sci. Pays-Bas, I897.-Conidiophores pale brown, erect, very numerous, not caespitose, but equally diffused over the infected part, $\frac{1}{4}$-I mm. high, branched upwards, branchlets 3-5, spirally arranged, spreading, simple or variously divided, tips dilated, muriculate. Conidia forming heads, oblong or ovate-oblong, colourless or tinged, attached to very slender sterigmata springing from the inflated tips of the branchlets. On the stems of cultivated paeonies.

Distr.-Holland, England.

Sclerotinia douglassii, Massee = Botrytis douglassii, Tubeuf.-Mycelium endogenous, fuliginous, septate, $x_{4} \mu$ thick; fertile hyphae subfasciculate, tinged brown, erect, 
dendroidly branched upwards, subcontinuous, branchlets spreading, tips dilated, toothed; conidia crowded in heads, ovoid, subhyaline, $9 \times 6 \mu$. Minute black sclerotia are formed in the parts attacked. Ascigerous stage unknown.

Peziza, Dill.-Ascophore sessile, fleshy, brittle, closed at first, gradually expanding, often until quite flat, or even recurved, externally warted or scurfy; flesh composed of large polygonal cells; asci cylindrical, 8-spored; spores in I row in the ascus, hyaline, elliptical, continuous; paraphyses present.

Peziza vesiculosa, Bull.-Clustered, fragile, globose, and closed at first, gradually expanding, disc pale brown, exter nally brownish, granular, whitish downy towards the base, I-2 in. across; tissue parenchymatous, cells irregularly polygonal, large ; asci cylindrical, 8-spored, spores in one row, smooth, hyaline, bluntly elliptical, $2 \mathrm{I}-24 \times \mathrm{II}-\mathrm{I} 2 \mu$; paraphyses septate, clavate. Conidial stage (=Oedocephalum fimetarium, Reiss) white, with erect fertile hyphae having the apex globose and studded with very delicate spicules, from which the conidia spring and form a dense head. Conidia hyaline, continuous, obovate, 8-10X 3-4 $\mu$.

Bulgaria, Fries.-Ascophore more or less gelatinous, erumpent, at first closed, the disc gradually expanding and becoming plane, narrowed into a short, thick, stemlike base ; asci narrowly clavate, 4-8 spored; spores in one row in the ascus, continuous, brown; paraphyses slender, tips curved.

Bulgaria polymorpha, Wettst.-Gregarious or clustered, bursting through the matrix as a rusty-brown, scurfy knob, 
the disc gradually expanding until flat, black, shining, $\frac{3}{4}$-I $\frac{1}{2}$ in. across ; flesh gelatinous, brown; asci usually containing only four elliptical, slightly curved, brown spores, measuring Io-I $4 \times 5^{-6} \mu$; paraphyses brownish, curved at the tip.

Rhizina, Fries.-Ascophore sessile, expanded from the first, and forming a crustlike, fleshy structure, furnished on the under surface with numerous fibrillose, rootlike strands ; asci cylindrical, 8-spored; spores continuous, hyaline, elliptical, or fusiform; paraphyses present.

Rhizina inflata, Quélet.-Crustlike, wavy, bay-brown, or umber, margin paler, form variable, often lobed, smooth, I-3 in. across, rhizoids pale, numerous; asci cylindrical ; spores 8, fusiform, tinged brown at maturity, 32-36 $\times$ 9-Io $\mu$; paraphyses septate, clavate, tips brown, mixed with the paraphyses are stouter, brown, clavate bodies without septa.

Cyttaria, Berk.-Ascophore obovate or subglobose, fleshy, stuffed, or hollow, surface furnished with alveolae lined by the hymenium, and at first covered by a veil; asci cylindrical, 8-spored; spores continuous, hyaline, elliptical, smooth; paraphyses numerous.

Cyttaria darwinii, Berk., Linn. Trans., xix. p. 37.Whitish, globose, 2-4 cm. diameter, at first even, then alveolate, always stuffed; asci I50-160× $10 \mu$; spores 8 , uniseriate, elliptical, ends obtuse, smooth; I 4-16 $68 \mu$.

Fischer states that spermogonia are immersed in the lower part of the ascophore, containing elliptical conidia $2 \times I^{\circ} 5 \mu$.

Cyttaria hookeri, Berk., Hook., Fl. Antarct., p. 452.- 
Yellowish-cinnamon, obovate, umbonate, I-2 cm. high, stuffed, even, glabrous, fertile loculi apical ; asci $200-250 \times$ $20 \mu$; spores elliptical, ends obtuse, tinged olive, ${ }_{15} \times$ ro $\mu$; paraphyses tinged olive at the tip.

Cyttaria gunnii, Berk., Hook., Lond. Journ., i848, p. 576, tab. xx., xxi.-Broadly piriform, at length hollow, smooth, loculi small, dehiscing by an irregular, large opening, densely gregarious, $\mathrm{x}^{\cdot 5-2} 5 \mathrm{~cm}$. broad, whitish; asci cylindrical ; spores broadly elliptical, I-seriate, hyaline.

Cyttaria berterii, Berk., Linn. Trans., xix., p. 37.Yellow or orange, obovate $\mathrm{I}-3 \mathrm{~cm}$. diam., loculi subglobose, at first closed; asci cylindric-fusoid, $100 \times 7-8 \mu$; spores elliptical, ends obtuse, $15 \times 5-6 \mu$ hyaline, 2 -guttulate -possibly becoming I-septate.

\section{BASIDIOMYCETES}

Spores produced (usually four in number) at the apex of continuous (non-septate) basidia. Basidia closely packed side by side to form the hymenium, which may be exposed from the first (Hymenomycetes), or enclosed in a peridium until maturity (Gastromycetes).

Agaricaceae.-Hymenium occupying the entire surface of radiating gills or lamellae. Sporophore with a central stem, dimidiate, or rarely resupinate.

Armillaria, Fries.-Pileus symmetrical, more or less fleshy; gills adnate or slightly decurrent; stem central, passing continuously into the flesh of the pileus, furnished with a ring; spores white, elliptical.

Armillaria mellea, Vahl.-Pileus 2-5 in. across, convex, then expanded, often dark or covered with olive down 
when young, then honey-colour, with minute scales; gills adnato-decurrent, white, with a pallid tinge; stem $3-5$ in. long, dingy ochraceous, honey-colour below, often more or less floccose below the ring; spores white, elliptical, $9 \times$ 5-6 $\mu$.

Usually tufted, with blackish, cordlike mycelium permeating the bark or soil.

Armillaria mucida, Schrad.-Pileus I-4 in. across, hemispherical, then flat, whitish, or grey, very glutinous; gills broad, white; stem 2-5 in. long, thickest at base, white, often with dark squamules, ring tumid; spores elliptical, I4- I $6 \times 8-9 \mu$.

\section{Often clustered.}

Marasmius, Fries. - Tough, thin, dry, reviving their form when moistened (not putrescent). Veil absent (except in one sp.) ; stem cartilaginous or horny; gills tough, subdistant or distant, often connected by veins, edge acute; spores white or pallid.

Marasmius semiustus, Berk. and Curt.-White, becoming rufous when dry; pileus excentric, convex, then plane, rugulosely sulcate, glabrous, $\frac{1}{2}-\frac{3}{4}$ in. across; gills approaching the stem, distant, connected by wrinkles; stem $\frac{1}{2}$ in. or more long, compressed, glabrous, producing a small, whitish sclerotium in the decaying tissues of the host, $2-3 \mathrm{~mm}$. diam.

Marasmius sacchari, Wakker, De Ziet. van het Suikerriet op Java, p. 194, pl. v. (1898).-Gregarious or fasciculate at the base, variable, flesh membranaceous, persistent ; pileus white, broadly campanulate, then dingy white and plane or cup-shaped, $15 \mathrm{~mm}$. diam.; gills white, simple, or bifurcate; stem central, white, $15 \mathrm{~mm}$. long, apex tubiform, 
base villous, hyphae white; spores hyaline, continuous, irregularly oblong, ends attenuated, rounded, I6-20 $\times$ 4-5 $\mu$.

Schizophyllum, Fries.-Pileus without flesh, dry; gills coriaceous, flabelliformly branched, edge split open longitudinally.

Schizophyllum commune, Fries.-Pileus very thin, fanshaped, white or grey, downy, often lobed, $\mathrm{x}-2$ in. broad; gills pale brown with a purple tinge, split portions of edge of gills revolute; spores dingy, $4-6 \times 2-3 \mu$.

Pholiota, Fries.-Pileus more or less fleshy; gills adnate, with or without a decurrent tooth, or rounded behind and adnexed, tawny or ferruginous at maturity, as are also the spores; stem central, furnished with a distinct interwoven ring.

Pholiota aurivella, Batsch, Consp., f. I I 5.-Pileus 3-6 in. across, fleshy, campanulate, then convex, gibbous, slightly viscid, tawny yellow, variegated, with adpressed, darker scales; gills sinuate, adfixed, 2-3 lines broad, white, then straw-colour, finally rusty umber; stem 4-6 in. long, almost equal, curved, yellowish, with scattered, adpressed, rustybrown, floccose squamules, stuffed, often hollow with age; ring rather distant, imperfect; spores elliptical, $5 \times 2{ }^{\circ} 5 \mu$.

Pholiota squarrosa, Müll, Fries, Syst. Myc. i. p. I43.Pileus $2-4$ in. across, fleshy, campanulate, then expanded, often gibbous, dry, yellowish-brown, covered with darker, innate, squarrose scales; gills slightly decurrent, crowded, about 2 lines broad, pallid olive, then ferruginous; stem 3-5 in. long, 3-5 lines thick, slightly narrowed towards the base, flexuous or ascending, pale tawny-brown and covered 
with darker, recurved scales as far up as the superior spreading, floccose ring, smooth and pale above the ring, stuffed ; spores ferruginous, $8 \times 4 \mu$.

Pholiota adiposa, Fries, Syst. Myc., i. p. 242.-Pileus 2-4 in. across, fleshy, compact, convex, obtuse, glutinous, yellow, with concentrically arranged, superficial, seceding, darker squarrose scales; flesh whitish; gills adnate, 3-4 lines broad, yellow, then ferruginous; stem glutinous, 3-6 in. long, up to $\frac{2}{3}$ in. thick, subequal, base somewhat bulbous, yellow, with concentrically arranged, ferruginous, evanescent squamules up to the superior, floccose, radiating ring, stuffed; spores elliptical, ferruginous, $7 \times 3 \mu$.

Pholiota destruens, Brond, Crypt. Agen., tab. 6.-Pileus fleshy, irregular, floccose with paler lanose squamules when dry, yellowish white, margin involute, fibrillose, 3-4 in. across ; stem solid, 4-7 in. long, up to $I$ in. thick at the base, narrowed upwards, albo-squamulose up to the fugacious ring; gills adnexed, striato-decurrent, crenulate, pallid, then umber-brown; spores elliptical, 8-9 $\times$ 5-6 $\mu$.

Hypholoma, Fries.-Pileus fleshy, margin incurved when young; stem central; veil interwoven, adhering in fragments to the margin of the pileus (appendiculate), not forming a distinct ring on the stem; gills adnate or sinuate ; spores purple-brown or deep purple.

Hypholoma fasciculare, Huds.-Fasciculate; taste intensely bitter; pileus I-3 in. across, convex, then expanded, subumbonate, thin, glabrous, tawny, margin yellow; gills adnate, closely crowded, narrow, yellow, then greenish, subdeliquescent; spores elliptical, $7 \times 4 \mu$. Stem $3-4$ in. long, 
fibrillose, hollow, yellow as is also its flesh; veil sometimes appendiculate.

Polyporaceae.-Sporophore with a central stem, dimidiate, or resupinate; hymenium lining the cavities of long or short, densely packed tubes, or shallow depressions; basidia tetrasporous.

Polyporus, Mich.-Stem central or lateral, or sessile and dimidiate, etc. ; pileus fleshy, tough, rather soft and moist, at length becoming harder (rarely of a cheesy texture and fragile), externally neither sulcate nor zoned, but the internal texture consisting of radiating fibres often more or less zoned; pores never stratose; tubes not separable from the sporophore, pores at first obsolete, then rounded, angular, or torn.

Polyporus schweinitzii, Fries, Syst. Myc., i. p. 35 1.Pileus $12-20 \mathrm{~cm}$. across, tomentose, tomentum matted into little rugged tufts, dark brown with a rusty tinge; flesh thick, spongy, fibrous, brown; stem thick, very short, brown, sometimes obsolete, more or less central when present; tubes about I cm. long, pores large, irregular, and variable in form, yellow, with a tinge of green; spores elliptical, obliquely apiculate, pale yellow, $7-8 \times 4 \mu$.

Polyporus squamosus, Fries, Syst. Myc., i. p. 343.Broadly flabelliform, fleshy but thin, pliant, pale yellow or whitish, with large adpressed, centrifugally arranged brown scales, I2-25 cm. across, single or usually several pilei springing from the same knob; stem excentric or lateral, short, base black; tubes very short, becoming large, angular, running down the under side of the stem, whitish; spores elliptical, colourless, $12 \times 5 \mu$.

Polyporus giganteus, Fries, Syst. Myc., i. p. 356.- 
Formed of numerous imbricated pilei forming clusters several feet across; stem short, much branched, springing from a tuberous base; pilei thin, fleshy, tough, then coriaceous, dimidiate, flaccid, slightly zoned, rivulose, depressed behind, bay-brown; tubes very short, pores minute, roundish, at length torn, pallid, becoming darkcoloured when bruised.

Polyporus sulphureus, Fries, Syst. Myc., i. p. 357.Horizontal, attached by a broad base, usually imbricated, undulate, almost glabrous, yellow, pale flesh-colour, or tinged red, $10-20 \mathrm{~cm}$. across; flesh thick, yellow; then whitish, cheesy; pores up to $\mathrm{r}_{5} 5 \mathrm{~cm}$. long, pores minute, plane, sulphur-colour; spores elliptical, hyaline, slightly papillose, $7-8 \times 4-5 \mu$; smell unpleasant.

Polyporus dryadeus, Fries, Syst. Myc., i. p. 374 (in part). -Pileus $10-25 \mathrm{~cm}$. across, 6-ro $\mathrm{cm}$. thick, semicircular, sessile, horizontal, attached by a broad base, pulvinate, fleshy, then corky, cuticle thin, soft, smooth, rugged, becoming even, ferruginous, then brown, margin often exuding drops of water; flesh ferruginous, somewhat zoned, rather velvety, fibrous when cut; tubes $2-5 \mathrm{~cm}$. long, thin, soft, ferruginous, pores round, paler, about $\frac{1}{3} \mathrm{~mm}$. across ; spores colourless, elliptical, $5 \times 3 \mu$.

Polyporus hispidus, Fries, Syst. Myc., i. p. 362.-Pileus sessile, attached laterally, horizontal, more or less convex, compact, fleshy, rusty-brown, hispid, ro-1 $8 \mathrm{~cm}$. broad; flesh spongy, ferruginous, formed of diverging fibres, 2-5 $\mathrm{cm}$. thick ; tubes 2-3 cm. long, yellowish, then brown, but paler than the pileus, pores minute, margin fimbriate, inclined to separate, often exuding water in drops; spores elliptic, oblong, orange-brown, $10 \times 7 \mu$. 
Alcohol dissolves out of any part of the fungus a yellowbrown colouring matter.

Polyporus betulinus, Fries, Syst. Myc., i. p. 358.-Pileus 8-I $5 \mathrm{~cm}$. across, thick, corky, elastic, hoof-shaped, sessile, obliquely umbonate behind at the point of attachment, margin obtuse, incurved, sterile, pileus covered with a thin, greyish, brownish, or whitish crust which peels off, exposing the white flesh, zoneless, glabrous; pores up to $\frac{3}{4} \mathrm{~cm}$. long, pores minute, unequal, whitish; spores white.

Polyporus borealis, Fries, Syst. Myc., i. p. 366.-Horizontal, subspathulate, or reniform, either narrowed behind into a short, more or less distinct stem, or thick and sessile, 4-8 cm. broad, whitish, then dingy yellow, spongy, then corky, compact, hairy, often radiately rugose, rigid and incurved when dry; flesh thick, whitish, formed of parallel fibres; tubes 4-8 $\mathrm{mm}$. long, pores unequal, white, dissepiments thin, torn; spores colourless, subglobose, $4 \mu$ diam. ; inodorous when fresh, but with a slight spicy smell when dry.

Fomes, Fries.-Pileus hard and woody from the first, flesh composed of interwoven hyphae, covered with a hard, crustaceous cuticle, not zoned but often concentrically grooved; perennial, forming successive strata of tubes, the last formed and external layer of pores only living.

Fomes fomentarius, Fries, Syst. Myc., i. p. 374.-Hoofshaped, $10-20 \mathrm{~cm}$. across, 8-I $5 \mathrm{~cm}$. thick at the base, distantly concentrically sulcate, glabrous, opaque, fuliginous or dingy brown, cuticle thick, hard, persistent, margin at first with a white bloom, then ferruginous; flesh rather soft, compactly floccose, foxy rust-colour; tubes very long, 2-6 cm. long, distinctly stratose, ferruginous, pores sub- 
angular, about $\frac{1}{4} \mathrm{~mm}$. across, powdered with white at first, then ferruginous; spores brown, elliptical, base abruptly truncate, $6 \times 3^{\cdot 5-4} \mu$.

Fomes igniarius, Fries, Syst. Myc., i. p. 375.-At first tubercular, immarginate, even, with a thin, flocculose, adpressed hoary covering, then thinly hoof-shaped, ferruginous, at length blackish-brown, opaque, cuticle very hard, margin rounded; $10-15 \mathrm{~cm}$. across, sometimes larger; flesh zoned, ferruginous, very hard; tubes $2-6 \mathrm{~cm}$. long, stratose, very small, when old, filled with white mycelium, general surface of hymenium convex, pores $\frac{1}{4}-\frac{1}{3} \mathrm{~mm}$. across, rounded, at first hoary; spores subglobose, hyaline, 6-7 $\mu$, cystidia few, $10-25 \times 5^{-6} \mu$.

Fomes pinicola, Fries, Elench., p. I05.-Pileus woody, pulvinate, then hoof-shaped, glabrous, unequal, tawny, then becoming blackish, margin cinnabar when mature; flesh hard, pallid; pores minute, pallid, then yellowish-white.

Large, truly perennial and reviving, growing by additions to the margin, pores not distinctly stratose; odour acid.

Fomes fulvus, Fries, Epicr., p. 465.-Pileus woody, very hard, triangular in section, sessile, attached by a broad base, even (not concentrically sulcate), at first villose, tawny inside and out, then hoary; pores short, rounded, minute, cinnamon, at first covered with a greyish-yellow bloom; three to four in. across, sometimes imbricated.

Fomes annosus, Fries, Syst. Myc., i. p. 375.-Very irregular in form, often horizontal and imbricated; pileus convex, becoming plane, tuberculoso-zoned, radiately rugulose, during the first year brown, silky, margin whitish, second season covered with a glabrous, blackishbrown rigid cuticle, ro-1 $6 \mathrm{~cm}$. across; flesh rather thick, 
whitish; pores at first pure white, about $\frac{1}{2} \mathrm{~cm}$. long, medium size; spores colourless, elliptic-oblong, $6 \times 4 \mu$.

Biscuit-like sporophores, entirely white, are often formed on subterranean roots.

Fomes ribis, Fries, Syst. Myc., i. p. 375.--Imbricated, horizontal, coriaceous, rigid, flattened, almost even, ferruginous, velvety, margin acute, base often thinner than the margin, 6-10 cm. across; flesh thin; tubes about $2 \mathrm{~mm}$. long, pores minute, tawny.

Poria, Pers.-Entirely resupinate, forming more or less extended patches or thin membranaceous expansions, often inseparable from the matrix; pores covering the entire surface except the extending margin.

Poria vaporaria, Fries, Syst. Myc., i. p. 382.-Broadly effused, thin, inseparable, the white mycelium penetrating the matrix ; pores large, angular, or inclined to be sinuous, often oblique, dissepiments often eroded; entire fungus white, then straw-colour or ochraceous.

Trametes, Fries.-Sporophore corky or woody, dimidiate or resupinate; pores roundish, often elongated radially; dissepiments rather thick, unequal in depth, and not forming a heterogeneous stratum, hence the trama is continuous with the flesh of the sporophore.

Trametes pini, Fries, Syst. Myc., i. p. 336.-More or less semicircular in outline, horizontal, attached by a broad, thick base; pileus rusty-brown, then blackish, concentrically sulcate, rough, margin strigose; flesh rusty, hard; pores irregular in form, deep and indistinctly stratified in old specimens, bright ferruginous with a yellow tinge, becoming dusky. 
More or less triangular in section, $2-5$ in. across ; smell slight, pleasant.

Trametes suaveoleus, Fries, Epicr., p. 491.-Horizontal, 3-6 in. across, often I in. or more thick at the point of attachment, becoming thinner towards the margin; pileus villose, whitish, zoneless ; flesh thick, white, corky; pores $\frac{1}{2}$ in. or more in length, irregularly rounded, rather large, white, becoming fuscous; spores cylindric-oblong, $6 \times 2{ }^{\circ} \mu$; odour distinctly spicy.

Daedalea, Pers.-Dimidiate or resupinate; firm, corky, or woody; pores becoming elongated and irregularly sinuous, dissepiments corky and often flexible; basidia tetrasporous; spores hyaline.

Daedalea quercina, Pers., Syn. Fung., p. 500.-Pileus dimidiate, sessile, 4-ro in. across; every part pale woodcolour, upper surface rugulose, uneven; fleshy, corky, elastic; pores at first rounded, becoming very much elongated and contorted, broad; dissepiments very thick, flexible.

Fistulina, Bull.-Hymenium formed on the under surface of a fleshy hymenophore, at first warted, the warts developing into cylindrical tubes which remain distinct and free from each other, and bearing the tetrasporous basidia in their interior; conidia produced in cavities of the hymenophore.

Fistulina hepatica, Fries, Syst. Myc., i. p. 396.-Pileus roundish in outline, or subspathulate, dimidiate, attached by a broad base, or substipitate, blood-red, fleshy, and soft, strẹaked internally; tubes at first pallid, then red; spores broadly elliptical, salmon-colour, $5-6 \times 3^{-4} \mu$; conidia 6-1о $\times 5 \mu$, salmon-colour. 
Merulius, Hall.-Hymenium developing on a loose weft of mycelium, surface variously plicate or wrinkled, the folds forming irregular pores, and sometimes obsoletely toothed; spores colourless or coloured; substance often subgelatinous.

Merulius lacrymans, Fries, Syst. Myc., i. p. 328 (I82 I). -Broadly effused, usually entirely resupinate, but sometimes effuso-reflexed, thick, soft, and rather moist, silky or velvety below, yellowish-brown in the centre, shading off to the tumid, silky, white, or yellow margin; folds of hymenium wavy, forming irregular pits; spores rustyyellow, obliquely elliptical, Io-I $2 \times 5^{-6} \mu$.

Hydnaceae.-Hymenium borne on acute spines, teeth, warts, or irregular folds; basidia tetrasporous except in Knieffia and Mucronella, where they are said to be monosporous.

Hydnum, Linn.-Hymenium inferior or superior, borne on pointed spines that remain perfectly free and distinct from each other at the base.

Hydnum schiedermayeri, Heufl., Oest. Zool. Bot. Zeitschr., I870, p. 33.-Fleshy, broadly effused, immarginate, 4-Io in. across, irregularly tuberculose, with tufts of pendulous, subulate spines up to I in. long, often compressed, and the tip more or less fimbriate; flesh yellow, becoming rufescent.

Hydnum diversidens, Fries, Syst. Myc., i. p. 4I I.Pileus 2-3 in. across, fleshy and irregularly tuberculose or lobed, sometimes substipitate, whitish or yellowish, upper surface with erect, irregularly notched teeth; the margin clothed with club-shaped, sterile teeth; under surface with simple, awl-shaped, regular spines 3-6 lines long. 
Thelephoraceae.-Sporophore with a central stem, dimidiate, or resupinate; hymenium smooth or with only very slight traces of inequality of surface; basidia tetrasporous.

Stereum, Pers.-Furnished with a central stem, sessile and dimidiate, or entirely resupinate; hymenium smooth, even, originating from a compact, intermediate layer; basidia tetrasporous, hyaline, or tinted.

Stereum hirsutum, Fries, Epicr., p. 549.-Wholly resupinate, or most frequently effuso-reflexed, the upper portion projecting at right-angles from the matrix, and often crisped or lobed; pileus coarsely strigose, dingy ochraceous, becoming pale and greyish, indistinctly zoned, flesh thin, tough, and pliant ; hymenium even, glabrous, naked, bright ochraceous, or pale tan colour; spores elliptical, hyaline.

Stereum frustulosum, Fries, Epicr., p. 552.-Tuberculose, woody, crowded, and almost confluent, looking like one much-cracked specimen, under surface and glabrous margin brownish-black ; flesh distinctly stratose; hymenium convex, cinnamon, becoming pale, pruinose ; spores elliptical, ends subacute, $4-5 \times 3.3 .5 \mu$.

Corticium, Fries.-Hymenophore broadly effused, entirely adnate to the substratum; hymenium smooth, waxy, consisting of basidia and paraphyses only which spring directly from the mycelium without an intermediate compact stratum; spores continuous, hyaline.

Corticium comedens, Fries, Epicr., p. 565 (1836-38).Effused, inseparable, formed below the cortex and exposed by the rupturing and recurving of the bark, dingy lilac, 
becoming pale, spores cylindric-ellipsoid (sausage-shaped), slightly curved, I4-16 6 6-7 $\mu$.

Hypochnus, Fries.-Resupinate, membranaceous, texture loose, homogeneous, floccose, collapsing; hyphae filiform, branched and anastomosing, the tips of the uppermost branches becoming changed into basidia bearing 2-4-6 sterigmata ; spores elliptical or globose, hyaline, or coloured ; epispore smooth or rough.

Hypochnus cucumeris, Frank, Hedw., I883, p. I27.Forming grey or greyish-brown membranaceo-fibrillose patches on the lower part of the stem of the host, up to I $\mathrm{mm}$. across; basidia elongated, bearing four sterigmata at the apex; spores ovoid, hyaline.

Hypochnus solani, Prill. and Del., Bull. Soc. Myc., I89r, p. 220, fig.-Membrane effused, thin, slightly granular, cracked when dry, scarcely adhering to the cuticle, greyish white, internally brownish; basidia globoso-ovate, apex rounded ; spores hyaline, ovate, base apiculate, $10 \times 6 \mu$.

Exobasidium, Woronin.--Effused, incrusting, waxy ; basidia crowded, cylindric-clavate, bearing a variable number of spores at the apex.

Typically parasitic on living plants, which are deformed by the fungus.

Exobasidium rhododendri, Cramer, in Rabenh. Fung. Eur., No. 1910.-Forming gall-like swellings on the leaves, at first pale-green, becoming more or less tinged red; basidia stout, number of sterigmata variable, often four; spores hyaline, smooth, broadly elliptical, 8-10 $\times 6-7 \mu$.

Exobasidium vexans, Massee, Kere Bulletin, I898, p. III, figs. 6-10.-Forming large blisters on the leaves, 
convex on the upper surface, remaining green (so far as observed), 4-1 $2 \mathrm{~mm}$. diam., the convex surface becoming minutely velvety from the hymenium; basidia cylindrical, 30-35 $\times 5-6 \mu$, bearing 2 sterigmata; spores ovate-oblong, continuous, hyaline, glabrous, $5 \times 3 \mu$; conidia developed before or along with the basidia, fusiform, hyaline, I-septate, slightly constricted, I 4-1 $6 \times 5^{-6} \mu$.

Exobasidium lauri, Geyl., Bot. Ztg., I874, p. 322, tab. vii.-Effused, yellowish, then brownish, smooth, forming woody club- or horn-shaped excrescences 5-10 $\mathrm{cm}$. long; basidia cylindric-clavate, apex rounded and bearing four sterigmata, mixed with filiform paraphyses; spores oblong, curved, base somewhat acute, hyaline, I 5-16 $\mu$ long.

Exobasidium vitis, Prillieux, Malad. des Pl. Agric., i. p. 298-Pustules numerous, distinct from each other, small, somewhat golden in colour; fertile branches forming the basidia; number of spores borne by the basidia variable, often six, cylindrical, slightly curved, 6-25 $\times \mathrm{I}^{\circ} 5 \mu$.

\section{HEMIBASIDIOMYCETES}

Basidia elongated, transversely septate, each cell producing a spore; básidia densely packed side by side to form the hymenium.

- Hirneola, Fries. - Cartilagineo-gelatinous, soft and tremelloid when moist, rigid when dry; sporophore cupshaped or saucer-shaped, thin; basidia rod-shaped or fusoid, transversely septate, each cell producing a single monosporous sterigma; spores hyaline, oblong, curved.

Hirneola auricula-judae, Berk., Outl., p. 289, pl. 18, f. 7. -Thin and elastic when moist, becoming dark brown or 
blackish, hymenium venoso-plicate, I-3 in. across; spores reniform, $20-25 \times 7-9 \mu$; pileus greyish-olive, minutely tomentose.

Helicobasidium, Pat.-Resupinate, incrusting, soft ; basidia straight at first, then distinctly curved at the apex, with a variable number of transverse septa, bearing 2-4 sterigmata from the convex surface of the curved portion; spores hyaline, continuous, ovoid, often slightly curved.

Helicobasidium mompa, Tanaka, Journ. Coll. Sci. Imp. Univ. Japan, vol. iv. pt. I. pl. xxiv.-xxvii. (1891).--Pileus sessile, resupinate, somewhat orbicular or oblong, often irregularly lobed, 5-10 cm. across, 2-4 mm. thick, at first velvety and membranaceous, then subcoriaceous, somewhat convex, incrustate, purplish-brown, at length albopruinose; hymenium white; basidia curved, I-3-septate, tetrasporous ; sterigmata elongated; spores ovoid, curved, hyaline, Iо-1 $2 \times 5-7 \mu$.

\section{USTILAGINACEAE}

Mycelium parasitic in the tissues of living plants, abundant, but soon disappearing; teleutospores formed in the interior of hyphal branches, which often become gelatinous; spores on germination producing a continuous or sparingly septate promycelium, which bears secondary spores. Secondary spores either producing a delicate germ-tube, or bearing conidia, which often reproduce themselves by gemmation.

Ustilago, Pers. - Vegetative mycelium spreading in the tissues of the host, soon disappearing; spore producing hyphae branched, the spores formed in the interior of gelatinised, clustered terminal branches; spores I-celled, 
on germination producing a short, septate promycelium, which bears minute, lateral, and terminal secondary spores.

Ustilago avenae, Jensen.-Spore-mass blackish-brown, soon pulverulent, formed in the ovary; spores globose or broadly elliptical, 6-8 $\mu$ diam., or $7-9 \times 6-7 \mu$, delicately verruculose; promycelium septate, sporidiola oblong, produced at the septa.

Var. levis, Kell. and Swing., II. Rep. Agr. Kansas, p. 25, tab. 5, f. 56-60.- Spores smooth and slightly darker in colour than in the type form.

Ustilago tritici, Jensen, in Kell. and Swing., II. Rep. Agr. Kansas, p. $2 \mathrm{I} 4$ and 262, tab. 2 and 6.-Spore mass dark olive-brown, loose, formed in the ovary; spores ovoid, elliptic, or subglobose, $5^{\cdot 5-7.5} \times 5^{-6} \mu$, dilute olive, minutely verruculose; promycelium branched, septate; secondary spores.

Forma folicola, P. Henn., Zeitschr. für Pflanzenkr., r 894, p. I39.-Developed on leaves and leaf-sheaths of Triticum vulgare; spores either quite smooth, or delicately punctulate, yellowish olive-brown, 4.5-7 $\times 4^{\circ} 5^{-6} \mu$.

Ustilago nuda, Kell. and Swing., II. Rep. Agr. Kansas, pp. $2{ }_{5}$ and 277 , pl. 2, f. 7-I 7.- Spore-mass olive-brown, produced in the ovary, soon free and powdery; spores elliptical to globose 5-7 $\times 5-6 \mu$, olive-brown. The promycelium does not produce secondary spores, but forms a sparingly branched, septate mycelium.

Ustilago hordei, Kell. and Swing., II. Rep. Agr. Kansas, pp. 2 I 5 and 268, pl. 2, f. 2-6.-Spore-mass black, compact, not becoming pulverulent, and enclosed in the 
ovary ; spores globose or subangular from mutual pressure, blackish-brown, 6-7.5 $\mu$; promycelium 3-4-septate, producing secondary spores.

Ustilago maydis, Corda.-Forming large tubercular masses on the inflorescence, often many centimetres in diameter, also corrugated pustules on the leaves; pustules at first covered by the silvery epidermis, then olive-brown and pulverulent; spores globose or broadly elliptical, 8-13 3 8-i r $\mu$, pale brown, pellucid, minutely aculeate; promycelium 3-4-septate, bearing fusoid secondary spores at the septa and apex.

Ustilago sorghi, Passer.-Spore-mass blackish-brown, formed in the ovary or in the anthers, soon pulverulent; spores globose, oblong, or angular, $5^{-9} 9^{\circ} 5 \times 4-5^{\circ} 5 \mu$, epispore smooth, pale olive; promycelium cylindrical, constricted near the spore; secondary spores oblong, numerous.

Ustilago cruenta, Kühn. - Spore-mass olive-brown, formed at the apex of the culm and in the branches of the inflorescence, forming large reddish-brown patches, rarely in the ovary, the attacked branches are usually much bent and distorted; spores globose or broadly elliptical, 5-I $2 \times$ 5-9 $\mu$; epispore olive-brown, smooth; promycelium cylindrical, generally 3 -septate ; secondary spores ellipticfusoid, produced laterally and at the apex.

Ustilago reiliana, Kühn. - Pustules formed in the inflorescence, often finger-shaped, at first enclosed in a silvery membrane, then becoming pulverulent, blackishbrown; spores subglobose, pellucid brown, delicately echinulate, 9-I $2 \mu$ diam. ; promycelium septate, producing elliptical secondary spores.

Ustilago emodensis, Berk., Hook, Journ. Bot., vol. iii. 
p. $202(\mathrm{I} 85 \mathrm{I}) .=$ Ustilago treubii, Solms, Ann. Gard. Bot. Buitenzorg, vol. vi., I 887 , p. 79, pl. ix.-Spore-mass violet, forming tubercles in the inflorescence, or causing the formation of clustered, elongated, furrowed outgrowths up to I in. long, and terminating in a capitate head containing the spore-mass. 'Spores violet or lilac, smooth, globose, or broadly elliptical, 5-6 $\mu$ diam.; promycelium short, continuous; secondary spores coalescing in pairs before germination.

Ustilago esculenta, P. Henn., Hedwigia, ı 895, p. го.Spore-mass olive-brown, forming spherical or elongated tubercles in the unexpanded inflorescence, which is destroyed: at first covered by the whitish cuticle; spores subglobose, 7-9 6-8 $\mu$, brown, smooth.

Ustilago sacchari, Rab., Isis, I870.--Spore-mass black ; spores globose or angularly globose, 8 -I $8 \mu$ diam., olivebrown or rufous; epispore thick, smooth.

Tilletia, Tul.-Spores isolated, formed by a swelling of the tips of fertile hyphae, forming a powdery mass at maturity; pronycelium bearing a terminal cluster of elongated, cylindric-fusiform secondary spores, which after conjugating in pairs either give origin to a curved sporidium, or protrude a delicate germ-tube.

Tilletia tritici, Winter, Krypt.-Flora, i. p. I Io (1884).Spore-mass produced in the ovary, blackish, with an olive sheen, fotid; spores globose, brown, I7-22 $\mu$ diam., border I-I.5 $\mu$, not paler; epispore furnished with ridges anastomosing to form a rather large-meshed network, meshes often variable in size and form.

Tilletia levis, Kühn, Rab., Fung. Eur., No. I697 (1873). 
-Spore-mass produced in the ovary, deep brown, with an olive tinge, fotid; spores globose, elliptical, etc., variable in form and size, averaging $17-2$ I $\mu$, or $15^{-2} 6 \times$ Io-I $5 \mu$; wall about $2 \mu$ thick, pale olive-brown, or sometimes almost cream-colour ; epispore perfectly smooth.

Tilletia decipiens, Winter, Krypt.-Flora., i. p. I I I ( I 884). -Spore-mass formed in the ovary, blackish-brown, fœetid ; spores globose, irregularly or angularly globose, or broadly elliptical, clear brown, 20-27 $\mu$ diam.; border about $3 \mu$ wide, not appreciably paler; epispore with raised ridges anastomosing to form an irregular, small-meshed network.

Urocystis, Rabenh.--Sori erumpent, large, black, pulverulent; glomerules of one or more large, central, dark-coloured, fertile spores, surrounded by smaller, pale-coloured, sterile spores; germination as in Tilletia.

Urocystis colchici, Rab., Fung. Eur., No. 396.--Sori black, usually large, elongated; spore-clusters globose or oblong, $20-33 \times 16.20 \mu$, central spores $2-4$, smooth, chestnut-brown, ro-I $5 \mu$ diam.; sterile peripheral spores with thickish walls, sometimes arranged in two strata, pale yellowish-brown, 7-I I $\mu$.

Urocystis cepulae, Frost, Ann. Rep. Mass. Bourd of Agric., p. I64 (1876-77).---Sori forming large black, pulverulent streaks on the leaves and bulb; spore-clusters I 8-25 $\mu$ diam., usually only one dark brown, central, fertile cell, surrounded by numerous small, pale, sterile cells.

Urocystis occulta, Rab., in Klotzsch Herb. Myc., ii. No. 393 ; Sacc., Syll., vii. p. 515.-Forming long streaks on leaf-sheath, leaves, culm, and also in the inflorescence, at first covered by the epidermis, then black and powdery; 
glomerules of spores globose or elliptical, I 7-24 $\times 15^{-20} \mu$, fertile central spores $\mathrm{I} 8-20 \mu$ diam., dark brown; peripheral, pale, sterile spores forming an interrupted zone; spores soon germinating; sporidiola rarely conjugating, producing a germ-tube from the base.

Sorosporium, Rudolphi.-Resting-spores of uniform size, small, all fertile, at first in dense clusters, soon breaking up, produced by tufts of intertwined hyphae which become gelatinised, the entire spore-mass at first involved in a gelatinous integument; promycelium filiform; sporidia unknown.

Sorosporium scabies, Fischer de Waldh., Aperçu, p. 33. =Tubercinia scabies, Berk.-Sori forming large, olive, scablike expansions; spore-clusters globose or elliptic-oblong, forming a hollow sphere, perforated, here and there, $20-5 \circ \mu$ diam.; resting-spores subangular from mutual pressure, smooth, pale olive-brown, about $5 \mu$ diam.

Described from Berkeley's specimens in Herb. Kew.

Oedomyces, Sacc.-Mycelium very delicate, intercellular, sporiferous branches bearing a terminal spore, immediately below which is a large vesicular swelling; spores rarely solitary, most frequently occurring in great numbers; epispore thin, brown, smooth.

Oedomyces leproides, Trabut, Rev. générale Bot., I894, No. 70, I pl. ; Sacc., Syll., xi. p. 234.-Forming large, nodulose, fleshy tumours on the upper part of the root of Beta vulgaris, var. rapacea; spores globoso-depressed, umber, $40-50 \times 30 \mu$, acrogenous; mycelium inflated into a vesicle below the spore; spores produced in masses within spherical cysts in the substance of the tumours. 


\section{UREDINACEAE}

Mycelium developed in the tissues of living plants. Spores produced at the tips of hyphae, usually of more than one kind, as spermogonia, aecidia, uredospores, teleutospores; the latter on germination form a promycelium, which is typically 4 -septate, each cell producing a conidium borne on a slender sterigma.

Uromyces, Link.-Spermogonia present in many species; aecidia having the pseudoperidia usually well developed; sori of uredospores flat, small; sori of teleutospores more or less pulverulent, flattened or pulvinate, teleutospores I-celled, with a single apical germ-pore, stipitate; secondary spores subhyaline, ovoid or elliptical.

Uromyces appendiculatus, Link., Obs., ii. p. 28.-Spermogonia on white spots; aecidia on spots I-2 mm. broad, shortly cylindrical, margin deeply cut, whitish, aecidiospores angularly globose, I 7-32 $\times$ I 4-20, hyaline, slightly punctulate; uredospores in small pale brown sori, $24-33 \times$ I6-20, pale brown, aculeolate; teleutospores forming small blackish sori, elliptical or subglobose, smooth, dark brown, apex much thickened, and with a small, hyaline, wartlike papilla, $26-35 \times 20-26 \mu$.

All forms produced on same leaf.

Uromyces colchici, Massee, Grev., xxi. p. 6. - Sori numerous, large, elliptical, sometimes circinating, blackishbrown, on both surfaces of leaf and on leaf-sheath; teleutospores broadly elliptical or subglobose apex, slightly prominent, germinating pore I; epispore dark brown, smooth, up to $2 \mu$ thick, $28-38 \times 2$ I- $28 \mu$, pedicel hyaline, persistent, base attenuated, $70-80 \times 5-6 \mu$. 
Uromyces fabae, De Bary, Ann. Sci. Nat., ser. Iv. vol. xx. I863.- Spermogonia yellowish, in little groups on leaves and stem; aecidia scattered in rings or orbicular patches, margin white, torn; aecidiospores orange, verruculose, I6-26 $\mu$ diam. ; uredospores forming powdery, pale brown sori, globose or irregularly elliptical, etc., ochraceous, aculeate, I 7-35 $\times$ I 7-2 $5 \mu$; teleutospores forming blackishbrown sori, often numerous and confluent, ovoid or clavateellipsoid, smooth, brown, apex darker and thickened, apiculate, $24-47 \times$ I 7-30 $\mu$; pedicel hyaline, long.

Uromyces betae, Kühn, Bot. Ztg., I869, p. 540.Spermogonia yellowish, in small groups; aecidia crowded on yellowish, often large patches, white, margin torn; aecidiospores angularly globose or elliptical, orange, smooth, 22-26× 6 6-22 $\mu$; uredospores forming small sori, often orbicularly arranged, yellowish-brown aculeolate, or almost smooth, $23-32 \times 17-24 \mu$; sori of teleutospores blackishbrown, scattered, or in groups; ovate or ellipsoid, smooth, brown, with an apical hyaline wart, $26-35 \times 19-25 \mu$; pedicel slender.

Hemileia, Berk. and Broome.-Sori pustular, orangebrown, hypophyllous; spores ovate or piriform, oblique, I-celled, one portion of the epispore smooth, the remainder warted; promycelium one or several; secondary spores spherical.

Hemileia vastatrix, Berk. and Broome, Gard. Chron., Nov. 6, I869, figs.-Pustules orange, then rufous: spores subreniform, attached obliquely at the base, convex free surface coarsely warted, the two lateral faces that are in contact with others during growth, smooth, $35-39 \times$ Io-I $4 \mu$.

Hemileia woodii, Kalchbr, and Cooke, Grev., ix. p. 22 
(1880).--Sori pulvinate, minute, often densely gregarious, orange; spores subreniform, convex, free portion warted, remainder smooth, 30-35 $\times$ 10-1 $2 \mu$.

The sterile cysts mentioned by the authors are only young, still smooth spores; the same occurs in $H$. vastatrix, when the pustules are examined while young.

Hemileia canthii, Berk. and Broome, Journ. Linn. Soc. (Bot.) xiv. p. 93 (1875).--Sori scattered on pale spots, hypophyllous; spores subreniform, free convex surface warted, remainder smooth, 25-30X 10-1 $2 \mu$.

Cronartium, Fries.-Aecidia produced on conifer leaves, pseudosporidia elongated, aecidiospores concatenate; uredospores included in a pseudoperidium, brown; teleutospores I-celled, aggregated into a column which springs from the sorus of uredospores.

Cronartium ribicolum, Deitr., Arch. Naturk. Liv. Esth. und Kurlands, ii. p. 287.-Aecidiospores large, epispore warted, one part smooth; sori of uredospores forming pustules, orange-rufous, minute, rounded, pseudoperidia hemispherical, perforated at the apex, uredospores elliptical or ovoid, $19-35 \times 14-22 \mu$, epispore hyaline, aculeate, contents orange; teleutospores forming a columella up to $2 \mathrm{~mm}$. high, curved, yellowish-rufous.

Cronartium asclepiadeum, Fries, Obs. Myc., i. p. $220 .-$ Aecidiospores 22-26, rarely $30 \times 16-20 \mu$, epispore partly reticulated, partly warted; uredospore sori hypophyllous, scattered, brown; uredospores variable in form, echinate, 16-32 $\times 12-18 \mu$, pale orange; columella of teleutospores terete up to $2 \mathrm{~mm}$. long; teleutospores oblong, truncatoobtuse, I2 $\mu$ broad; sporidiola globose, smooth, pale yellow. 
Cronartium flaccidum, Winter, Krypt.-Flora, i. p. 236.Uredospore sori forming pustules, minute, ochraceous, or pale brown, pseudoperidium very firm, plano-convex; uredospores roundish, ovate, piriform, etc., $\mathrm{x} 8-44 \times \mathrm{I} 2-20 \mu$, aculeate, pale orange; teleutospores forming a cylindricoblong, often curved or tortuous column $2 \mathrm{~mm}$. high, pale brown, teleutospores oblong or cylindrical, ends obtuse, brown, 8-I $2 \mu$ diam.

Aecidium condition unknown.

Melampsora, Cast.-Spermogonia forming minute, orbicular, covered patches; aecidia (Caeoma form), destitute of a pseudoperidium; spores in chains; uredospores produced singly at the tips of sterigmata, aculeolate, enclosed in a more or less developed pseudoperidium; teleutospores I-celled, obovate-cuneate, compacted into a firm, crustlike, plane stratum; sporidiola subglobose, yellow, or orange.

Melampsora pinitorqua, Rost. $=M$. populina, Lév.Caeoma stage, sori mostly linear, up to $2 \mathrm{~cm}$. long, solitary or crowded, orange, spores round or polygonal, $15-20 \mu$, warted, pale rufous yellow ; uredospore sori rounded, often bullate and confluent, orange-rufous, spores elliptic or ovoid, $28-38 \times 13-20 \mu$, aculeate, orange; paraphyses more or less abundant, up to $5 \circ \mu$ long, swollen apex I $_{7-20} \mu$ broad; teleutospore sori epiphyllous, flattened, often confluent, at first rufous-brown, then blackish-brown, teleutospores $40-45 \times$ I $3 \mu$; sporidiola globose, orange.

Melampsora laricis, Rost., Caeoma laricis, Hartig.Melampsora tremula caeoma stage, sori narrow, $500 \mu$ to $5 \mathrm{~mm}$. long, on a yellow spot; spores round or elliptical, I6-24 $\times$ I 2-I $7 \mu$, delicately warted, orange-yellow; uredospore sori often expanded on twigs, rufous orange, rounded 
on the leaves, spores elliptical or ovoid, $15-24 \times 13^{-1} 8 \mu$, aculeate, orange rufous, paraphyses numerous, clavate; teleutospore sori hypophyllous, very numerous, rufousbrown at first, then pitch-brown, crustlike teleutospores, 43-55 X I I-I $2 \mu$.

Melampsora lini, Tul., Ann. Sci. Nat., r854, p. 93.Uredospore sori scattered, covered with a deciduous pseudoperidium, rotund, orange, minute; spores subglobose or obovoid, pedicellate, echinate, I 5-24X I 4-1 $8 \mu$, orange-yellow ; paraphyses curved, apex strongly sphaeroidally or ovoidly incrassated, $\mathrm{I}$ 7-20 $\mu$; teleutospore sori flattened, at first rufous-brown, then blackish ; teleutospores densely packed under the epidermis, cylindrico-prismatic, 45-60 × I 7-20 $\mu$.

Puccinia, Pers.-Aecidia, spermogonia, and uredospores as in Uromyces; teleutospores transversely I-septate, rarely 2-septate, each cell having one germ-pore; sori flattened or convex, at first covered by the epidermis of the host; sporidiola ovoid or reniform, generally hyaline.

* Eupuccinia, Schröt. - Spermogonia, aecidia, uredospores, and teleutospores produced in a living host; teleutospores germinating after a period of rest. (Not on a living host.)

$\uparrow$ Auto-Eupuccinia, De Bary.-Spermogonia, aecidia, uredospores, and teleutospores produced on the same host.

Puccinia asparagi, D.C., Flor. Fr.ii.p. 595.-Spermogonia in small clusters; aecidia forming longitudinal lines on the stem, margin whitish, torn; spores I $_{5}-28 \mu$, epispore hyaline, delicately verruculose, contents yellow; uredospores 20-30 $\times$ I 7-25 $\mu$, delicately echinulate, pale brown; teleutospores 
elliptical or elongate-clavate, base rounded, slightly constricted ; apex rounded, 35-52 × 17-26 $\mu$, smooth, chestnutbrown; pedicel persistent ; forming elongated blackish sori on the stem, rarely on the leaves.

Puccinia menthae, Pers.,Syn.Fung., p. 22 7.--Spermogonia honey-colour, in little clusters; aecidia on stem or leaves forming large, inflated, coloured spots, large, plane, spores verruculose, pale yellow, $40 \times$ 1 7-26 $\mu$; uredospores elliptic or ovoid, aculeate, pale brown, I 7-28 $\times$ I4-19 $\mu$; teleutospore sori hypophyllous, rarely on the stem, scattered or aggregated ; spores elliptical, or shortly cylindrical, ends rounded, scarcely constricted, apex slightly thickened, 26-35 $\times$ i9$23 \mu$, minutely warted, with a broad, colourless, or pallid apical papilla, dark brown; pedicel longer than the spore, hyaline, slender.

Puccinia hieracii, Mart., Fl. Mosq., p. 226.-Spermogonia in little groups; aecidia arranged in rings or without order on purplish spots, margin broad, white, torn; spores $30 \times$ ı 6-2 $3 \mu$, pale yellow, smooth or minutely verruculose ; uredo sori on both surfaces, rounded, scattered, or gregarious; spores globose or elliptic, I7-32 2 16-26 $\mu$, chestnut-brown, aculeate, with two or three germ-pores; teleutospores in similar sori, crowded, spores elliptic or ovoid, apex rounded, often narrowed below, very finely punctate, $24-45 \times$ I 7-28 $\mu$ brown; pedicel slender, longish, hyaline, soon deciduous.

$\uparrow \uparrow$ Hetero-puccinia, Schröt. - The sporidiola do not infect the same species of host-plant that produces the teleutospores, but a different one which bears the spermogonia and aecidia.

Puccinia pringsheimiana, Kleb., Zeitschr.f. Pflanzenkr., v. p. 79.-Spermogonia honey-yellow, in small groups; 
aecidia often forming concentric rings, crowded on rounded, reddish spots, peridia shortly cylindrical, margin white, torn; spores ro-20 $\mu$, orange ; epispore hyaline, scarcely wrinkled; teleutospores forming sori on leaves or culms, elongated, brown, pulverulent, blackish; spores clavateoblong or oblong, apex much thickened, rounded, or truncate; base often narrowed, smooth, brown, $35-50 \times$ I5-20 $\mu$; pedicel rigid, persistent.

Puccinia graminis, Pers., Tent. Disp. Meth. Fung., p. 39, tab. 3, f. 3 (1 797).

I. Diseased spots on the leaves 3-4 mm. diam., centre red, margin yellowish, sometimes also formed on twigs, flower, and fruit ; aecidia shortly cylindrical, margin spreading and torn; spores subglobose, smooth, yellow, I4-26 $\mu$ diam. ; spermogonia on opposite side of leaf to the aecidia.

II. Sori forming yellowish, rust-coloured streaks $2-3 \mathrm{~mm}$. long, or sometimes much longer; uredospores broadly elliptic, dingy yellow, spinulose, 1 7-40 $\times$ I 4-22 $\mu$.

III. Sori forming blackish streaks up to ro $\mathrm{mm}$. long, often much shorter; teleutospores fusiform or club-shaped, with a long pedicel, slightly constricted at the septum, smooth, chestnut-brown; apex rounded or narrowed, with the wall thickened, $35-60 \times 12-22 \mu$.

Puccinia coronata, Corda, Icon. Fung., i. p. 6, tab. 2, f. 96 .

I. Aecidia on irregular yellow patches on the under surface of the leaves, especially along the nerve; also on the flower-buds and fruit; aecidiospores spinulose, I 8-25 $\times$ I4-19 $\mu$.

II. Sori orange-red, narrow, and elongated, mostly on the 
upper surface of the leaf, rarely on the leaf-sheath, culm, or glumes; uredospores globose or broadly elliptic, spinulose, yellow, $20-32 \mu$, or $2 \mathrm{I}-32 \times 20-24 \mu$.

III. Sori blackish, small, numerous, often forming rings on the leaf, surrounded by brown paraphyses ; teleutospores shortly stalked, mostly clavate, apex truncate, with a variable number of processes of variable length, 25-57 $\mu$ long, basal cell 8-19 $\mu$ wide, terminal cell Io-19 $\mu$ wide.

Puccinia dispersa, Eriksson and Henn., Getreidr., p. 2 го, tab. x., xi., figs. I 1 9-1 23.

I. Aecidia forming large orange patches on stem, leaves, and calyx; aecidiospores spinulose, $20-30 \mu$ diam., or 20-30X $19-22 \mu$.

II. Sori small, I mm. long, and nearly as broad, crowded in groups on the leaves, ochraceous brown; uredospores globose or broadly elliptical, spinulose, yellow, 19-29 $\mu$ diam.

III. Sori blackish, irregularly scattered on the under side, rarely on the upper side of the leaf, each sorus surrounded by curved, brown paraphyses; teleutospores shortly stalked, mostly elongate club-shaped, unsymmetrical, 40-50 $\mu$ broad, terminal cell $14-19 \mu$ broad; promycelium colourless.

Puccinia glumarum, Eriksson and Henn., Getreidr., p. I4I, tab. v.-ix., figs. 52, and 57-108.

I. Unknown (wanting?).

II. Sori minute, yellow-brown, densely crowded on the leaves, more scattered on the inner surface of the glumes; uredospores globose or shortly elliptical, spinulose, yellow, 25-30 $\mu$ diam.

III. Sori forming crowded, blackish streaks on the leaf- 
sheaths, more scattered on the inner surface of the glumes; each sorus encircled with curved, brownish paraphyses; teleuto-spores shortly stalked, mostly elongated, clubshaped, unsymmetrical, apex flattened or with $1-2$ blunt prominences, 30-40 $\mu$ long, basal cell 9-1 $2 \mu$ wide, terminal cell r6-24 $\mu$ wide; promycelium contents yellow.

Puccinia simplex, Eriksson and Henn., Getreidr., p. 238 , tab. xi., figs. I 24 -I 28 .

I. Unknown (absent ?).

II. Sori very minute, up to $0^{\circ} 5 \mathrm{~mm}$. long, sparingly scattered on the upper side of the leaves, citron-yellow; uredospores globose or shortly elliptical, spinulose, yellow, 19-2 $2 \mu$ diam., or 22-27 $\times$ 15-19 $\mu$.

III. Sori very minute, blackish, scattered on the leaves, somewhat longer on the leaf-sheath, each sorus with brown paraphyses; teleutospores stipitate, mostly I-celled, unsymmetrical, $24-30 \times$ I6-i $8 \mu$, rarely 2-celled, clavate, apex blunt or narrowed, 40-48 $\mu$ long, basal cell r6-18 $\mu$ broad, terminal cell I9-24 $\mu$ broad.

Puccinia phlei-pratensis, Eriksson and Henn., Getreidr., p. I30, tab. v., f. 55,56 .

I. Unknown (absent ?).

II. Sori often crowded, yellowish brown, I-2 $\mathrm{mm}$. long, on leaf-sheaths and culm ; uredospores oblong, pear-shaped, spinulose, dirty yellow, I 8-27 $\times$ I 5-1 $9 \mu$.

III. Sori blackish, on leaf-sheath and culm, 2-5 mm. long; teleutospores fusiform or club-shaped, constricted at the septum, chestnut-brown, apex rounded or narrowed, wall much thickened, 38-52 1 4-I $6 \mu$.

* Brachypuccinia, Schröt.-Spermogonia, uredospores, 
and teleutospores produced on the same host-plant; aecidia not produced.

Puccinia bullata, Schröt., Pilze Schles., p. 335.-Spermogonia honey-colour, arranged in rounded groups; uredospores irregularly globose, aculeate, ochraceousbrown, apex incrassated, $23-38 \times 20-26 \mu$, with two lateral germ-pores, shortly pedicellate; teleutospores deformed, slightly constricted at the septum, both ends rounded, rarely narrowed at base or apex, smooth, brown, apex thickened, $30-56 \times 17-28 \mu$; pedicel deciduous, slender, longish.

*** Hemipuccinia, Schröt.-Uredospores and teleutospores produced on the same host; spermogonia and aecidia unknown.

Puccinia tanaceti, D. C., Flor. France, ii. p. 222.Uredo sori hypophyllous, scattered, erumpent, orbicular, plane, very minute, brownish, crowded, spores elliptic or ovate, I9-35 × I6-25 $\mu$, muricato-aculeate, ochraceous; teleutospores forming sori on both sides of the leaf, blackish, pulvinate, erumpent, orbicular, scattered, or crowded, spores elliptical or clavate, apex much thickened, cells almost equal, constricted at the septum, $32-60 \times$ I 7-28 $\mu$, smooth or apex punctulate, chestnut-brown; pedicel hyaline, up to i o $\mu$ long.

Puccinia pruni, Pers., Syn. Fung., p. 226.-Uredospores hypophyllous, sori minute, orbicular, confluent, cinnamonbrown, r0-35 $\times$ I0-1 $8 \mu$, spinulose, sessile, apex generally thickened; paraphyses numerous; sori of teleutospores hypophyllous, scattered or confluent, plane, brown; spores oblong formed of two globose cells, lower one generally smallest, $28-45 \times \mathrm{I} 7-24 \mu$, covered with aculeate warts, 
brown, pedicel short, hyaline, deciduous; paraphyses numerous, brown.

**** Leptopuccinia, Schröt.-Teleutospores only known, generally in compact, crowded, pulvinate sori germinating on the living host; sori often powdered with the whitish or rufescent sporidiola.

Puccinia malvacearum, Mont., Gay's Hist. fis. y. polit. de Chile, viii. p. 43.-Hypophyllous, sori hemispherical, hard, gregarious, small, brown ; teleutospores ovoid-oblong, 35-75 $\times$ 12-26 $\mu$, fuscous, smooth, slightly constricted at the centre, obtuse or acuminate, pedicel very long; up to I $20 \mu$, hyaline.

Puccinia arenariae, Schröt., Pilze Schles., p. 345.Teleutospore sori rounded, pulvinate, often arranged in an orbicular manner or in elongated crusts, pale brown, then blackish-brown, often becoming pulverulent and greyish from the sporidiola; spores fusoid or clavate, apex rounded or conoidly incrassated, slightly constricted, base narrowed, ochraceous-brown, smooth, 30-50 $\times$ 10-20 $\mu$; pedicel hyaline, equal or longer than the spore, persistent.

Gymnosporangium, Hedw.-Teleutospores forming large subgelatinous masses distinct from the substratum, rarely forming small, adnate, convex patches, transversely I-septate, very rarely biseptate, each cell with 2 or 4 germ-spores.

All known species have spermogonia and aecidia on one host, teleutospores on another distinct host; uredospores unknown.

Gymnosporangium sabinae, Winter, Krypt.-Flora, i. p. 232.-Spermogonia rufous-orange, then black, conoidly 
prominent, epiphyllous, rarely on fruit or branches, rather large, in small groups on yellow or rufescent spots ; sporules minute, pale orange; aecidia hypophyllous, opposite the spermogonia, forming large, convex tubercles, numerous, yellowish, ventricose, $2 \mathrm{~mm}$. long, I-I $5 \mathrm{~mm}$. broad, apex closed, sides perforated or subcancellate; aecidiospores in chains, 22-44 $\times 17-26$, brownish, angularly rounded, delicately warted; sori of teleutospores irregularly conoid or cylindrical, obtuse, sometimes compressed or branched, yellowish-rufous, gelatinous, 8-10 $\mathrm{mm}$. long; teleutospores ellipsoid $38-50 \times 23^{-26} \mu$; scarcely constricted at the septum, chestnut-brown, each cell having four germ-pores.

Gymnosporangium juniperinum, Fries, Syst. Myc., iii. p. 506.--Spermogonia epiphyllous, rather large, subprominent, conoid, brownish-orange, in small groups on yellowish or orange spots; pseudoperidia hypophyllous, aggregated, tubular, cylindrical, very long (up to $8 \mathrm{~mm}$. long and $\mathrm{r} \mathrm{mm}$. wide), seated on orange spots, incurved, whitish, then yellowish, margin denticulate, spreading; aecidiospores in chains, angularly spherical, brownishyellow, $20-28 \times 10-24 \mu$, delicately verruculose, with six germ-spores; sori of teleutospores simple or caespitose, subgelatinous, hemispherical or conoid, tawny, becoming swollen, orbicular, piriform, etc., in damp weather, golden, finally wrinkled and collapsed; teleutospores ellipsoid or oblong, ends attenuated, 40-75 $\times 17-27 \mu$, not constricted at the septum, slightly tinged brown, pedicel very long.

Gymnosporangium clavariiforme, Rees, Wint., Krypt.-Fl., i. p. 233.-Spermogonia epiphyllous or fruticolous, erumpent from a thickened, orange or yellow patch, spermatia yellow, oblong; pseudoperidia springing from coloured 
spots like the spermogonia, gregarious, cylindrical, whitish, splitting from apex to base into reflexed filaments, aecidiospores warted, catenulate, yellowish, $22-45 \times 19-35 \mu$; teleutospores oblong-fusoid, I-septate, not constricted, yellow, 90-1 $20 \times 15-18 \mu$, with very long, slender, hyaline pedicels, forming subgelatinous, elongato-clavate, compressed, simple or bifid, yellowish-orange masses about I $\mathrm{cm}$. long, or sometimes longer.

Gymnosporangium confusum, Plow., Brit. Ured. and Ustilag., p. 232.- Pseudoperidia on thickened, reddish spots, orange above, and often surrounded by a reddish or purple line, cylindrical, or cylindric-fusiform, opening by lateral, longitudinal fissures, at length fimbriate; spores subglobose, pale brown, I5-20 $\mu$ diam.; teleutospore mycelium perennial; spore-masses vernal, at first tuberculate, dark chocolate-brown, almost black, soon becoming cylindrical, often compressed, 5-8 $\mathrm{mm}$. long, then rich chestnut-brown, swelling when moist, and speedily covered with golden-yellow pronycelium spores; spores smooth, oval, or elliptical, generally acute at both ends, of two kinds, the more numerous with hyaline walls and orangeyellow contents, the other with dark brown, thick walls, 40-50 $\times 20-25 \mu$, with from 2-4 germ-tubes; pedicel long, 80-100 $\mu$, hyaline.

Phragmidium, Link.-Spermogonia flattened, orbicular ; aecidia (Caeoma) in roundish clusters, confluent, and broadly effused; aecidiospores in chains; uredospores formed singly at the tips of hyphae; teleutospores transversely 3 -many-septate, upper cell with I germ-spore, the remainder with 4 germ-spores each.

Phragmidium rubi-idaei, Karst., Myc. Fenn. Hypoderm., 
p. 52.-Aecidia generally hypophyllous, rarely on petiole or stem, in chrome-yellow, orbicular groups having the centre depressed, or forming oblong pustules on petiole and stem ; aecidiospores aculeolate, orange-yellow, 20-28 $\mu$; paraphyses clavate, orange; uredospore sori minute, scattered or circularly arranged, yellow, spores aculeate, orange, 16-2 $2 \mu$; teleutospore sori hypophyllous, minute, black ; teleutospores oblong, apiculate, warted, 5-ro-septate, black, opaque, 90-140 $\times 20-35 \mu$, pedicel slightly incrassated below, I r $0-160 \times$ I 7-20 $\mu$.

Phragmidium subcorticatum, Winter, Krypt.-Fl., i.p. 228. -Aecidia hypophyllous, effused, various in form, often confluent, reddish-orange becoming pale, large, aecidiospores irregularly globose; epispore hyaline, contents orange, aculeolate, I 7-28 $8 \mathrm{I2-20} \mu$; uredospore sori soon naked, hypophyllous, scattered or crowded, on pale spots, orbicular, yellow, minute ; uredospores variable in form, $17-32 \times 12-24$ $\mu$, delicately aculeolate; teleutospore sori hypophyllous, scattered or aggregated, orbicular, black, minute; teleutospores oblong, obtuse with a white apiculus, 3 -8-septate, verrucose, dark brown, 75-100 $\times 26-30 \mu$, pedicel го०-1 $20 \mu$ long, thickened in the middle up to $22 \mu$.

Coleosporium, Lév.--Spermogonia and aecidia developed on leaves of conifers; uredospores at first grouped in moniliform series, orange or yellow, echinulate; teleutospores transversely 3 to many-septate, forming a flat, somewhat mucous, orange or yellow, flat layer, closely compacted, on living host plant; sporidiola large.

Coleosporium senecionis, Fr., Summa Veg., p. 512.Spermogonia scattered ; aecidia of two forms, one solitary or few in number, on the leaves, cylindrical, up to $2.5 \mathrm{~mm}$. 
long; others on the bark, often $6 \mathrm{~mm}$. broad, saccate, torn, crowded, white, spores various in form, up to $40 \times 17-28 \mu$, warted, orange; sori of uredospores yellowish-rufous, soon pale, pulverulent; spores in short chains, soon separating, elliptical or subcylindrical, orange, warted, $20-40 \times 14-26 \mu$; sori of teleutospores forming waxy, slightly convex crusts, yellowish-rufous then red, spores cylindrical or cylindricclavate, up to II0XI7-35 $\mu$, apex flattened, generally 4-celled, bright rufous-orange.

Chrysomyxa, Unger.-Teleutospores transversely manyseptate, arranged in a single series, or sometimes branched, lower loculi sterile, coalescing in a yellow or reddish, somewhat waxy, flat or slightly convex stratum; promycelium generally 4 -septate, each cell producing a single secondary spore on the apex of a slender sterigma; uredospores as in Coleosporium; aecidia as in Puccinia.

Chrysomyxa rhododendri, De Bary, Bot. Ztg., I879, p. 809, t. X., f. I-6.-Aecidia on yellowish spots, in I-2 rows on the needles; pseudoperidia cylindric, margin torn, white, up to $3 \mathrm{~mm}$. long, cells much compressed; aecidiospores variable in form, $17-45 \times 12-22 \mu$, warted, orangeyellow; uredospore sori rounded, oblong, or angular, scattered or gregarious, on variously coloured spots ; uredospores generally subpolygonal, globose, or oblong, 1 7-28X I 5-22 $\mu$, warted, orange-yellow; teleutospore sori convex, irregularly arranged in large or small groups on reddishbrown spots; teleutospores ro-r $4 \mu$ broad, not dilated upwards, obtusely rounded.

Chrysomyxa abietis, Unger, Beitr. zur Vergl. Pathol., p. 24, fig.-Sori of teleutospore stage (hybernating mycelium) linear, seriate, waxy, reddish-yellow, seated on yellowish 
spots ; teleutospores cylindrical, slightly clavately thickened upwards, often branched, up to roo $\mu$ long, and 9-1 $2 \mu$ broad, having up to 12 cells; epispore hyaline, contents reddish-orange; secondary spores globose, $4-6 \mu$, rufousorange.

Aecidium, Pers.-Pseudoperidium cupulate or suburceolate, rarely cylindrical, generally pale-coloured, margin often crenate or laciniate and revolute; aecidiospores globose or angular, continuous, most frequently orangeyellow, catenulate, smooth, or verrucose.

Uredo- and teleutospore conditions, if present, not correlated with the Aecidium.

Aecidium magelhaenicum, Berk., Hook., Fl. Antart., ii. p. 450.-Aecidia generally scattered over the entire under surface of the leaf, cylindrical, whitish, margin incised; spores polygonal, $20-40 \times 16-24 \mu$, epispore hyaline, verruculose, contents orange.

Aecidium ornamentale, Kalchbr., Flora, 1876, p. 362.Aecidia very numerous, occupying the entire surface of the branch, pale flesh-colour, concave or often obconic, or narrowly cylindrical, margin slightly torn; spores angularly globose, orange-red.

Aecidium esculentum, Barcl.-Pseudoperidia gregarious, immersed, conoid, for a long time closed, I mm. diam.; spores very abundant, in long series, subcuboid, $28-40 \times$ I6-г9 $\mu$; spermogonia minute, depressed, superficial, I००-I $20 \mu$ diam., 30-4० $\mu$ high.

Aecidium strobilinum, Rees, Rostp., p. r05.-Aecidia densely gregarious, numerous, generally covering the inner surface of cone scales, brownish, hemispherical, or polygonal 
from mutual pressure, up to $\mathbf{I} \mathrm{mm}$. diam., dehiscing in a circumscissile manner; aecidiospores $18-35 \times 16-22 \mu$, epispore hyaline, contents yellowish rufous, then pale.

Aecidium pseudo-columnare, Kühn, Hedw., ı884, p. 168. -Aecidia hypophyllous, 2-seriate, discolouring but not deforming the leaves, $0^{\circ} 5^{-2} \mathrm{~mm}$. high, margin irregularly torn, whitish; spores variable in form, $22-37 \times 18-26 \mu$, whitish, delicately verruculose.

Peridermium, Lév.-Pseudoperidia growing on bark, cone scales, or leaves, erumpent, saccate or tubular, apex torn ; spores in chains, becoming free, globose or elliptical ; epispore hyaline, warted or reticulated, contents orange; spermogonia truncato-conoid.

Peridermium harknessii, Moore, in Ellis and Harkn., Calif. Fungi, p. I 7.-Pseudoperidia crowded, irregular, large, growing all round the branch; aecidiospores irregular in form, orange, at length whitish, $35-40 \mu$ diam., very minutely echinulate.

Peridermium orientale, Cke., Indian Forester, iii. p. 9г. -Pseudoperidia solitary or scattered, large, for a long time closed and triquetrous, at length opening at the apex, orange-rosy; spores generally subglobose or broadly elliptical, very uniform, orange, 15 -1 $8 \times$ I0-I $2 \mu$, epispore thin, densely verruculose.

Peridermium coruscans, Fries, Summa Veg. Scand., p. 5 I 0. -Pseudoperidia numerous, longitudinally arranged, at first closed, ellipsoid, then membranaceous, elongated, whitish, tubular, apex divaricating, pale red ; spores usually globose, orange-yellow, $30-35 \times 20-24 \mu$, epispore thin, obsoletely but very densely verruculose.

Peridermium conorum, Thüm., Mon., p. 313.-Aecidia 
more or less covering the outer surface of cone scales; spores oblong-polyhedric, about, $24-33 \times 18-22 \mu$, warted, areolate, orange-yellow.

Peridermium elatinum, Kze. and Schw., D. Schw., No. 142.-Spermogonia immersed, conoidly prominent, honey-colour; aecidia hypophyllous, in $\mathrm{I}-2$ rows, white, irregularly torn; spores elliptic or polygonal, I6-30 $\times$ I 4 -I 7 $\mu$, epispore hyaline, coarsely warted, contents orange.

Uredo, Pers.-Sori generally orange-yellow, subpulverulent, superficial or erumpent, pseudoperidium absent; uredospores formed singly at the tips of fertile hyphae.

Uredo vitis, Thüm., Die Pilze des Weinstockes, p. I8z. Sori hypophyllous, usually minute and more or less crowded, bright yellow, resembling minute aecidia under a lens, due to the elevated margin composed of paraphyses ; spores piriform or broadly elliptical ; epispore thin, minutely verruculose, colourless, contents orange-yellow, r8-30X I 5-1 $8 \mu$; paraphyses colourless, cylindrical, slightly curved, $33-35 \times 7-9 \mu$.

Uredo cannae, Wint., Hedie., I884, p. I72. - Sori generally hypophyllous, rarely also epiphyllous, without spots, either densely scattered over the entire surface, or collected in groups, minute, pale yellow, for a long time covered by the epidermis; spores variable in form, yellowish, echinulate, $25-45 \times$ I6-23 $\mu$.

\section{SPHAEROPSIDIACEAE}

Fungi with perithecia containing conidia borne at the tips of slender conidiophores; asci absent.

Probably representing phases in the life-cycle of ascigerous fungi. 
Phyllosticta, Pers--Perithecia formed under the epidermis, lenticular, membranaceous, mouth or pore of dehiscence often protruding, seated on discoloured spots on leaves, rarely on branches. Conidia minute, ovoid or oblong, continuous, hyaline or tinged greenish-yellow.

Phgllosticta prunicola, Sacc, Mich., i. p. 157.-Spots epiphyllous, subcircular, dingy brown or ochraceous, margin similarly coloured; perithecia scattered, dotlike, slightly prominent; spores ovoid or elliptical, dilute olive, $5 \times 3 \mu$.

On leaves of Prunus domesticus, P. cerasus, and Pirus malus, also on various cultivated rosaceous fruit-trees.

Distr.-Western Europe, United States.

Phoma, Fries-Perithecia subcutaneous, then erumpent, membranaceous, subcoriaceous, or subcarbonaceous, globose or compressed, glabrous, not beaked, ostiola minute, sometimes obsolete; conidia hyaline, continuous, often 2-guttulate, elliptical, cylindrical, fusoid or globose; conidiophores slender, usually simple.

Phoma rostrupii, Sacc., Syll., xi. 490; Phoma sanguinolenta, Rostrup, Zeitschr. f. Pflanzenkr., iv. p. 195, pl. 4. (1894).-Perithecia hemispherical, gregarious, or crowded, greyish-black; conidia elliptical, $4-6 \times \mathrm{I}^{\circ} 5-3 \mu$ oozing out of the mouth of the perithecium in damp weather in the form of a long, curved, blood-red or violet-red tendril.

Phoma sanguinolenta, Rostrup, Tidssk. for Landök v. Rackke., Bd. vii. p. $3^{84}$ (1887).-Perithecia gregarious on depressed areas on the stem, or causing large cankerlike depressions on the root; conidia $4-6 \times \mathrm{r}^{-} 5-3 \mu$, escaping in the form of a flesh or blood-red tendril.

Hab., the carrot (Daucas Carota), Europe, United States. 
Phoma hennebergii, J. Kühn, Hedw., 1877, p. I21.Perithecia scattered on brown spots, erumpent, rounded, black, $100 \mu$ diam. ; conidia cylindrical, continuous, sometimes slightly curved, $14-18 \times 2-2 \cdot 5 \mu$, hyaline.

Hab., Paleae and leaves of Triticum sativum, Germany, Denmark.

Vermicularia, Fries.-Perithecia erumpent or subsuperficial, membranaceo-carbonaceous, black, globoso-conical, at length concave, apex perforated or mouthless, clothed with long, rigid, septate, fuliginous hairs; conidia typically cylindric-fusoid, often inaequilateral, continuous, borne on variously formed basidia.

In some species the perithecium is imperfect or pezizoid.

Vermicularia circinans, Berk., Gard. Chron., 1851, p. 595. - Spots orbicular, perithecia concentrically arranged, seated on radiating, hyaline, septate mycelium, very minute, furnished with long, rigid hairs; conidia oblong, obtuse, 2 -many-nucleate, hyaline, Io-I $4 \times 3-4 \mu$.

Fusicoccum, Corda.-Stroma subcutaneous, erumpent, black, internally divided into several cells or cavities, the walls of which are lined with spindle-shaped, continuous, straight conidia.

Differs from Cytispora in the larger, fusiform conidia.

Fusicoccum abietinum (Hartig), Prill. and Dela., Bull. Soc. Myc. France, Feb. 1890; Sacc., Syll., x. p. 24r.Stromata black, conical, subgregarious, apex piercing the tumid cortex, 400-600 $\mu$ diam. pluricellular within; conidia hyaline, fusoid, ends acute, straight, pluriguttulate, I 2-I4 $\times 5^{-6} \mu$; conidiophores acute, I0-1 $5 \times \mathrm{I}^{\cdot} 5^{-2} \mu$.

In living bark of Abies excelsa.

Distr.--Germany, France.

Quite distinct from Dothiorella pitya, Sacc. 
Ascochyta, Lib.-Perithecia generally gregarious on discoloured patches on leaves or branches, membranaceous, innate, an apical mouth or pore protruding, compressedglobose; conidia elliptical or elliptic-oblong, I-septate, hyaline or tinged greenish-yellow.

Ascochyta pisi, Lib., Ex. Pl. Ard., No. I 2.-Spots subrotund, yellowish with a darker margin, perithecia gregarious, brown, ostiolum protruding; conidia oblong, hyaline, I-septate, I4-I $6 \times 4^{-6} \mu$; extruded in reddish viscid tendrils.

Septoria, Fries.-Perithecia subcuticular, globoso-lenticular, furnished with a pore, laxly membranaceous, typically developed on decoloured areas on leaves; conidia rod-shaped or filiform, pluriseptate or pluriguttulate, rarely eguttulate, hyaline; basidia minute.

Septoria petroselini, Desm., Crypt. France, Exs., No. 674. - Spots brown, then white, determinate, on both surfaces; perithecia minute, delicately membranaceous, perforated, lenticular, parenchymatous, olive; conidia filiform, straight or flexuous, 6-1o-guttulate or delicately septate, hyaline, $35-40 \times$ I-2 $\mu$.

Entomosporium, Lév.-Perithecia hemispherico-applanata, mouthless, black (spurious?) ; conidia consisting of two superposed cells, with two or more cells springing from the median septum, all the cells setigerous.

Entomosporium maculatum, Lév., in Moug. Stirp. Vog., No. 1458.-Perithecia epiphyllous, flattened, imperfectly ostiolate; conidia 4-celled, $18-20 \times$ I $2 \mu$, hyaline, lateral cells smaller, depressed, with very long setae; pedicel filiform, $20 \times \mathrm{I} \mu$. 


\section{MELANCONIACEAE}

Perithecia and asci absent; conidia produced on a more or less developed cushion or stroma formed beneath the surface of the matrix, and becoming erumpent.

Probably forms of higher species.

Gloeosporium, Desm. - Sporodochium formed below the epidermis of the host, discoid or pulvinate, at length often erumpent, pallid or brown; conidia ovate-oblong, rarely oblong, hyaline, continuous, often extruded in the form of a sphere or tendril consisting of the conidia held together by mucilage; basidia usually acicular, fasciculate.

Gloeosporium nervisequum, Sacc., Mich., ii. p. $3^{81 .-}$ Pustules hypophyllous, erumpent, slightly prominent, brown, then black, seated on brown, dry patches of the leaf, most frequently following the larger veins, but sometimes forming broad patches; conidiophores slender, $12-15 \times 4-6 \mu$; conidia oblong-ovate or pear-shaped, hyaline, I 2-1 $5 \times 5-6 \mu$.

On living leaves of Platanus orientalis, $P$. occidentalis, also other species of Platanus, and said to occur on oak leaves in the United States.

Distr._Europe, United States.

Gloeosporium ribis, Mont. and Desm. in Kickx' Fl. Crypt. Fland., ii. p. 95.-Spots minute, rounded, often confluent, brown; pustules epiphyllous, blackish, flattened; conidia hyaline, oblong, curved, apex obliquely pointed, 10-I $2 \times 5^{-6} \mu$.

On living leaves of Ribes nigrum, $R$. rubrum, $R$. aciculare, and $R$. grossulariae.

Distr.-Europe, Asiatic Siberia, Australia, United States. 
In the American form on $R$. nigrum the conidia are larger, equal at both ends, $15^{-25} \mu$ long. An apparently distinct var. or species.

Gloeosporium venetum, Speg., Mich., i. p. 477.--Spots yellowish or ochraceous, small and rounded, or larger and irregular towards the margin of the leaf, and surrounded by a dusky purple line; pustules minute, prominent, solitary or gregarious; conidia elliptico-cylindrical, hyaline, contents granular and guttulate, $7-8 \times 2-2.5 \mu$.

On living leaves and stems of Rubus chamaeodorus and R. idaeus.

Distr.-Europe, North America, Australia.

Gloeosporium ampelophagum, Sacc., Mich., i. p. 2 I 7.Spots or pustules subcircular, often confluent, blackening, drying, and hardening the cortical strata of grape berries, centre of spots greyish or rosy-primrose, due to the presence of the extruded conidia; pustules originating beneath the epidermis, minute, densely gregarious, stroma thin, pulvinate, pallid, prosenchymatous, component cells minute, the superficial ones shortly apiculate and bearing the conidia; conidia oblong, ellipsoid or ovate, $5-6 \times 3.5 \mu$, 2-guttulate, hyaline.

Gloeosporium fructigenum, Berk., Gard. Chron., I856, p. 245.-Pustules concentric, dingy rose-red, erumpent through a simple or laciniate pore, pulvinate; conidia oblong or cylindrical, often curved, $20-30 \times 5^{-6} \mu$, hyaline ; basidia subequal in length, simple, rarely furcate, continuous.

Gloeosporium musarum, Cke. and Mass., Grev., xvi. p. 3.-Pustules innate, erumpent, gregarious, with a rosy tinge; conidia elongate ellipsoid, ends rounded, continuous, hyaline, I0-1 $2 \times 4-5 \mu$, contents granular. 
Gloeosporium rhododendri. - Briosi e Cavara, Fung. Par., No. 198.--Spots very large, irregular, dry, zoned; pustules black, rugulose, shining, concentrically arranged with a black bounding line; conidia cylindric-oblong, straight or slightly curved, ends obtuse or obliquely truncate, I $^{-20} \times 4^{-5}-5$.

Colletotrichum, Corda. - Acervuli innato-erumpent, plane, discoid or elongated, black, surrounded by long, blackish setae; conidia tereti-fusoid, continuous, hyaline, springing from the tips of short, fasciculate conidiophores.

Colletotrichum lindemuthianum, Briosi e Cavara, Piante Dan. Exs., No. 50.-Forming spots on the epicarp, rarely on stem or leaves, subrotund, dry, and brownish, at first bounded by a red line; conidiophores bursting through the epidermis in tufts on the diseased spots, fasciculate, cylindrical, simple, $45-55 \mu$ long; conidia acrogenous, oblong, straight or curved, ends rounded, I $5.19 \times 3.5-5.5 \mu$, hyaline; spines few in number, or sometimes apparently absent.

Colletotrichum spinaciae, Ellis and Halst., Journ. Myc., 1890, p. 34.-Maculicolous, spots round, dirty-white or greenish, 2-4 $\mathrm{mm}$. diam., with a slightly raised border; acervuli on both sides, punctiform, 40-75 $\mu$ in diam., clothed with a few (3-12) erect or spreading bristle-like hairs 60-75 $\mu$ long $\times 4-4.5 \mu$ thick at the sub-bulbous base, hyaline and subacute above, dark brown below, continuous (or faintly septate?) ; conidia subfalcate-fusoid, hyaline, 2-4 nucleate, $14-20 \times 2 \cdot 5-3 \mu$, ends subacute, basidia short.

Colletotrichum althaeae, Southw., Journ. Myc., 1890, p. 46, pl. iii.-Epiphyllous and caulicolous, erumpent, 
forming brown spots on the leaves, and light yellowishbrown to black sunken spots on the petiole and stalk; spores irregularly oblong, hyaline, flesh-colour in the mass, I I-28 $\times 5 \mu$; conidiophores colourless, cylindrical ; setae dark brown, abundant, once or twice septate, usually colourless below, 60-109 $\times 3-5 \mu$.

Colletotrichum gossypii, Southw., Journ. Myc., 189o, p. Ioo, pl. iv.-Sori orbicular, dark-coloured, or covered with a pink powder; acervuli erumpent ; conidia irregularly oblong, usually with a lighter spot in the centre, often acute at one end, colourless singly, flesh-coloured in mass ; conidiophores colourless, varying in length, at least longer than the mature spore, produced on a stroma; setae single or in tufts, dark brown at base, nearly colourless at the apex.

Cylindrosporium, Unger.-Pustules or nuclei formed under the epidermis, white or pallid, discoid or subeffused ; conidia filiform, continuous, hyaline, often flexuous.

Considered as conidial forms of species of Entyloma.

Cylindrosporium chrysanthemi, Ellis and Dearn., Can. Rec. Sci., 1893, p. 27 I.-Spots rather indefinite, I cm. and more broad, becoming blackish; pustules innate, on both surfaces, ro0-1 $70 \mu$ diam.; conidia fusoid, almost straight, 50-100 $\times 3-4.5 \mu$, at length escaping.

Cylindrosporium padi, Karsten, Symb. Myc. Fenn., pt. xv. p. 159.-Forming angular, brownish spots on both sides of the leaf; pustules hypophyllous, covered by the inflated epidermis; conidia filiform, flexuous, hyaline, eventually appearing at the surface, $48-62 \times 2 \mu$.

Libertella, Desm.-Acervuli or conidia masses of various 
form, for a long time covered by epidermis, which is eventually ruptured, the conidia usually escaping in the form of mucilaginous tendrils, bright-coloured or pallid; conidia slenderly fusiform, elongated, continuous, hyaline.

Libertella ulcerata, Massee ( $s p$. nov.).-Pustules gregarious, numerous, minute, eventually rupturing the epidermis, the conidia being extruded in the form of palecoloured, viscid tendrils; conidia fusiform, ends acute, continuous, curved, hyaline, $55-60 \times 4 \mu$.

Melanconium, Link.-Pustules or nuclei subcutaneous, conoid or discoid, black; conidia produced singly at the tips of basidia, globose or oblong, continuous, fuliginous, often extruded as viscid masses or tendrils.

Melanconium pandani, Lév., Ann. Sci. Nat., Bot., r 845, p. 66.-Acervuli erumpent, large, black, conoid, often aggregated in black, warty lines, $\mathrm{i}-2 \mathrm{~mm}$. diam.; conidia oozing out in black tendrils or irregular masses, pale olive, elliptic, oblong, straight or slightly bent, often 2-guttulate, size variable, $5-9 \times 3-4 \mu$; conidiophores elongated, branched, curved.

Described from a portion of Léveille's specimen, now in Herb., Kew.

Coryneum, Rees.-Fruit pustules discoid or pulvinate, subcutaneous, erumpent, compact, black ; conidia oblong or fusoid, 2-many-septate, fuliginous; basidia filiform. Conidia never extruded as a viscid tendril.

Coryneum beyerinckii, Oud., Hedw., I883, p. I I3.Fruit clusters very minute, dotlike, black, gregarious; conidia springing from a brownish, parenchymatous, pulvinate stroma, crowded, oblong or oblong-obovate, pale 
olive, usually 3 -septate, very slightly constricted at the septa, $28-32 \times$ I I-I $3 \mu$; conidia slightly thickened below, hyaline, $28-32 \times 2-3 \mu$.

Pestalozzia, De Notaris.-Pustules subcutaneous, at length erumpent, discoid or pulvinate, black; conidia oblong, 2-many-septate, coloured (at least the median cells), rarely entirely hyaline, apex hyaline, I-many-ciliate, apical on slender, hyaline basidia.

Pestalozzia guepini, Desm., Ann. Sci. Nat., r840, vol. xiii. p. I82, tab. 4, figs. I-3.-Pustules minute, dotlike, slightly convex, black, at first covered by the epidermis, then erumpent, seated on large, bleached spots; conidia elliptical ends narrowed, 3-4-septate, end cells hyaline, intermediate ones coloured, terminal cell conoid, terminated by 3.4 hyaline hairs as long or longer than the conidia, which are 20-25 $\mu$ long; conidiophores slender, hyaline.

Pestalozzia hartigii, Tubeuf, Beitr. Baumkr., p. 40, tab. 5.-Pustules immersed, globose, springing from a flattened stroma; conidia emerging in black masses, at first hyaline, continuous, then 3 -septate, ovate-oblong, the 2 central cells large, multiguttulate, coloured, terminal cells small, hyaline, I 8-20 $\mu$ long, setae $\mathrm{I}-4$, slender, hyaline, $20 \times \mathrm{I} \mu$; basidia slender, hyaline, 30-50 $\mu$ long.

Septogloeum, Sacc.-Pustules growing on living plants, minute, produced beneath the epidermis, sometimes erumpent, pallid; conidia oblong, 2-pluriseptate, hyaline; resembling Gloeosporium, but with septate conidia.

Septogloeum hartigianum, Sacc., in Hartig, Forst Zeitschr., 1892.-Pustules innato-erumpent, sparsely longitudinally gregarious, oblong-linear, bordered by the 
ruptured periderm, I-2 $\mathrm{mm}$. long, $0^{*} 3 \mathrm{~mm}$. wide, brown, stromatic base white, producing on its surface the crowded, parallel, cylindrical with inflated base, hyaline conidiophores 30-35 $\times 6-7 \mu$; conidia ovate-oblong, ends obtuse, almost straight, typically 2 -septate, $24-36 \times$ Io-1 $2 \mu$, subhyaline.

\section{HYPHOMYCETACEAE}

Superficial or subsuperficial, rarely endoparasitic on insects; hyphae often profuse, bearing naked, free conidia; asci, perithecia, and ascophore absent.

Mostly representing phases in the life-cycle of higher fungi.

Mucedineae. - Hyphae and conidia hyaline or clearcoloured; not brown or blackish.

Oospora, Wallr.-Tufts delicate, effused or pulvinate, lax or rather compact ; fertile hyphae short, slender, simple, or sparingly branched; conidia concatenate, globose or elliptical, colourless or clear-coloured.

Oospora abietum, Oud., Ct. Rend. de l'Acad. Roy. d. Sc. des Pays-Bas, séance de Jan. I897.-Tufts minute, subpulvinate, forming lines on the leaf near the nerve, emerging from the stomata; conidiophores short, simple; conidia elliptical, ends rounded, continuous, ro-1 $2 \times 6-7 \mu$, caducous.

Oospora scabies, Thaxter, Ann. Rep. Conn. Agric. Expt. Station, 1891, p. 152. - Vegetative hyphae hyaline or brownish from the general discoloration of the substratum, 4- $6 \mu$, rarely as much as I $\mu$ diam., curving irregularly, septate or pseudoseptate, branching; aërial hyphae at first white, then greyish, evanescent, breaking 
up into bacteria-like segments, after producing terminal spirillum-like 'spores' by the coiling of their free extremities. Forming a firm, lichenoid pellicle on nutrient jelly, and usually when growing in contact with the air producing a deep, black-brown discoloration of the substratum. Producing the disease known as 'Scab' on potato tubers, and a similar affection of beetroots.

The above is the author's amended diagnosis given in Journ. Mycol., vii. p. 280 (1893). It is stated that the fungus obtained accidentally from water by Sauvageau, and described as Oospora metchnikowi(Ann. d. l'Inst. Pasteur, tab. vi. p. 242) is probably identical with $O$. scabies.

Monilia, Pers.-Hyphae erect, vaguely branched, often forming dense tufts, rarely effused, producing denticulate conidiophores here and there; conidia rather large, formed in chains.

Monilia fructigena, Pers., Syn., p. 693.-Tufts compact, pulvinate, often confluent and forming concentric rings; hyphae fasciculate, with short branchlets, which bear simple or branched chains of ovoid, oblong, or lemonshaped, hyaline, or pinkish conidia, $25 \times 10-12 \mu$.

Dematiae.-Hyphae or conidia, or both, brown or blackish.

Fusicladium, Bon.-Hyphae short, straight, sparingly septate, somewhat fasciculate, olivaceous; conidia ovoid or subclavate, for a long time continuous, at length often I-septate, acrogenous, solitary or in pairs.

Fusicladium pirinum, Fckl., Symb. Myc., p. 357.Effused, olive, velvety; conidia ovate-fusoid, 28-30 $\times 7$ $9 \mu$, continuous (always?), guttulate, olive ; conidiophores short, terete, apex denticulate. 
Fusicladium dendriticum, Fckl., Symb. Myc., p. 357.Effused, velvety, olive, often epiphyllous, and forming dendritic patches; hyphae filiform, fasciculate, erect, 50$60 \times 5 \mu$, sparingly septate; conidia apical on the conidiophores, fusoid-obclavate, $30 \times 7-9 \mu$, for a long time continuous, at length $\mathrm{I}$-septate, not constricted, olive.

Fusicladium fagopyri, Oud., Ct. Rend. des Séance Acad. Roy. Sc. Pays-Bas, 1897, p. 88.-Conidiophores erect, solitary, almost contiguous, straight or flexuous, sometimes nodulose, continuous or I-septate, olive, 70-80 $\times 7 \mu$; conidia apical, solitary, for the most part ovate, pale olive, continuous or $\mathrm{I}$-septate, $\mathrm{I} 4 \times 9 \mu$.

Acrospeira, Berk. and Broome.-Sterile hyphae decumbent, forming a weft, fertile hyphae erect, branched, septate, tips of branches curved, septate; conidia more or less globose, warted, produced laterally near the tips of the curved branches, dark-coloured, as is also the mycelium.

Acrospeira mirabilis, Berk., Intr. Crypt. Bot., p. 305, f. 69A.-Sterile hyphae blackish-olive, floccose, interwoven, fertile, erect, vaguely branched above, tips of branches curved and closely septate ; conidia subglobose, lateral near the tips of the branches, dark-coloured, minutely warted, I 5-20 $\mu$ diam.

Cladosporium, Link.-Hyphae subdecumbent, branched, olive; conidia at first subglobose, then elliptical, typically becoming I-septate, rarely 2 -3-septate.

Cladosporium fulvum, Cke., Grev., I883, p. 32 .Effused, somewhat felted, tawny; conidiophores erect, wavy, septate, nodulose, sparingly branched, tawny; conidia elliptical or elliptic-oblong, I-septate, scarcely constricted, pale tawny, translucent, $10-20 \times 4-6 \mu$. 
Cladosporium citri, Penzig.-Sporophores tufted, erect, brown, branched, septate, $30-75 \times 2-4 \mu$; conidia fusiform, dusky, usually continuous, occasionally I-3-septate, 8-9 $\times$ 2.5-4 $\mu$.

Cladosporium elegans, Penzig, Mich., ii. p. 47 I.-Tufts epiphyllous, gregarious, distinct, seated on arid spots; conidiophores erect, fasciculate, simple, sparingly septate, distinctly sinuous, brown, $160-200 \times 5^{-6} \mu$; conidia apical and lateral, continuous or I-septate, elliptic-oblong, epispore delicately granulated, pale brown or yellowish, I $8-20 \times 5-6 \mu$.

Cladosporium epiphyllum, Mart., Erl., p. 351.-Tufts arranged in dark olive patches, which are often large and dense; hyphae at first erect, then more or less flaccid, branched and interwoven, pale olive ; conidia very abundant, pale olive, at first continuous then I-septate; produced in short chains, which sometimes remain attached, and then the conidium appears large and more than I-septate, averaging 10-1 $2 \times 4-6 \mu$.

Cladosporium carpophilum, Thüm., Fung. Pomic., p. I3. -Spots orbicular, often confluent, blackish-green, forming circles; hyphae short, erect, continuous, slightly branched, slender, fuscous; conidia ovate, ends obtuse, continuous or rarely I-septate, $20 \times 5 \mu$, pale brown.

Helminthosporium, Link.-Conidiophores almost simple, few septate, often nodulose, oliveaceous, scattered or usually fasciculate; conidia apical, elongated, cylindrical, clavate, fusiform, etc., 3-many-septate, epispore smooth, olive.

Helminthosporium teres, Sacc., Fung. Ital., tab. 833 ; Sacc., Syll., iv. p. 4 I 2.- Spots oblong, on both surfaces, 
olive; conidiophores fasciculate, Ioo- $30 \times \mathrm{I} 2 \mu$, cylindrical base slightly thickened, fuliginous; conidia acrogenous, cylindrical, both ends rounded, straight, Ioo- I I 5 $\times$ I $8 \mu, 4$-5-septate, not constricted, dark olive.

Forma Avenae sativae, Briosi e Cavara, Fung. Par. Exs., No. 80, differs from type in the conidiophores not

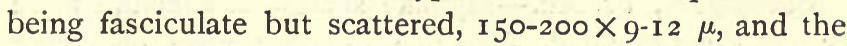
slightly smaller conidia, 80- I I0X I 5-16 $\mu$.

Helminthosporium turcicum, Pass., Boll. Comiz. Agr. Parm. Ott., 1876; Helminthosporium inconspicuum, Cke. and Ellis, Grev., vi. 88, pl. 99, f. I 7 (1877).-Conidiophores gregarious or subfasciculate on large, dry, brownish spots, I 50-180 $\times 6-9 \mu$, few septate, pale olive, apex almost hyaline, sometimes more or less nodulose ; conidia spindleshaped, ends acute, 5-8-septate, pale olive, $80-140 \times 20-$ $26 \mu$. Examination of authentic specimens from both authors enabled me to prove their identity.

Helminthosporium gramineum, Erikss., Bot. Centralbl., xxix. p. 92 (r887).-Conidiophores solitary, or in clusters of $2-4$, yellowish, I-5-septate, often angularly bent ; conidia yellowish, straight, elongato-cylindrical, I-5-septate, 50roo $\times$ r 4-20 $\mu$.

Brachysporium, Sacc.-Hyphae rigid, subsimple, brown; conidia ovoid or piriform, brown, 2 or few septate, brown. Often growing on wood.

Distinguished from Helminthosporium by the shorter conidia; doubtfully valid.

Brachysporium pisi, Oud., Nederl. Bot. Ver., ı 898, p. 527.-Tufts effused, delicate, blackish; conidiophores fuliginous, solitary or spuriously caespitose at the base, septate, smooth, or sometimes torulose near the septa, 
100-250 $\times$ 5-6 $\mu$; conidia solitary at the apex of the conidiophores, elliptical, ends broadly rounded, 3-septate at maturity, slightly constricted at the septa, pale fuliginous, 28-30XII-I $2 \mu$; epispore densely and very minutely echinulate under a high power.

Cercospora, Fresen.-Hyphae somewhat flaccid, simple or slightly branched, fuscous; often growing on living leaves and forming pallid, dry spots; conidia wormshaped, olive or subhyaline, multiseptate.

Cercospora circumscissa, Sacc., Fung. Ven., ser. v. p. 189.-Forming spots on both sides of living leaves; spots circular, pallid, dry, the dry portion at length falling out; hyphae fasciculate, nodulose, brownish ; conidia acicular, attenuated towards the apex, septate, tinged brown, $50 \times$ $3 \cdot 5-4 \mu$.

Cercospora apii, Fresen., Beitr., p. 91, pl. xi. figs. 46-54. -Spots subcircular, on both surfaces, pale brown, 4-6 mm. diam., with an irregularly narrow raised margin; hyphae generally hypophyllous, in minute, brown, gregarious tufts, I-2-septate, subundulate, 40-60 $\times 4-5 \mu$; conidia slightly obclavate, 3 -10-septate, 50-80 $\times 4 \mu$, subhyaline.

Cercospora violae, Sacc., Fung. Ven., ser. v. p. 187.Forming spots on both surfaces of the leaf; spots subrotund, dry, pallid; hyphae short, simple, $30-35 \times 4 \mu$, fuliginous; conidia very long, I 50-200 $\times 3.5 \mu$, rod-shaped, suberect, multiarticulate, hyaline.

Cercospora resedae, Fuckel.-Tufts gregarious, grey, minute, appearing on dry spots on the leaf, $2-4 \mathrm{~mm}$. diam.; hyphae closely crowded, quite simple, continuous or 
sparingly septate, straight, slightly tortuous upwards, 50$70 \times 4-5 \mu$, brown ; conidia acrogenous, narrowly obclavate, 4-5-septate, hyaline, Io0-1 $40 \times 2 \cdot 5-3 \mu$.

Cercospora viticola, Sacc., Syll., iv., No. 2200.-Spots appearing on both surfaces of the leaf, subcircular or irregular, 2-10 $\mathrm{mm}$. diam., often numerous and growing into each other; hyphae often hypophyllous, in densely fasciculate tufts, filiform, septate, $50-200 \times 4-5 \mu$, straight, ochraceous, apex obtuse and obsoletely denticulate; conidia elongate-obclavate, narrowed upwards, 3-4-septate, guttulate, $50-70 \times 7-8 \mu$, ochraceous-olive.

Cercospora beticola, Sacc., Fung. Ven., ser. v. p. I89.Forming spots on both surfaces of the leaf ; spots vague in form, dry, $2-3 \mathrm{~mm}$. or more across, often bordered with red; hyphae fasciculate, often continuous, cylindrical, 405० $\times 4-5 \mu$, brownish, apex nodulose; conidia acicular, 70r $20 \times 3 \mu$, densely and delicately septate, hyaline.

Heterosporium, Klotzsch, Herb. Myc., i., No. 67 (1832). -Conidiophores fasciculate, simple or sparingly branched, septate, often nodulose, olive-brown ; conidia solitary or in chains of two or three, cylindric-oblong, 2-5-transversely septate; epispore minutely warted or granular, pale olive, springing from the apex of the conidiophores.

Growing on branches, twigs, and leaves ; often forming blackish-olive, velvety patches. Helminthosporium only differs from the present genus in the conidia having the epispore smooth.

Heterosporium echinulatum, Cke.-Clusters small, often numerous, seated on brown spots usually on the upper 
surface of the leaf; conidiophores, springing from a small stroma, roo-200 $\times 8-10 \mu$, olive, septate, nodulose; conidia terminal or lateral near the apex of the conidiophores, olive, minutely warted, 2-5 septate, cylindrical, constricted at the septa, $30-50 \times$ 10-1 $5 \mu$.

Heterosporium gracile, Sacc., Syll., iv., No. 2308.-Forming rather large, elliptical, or roundish brown spots bounded by a darker line; conidiophores septate, nodulose, olive, 70-90 $\times$ 10-I $4 \mu$; conidia elliptic-oblong, I-3-septate, obtuse at the ends, minutely warted or granular, pale olive, 35$70 \times 14-20 \mu$.

On living leaves of species of Iris, Freesia, Antholyza, and Hemerocellis.

Distr.-Europe, Cape of Good Hope, New Zealand, United States.

Macrosporium, Fries. - Conidiophores subfasciculate, softish, erect or ascending, subsimple or branched, coloured, bearing at or near the apex oblong or clavate, muriform, coloured conidia.

Some are known to be, and others are suspected of being, conidial forms of ascigerous fungi.

Macrosporium nobile, Vize, Grev.-Conidiophores fasciculate, short, erect, septate, brown, simple; conidia subpiriform or irregular, 4-10 septate, muriform, constricted at the septa, brown, $60-80 \times 40 \mu$.

Macrosporium tomato, Cke., Rav. Amer. Fung. Exs., No. 603.-Spots orbicular, black; hyphae short, robust, flexuous, septate; conidia clavate, apex slightly narrowed, scarcely stipitate, parenchymatous, brown, 100-I $20 \times 20-22 \mu$.

Macrosporium solani, Ellis and Mart., Amer. Nat., r892, 
p. 1003.-Conidiophores erect, curved, caespitose, septate, 50-70 $\times 3-4.5 \mu$; conidia brown, obovate-oblong, manyseptate, muriform below, septate above, apiculus hyaline, length including apiculus 100-I40X $\times$ 5-1 $8 \mu$.

Mystrosporium, Corda.-Conidiophores simple or sparingly branched, rather short, rigid, typically brown; conidia elliptical, oblong, or subglobose, many-septate, muriform, dark brown, acrogenous, solitary or rarely subsolitary.

Mystrosporium adustum, Massee. - Forming black patches on bulbs of Iris reticulata; hyphae forming a crust, dark brown, $5^{-8} \mu$ thick, certain cells often inflated; conidia elliptic-oblong or ovate, ends obtuse, with 5-7 transverse septa, becoming muriform, septa often oblique, sometimes with transverse septa only, $45-60 \times 20-22 \mu$, smooth, dark brown, translucent, terminal or at the tips of short branches, solitary.

Mystrosporium alliorum, Berk., Sacc., Syll., iv., No. $259^{2}$. -Conidiophores brown, septate, often flexuous; conidia terminal or on short lateral branches, elliptic-oblong or subpiriform, constricted in the middle, becoming multiseptate and muriform, septa sometimes oblique, epispore brown, minutely but distinctly warted, $30-45 \times 8-12 \mu$.

Described from Berkeley's type, which has been discovered in the Kew Herbarium.

Stilbum, Tode.-Stroma terete; apex capitate, bearing the conidia on the tips of the component hyphae; conidia minute, continucus, at first involved in mucus.

Stilbum nanum, Massee, Kew Bull., I898, p. I12, figs. I I-I 3. - Conidiophore very minute, scarcely $0.5 \mathrm{~mm}$. high, gregarious, pale yellow; stem equal, thin; capitulum 
globose or obovate; conidia very numerous, minute, hyaline, continuous, elliptical, at first involved in mucus, $5 \times 2 \cdot 5 \mu$.

Necator, Massee.-Sporodochia shieldlike or discoid, slightly convex, orange-red, erumpent, gelatinous, covered by a layer of conidia agglutinated together; conidia oblong or elliptic, continuous, catenulate, chains at length breaking up, contents orange.

Necator decretus, Massee, Kew Bulletin, I898, p. I I9.Sporodochia discoid, loosely gregarious, sessile, erumpent, I-I.5 mm. diam., sometimes oblong, $2-2 \cdot 5 \times I^{\circ} 5 \mathrm{~mm}$., white, then orange-red; conidia continuous, ellipsoid, catenulate, I 4 - $8 \times 7-8 \mu$.

Fusarium, Link.-Sporodochium pulvinate or subeffused, often more or less gelatinous when moist; conidia fusoid or falcate, typically pluriseptate at maturity, acrogenous on branched sporophores.

Subg. Fusamen.-Conidia elongated, continuous.

Subg. Septosporium.-Conidia short, continuous.

Fusarium solani, Sacc., Mich., ii. p. 296.-Globose, irregular, tomentose, whitish; hyphae branched; conidia fusiform-falcate, 3-5-septate, 40-60 × 7-8 $\mu$, subhyaline.

Fusarium lycopersici, Sacc., Mich., ii. p. 296.-Hyphae creeping, variously branched, bearing scattered, subsimple sporophores; conidia falcate, ends acute, $25-30 \times 3.5-4 \mu$, hyaline, then orange.

Fusarium heterosporum, Rees, Nat. Act. Cur., ix. p. I35. - Sporodochium subtremelloid, spreading, deep red; conidia at first globose then fusiform, 30-35 long, 3-septate. 
Fusarium pannosum, Massee, Kere Bulletin, I898, p. I 7 .- Sporodochia erumpent, 5-10 cm. diam., suborbicular, often confluent, bright vermilion, fleshy, subgelatinous, compact; hyphae creeping, densely interwoven, branched, sparingly septate, 4-5 $\mu$ thick, hyaline; conidiophores sparingly branched, branchlets fusoid; conidia fusoid, falcate, ends acute, 3 -septate, $35-38 \times 5 \mu$.

Fusarium limonis, Briosi, Act. Staz. Chim. Agrar. Roma, 1878.--Sporodochia gregarious, confluent, white; hyphae spreading, branched, septate; conidiophores erect or ascending, oppositely or alternately branched; conidia very variable, acrogenous, continuous, or septate at the middle, or 2-3-septate, oblong or fusiform, slightly curved, attenuated, slightly constricted at the septa, hyaline, 26$27 \times 2 \cdot 4 \cdot 2 \cdot 8 \mu$.

Chaetostroma, Corda.-Sporodochium discoid or pulvinate, black, bordered with black, rigid hyphae; conidia ovoid or subfusiform, rarely subglobose, borne solitary at the tips of slender conidiophores, rarely in chains.

Chaetostroma cliviae, Oud., Ct. Rend. Acad. Sc. PaysBas, I896, p. 226.-Sporodochia innate on large yellow spots, inordinate, shining black, orbicular, elliptical or irregular in shape, up to $\frac{1}{3} \mathrm{~mm}$. long, finally with a central opening or a longitudinal slit; surrounded by black, pointed, septate, more or less flexuous hairs about 2 ro $\times 5$ $\mu$; conidia cylindrical, ends rounded, continuous, hyaline, $23-28 \times 5-7 \mu$.

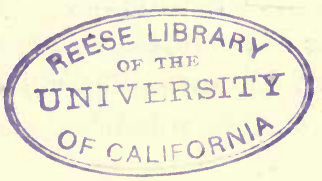




\section{ADDENDA}

THE following were unfortunately omitted from their proper place in the book:-

\section{ROSE MILDEW}

(Sphaerotheca pannosa, Lév.)

Too frequently the foliage, young shoots, and flowerbuds of cultivated roses become more or less covered with a delicate white mildew, which soon presents a mealy appearance, due to the formation of myriads of conidia. The conidia are scattered by wind, insects, birds, or syringing; and generally the disease spreads at an alarming rate, unless prevented, after having once appeared. As a rule the leaves curl and fall early in the season, while formation of conidia is still progressing. On the young shoots and fruit, the more permanent parts, after the crop of conidia is completed, the mycelium increases in quantity, finally presenting a dense, velvety appearance, and often with a dingy yellow tinge. Later in the season winter fruit, under the form of minute black points, may be found imbedded in the dense mycelium. The spores of the winter form of fruit germinate the following spring, and produce the conidial phase of the disease.

Preventive Means.-Flowers of sulphur mixed with about one-third of its volume of slaked lime dusted on the 
foliage prevents the spread of the disease. Spraying with potassium sulphide solution answers the same end, and is not so unsightly on the foliage. Diseased shoots and fruit should be cut off in the autumn before the winter fruit falls to the ground.

Sphaerotheca pannosa, Lév.-Mycelium forming a white, pruinose stratum on living leaves, fruit, and young shoots of wild and cultivated species of Rosa. Diseased leaves usually curl and fall after producing conidia only. On the shoots and fruit the mycelium becomes felted and velvety, and bears later in the season minute blackish perithecia immersed in its substance; perithecia subglobose, appendages hyaline, short, ascus solitary, subglobose, 8-spored; spores elliptical, $20-27 \times$ I 2-1 $5 \mu$.

\section{AMERICAN COFFEE DISEASE}

(Stilbum flavidum, Cooke.

= Pistillina flavida, , Speg.)

This disease is almost as destructive to the coffee industry in the New World as Hemileia vastatrix is in the Old World.

The symptoms of the disease are unmistakable ; circular whitish blotches occur on the leaves, often in considerable numbers, and are equally marked on both surfaces. Using a pocket-lens, very minute fungi resembling a miniature pin in shape, and of a clear yellow colour, can be seen grouped on the spots on the upper surface of the leaf. The berries are also sometimes attacked, being marked with circular spots. On the young shoots the pale diseased spots are elongated. 
The disease occurs in Costa Rica, Venezuela, Guatemala, and New Granada.

Preventive Means.-Although by no means a new disease, no serious attempt appears to have been made to arrest its progress. Being quite superficial, it is quite probable that spraying with Bordeaux mixture, or with ammoniacal solution of carbonate of copper, would prove effective. All diseased leaves and fruit should be collected and burned, otherwise spraying is of little avail.

Stilbum flavidum, Cooke, Grev., i880, p. I I.-Forming circular bleached spots on living leaves, the bleached patches pass quite through the leaf; sporophores occur on upper surface of the leaf, gregarious on the patches, very minute, entirely clear yellow, I-2 $\mathrm{mm}$. high, stem very slender, straight, or flexuous, head globose; conidia elliptical or subglobose, $2^{-2} \cdot 5 \times \mathrm{I}^{\circ} 5^{-2} \mu$.

This is considered by Spegazzini to be a Basidiomycete, and renamed Pistillina flavida; however, I have failed to find basidia, and so prefer to retain the species under Stilbum. 


\section{INDEX OF PARASITES, FUNGICIDES, AND BOTANICAL TERMS}

ACANTHOSTIGMA PARASITICUM, II 4,369 .

Acrospeira mirabilis, 305,435 .

Aecidium, I r.

- conorum-picae, 266.

esculentum, 264, 421.

- magelhaenicum, 263, 421.

— ornamentale, 264,421 .

- - pseudo-columnare, $263,422$.

strobilinum, 263, 42r.

thomsoni, 267.

Aglaospora taleola, rr2.

Algae, 29.

Alternaria, I ro.

Ammoniacal solution of copper carbonate, preparation of, 36 .

Anbury, 334.

Anthracnose of scarlet-runner, 288. Armillaria mellea, r4, 201, 386.

— mucida, 204, 387 .

Arsenic, 40.

Arthrogenous, $3 \mathrm{r}$.

Aschersonia, I02.

Ascochyta pisi, 275, 426.

Ascospora beyerinckii, 294, 362 .

Asterula beyerinckii, 362 .

Aureobasidium vitis, $\mathbf{1} 70$.

BACILLI, 30.

Bacillus oleae, 34r.

- solanacearum, 342.

Bacteria, 30.

Bacterium hyacinthi, 339.

Black blight, ro3.

knot, 136.

rot of grapes, ro5.

rust, 247 .

Bladder plums, 85 .
Blister-blight of tea plant, $\mathbf{x} 68$.

Blood, dried, 53 .

Bordeaux mixture, preparation of,

32.

Botry tis cinerea, 148 .

- douglassii, 160 .

— galanthina, 159 .

— paeoniae, $\mathbf{r}_{57}$.

- parasitica, $\mathbf{1} 58$.

Brachysporium pisi, 315, 437.

Bremia lactucae, 74,354 .

Brown rot of fruit, 300 .

Brunissure, 338.

Bulgaria polymorpha, 162,384 .

CAEOMA LARICIS, 238. pinitorquum, 235, 236.

Calospora vanillae, 113,368 .

Canker, apple-tree, 127 .

Capnodium citricolum, ro3, 364 .

mangiferum, ro3.

Carbolic acid, 73 .

Cephaleurus minus, 345 .

- parasiticus, 344 . mycoidea, 343 .

virescens, 343 .

Cercospora circumscissa, $317,43^{8}$.

- gossypina, 290. resedae, 319,438 .

violae, 3r9, 438 .

viticola, $3 \mathbf{1 9}, 439$.

Cercospora apii, 3I6, $43^{8}$.

Chaetostroma cliviae, 333,433 .

Cherry leaf scorch, Iro.

Chrysomyxa abietis, 263,420 .

rhododendri, 262,420 .

Chytridium brassicae, 53 .

Cladosporium, r ro. 
Cladosporium carpophilum, 3ro, 436.

- citri, 310, 436 .

elegans, 3I $x, 3^{1} 3,436$.

epiphyllum, 306, 436.

fulvum, 3 I I, 435 .

Claviceps purpurea, 122, 372.

Club-root, 334 .

Cluster-cup, II.

Cocci, 30.

Coleosporium senecionis, 26I, 4I9.

Colletotrichum althaeae, 290, 429.

- gossypii, 290, 430.

— lindemuthianum, 288, 429.

- spinaceae, 29I, 429 .

Condy's fluid, 38 .

Conidia, 8.

Coral spot disease, I3r.

Corticium comedens, 172, 397.

Coryneum beyerinckii, 294, 43I. gummiparum, 122.

Cronartium asclepiadeum, 235, 408. flaccidum, 235,409 . ribicolum, $233,408$.

Crown rust, 249.

Cylindrosporium chrysanthemi, 292, 430.

- padi, 29r, 430.

Cystopus candidus, 59, 352.

- cubicus, $6 \mathbf{r}$.

tragopogonis, 6r, $35^{2}$.

Cytispora, I 13 .

Cyttaria berteri, $16_{5}, 3^{86}$.

darwinii, 165,385 .

gunnii, $16_{3}, 3^{86}$.

hookeri, 165,385 .

DAEDALEA QUERCINA, I98, 395 .

Damping off, 54 .

Dasyscypha calycina, 145, 379 .

Dematium pullulans, 309.

Dematophora necatrix, ir6.

Diaporthe (Chorastate) taleola, I 12, 368.

Diatraea saccharalis, 104 .

Dimerosporium mangiferum, Io3, 363.

Diplocladium, 329.

Disease, spread of, 17 .

Doryphora decemlineata, 342.

Drooping disease of Paeony, I57.

Dry rot, 198.
ECONOMIC CONSIDERATIONS, 47.

Écoulement blanc, 348 .

Egg, dessicated white of, 53 .

Endogenous, 3I.

Endomyces magnusii, 349.

Entomosporium maculatum, 276, 426.

thumeni, 278.

Epichloe typhina, 125, 372.

Ergot, 122.

Eriksson's theory of the grain rusts, 245.

Erysiphe communis, 362 .

Exoascus amentorum, 89, 359.

- cerasi, 89, $35^{8}$.

- deformans, $83,35^{8}$.

- pruni, $85,35^{8}$. turgidus, 89, 359.

Exobasidium lauri, I68, 399.

—_ rhododendri, $x 67,398$. vexans, $168,398$.

vitis, 170, 399 .

—— var, album, I70.

- var. tuberculatum, $\mathbf{1} 70$.

FAIRY-RING OF CARNATION, 3I9.

False tinder fungus, 188 .

Finger-and-toe, 334 .

Fistulina hepatica, I98, 395.

Fomes annosus, 182,393 .

- fomentarius, $185,392$.

— fulvus, 197,393 .

- hartigii, 197 .

- igniarius, $\mathbf{1} 87,393$.

— pinicola, 197, 393.

- ribis, 185, 394.

Foot-rot of orange and lemon, 332.

Formalin, 32.

Fumigation with hydrocyanic acid

gas, 43.

Fungi, definition of, 4 .

- dispersion of spores of, $\mathrm{I}_{5}$.

— how they attack plants, I4.

- mode of growth of, 5 .

reproduction of, 7 .

Fungicides, 3r.

- poisonous properties of, 46 .

Fusarium culmorum, 333 .

- heterosporium, 331, 442.

- hordei, $33 \mathbf{I}$.

— limonis, 332,443 .

— lycopersici, 328, 442 . 
Fusarium pannosum, 333, 443 . solani, 333,442 .

Fusicladium dendriticum, 302, 435 . fagopyri, 435 . pirinum, 304, 434.

Fusicoccum abietinum, 275, 425 .

Fusisporium lolii, 33r.

\section{GLOEOSPORIUM AMPELOPHAGUM,} $278,428$.

- bicolor, 288.

fructigenum, 28I, 428 .

musarum, $287,428$.

nervisequum, 284,427 .

rhododendri, 288, 429.

ribis, $286,427$.

venetum, 286,428 .

Gnomonia erythrostoma, IIo, 367 .

Grain rusts, 243.

Grapholitha pactolina, 130.

Grey blight of tea plant, 295.

Guignardia bidwellii, I05, 365 .

Gummosis of Prunus japonica, 306. Gymnosporangium clavariaeforme,

\section{$253,4 \mathrm{I} 7$.}

confusum, 257, 4I8.

juniperinum, 258,417 . sabinae, 257, 4I6.

\section{Hainesia, II 3 .}

Haustoria, 7.

Heart-wood rot, I9I, I93.

Helicobasidium mompa, I66, 400.

Helminthosporium gramineum, $3 \mathbf{I} 5$,

437.

inconspicuum, $33^{1} 3$.

teres, 315, 436 .

turcicum, 3I3, 437 .

Hemileia canthii, 27, 408 .

— vastatrix, 27, 231, 407 .

woodii, 27,407 .

Herpotricha nigra, II3, 369 .

Heteroecism, Ir.

Heterosporium echinulatum, 3I9, 439.

- gracile, $32 \mathrm{I}, 440$.

Hirneola auricula-judae, I65, 399.

Honey-dew, roo.

Hot-water treatment, Jensen's, 40.

Hydnum diversidens, $177,396$. scheidermayeri, I77, 396.

Hydrocyanic acid gas, 43 .
Hyphae, 7.

Hypholoma fasciculare, 210, $3^{89}$.

Hypochnus cucumeris, $171,398$.

- solani, I72, 398.

Hypomyces, I33.

Hysterium macrosporum, I4I.

- nervisequum, I4I.

IRON SULPHATE SOLUTION, preparation of, 37 .

JAPAN LILY DISEASE, 57.

Jensen's hot-water treatment, 40.

'Jew's ears' fungus, 165 .

KAINIT, 45 .

LEAF CURL, 83.

- scald, 276.

Leptosphaeria circinans, 345 .

- pomona, 269.

Leuconostoc lagerheimi, 349.

Libertella ulcerata, 292, 43I.

Lichenes, 29, 342.

Loose smut of oats, 2 Io.

- wheat, 2 IO.

Lophodermium macrosporium, 376.

- nervisequum, 376 .

— pinastri, 139,377 .

Lysol, 32, 73 .

MACROSPORIUM, IIO.

- nobile, 322, 440. solani, 323,440 . tomato, 324,440 .

Mal-di-gomma, 333.

Marasmius sacchari, 207, $3^{87}$.

Matrix, 6.

Melampsora betulina, 238.

- laricis, 238, 409 .

— lini, 238, 410.

— pinitorqua, 235,409 .

- tremulae, 236 .

Melanconium pandani, 293, 43I.

Meliola camelliae, ror. penzigii, IOI, 363 .

Merulius lacrymans, I98, 396.

Metabolism, 3I.

Micrococcus tritici, 339.

Microsphaera grossulariae, 95,360 .

Monilia fructigena, 300,434 . 
Morel, tree, 163.

Moth-borer, I04.

Mutualism, 29.

Mycelium, 6.

hibernating, 87 .

Mycogone, I34.

Mycoidea parasitica, 343 .

Mycoplasma, 246.

Mystrosporium abrodens, 326.

- adustum, 325, 44I.

- alliorum, 326, 44I.

Myxogastres, 29.

NeCATOR DECRETUS, 327, 442.

Nectria ditissima, 127.

_- cinnabarina, 131, 373.

__ cucurbitula, 130, 373 .

- goroshankiniana, 132,374 .

- ipomeae, 132, 374.

— pandani, 293, 374 .

- vandae, 132,374 .

New Zealand white root-rot, 115.

Nitrate of soda, 45 .

Nitrification of soil, 3 I.

OEDOCEPHALUM FIMETARIUM, 384 .

Oedomyces leproides, 225, 405 .

Oidium tuckeri, 92.

Olpidium brassicae, $53,349$.

Oospora abietinum, 298, 433 .

scabies, 299, 433 .

Oospores, ro.

Ozonium auricomum, 346.

Paraffin, 40.

Parasites, 5 .

Partridge wood, 172 .

Peridermium cerebrum, 267.

- conorum, 266. cornui, 235, 422 .

coruscans, 266, 422 .

elatinum, 266, 423.

filamentosum, 264 .

giganteum, 267.

harknessi, 264 .

- ornamentale, 264 .

- pini, 26r, 264.

strobi, 233.

thomsoni, 267.

Permanganate of potash solution, preparation of, $3^{8}$.
Peronospora cubensis, 8o, 356 .

effusa, 79,355 .

gangliformis, 74 .

hyoscyami, 8I, 357 .

maydis, $8 \mathrm{I}, 357$.

parasitica, 79, 355 .

sachtii, 79, 356 .

schleideni, $75,356$.

trichotoma, 78,355 .

trifoliorum, 78,356 .

violae, 80,356 .

Pestalozzia guepini, 295, 432.

hartigii, 297,432 .

Peziza, I59.

— vesiculosa, 16I, 384 . willkommii, $\mathbf{1} 45$.

Pholiota adiposa, 207, 389 .

- aurivella, 208, $3^{88}$.

- destruens, 208, 389 . squarrosa, 208, $3^{88 .}$

Phoma abietina, 275.

- betae, rog.

- hennebergii, 272,425 .

- sanguinolenta, 270, 424 .

- solani, 272.

- tabifica, I09.

- tuberculata, 27 I.

Phragmidium rubi-idaei, $258,418$.

- subcorticatum, 260, 4I9.

Phycomycetes, 53.

Phyllactinia suffulta, 98, 36r.

Phyllosticta apii, 270.

- prunicola, 268, 42.4.

Phylloxera, 69.

Phytophthora cactorum, 66, 353.

- infestans, 62, 353 .

- omnivora, 66, 68, 353 .

phaseoli, 65,353 .

Pistillaria flavida, 445 .

Plasmodiophora brassicae, 334. californica, $33^{8}$. vitis, $33^{8}$.

Plasmodium, 30.

Plasmopara viticola, 8, 69, 354 .

Ploeospora gummipara, 122, 37 1 .

Plowrightia morbosa, 136,375 .

- ribesia, $\mathbf{1 3 9}, 376$.

Pocket plums, 85 .

Podosphaera oxyacantha, 98.

Polyporus betulinus, 189,392 . borealis, I97, 392. dryadeus, I97, 391. 
Polyporus giganteus, 198,390 .

- hispidus, I9I, 39I.

schweinitzii, 196, 390.

squamosus, 197, 390.

sulphureus, 193, 391.

Polystigma rubrum, $\mathbf{3} 35,375$.

Poria laevigata, 198 .

- vaporaria, I80.

Potassium sulphide solution, preparation of, 37 .

Powdery mildew of vine, 92.

Pruning, 23.

Pseudomonas campestris, 340 .

Pseudopeziza trifolii, $144,378$.

Ptychogaster aurantiacus, I94.

Puccinia arenariae, 253, 4I6.

- asparagi, 239, 4IO. bullata, 250, 4I 5 . coronata, 249, 4I2. dispersa, 249, 413. glumarum, 249, 4ז3. graminis, II, 247, 4I2. hieracii, 24I, 4II.

malvacearum, 252, 416.

menthae, 230, 4II. phlei-pratensis, 249, $4 \mathrm{I} 4$. pringsheimana, 243, 4II. pruni, 25I, 4I 5 . rubigo-vera, 249. simplex, 250, 4I4. tanaceti, 242, 250, 415.

Pythium de baryanum, 54, 350 . intermedium, 56, 350 .

QUICKLIME, 39.

RAMULARIA TULASNEI, IO7.

' Red stripe ' in wood, 200.

Reed-mace fungus, 125 .

Resin wash, 39, 42.

Resting-spores, Io.

Rhizina inflata, $162,385$.

- undulata, 162 .

Rhizoctinia violacea, 345 .

Rhizomorphs, 203.

Rhizopus necans, 57, 35I.

nigricans, 59, 35I.

Rhytisma acerinum, I42, 377.

- punctatum, I43, 378 .

- salicinum, 144, 378 .

Root-rot of conifers, 182. —— New Zealand, Ir5.
Root-rot, white, I 6 .

Rosellinia ligniaria, I22, 370.

- necatrix, I16, 370.

quercina, I21, 369.

radiciperda, I I 5, 370 .

Rotation of crops, 26.

SACCHAROMYCES LUDWIGII, 349 .

Saprophytes, 4.

Scab, 299.

- of apple, 302 .

Schizomycetes, 30 .

Schizophyllum conmune, 207,388 .

Schleimfluss, 348.

Sciara ingenua, I34.

Sclerotia, $\mathbf{1 3}$.

Scolytus rugulosus, 348 .

Sclerotinia baccarum, I54, 381.

- bulborum, 156,380 .

- douglassii, 160, 382 .

— fuckeliana, 148,379 .

- galanthina, $\mathbf{1} 59,382$.

- libertiana, 150 .

- megalospora, I55, 38I.

oxycocci, I 54,380 .

paeoniae, 157,383 .

- parasitica, 158,383 .

- sclerotiorum, I50, 38I.

- trifoliorum, 155,382 .

- tuberosa, I 57, 382 .

- urnula, 153,380 .

- vaccinii, 153 .

Secondary spores, 13.

Septogloeum hartigianum, 297, 432.

Septoria petroselini, var. apii, 270 , 426.

Shade trees, 27.

Shot-borer, ro4.

Shot-hole fungus, Australian, 268.

3I7.

Sleeping disease of tomato, 328.

Slime-flux, 348 .

- fungi, 29.

Soil, nitrification of, $3 \pi$.

- to sterilise, 44 .

Sorosporium scabies, 225, 405.

Spermogonia, II.

Sphaerella fragrariae, 107, 366. tabifica, 109, 367 .

Sphaerotheca castagnei, 95, 36I.

- mors-uvae, 97,362 .

- pannosa, 36I, 444 . 
Spirilla, 30.

Sporocarp, 6.

Spraying apparatus, 52 . methods of, 5 I.

Squirt berry, $27 \mathrm{I}$.

Stereum frustulosum, 172, 397. hirsutum, I74, 397.

Sterilising soil, 44 .

Stigmatea mespili, 278.

Stilbum flavidum, 445 . nanum, 326, 44I.

Stinking smut of wheat, 218 .

Sulphur, 38.

- flowers of, 94.

Summer fruit, 8.

TAPHRINA AUREA, 9I, 360 . bullata, 90, 359 . johansonii, 92,359 . sadebeckii, 91, 359 . ulmi, 92, 359 .

Thread blight of tea plant, 326 . Tilletia caries, $2 x 8$.

- decipiens, 220, 404 . foetens, 220 .

—_ levis, 220, 403 .

- secalis, 220 . tritici, 218, 403 .

Tinder fungus, 185 .

Trametes pini, I79, 394 .

— radiciperda, 182 . suaveoleus, $180,395$.

Trap-crop, 26.

Trichosphaeria parasitica, II4. sacchari, 103, 365 .

UNCINULA SPIRALIS, 92, 360 . Uredo cannae, 368,423 .
Uredo vialae, 268. vitis, 268, 423 .

Urocystis cepulae, 223,404 . colchici, 227, 404. occulta, 221, 404 .

Uromyces appendiculatus, 230, 406. betae, 228,407 . colchici, 226, 406 . fabae, 228,407 .

Urophlyctis leproides, 225.

Ustilago avenae, 2 ro, 401 .

- cruenta, 216, 402 .

- emodensis, 2r6, 402. esculenta, 217, 403 . hordei, 2I4, 40r. mays zeae, 213, 402 . nuda, 215,401 . reiliana, 216,402 . sacchari, 217, 403 . sorghi, 216, 402. treubii, 216. tritici, 213, 40 .

—— var. folicola, 2r3, 40r.

VERMICULARIA CIRCINANS, 273 , 425.

Verticillium, 134 .

WHITE ROOT-ROT, II6.

- rust of crucifers, 59.

Winter fruit, Io.

Witches' brooms, 89.

Wound-parasites, 15 .

XYLEBORUS PERFORANS, IO4.

ZOOSPORES, 64. 


\section{INDEX.OF HOST-PLANTS}

AbIEs, I82.

excelsa, II3, $263,298$.

douglassii, 298.

nordmannia, 298.

pectinata, $\mathbf{I}_{4}, 16_{3}, 26_{3}$. pinsapo, 266, 298.

Acacia dealbata, 28.

eburnea, 264.

gummosis of, 122 . horrida, 264 .

Acer, 66.

- campestre, I42, I43.

platanoides, $\mathrm{I}_{42}$.

pseudoplatanus, I42, I43.

rubrum, I42.

spicatum, 143.

Agrostis canina, 125 .

— pumila, 22 .

vulgaris, $22 \mathrm{I}$.

Albizzia stipitata, 28.

Alder, 89, 91, I27, I93.

Alkanet, 249.

Allium cepa, 224.

- magicum, 224.

- rotundum, 224.

Almond, 83, 135, 251, 3 I7.

Alphitonia, 296.

Anchusa arvensis, 249.

- officinalis, 249.

Andromeda, I68.

Anemone nemorosa, ${ }_{57}$.

- sclerotinia, 157 .

Anona, 343.

Antholyza, 32 I.

Apple, II5, I77, I9I, I93, 276, 268, 300.

rot, $28 \mathrm{r}$.

scab, 302.

-tree canker, I27.

Apricot, 25I, 268, 317 .
Arctostaphylos, 168.

Arrhenatherum, 168.

Asclepia speciosa, 235.

Ash, I27.

Asparagus rust, 239, 345 .

BALsAmiNA, I6r.

Banana anthracnose, 287. disease, 206.

Barley, 2I4, 247, 249, 3I3.

- red mould of, 33I.

Beans, II6.

Beech, II6, I27, I62, I78, 204, 208. seedling mildew, 66 .

Beetroot, 79, II6, 3I9, 345 .

rot, Iog.

- tumour, 225.

Beet rust, 228.

Berberis, 247, 263.

- vulgaris, II.

Beta vulgaris, 3 I9.

Betula, I82.

Birch, I78, I89, I98. polyporus, 189 . silver, 89.

Bird-cherry, 87, 127.

Black currant, $233,286$.

Blackthorn, 87.

Broad bean rust, 228.

Bromus, r68, 250.

Bullace, 87.

Cabbage, 6r, 79, II5, 334 . black rot of, 340 .

- seedling disease, 53 .

Cacao disease, 132 .

- pod disease, 68.

Cactus, 66.

Calathea, 344 .

Camellia, 296, 343 . 
Canna disease, 368.

Canthium campanulatum, 27.

Capsella bursa-pastoris, 59 .

Carex, 243.

Carnation, 253.

— fairy ring, 319.

macrosporium, 322.

Carrot disease, 270, 345 .

Cassandra, I68.

Castanea vesca, r63.

Celery leaf blight, 3 I6. leaf spot, 270.

Cercis, 275.

Chenopodium, 79.

Cherry tree, 89, 136, 268, 276, 300, 317.

\section{_leaf blight, $29 r$. mildew, 98. rust, 250. spot, 294.}

Chestnut disease, 305 .

Chrysanthemum, I5I.

__ leaf blight, 292.

rust, 24I.

Cineraria, 242.

Cinnamomum, 343 .

Citrus, 296, 343 .

bigaradia, 3II.

Clarkia, 66.

Clivia leaf blotch, 333 .

nobilis, 333 .

Clover, I44, I72.

leaf spot, I44. sclerotinia, 155 .

Cocoes, 78.

Coffea, 343 .

Coffee disease, 27.

American, 444.

leaf disease, $23 \mathrm{I}$.

twig disease, 327 .

Colchicum autumnale, 224, 227.

- bavaricum, 227.

smut, 224, 227. speciosum, 227.

Colocasia disease, 78 . esculenta, 78 .

Comandra pallida, 235 . umbellata, 235 .

Conifer root-rot, I82. seedling disease, 297.

Coronilla, 78 .

Cotton anthracnose, 290.
Cotton root-rot, 346.

Cowberry sclerotinia, I $_{53}$.

Crataegus, 278.

Cress, 6I, 79 .

Cucumber, ${ }_{5}$ I.

- mildew, 8 o. plant disease, I7I.

Cucumis sativa, 80 .

Cucurbita pepo, 80.

Currant, black, 139 .

- red, I3I, I39. leaf spot, 286 .

Cynanchum vincetoxicum, 235.

DAHLIA, 242.

Dalbergia assamica, 28 .

Diospyros, 99.

Dock, II 5 .

Dogwood, 127.

Douglass pine blight, $\mathbf{1 6 0 .}$

EDdoEs, 78.

Egg-plant, 272. bacterial disease, 342 . rot, 132.

Elder, 165 .

Elm, 92, I78, I86.

Equisetum, 54 .

FAGopyrum, 66.

Fagus, I82.

- antarctica, 165 .

betuloides, 165 .

- cunninghamii, r63.

- obliqua, 165 . sylvatica, 66,185 .

Fenu-grec, I 55 .

Fern, II 5 .

Fig-tree disease, 292.

Filbert leaf mildew, 98.

Flax rust, 238.

Fraxinus, 66.

Freesia recurva, 32r.

French beans, 288 .

GOAT'S-BEARD, 6 I.

Gooseberry, r39, 286.

- American, mildew, 97. leaf cluster-cups, 243. mildew, 95 . polyporus, 185 .

Grape disease, 27I. 
Grape fleck, r7o.

- mildew, 69 . rot, 278.

Grapes, 282, 288.

—_ black rot of, I05.

HARICOT BEANS, I5I. bean rust, 230.

Hawkweed, 242.

Hawthorn cluster-cups, 253.

Hazel, I27, 172.

- leaf mildew, 98 .

Heartsease, 80.

Helianthus annuus, 250.

Hemerocallis, $32 \mathrm{r}$.

Hemp, I5r.

Hieracium, 242.

Holcus, 33r.

- lanatus, 126. mollis, r26.

Hollyhock anthracnose, 290. rust, 252.

Hop mildew, 95.

Hornbeam, 127, 197.

Horse-chestnut, I3I. -radish, 6r.

Hyacinth, I56, I6r. bacteriosis, 339.

Hyoscyamus niger, 8I.

INDIAN CORN, 8I.

Ipomaea batatas, 132 .

Iris, $32 \mathrm{I}$.

bulb scab, 325 .

reticulata, 325 .

JUNIPERUS COMMUNIS, II3, I82, $254,257,258$.

- nanus, $\operatorname{Ir} 3,258$.

- oxycedrus, 257.

— phoenica, 257.

__ virginiana, 257.

Kerguelen's land CABbage, 6r.

LARCH, 193, I96. canker, 145 . - leaf rust, 238.

Larix europaea, 163 .

Laurus canariensis, I68.

- nobilis, $\mathbf{1 6 8 .}$

Ledum, I68.
Lemon, foot-rot of, $33^{2}$.

— scab, 3 Io.

- tree, IO3.

Lettuce mildew, 74 .

Lilium auratum, 57 . candidum, r6r. speciosum, 57.

Lily disease, r6r.

Lima bean mildew, 65 .

Lime, 39.

— tree, 127, 131.

Linum catharticum, 239. usitatissimum, 238.

Lolium, 33r.

Lotus, 78.

Lucerne, I44, I 55, 343.

Lupin, $\mathbf{1 7 2 .}$

Lupinus, 78.

Lycopodium, 54.

MAGNOLIA, 296.

Mahonia, 247.

Maize, 8I.

— blight, 3I3.

- mildew, $8 \mathrm{r}$.

- smut, 213.

Mango black-blight, I03.

Mangold, 79.

- rot, Iog.

Maple, I16, 127. blight, 297.

Medicago, 78 .

- lupulina, I 55 . sativa, I44, I 55, 345 .

Medlar cluster-cups, 257.

Melilotus, 78 .

Melon mildew, 8o.

Mignonette disease, 3r9.

Mint rust, 230.

Molinia, 33I.

Mountain ash cluster-cups, $25^{8}$.

Mulberry tree, $16_{5}, 207$.

- root disease, $\mathbf{1 6 6 .}$

Muscari comosum, 224. racemosum, 224.

Mushroom disease, I33.

Myrtle tree, Tasmanian, 163.

Nectarine, 3 I7.

Nicotiana glauca, 8r.

Niphobolus, 296.

Norway spruce, 263. 
ОАк, I 6, I62, I72, I78, I93, I97, I98, 285,348 . canker, II2. - seedling disease, I2r.

Oats, 247. loose smut of, 2 Io.

Olive tuberculosis, 34 r.

Onion mildew, 75 .

- scab, 273. sclerotinia, I56. smut, 223.

Onions, 326.

Onobrychis sativa, 155 .

Orange, foot-rot of, 3 .

- scab, 3 ro.

- sooty mould of, roo.

PAEONY,DROOPING DISEASE OF, I 57 .

Pandanus disease, 293, 344.

Panicum, 33r.

Paris quadrifolia, 224.

Paspalum, 331.

Pea seedling blight, $3^{\text {I } 5}$. spot, 275.

Peach, 83, II5, 25I, 276, 282, 317. rosette, 347 .

Pear, II5, I93, 268, 276, 282.

- leaf blister, 90 . cluster-cups, 257. scab, 304 .

Peridermium orientale, 267.

Petunia, I 5 I.

Phaseolus lunatus, 65 . vulgaris, 275 .

Phleum pratense, 249.

Picea, I82.

- morunda, 267.

Pine, r 16. sitkaensis, $\mathbf{r} 63$.

- blister-blight, 235. branch twist, 235 . cone fungus, 263 .

- cluster-cups, $26 \mathbf{1}$. leaf-cast, 139.

Pink rust, 253. fungus, I 13 .

Pinks, 3 I9.

Pinus, 182.

- contorta, 264 . densiflora, 267. excelsa, 267. insignis, 262, 264 .
Pinus lambertiana, 233.

longifolia, 267.

maritima, 262. ponderosa, 264, 267. sabiniana, 254 . silvestris, 262. strobus, $163,233,262$. thunbergii, 267.

Pisum sativum, 275, 315.

Plane leaf scorch, 284 .

Platanus occidentalis, 284 .

- orientalis, 284 . racemosa, 285 .

Plum, 85, 136, 197, 208, 268, 300.

— leaf blight, 29 r.

- blister, I35.

- rust, $\$ 57.25$ I scab, 3 Io.

Polygonum chinense, 217.

Poplar, 9r, 92, 193, I97, 208.

Populus nigra, 238. tremula, $236,23^{8}$.

Potato, I I5, I I6, I 57, I72, 345.

- bacterial disease, 342 .

- disease, 62 .

— leaf curl, 323. rot, 333 . scab, 225.

- American, 299.

- sweet, 59.

Pringlea antiscorbutica, 6r. Prothallia, damping-off, 56.

Prunus americana, 137. chicasa, 136.

_- japonica, gummosis of, 306 . - maritima, I37.

- pensylvanica, 137 .

- serotina, 137. virginiana, 137 .

Pseudotsuga douglassii, r6c.

Purging flax, 239.

QUASSIA, 343.

Quercus nigra, 235. tinctoria, 235.

Quince, 90, 276.

RADISH, 6r, 79, 334 .

Rape, 79.

Raspberry, 2ro. rust, $25^{8}$. spot, 286. 
Red currant, I3I, I39, 286.

Rhododendron, 296.

- ferrugineum, 167 .

galls, 167.

hirsutum, I67, 262. rust, 262.

Ribes alpinum, 233.

- aureum, 233. nigrum, 233.

Robinia, 66, I93.

Rose mildew, 444.

- rust, 260.

Rye, I22, 247, 249.

- grass, 33I.

smut, $22 r$.

SAFFRON, 345.

Sainfoin, I 55 .

Salsify, 6r.

Sambucus nigra, 165 .

Saxifraga, 168.

Sau tree, 28.

Scarlet-runner, 230, 288.

Scilla bifolia, 224. anthracnose, 288.

Scorzonera, 6r.

Scots fir, I30, I96.

Screw pine disease, 293.

Sedge, 243.

Sempervivum, 66.

Senecio jacobea, 262.

vulgaris, 262.

Sequoia gigantea, r6o.

Shepherd's-purse, 59.

Sidalcea, r6r.

Silver birch, 89.

— fir, I30, I4I, I97, 208, 266, 297.

—- girdling of, 275 .

Sloe, 135 . leaf disease, Ir4.

Snowdrop mildew, $\mathbf{r}_{59}$.

Solanum dulcamara, 62 .

- melongena, 132 . tuberosum, 62 .

Sorghun halapense, 216. saccharatum, 216. vulgare, 216 .

Sorrel, II5.

Spinach, 79.

anthracnose, $29 \mathrm{I}$.

Spruce, II6, 130, 197, 297.

Strawberry leaf blight, I07.
Sugar-cane agaric, 207.

- brand, 217.

Sunflower rust, 250 .

Swedes, ${ }_{5}$ I.

Sycamore, I3I. leaf blotch, 142 .

Symplocus, I68.

TANACETUM, 25 I.

Tanias, 78.

Tanniers, 78 .

Tayas, 78 .

Tea plant, blister blight of, $\mathbf{I} 68$.

—_ grey blight of, 295 .

Timothy grass, 249. grey blight of, 295 .
thread blight of, 326 .

Tobacco mildew, 8I.

Tomato, bacterial disease of, 342 .

- bacteriosis, 338 .

- black rot, 324 .

_ leaf rust, 3 II.

- sleeping disease, 328 .

Trifolium, 78, I44. incarnatum, 155 .

Trigonella fenu-graecum, I 55 .

Trisetum, 250.

Triticum, 250.

Tsuga mertensiana, 163 .

Tulip mould, $\mathbf{r}_{5} 8$.

Turnips, I 51, 334.

ULMUS CAMPESTRIS, I86.

Unonis, 78.

VACCINIUM, 99, I68.

- myrtillum, $\mathbf{1}_{54}$. oxycoccos, 154 . uliginosum, 155 . vitis-idaea, 153 .

Vanda tricolor, 132 .

- suavis, I32.

Vangueria infausta, 27. latifolía, 27.

Vanilla disease, II3. planifolia, II3.

Vicia, 275.

Vine, 1 16, 170, 319. leaf rust, 268. powdery mildew of, 92 . sclerotinia, 148 .

Viola odorata, 3r9. 
Viola tricolor, 80.

Violet, 3 r9. Neapolitan, 80.

WALL-FLOWER, 6I, 79, 334.

Wellingtonia, I60.

Weymouth pine, I96. rust, 233 .

Wheat, 220, 22I, 247, 249, 326. bacteriosis, 339 . disease, 272.
Wheat, loose smut of, ir3. red mould of, 333 . stinking smut of, 2 I8.

Whitethorn, II5, I35.

Willow, 180, 193.

ZEA MAYS, 2I6, 3I3.

Zinnia, I5I.

Zizania latifolia, 2I7.

Zizyphus jujuba, 345 .

Printed by T. and A. Constable, Printers to Her Majesty at the Edinburgh University Press 



\section{TNIVLRSITY UE :}
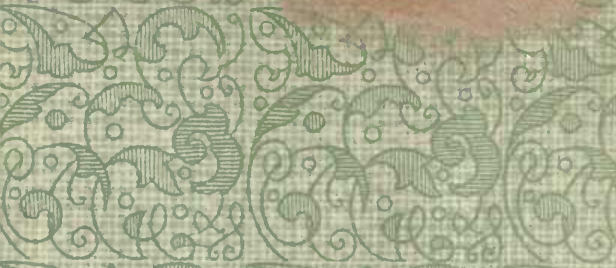

(100)
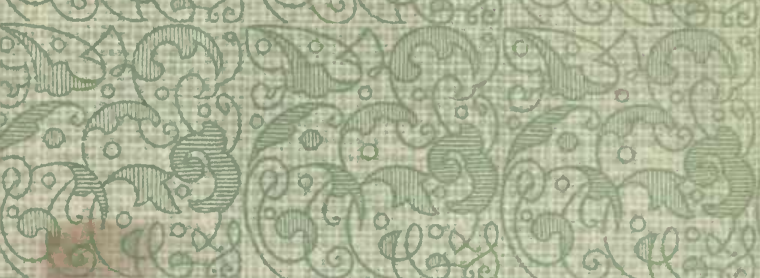

$(20)=0$

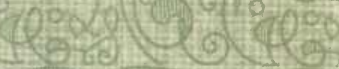

Fin

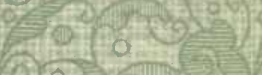

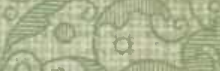
(a)

(a) on a 0 a (F)
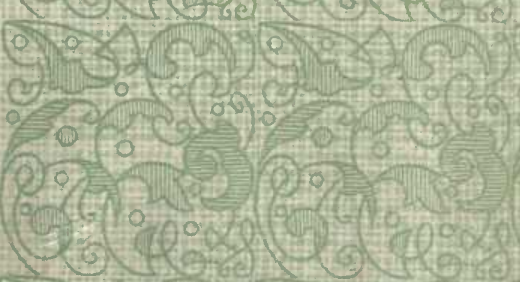

(50)
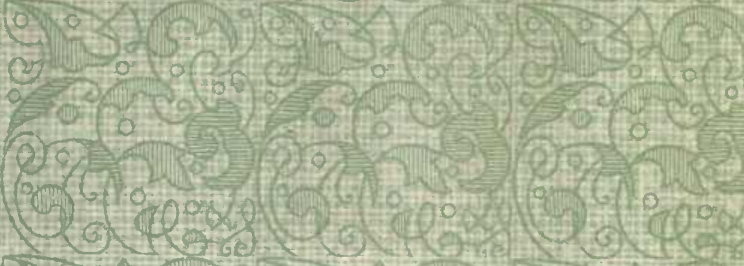

y)

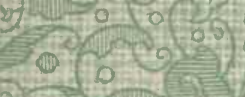

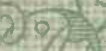

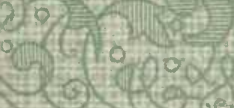

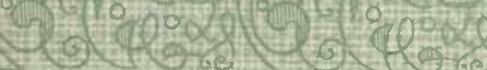

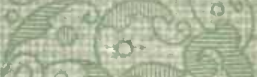

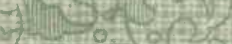

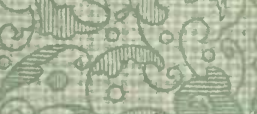

6.

$30 \frac{1}{20}$
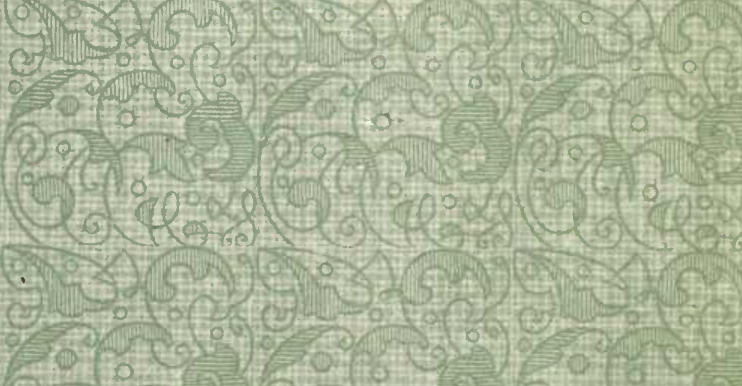
. 

(3)

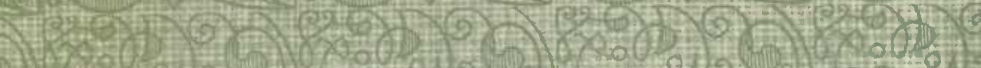

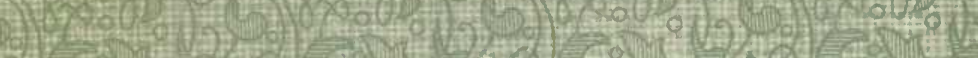
a (1) (5)

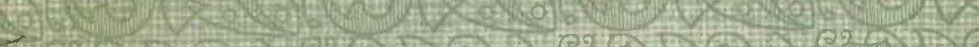
W.9.5. (4)

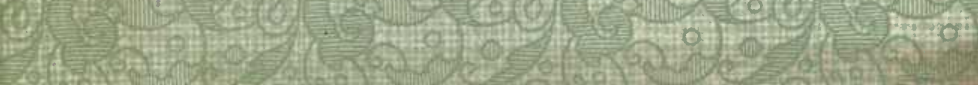

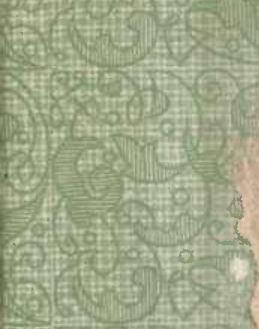

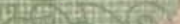

$\frac{3}{3}$

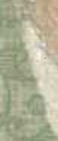

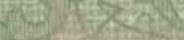
in

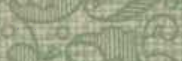

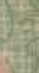

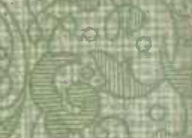

(4)

(4) 4 .

क्त.

50

86
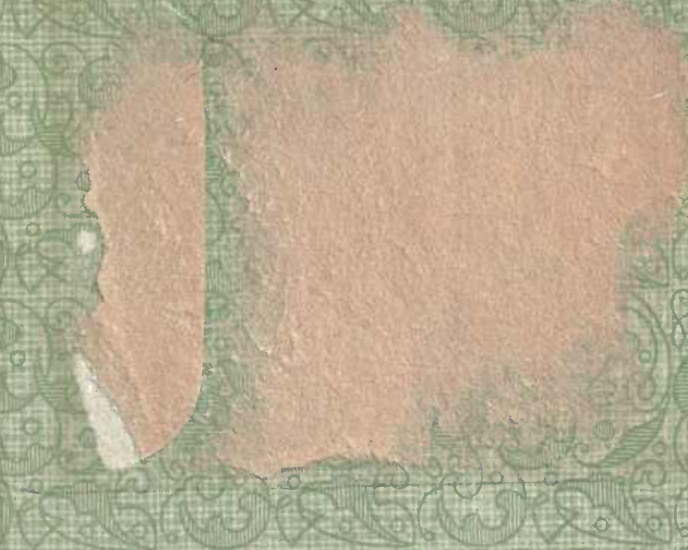

cosis

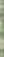


